\title{
BioGreenhouse
}

\section{Guidelines for Experimental Practice in Organic Greenhouse Horticulture}

Edited by Martin Koller, Francis Rayns, Stella Cubison and Ulrich Schmutz

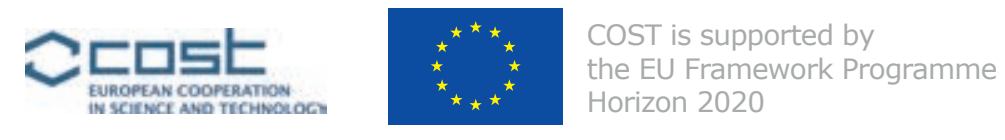

Research 


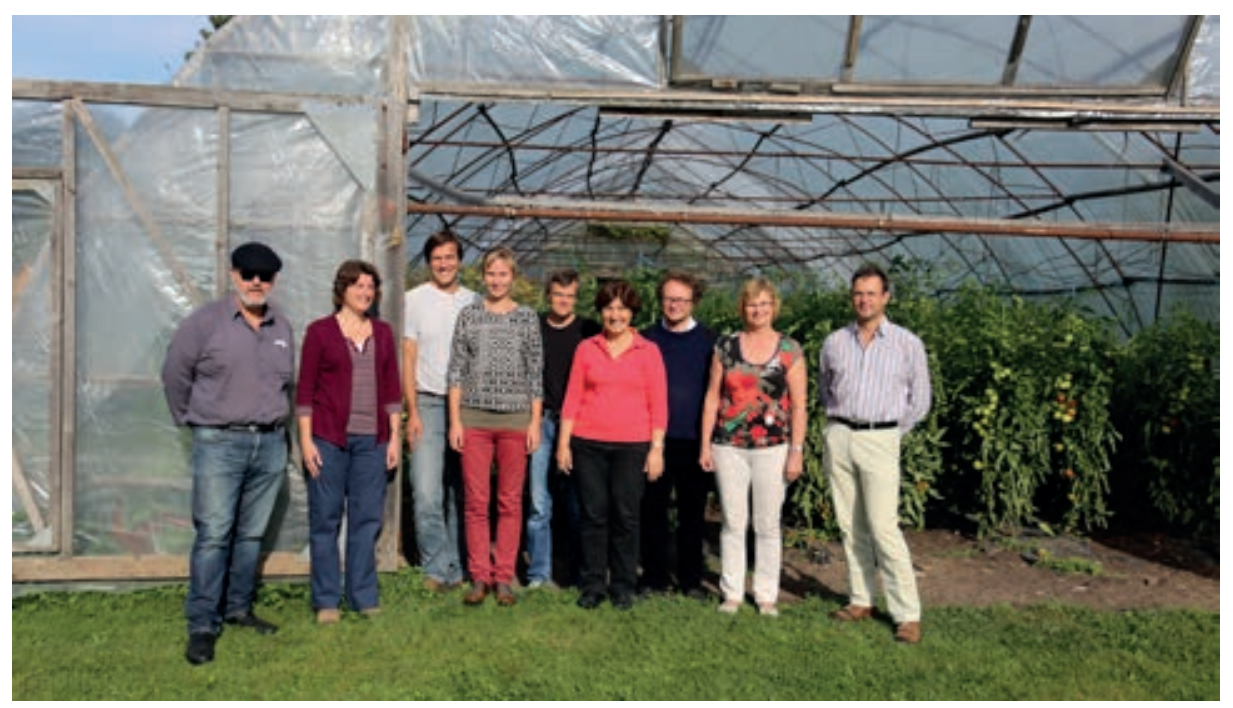

The Editorial Board This picture was taken at the final meeting to discuss these guidelines, held in Tori, Estonia in September 2015. A commercial organic greenhouse with a tomato crop is shown in the background. Left to Right: Pedro Gomez, Stella Cubison, Wolfgang Palme, Justine Dewitte, Martin Koller, Yüksel Tüzel, Francis Rayns, Ingrid Bender and Ulrich Schmutz.

\section{Correct citation of this document:}

Koller, M., Rayns, F., Cubison, S. and Schmutz, U. (Editors) 2016. Guidelines for Experimental Practice in Organic Greenhouse Horticulture. BioGreenhouse COST Action FA 1105, www.biogreenhouse.org.

ISBN: 978-94-6257-534-9

DOI (Digital Object Identifier): http://dx.doi.org/10.18174/373581

The guidelines were initially based on the following publication with many new chapters contributed by European and international authors:

Lindner, Ulrike and Billmann, Bettina (Eds.) 2006. Planung, Anlage und Auswertung von Versuchen im Ökologischen Gemüsebau. Handbuch für die Versuchsanstellung ["Planning, Setup and Evaluation of Trials on Organic Vegetable Cultivation. An Experimental Design Manual"]. Forschungsinstitut für biologischen Landbau (FiBL), Frick, Schweiz und Frankfurt, Deutschland, ISBN 978-3-906081-97-7, http://orgprints.org/9863.

\section{Pictures}

All pictures are by members of the Biogreenhouse COST Action FA1105. Contributors to the pictures (in alphabetical order) are: Ingrid Bender, Stella Cubison, Justine Dewitte, Pedro Gomez, Martin Koller, Carolyn Mitchell, Jérôme Lambion, Wolfgang Palme, Virginia Pinillos, Ulrich Schmutz, Yüksel Tüzel and Anja Vieweger.

\section{Disclaimer}

The information in these guidelines is based on the expert opinions of the various authors. Neither they, nor their employers, can accept any responsibility for loss or damage occurring as a result of following the information contained in these guidelines.

\section{Acknowledgement}

This book is based upon work from COST Action FA1105 BioGreenhouse, supported by COST (European Cooperation in Science and Technology).

The authors and editors wish to thank many colleagues for their assistance in providing the material for these guidelines. In addition Rob Meijer (Chair, COST Action FA1105 Biogreenhouse), Karin Postweiler (DLR Rheinpfalz, Germany), Birgit Rascher (LWG Bayern, Germany) and Catherine Mazollier (GRAB, France) provided critical comments on the text. We want to thank Ms. José Frederiks (Wageningen UR Greenhouse Horticulture) for processing layout and printing. We are grateful for financial support and the opportunity to build this network. Link to the Action: http://www.cost.eu/COST_Actions/fa/FA1105 and: http://www.biogreenhouse.org/ 


\section{Table of contents}

$\begin{array}{lr}\text { Authors } & \mathbf{5}\end{array}$

$\begin{array}{lr}\text { Preface } & 7\end{array}$

$\begin{array}{lr}\text { Abbreviations } & 9\end{array}$

$\begin{array}{llr}2.1 & \text { Separation from conventional cropping } & 13\end{array}$

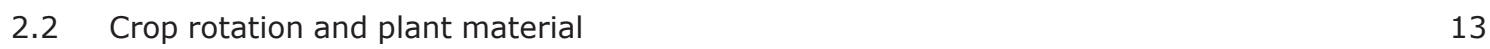

$\begin{array}{ll}2.3 & \text { Trial designs } \\ & 2.3 .13\end{array}$

$\begin{array}{lll}\text { 2.3.1 Plots and treatments } & 14\end{array}$

$\begin{array}{lll}\text { 2.3.2 Controls and other comparisons } & 14\end{array}$

$\begin{array}{ll}2.3 .3 & \text { Replications and randomisation } \\ \end{array}$

$\begin{array}{lll}2.3 .4 & \text { Fully randomised design } & 15\end{array}$

$\begin{array}{lll}2.3 .5 & \text { Block design } & 15\end{array}$

2.3.6 Latin Square design $\quad 16$

$\begin{array}{lll}2.3 .7 & \text { Split plot design } & 16\end{array}$

$\begin{array}{lll}2.3 .8 & \text { Fully factorial design } & 17\end{array}$

2.3.9 Simplified designs for on-farm trials $\quad 17$

$\begin{array}{llr}2.4 & \text { Recording results } & 18\end{array}$

$\begin{array}{lll}2.4 .1 & \text { Recording information } & 18\end{array}$

$\begin{array}{ll}2.4 .2 & 19\end{array}$

$\begin{array}{lll}2.4 .3 & \text { Harvest records } & 19\end{array}$

2.4.4 Time measurement $\quad 19$

$\begin{array}{ll}2.5 & \text { Data analysis and statistics } \\ \end{array}$

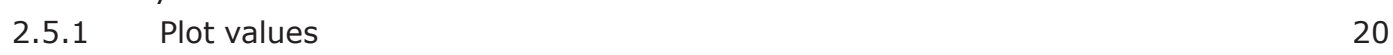

$\begin{array}{lll}2.5 .2 & \text { Statistical analysis } & 21\end{array}$

$\begin{array}{ll}2.6 & \text { Writing up an experimental report } \\ \end{array}$

$\begin{array}{llr}3.1 & \text { Crop variety trials } & 23\end{array}$

3.1.1 Variety comparison experiments 23

$\begin{array}{lll}3.1 .2 & \text { Grafting experiments } & 25\end{array}$

$\begin{array}{lll}3.2 & \text { Fertilisation experiments } & 28\end{array}$

3.2.1 Experiments with solid fertilisers, manures and commercial products 28

3.2.2 Experiments with liquid fertilisers 32

3.2.3 Experiments with compost $\quad 34$

3.2.4 Experiments with green manures $\quad 35$

3.2.5 Fertilising experiments in growing media used for transplant production, potted herbs or ornamentals $\quad 38$

$\begin{array}{lll}\text { 3.2.6 Evaluation of container growing media } & 40\end{array}$

$\begin{array}{lll}3.3 & \text { Experiments on weed control } & 41\end{array}$

$\begin{array}{lll}\text { 3.3.1 Weed control } & 41\end{array}$

3.3.2 Evaluation of mulching materials 42 
3.4 Plant protection experiments

3.4.1 Evaluation of fungicides and insecticides in organic cropping 43

3.4.2 Evaluation of bio control agents and natural enemies 45

3.4.3 Enhancements to biodiversity using flower strips 48

$\begin{array}{ll}3.5 & \text { Other types of experiments } \\ \end{array}$

$\begin{array}{lll}3.5 .1 & \text { Evaluation of greenhouse infrastructure } & 50\end{array}$

$\begin{array}{lll}3.5 .2 & \text { Irrigation systems } & 53\end{array}$

3.5.3 Pollination $\quad 59$

$\begin{array}{lll}3.6 & \text { Economic evaluation of crop trials } & 61\end{array}$

$\begin{array}{llr}3.7 & \text { Participative experiments and on farm research } & 65\end{array}$

4.1 Introduction

4.2 Fruit vegetables

$\begin{array}{lll}4.2 .1 & \text { Tomatoes } & 71\end{array}$

4.2.2 Eggplant $\quad 76$

4.2.3 Peppers

$\begin{array}{lll}4.2 .4 & \text { Courgette } & 87\end{array}$

4.2.5 Cucumbers $\quad 91$

4.2.6 Watermelon $\quad 95$

$\begin{array}{lll}4.2 .7 & \text { Melons } & 99\end{array}$

$\begin{array}{ll}4.3 & \text { Leafy vegetables } \\ & 4.3 .1\end{array}$

$\begin{array}{ll}\text { 4.3.1 Lamb's lettuce } & 102\end{array}$

$\begin{array}{ll}4.3 .2 & \text { Lettuce } \\ 4.3 .3 & 105\end{array}$

4.3.3 Rocket and other baby leaf brassica salads $\quad 108$

$\begin{array}{ll}4.4 & \text { Other vegetables } \\ \end{array}$

4.4.1 Climbing beans $\quad 110$

$\begin{array}{lll}4.4 .2 & \text { Kohlrabi } & 115\end{array}$

$\begin{array}{lll}4.4 .3 & \text { Radish } & 118\end{array}$

$\begin{array}{ll}\text { 4.4.4 Spring onion } & 121\end{array}$

$\begin{array}{llr}4.5 & \text { Transplants } & 123\end{array}$

4.5.1 Vegetable transplants $\quad 123$

$\begin{array}{llr}4.6 & \text { Herbs } & 125\end{array}$

$\begin{array}{lll}\text { 4.6.1 Parsley } & 125\end{array}$

$\begin{array}{ll}\text { 4.6.2 } & \text { Basil - grown in pots }\end{array}$

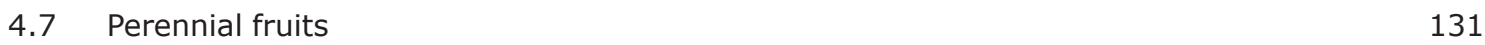

$\begin{array}{ll}\text { 4.7.1 Strawberries } & 131\end{array}$

$\begin{array}{lll}4.7 .2 & \text { Raspberries } & 135\end{array}$

$\begin{array}{lll}\text { 4.7.3 Table grapes } & 138\end{array}$

$\begin{array}{lll}4.7 .4 & \text { Papaya } & 141\end{array}$

$\begin{array}{lll}4.7 .5 & \text { Mango } & 145\end{array}$

$\begin{array}{llr}4.8 & \text { Ornamentals } & 148\end{array}$

$\begin{array}{lll}\text { 4.8.1 Pelargoniums cultivated in pots } & 148\end{array}$

5.1 Appendix A: General information $\quad 151$

5.2 Appendix B: Summary table of crop nutrient demand 152

$\begin{array}{ll}5.3 & \text { Appendix C: Summary of nutrient content of crop tissues } \\ \end{array}$ 


\section{Authors}

Samih Abu Baker, Jordan. Is a full professor at the department of plant production and protection, Dean of Faculty of Agricultural Technology at Al Balqa`Applied University. He is involved with studies related to sustainability of agriculture and organic farming research aspects. samih_abubaker@yahoo.com.

Ingrid Bender, Estonia. A researcher at the Estonian Crop Research Institute. Her work focuses on vegetable breeder seed production, breeding, variety trials and organic trials in greenhouse and open field. ingrid.bender@ etki.ee.

Stella Cubison, United Kingdom. An associate of Garden Organic (formerly HDRA) and fruit researcher. She currently works on an organic fruit farm and is experienced in trials work (varieties, pest and disease monitoring), specialising in apple and strawberry production. stella@laton.co.uk.

Justine Dewitte, Belgium. Works at the Vegetable Research Centre East Flanders (PCG) where she is researcher and advisor. Her work focuses on practically oriented research of organic vegetables under protection, and aromatic plants. justine.dewitte@pcgroenteteelt.be.

Martine Dorais, Canada. Senior Research Scientist at Agriculture and Agri-Food Canada and adjunct professor at Laval University. She currently works on organic sustainable production systems for horticultural crops. martine.dorais@agr.gc.ca.

Jacques Fuchs, Switzerland. Has worked in the Department of Crop Sciences of the research institute of organic agriculture (FiBL) in $\mathrm{CH}$-Frick. He is specialises in the biological quality of compost, compost utilization and development of compost based products.www.fibl.org, jacques.fuchs@fibl.org.

Pedro Gomez, Spain. His main expertise is conservation and development of vegetables varieties in Mediterranean greenhouses at Andalucía Institute of Agricultural Training and Research (IFAPA). pedro.gomez.j@ juntadeandalucia.es.

Nikki Jennings, United Kingdom. A breeder at the James Hutton Institute in Scotland. She currently works on the commercial raspberry breeding programme and has experience in variety trials and protected cropping.

Frank Kempkes, The Netherlands, Works for over 20 years at Wageningen UR greenhouse horticulture, the department of greenhouse technology. His work focusses mainly on energy saving techniques, covering materials and greenhouse climate. Frank.Kempkes@wur.nl.

Robert Koch, Germany. Works at the State Horticultural College and Research Institute in Heidelberg. His work focuses on practically oriented research of organic ornamentals crops and herbs. Robert.Koch@lvg.bwl.de.

Martin Koller, Switzerland. Works in the extension service of the research institute of organic agriculture $(F i B L)$ in Frick. A main focus is on-farm experiments on plant protection, variety trials and organic fertiliser testing in vegetable and ornamentals crops and herbs. www.fibl.org, martin.koller@fibl.org.

Jérôme Lambion, France. Works at GRAB (Research Group on Organic Farming) in Southern France, as a researcher. His main focus is on-farm experiments on crop protection, especially functional biodiversity and biological control.

Gerben Messelink, The Netherlands, is research entomologist at Wageningen UR Greenhouse Horticulture. His work focuses on evaluation of natural enemies and the development of biological control systems for pests in greenhouse crops. gerben.messelink@wur.nl.

Carolyn Mitchell, United Kingdom. A researcher at the James Hutton Institute. Her work focusses on developing sustainable pest and disease control in perennial and arable crop production. 
Wolfgang Palme, Austria. Head of department of Vegetable Growing at the Horticultural College and Research Institute in Vienna. His work focuses on vegetable diversity, variety trials and sustainable organic production alternatives.w.palme@gartenbau.at.

Virginia Pinillos, Spain. Professor in the Department of Agronomy at the University of Almería. Her work focuses on flowering and fructification of Mediterranean and subtropical fruit crops, and currently, her main research is on protected fruit crops.

Karin Postweiler, Germany. Works at the Experimental Station for Vegetables Queckbrunnerhof, Schifferstadt (DLR Rheinpfalz). Her main focus is on trials in organic fertilizers, weed control, crop care (karin.Postweiler@dlr.rlp.de).

Ellen Richter, Germany. Head of the plant protection service of North Rhine-Westphalia. She is responsible for plant protection in general but main interest is still vegetable production under field and protected conditions. ellen.richter@Iwk.nrw.de.

Francis Rayns, United Kingdom. Is a Research Associate of Garden Organic (formerly known as the Henry Doubleday Research Association) and Coventry University's Centre for Agroecology, Water and Resilience (CAWR). He specialises in the soil fertility of organic vegetable systems. www.gardenorganic.org.uk. francis. rayns@coventry.ac.uk.

Ulrich Schmutz, United Kingdom. Is a senior research fellow at Coventry University's Centre for Agroecology, Water and Resilience (CAWR) and a Research Associate of Garden Organic (formerly known as the Henry Doubleday Research Association). He specialises on organic horticultural and ecological economics. www. coventry.ac.uk/CAWR, ulrich.schmutz@coventry.ac.uk.

Yüksel Tüzel, Turkey. Is a full professor at the Department of Horticulture in Ege University Faculty of Agriculture. She works on protected cultivation mainly on vegetable production through sustainable production techniques. yuksel.tuzel@ege.edu.tr.

Wim Voogt, The Netherlands. Is scientific researcher at the Greenhouse Horticulture unit of Wageningen University and Research. His expertise is on plant nutrition, soils and water, in greenhouse grown crops. wim. voogt@wur.nl. 


\section{Preface}

In 2008, at the occasion of the 16th IFOAM Organic World Congress in Modena, Italy, about 25 participants expressed their interest to work together in the field of research and development for organic greenhouse or protected horticulture. To materialize this a two day workshop was organised in Cologne in 2009 to discuss the subject and how a collaboration could be formalised. This was attended by 45 people from all over Europe and from Canada. It was decided to work together in the field of organic protected horticulture concerning planting material, soil fertility, water management, disease and pest management, climate control and energy conservation, and sustainability. The group also agreed to submit a COST (European Cooperation in Science and Technology) Action on the same subject. In mid 2011 the proposal Towards a sustainable and productive EU organic greenhouse horticulture, in short, BioGreenhouse, was submitted.

At the end of 2011 COST approved this proposal as COST Action FA1105 (see http://www.cost.eu/COST_ Actions/fa/FA1105 and www.biogreenhouse.org), which aims to build a network of experts working in the field of organic protected horticulture and to develop and communicate, through coordinated international efforts, knowledge for new and improved production strategies, methods and and technologies to support sustainable and productive organic greenhouse/protected horticulture in the EU.

This project offered the framework and funds for the experts of the 27 participating COST countries and two COST Neighbouring countries to meet and to work together in Working Groups concerning the objectives of the Action. One of these objectives is to develop standardized methods and protocols for variety testing and for evaluation of seed treatments to enable interchangeability and joint interpretation of research.

Twenty one experts from all over the Action worked together on this objective. They have taken their task/ command very seriously, because they have not limited the proposal for these standards to variety testing and seed treatment, but extended their work to all fields of experimental practice in organic greenhouse horticulture.

Together they produced this booklet:

\section{Guidelines for experimental practice in organic greenhouse horticulture.}

It is an indispensible source of information for all the people and institutes involved in research in organic protected horticulture; for researchers, students, teachers and consultants. On behalf of the COST Action Biogreenhouse I want to thank the team of the authors and editors for the work they have done, their cooperative spirit and their perseverance. This work will certainly contribute to an improved experimentation, collaboration and exchange of information in organic greenhouse horticulture.

Rob J.M.Meijer

Wageningen UR Greenhouse Horticulture

Chair, COST Action FA1105 Biogreenhouse 
8 I Guidelines for Experimental Practice 


\section{Abbreviations}

$\begin{array}{ll}\text { EGTOP } & \text { Expert Group for Technical Advice on Organic Production } \\ \text { CPVO } & \text { Community Plant Variety Office } \\ \text { UPOV } & \text { International Union for the Protection of New Varieties of Plants } \\ \text { EU } & \text { European Union } \\ \text { COST } & \text { European Cooperation in Science and Technology } \\ \text { ANOVA } & \text { Analysis of Variance } \\ \text { n } & \text { Number of replicates } \\ \text { ha } & \text { Hectare } \\ \text { GM } & \text { Gross margin } \\ \text { VC } & \text { Variable costs } \\ \text { O } & \text { Output (financial) } \\ \text { Y } & \text { Yield } \\ \text { P } & \text { Price } \\ \text { ISHS } & \text { International Society for Horticultural Science } \\ \text { BBCH } & \text { Biologische Bundesanstalt, Bundessortenamt und Chemische Industrie } \\ & \text { (a type of key used to describe plant growth stages) } \\ \text { PAR } & \text { Photosynthetically active radiation } \\ \text { UV } & \text { Ultra violet } \\ \text { dS } & \text { Deci Siemens } \\ \mu S & \text { Micro Siemens } \\ \text { V/v } & \text { Volume/volume } \\ \text { m/m } & \text { Mass/mass } \\ \text { TDR } & \text { Time-domain reflectometry } \\ \text { AEI } & \text { Agro Ecological Infrastructure } \\ \text { EC } & \text { Electrical conductivity } \\ \text { PAR } & \text { Participatory action research } \\ \text { DM } & \text { Dry matter } \\ & \end{array}$


10 | Guidelines for Experimental Practice 


\title{
1 Introduction
}

\author{
By Martin Koller, Francis Rayns and Ulrich Schmutz
}

The aim of this handbook of experimental guidelines is to help conduct experiments for organic horticulture in greenhouses throughout Europe. It considers vegetables, fruit and ornamental production. Using standardised research procedures for experiments will aid a comparison of results and dissemination of knowledge. The editors have tried to incorporate as many climatic zones, countries and crops as possible in order to represent a wide area of Europe although some smaller crops or certain specific climates could not be included.

The term greenhouse will be used in these guidelines in accordance with the EGTOP report on organic cultivation in greenhouses as follows (EGTOP, 2013): "All permanent structures, with or without heating, covered by glass or plastic or other material that lets daylight through, in which crops, transplants or ornamentals are cultivated, are considered as 'greenhouses'". Usually only glass structures are heated (see Figure 1.1 and 1.2). In contrast to the term greenhouse "under cover" would mean cropping in low plastic tunnels (cloches), floating row covers or flat layers of plastic fleece or mesh (shown in Figures 1.4 and 1.5).

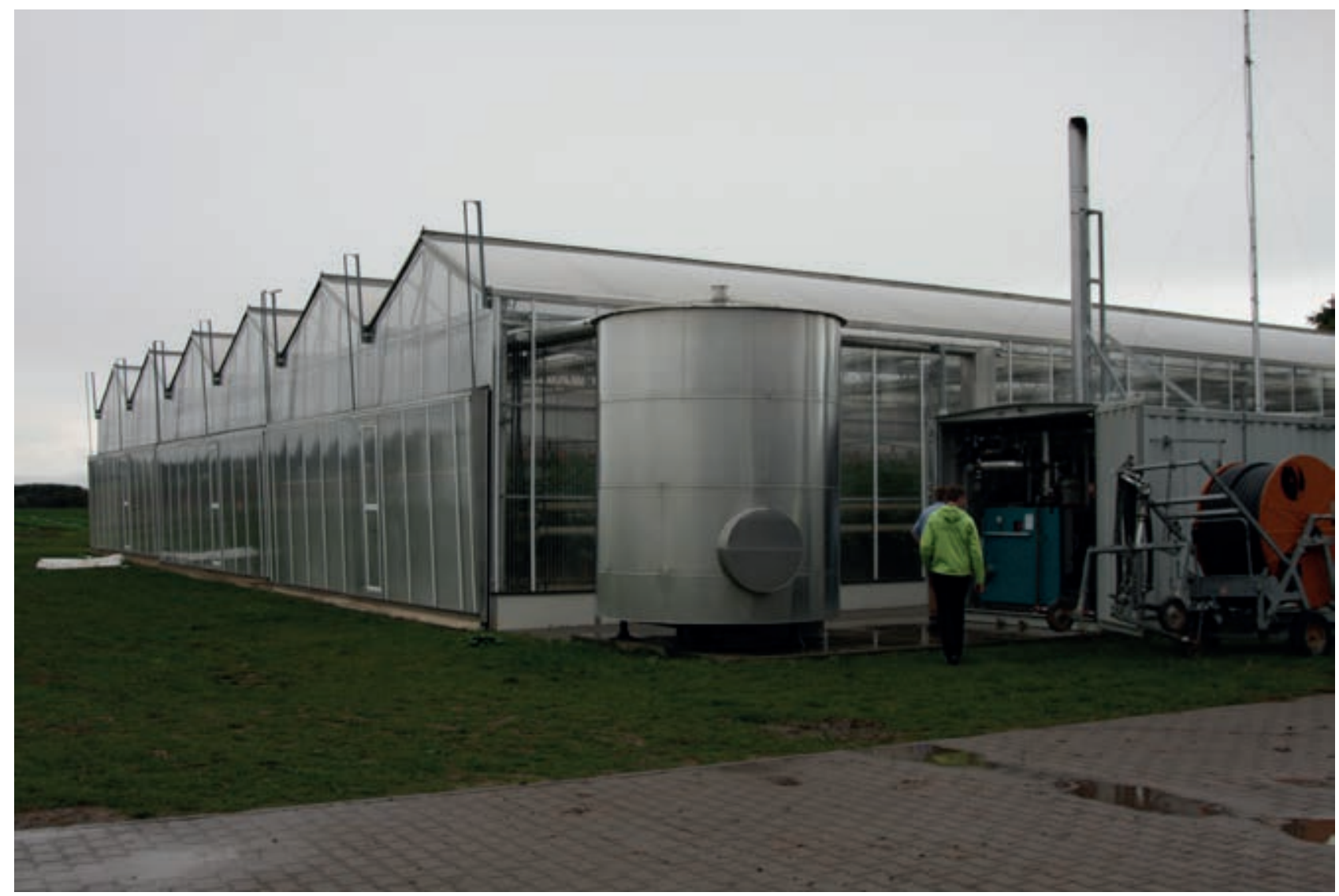

Figure 1.1 A typical greenhouse/glasshouse structure, in this case with a renewable heating boiler. 

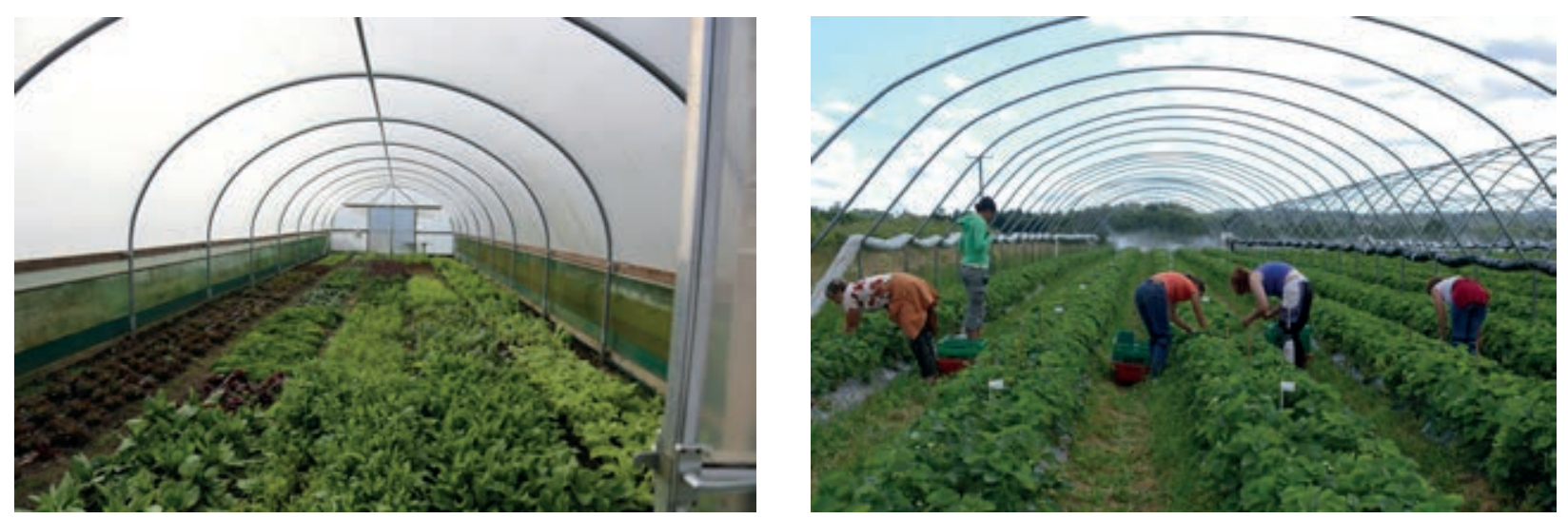

Figure 1.2 Polytunnels, either permanently covered (left) or with removable covers (right).
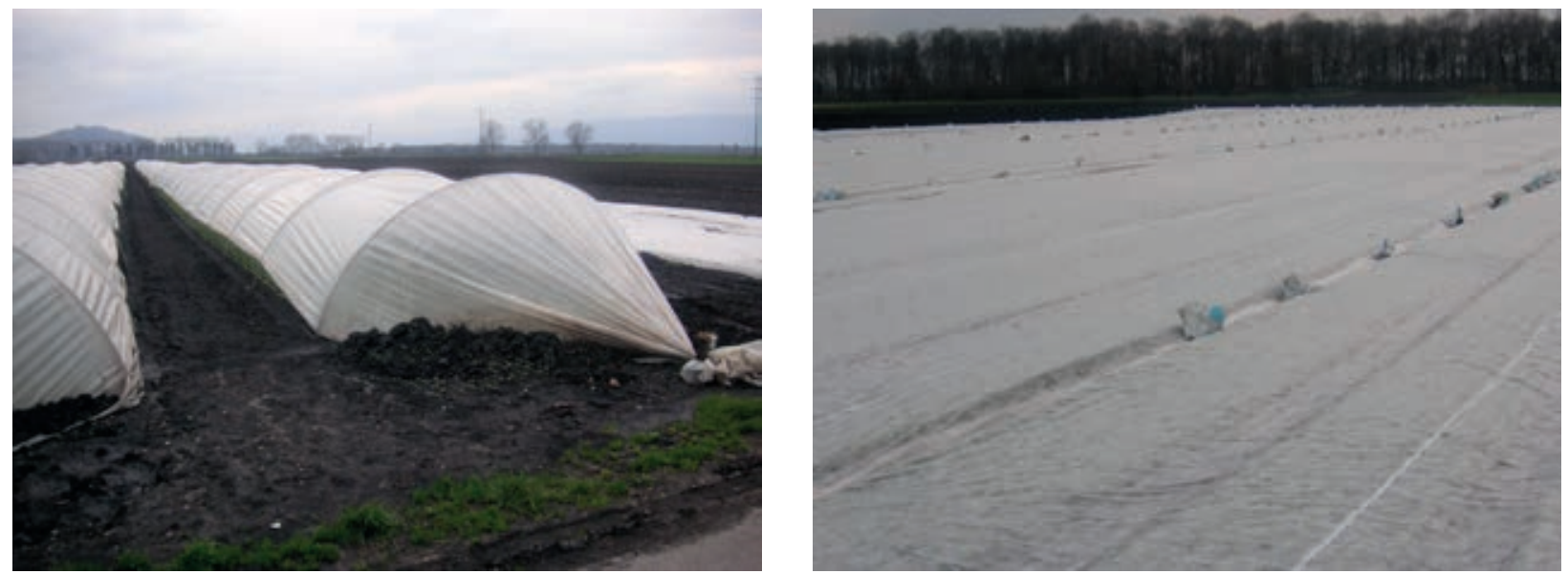

Figure 1.3 Temporary field coverings, either supported on hoops (left) or loose (right).

These guidelines were inspired by a handbook written in 2006 for German speaking countries in Central Europe. The title of this is "Planung, Anlage und Auswertung von Versuchen im Ökologischen Gemüsebau. Handbuch für die Versuchsanstellung" (Planning, Setup and Evaluation of Trials on Organic Vegetable Cultivation. An Experimental Design Manual). With the support of EU COST action BioGreenhouse (FA 1105) from 2012-2016 this text has been largely rewritten with many new chapters from European and international authors. It now includes organic fruit crops (soft fruit and top fruit), important aspects of organic systems like green manure crops and a description of economic analysis and participatory research methods.

The guidelines are intended to help when planning and designing research for organic production systems, especially for young researchers or researchers who have to deal with a new crop. Moreover, they should help an experienced researcher to think of the important points on a certain experiment. Naturally not all aspects can be covered in such guidelines and not all methods presented may be applicable for a specific research question or approach. Sometimes the recommendation (e.g. on the minimum number of replications when using mature trees) cannot be followed and compromises in the research design are necessary, but equally the minimum replications should be exceeded were possible to produce more statistically significant results.

Even if some information about the crop management is provided, these guidelines cannot be a substitute for a good growing handbook or growing experience - nor will they cover all aspects in each region of the European Union and the neighbouring countries. We therefore advise researchers (and students) to read, in addition to these guidelines, a textbook on organic growing of the relevant crop and to speak to experienced growers before setting up an experiment. 


\title{
2 Trials in Organic Horticulture
}

\author{
By Martin Koller, Francis Rayns and UIrich Schmutz
}

A pre-condition for trials concerning organic vegetable and fruit crops is the EU regulation 834/2007 on organic farming, or any other equivalent regulation in countries outside the EU. Inside the EU, in addition to the public (legally binding) EU standard, private standards of certification bodies defining organic or bio-dynamic production are also relevant. Research should always be conducted on well-established organic land (ideally converted for at least 5 years), and the history of conversion should be documented in the Materials and Methods section of any report (for research studying the process of conversion this is obviously not applicable).

If the research involves methods and products which are currently not part of organic standards (public or private) the protocol has to be discussed with the certification body first. In the case of on-farm trials the farmer also needs to be involved. Prior approval from the certification body and written documentation on the extent of the trials and the new methods tested should always be kept.

\subsection{Separation from conventional cropping}

In any organic research care has to be taken to avoid the influence of any adjacent conventional farming or horticulture - for example spray drift of herbicides or other pesticides. For outside cropping a distance of $10 \mathrm{~m}$ or a high physical barrier (such as a mature hedge, stone field wall or solid wooden fence is accepted as sufficient). The issue is of less significance in protected horticulture but consideration needs to be given to the danger of contamination through windows open for ventilation etc.

\subsection{Crop rotation and plant material}

The guidance given in the organic standards on crop rotation, the use of green manures and other good practice in organic soil care should also be used for all organic research trials and this includes those in polytunnels and greenhouses. The full crop rotation history for at least 3 years, including any fallow periods should always described in the Materials and Methods of the trial reports. If trials use potted plants or nursery stock details of the origin and composition of the growing media are important. Seeds and transplants should be from an organic source. If none are available a derogation from the certification body is often required and conventional seeds without chemical seed treatments are usually acceptable.

The crop grown immediately before the trial should be as uniform as possible and any plants propagated for the trial should be equally treated under the same standardised nursery conditions as documented in the Materials and Methods. For organic fertiliser trials the land should be cropped for at least 2 years beforehand with high nutrient demanding crops (and the crop residues removed) in order to deplete the fertility.

The microclimate has an important effect on crop performance. This is not only the case in the field but is particularly important in polytunnels and greenhouses. Factors include the effects of walls, heating pipes, position of the plants (in the middle or end of the house), general setting of the house (in a north-south or eastwest direction), temperature of the irrigation water and radiation from different surface materials.

\section{$2.3 \quad$ Trial designs}

There is normally a distinction between 'demonstration' and 'scientific' trials. The former are often unreplicated and are therefore smaller, easier (and cheaper) to run and may be linked to open day events aimed at farmers or a pilot study in advance for more detailed work. Results from such trials are not usually acceptable for scientific publication where replication allows statistical analysis to be performed to show that any differences between treatments are not just due to random variations in the experimental area. 
Despite care full homogeneity can rarely be achieved and any known gradients should be incorporated into the trial design. This can be done by having randomized blocks with all treatments placed along the gradient or gradients of change (see section 2.3.5). A higher number of replications can also be used if the field or greenhouse is very heterogenic.

Border plants, strips or plots ('guard areas') can be used to separate the research trial area from other land but also to separate different treatments. The appropriate size of the border depends on the research question. Variety trials usually require no borders between treatments unless plants with different harvest times are tested. For fertiliser, plant protection and irrigation trials (especially if these are run for several years) a sufficient border between treatments is necessary to avoid one plot affecting its neighbours (perhaps as a result of mixing of soil during cultivations).

\subsubsection{Plots and treatments}

A trial plot is the smallest unit of land to which a particular experimental treatment is applied. It can contain many plants, or in case of trees, may only include a few. The plots should be clearly labelled and a plan, with reference to external landmarks, be kept in case the field labels are lost or displaced.

If borders or 'guard areas' are necessary the plot consists of a core-plot (surrounded by the border) and the total-plot, which includes the border. There may be additional uncropped pathways between the plots for access. The plot yield can be measured as the sum of the individual plants in the core-plot or as the total yield of the core-plot without separating individual plants. In some circumstances measuring the yield of the total-plot may also useful to assess the effect the border had on the research design.

The recommendation for the minimum core-plot size (and the number of plants it should contain) is given for each species in Chapter 4. This size is important and if the research effort/funding is limited the number of treatments should be reduced rather the minimum plot size or minimum number of replications

All plots should ideally be the same size. If this is not possible the differences need to be included in the yield calculations and this should be clearly documented in the Material and Methods section of the report. In greenhouses and poly-tunnels plots can be positioned along the main house direction or across it. Usually long narrow plots are easier to work with especially for tomatoes, peppers and cucumbers.

A 'treatment' or 'variant' is the term used to describe each thing that is varied within an experiment. Experimental treatments could, for example, be different varieties or different rates of fertiliser application. Normally there are only one set of treatments in a trial - this is known as a monofactorial experiment. Multifactorial experiments are also possible but are more complicated, larger and so more expensive. An example of a multifactorial experiment would be one to compare both the type and application rate of fertilisers.

\subsubsection{Controls and other comparisons}

Controls are usually un-treated variants of a trial - they are important as a reference point and necessary in nearly all trial designs. It must be clearly specified what untreated means in relation to the other treatments. A control can be a standard well-known variety or a standard fertiliser and the measured effects can be calculated and presented in relation to the control. This gives farmers and growers a familiar reference point to relate the result to.

If the test product is applied in water or together with a surfactant or other additive the experiment should include a control with only water and a second control with water and surfactant (without the test product). Any water should also have the same temperature and pre-treatment (e.g. stirring) to make the treatments as comparable as possible. 


\subsubsection{Replications and randomisation}

For statistical validity each variant or treatment should be replicated. A trial with no replications is called 'demonstration trial'; it can have value as a demonstration to farmers and growers and proof-of-concept research; a statistical analysis is not possible. Crop trials have usually 3-6 replications and with more replications more statistically significant results can be measured. However, the cost of the trial also increases as it becomes larger and more time consuming to conduct. For a one factorial trial four replicates may be considered typical. Statistical analysis is still possible with three replicates but more allows more subtle effects to be detected and gives a degree of security in case one of the replicates is unusable (e.g. due to pest damage).

All variants are usually grouped in blocks. A complete block design has each variant once in the block, and the number of blocks is equivalent to the replications of the experiment. Within a block the treatments need to be randomised allocated - this can be done using an electronic random number generator or simply dice. The block location itself can also be randomized. If there is a known gradient across the site (e.g. of soil fertility) then the blocks should be laid out at right angles to this.

\subsubsection{Fully randomised design}

This is illustrated in Figure 2.1. It is quite possible that two randomly allocated treatments will appear next to one another; this is the case for 3 in the first column of this example. For field trials a completely randomised design is often not useful as known differences are not accounted for in either fields or glasshouses. Only in trials with pot plants in uniform growth chambers is this not an issue.

\begin{tabular}{|l|l|l|l|}
\hline 3 III & 5 II & 6 IV & 5 IV \\
\hline 1 II & 4 I & 6 I & 1 III \\
\hline 4 II & 3 IV & 2 II & 6 II \\
\hline 3 II & 4 IV & 2 I & 5 I \\
\hline 3 I & 2 III & 1 IV & 5 III \\
\hline 4 III & 2 IV & 6 III & 1 I \\
\hline
\end{tabular}

Figure 2.1 Fully randomised design with 6 treatments (1-6) and 4 replications (I-IV).

\subsubsection{Block design}

The block design is likely to be the best design for most research questions in a greenhouse or poly-tunnel. Each replication block should have the same conditions inside the block and with a two way analysis of variance the 'block-effect' can be removed from the analysis.

The treatments inside the block should ideally be randomized but often 'Block-1' is ordered simply from 1 to 6 as this gives the advantage of having an easily understood demonstration row of plots for visitors (see Figure 2.2). Sometimes a non-randomised block design is used. This is typical of plant variety and breeding trials where there may be a lot of varieties (perhaps as many as 20) in each replication. In such a layout it is easier to keep track of the treatments but statistical analysis of the results is not so robust. Because the same treatments are always adjacent there may be an influence of position (for example in a variety trial if one variety is much taller than the others). An example of this design is shown in Figure 2.3. 


\begin{tabular}{|l|l|l|l|}
\hline 6 I & 1 II & 3 III & 6 IV \\
\hline 5 I & 3 II & 2 III & 1 IV \\
\hline 4 I & 4 II & 5 III & 2 IV \\
\hline 3 I & 6 II & 4 III & 5 IV \\
\hline 2 I & 2 II & 1 III & 3 IV \\
\hline 1 I & 5 II & 6 III & 4 IV \\
\hline
\end{tabular}

Block I Block II Block III Block IV

Figure 2.2 Block design with 6 treatments (1-6) and 4 replications (I-IV) randomised in Blocks II to IV.

\begin{tabular}{|l|l|l|l|}
\hline 6 I & 5 II & 4 III & 3 IV \\
\hline 5 I & 4 II & 3 III & 2 IV \\
\hline 4 I & 3 II & 2 III & 1 IV \\
\hline 3 I & 2 II & 1 III & 6 IV \\
\hline 2 I & 1 II & 6 III & 5 IV \\
\hline 1 I & 6 II & 5 III & 4 IV \\
\hline
\end{tabular}

Block I Block II Block III Block IV

Figure 2.3 Block design with 6 treatments (1-6) and 4 replications (I-IV) in a fixed order.

\subsubsection{Latin Square design}

The Latin square, or rectangle if plots are longer then wide, is a special form of block design. With this design the effect of both block and column can be measured. For a true Latin square the number of treatments should be the same as the number of replications. Then each treatment is found once in each block and each column. If the number of replication is limited to four a 'modified' Latin square is possible, however this also limits the power of the statistical analysis considering block and row effects. An example is shown in Figure 2.4.

\begin{tabular}{|c|c|c|c|c|}
\hline \multirow[t]{2}{*}{ Block IV } & $4 \mathrm{IV}$ & $3 \mathrm{IV}$ & $2 \mathrm{IV}$ & $5 \mathrm{IV}$ \\
\hline & 3 III & 2 III & $1 \mathrm{IV}$ & 6 IV \\
\hline Block III & 6 III & $1 \mathrm{III}$ & 5 III & 4 III \\
\hline Block II & $5 \mathrm{II}$ & $4 \mathrm{II}$ & 3 II & $1 \mathrm{II}$ \\
\hline & $5 \mathrm{I}$ & $6 \mathrm{I}$ & 6 II & 2 II \\
\hline Block I & $1 \mathrm{I}$ & $2 \mathrm{I}$ & $3 \mathrm{I}$ & $4 \mathrm{I}$ \\
\hline
\end{tabular}

Figure 2.4 'Modified' Latin square with 6 treatments and 4 replications, showing four blocks (I-IV) and four columns $(A-D)$.

\subsubsection{Split plot design}

This allows for the testing of two factors in combination. These are known as the main effect and the split effect. An example might be the effect of different fertilisation effects on two different varieties of a glasshouse grown crop (see Figure 2.5). Because all the different treatment combinations are not fully randomised statistical tests require there to be bigger effects before they can be shown to be significant. However, split plot designs can be easier to manage than fully factorial layouts. 


\begin{tabular}{|c|c|c|c|c|}
\hline Split effect 1 & Main effect 1 & Main effect 2 & Main effect 3 & Block 1 \\
\hline Split effect 2 & Main effect 1 & Main effect 2 & Main effect 3 & \multirow{3}{*}{ Block 2} \\
\hline Split effect 1 & Main effect 2 & Main effect 1 & Main effect 3 & \\
\hline Split effect 2 & Main effect 2 & Main effect 1 & Main effect 3 & \\
\hline Split effect 1 & Main effect 3 & Main effect 2 & Main effect 1 & \multirow[t]{2}{*}{ Block 3} \\
\hline Split effect 2 & Main effect 3 & Main effect 2 & Main effect 1 & \\
\hline Split effect 1 & Main effect 1 & Main effect 3 & Main effect2 & \multirow[t]{2}{*}{ Block 4} \\
\hline Split effect 2 & Main effect 1 & Main effect 3 & Main effect2 & \\
\hline
\end{tabular}

Figure 2.5 Layout of a split plot design with 4 replications, three main effects and two split effects.

\subsubsection{Fully factorial design}

In this design all the combinations of two factors are randomised together within each block, allowing straightforward Analysis of Variance to demonstrate the significance of any treatment effects. Statistically this is much more robust than the split plot design. An example layout is given in Figure 2.6.

\begin{tabular}{|l|l|l|}
\hline $\begin{array}{l}\text { 1: fertiliser 1, } \\
\text { variety 1 }\end{array}$ & $\begin{array}{l}\text { 4: fertiliser 1, } \\
\text { variety 2 }\end{array}$ & $\begin{array}{l}\text { 2: fertiliser 2, } \\
\text { variety 1 }\end{array}$ \\
\cline { 1 - 2 } $\begin{array}{l}\text { 6: fertiliser 3, } \\
\text { variety 2 }\end{array}$ & $\begin{array}{l}\text { 5: fertiliser 2, } \\
\text { variety 2 }\end{array}$ & $\begin{array}{l}\text { 3: fertiliser 3, } \\
\text { variety 1 }\end{array}$ \\
\hline $\begin{array}{l}\text { 2: fertiliser 2, } \\
\text { variety 1 }\end{array}$ & $\begin{array}{l}\text { 1: fertiliser 1, } \\
\text { variety 1 }\end{array}$ & $\begin{array}{l}\text { 6: fertiliser 3, } \\
\text { variety 2 }\end{array}$ \\
\hline $\begin{array}{l}\text { 3: fertiliser 3, } \\
\text { variety 1 }\end{array}$ & $\begin{array}{l}\text { 5: fertiliser 2, } \\
\text { variety 2 }\end{array}$ & $\begin{array}{l}\text { 4: fertiliser 1, } \\
\text { variety 2 }\end{array}$ \\
\hline $\begin{array}{l}\text { 6: fertiliser 3, } \\
\text { variety 2 }\end{array}$ & $\begin{array}{l}\text { 5: fertiliser 2, } \\
\text { variety 2 }\end{array}$ & $\begin{array}{l}\text { 2: fertiliser 2, } \\
\text { variety 1 }\end{array}$ \\
\hline $\begin{array}{l}\text { 3: fertiliser 3, Block 3 } \\
\text { variety 1 }\end{array}$ & $\begin{array}{l}\text { 4: fertiliser 1, } \\
\text { variety 2 }\end{array}$ & $\begin{array}{l}\text { 1: fertiliser 1, } \\
\text { variety 1 }\end{array}$ \\
\hline $\begin{array}{l}\text { 1: fertiliser 1, } \\
\text { variety 1 }\end{array}$ & $\begin{array}{l}\text { 2: fertiliser 2, } \\
\text { variety 1 }\end{array}$ & $\begin{array}{l}\text { 5: fertiliser 2, } \\
\text { variety 2 }\end{array}$ \\
\hline $\begin{array}{l}\text { 6: fertiliser 3, } \\
\text { variety 2 }\end{array}$ & $\begin{array}{l}\text { 4: fertiliser 1, } \\
\text { variety 2 }\end{array}$ & $\begin{array}{l}\text { 3: fertiliser 3, } \\
\text { variety 1 }\end{array}$ \\
\cline { 1 - 3 }
\end{tabular}

Figure 2.6 Layout of a fully factorial design with 4 replications and six treatments in total (two factors).

\subsubsection{Simplified designs for on-farm trials}

In on-farm trials (both in the field and in polytunnels and greenhouses) it is often not possible to use the recommended 3 or 4 replications although wherever possible two fully randomised blocks should be used to provide at least some robustness to the findings. Simplified designs can include 'false replications' where e.g. plots are all in the same row to help with large machinery. This can be considered under the following conditions:

- The fields need to be well known and the plots should be placed along any established soil differences to exclude this effect as much as possible.

- A standard treatment is repeated 2, or better 3 times, randomized across the field to assess the trial error.

- The trial error is smaller if the treatments are close together and within an area of known soil homogeneity.

- Differences from prior soil treatments or crops could affect only one treatment; the experiment should therefore be set out and observed closely with the local knowledge of the farmer or grower. 
This approach is particularly suited to preliminary screening work, for example to see if a new crop will grow at all in a particular area. If the results are promising a more detailed scientific trial with grater replication can be set up later. During the data analysis the following considerations are important:

- Analyse the repeated treatment separately. If the 'false replications' within one row are not statistically different it can be assumed that no major external influence factors exist and that the differences measured in different treatments are mainly caused by the different treatments.

- If significant differences are found between 'false replications' the interpretation of the whole on-farm experiment has to be careful and descriptive, and all results of the statistical analysis have to be fully disclosed.

- If treatment data are presented in graphs the lack of a statistical analysis should be indicated in the description of the graph. If 'false replications' are used only mean values and standard deviation should be shown.

Additional statistical analysis tools can be used if non-replicated on-farm trials are conducted over many sites and multiple years. This is also the case when treatments are increased in fixed steps, e.g. compost: 1t/ha, $2 \mathrm{t} / \mathrm{ha}, 3 \mathrm{t} / \mathrm{ha}, 4 \mathrm{t} / \mathrm{ha}=$ four different treatments of compost with increasing tonnage per hectare. There is increasing interest in research work done using a 'citizen science' approach (see section 3.7)

\section{$2.4 \quad$ Recording results}

In the Materials and Methods section of any report all general information concerning the research trial must be documented. This can include location, site details (rainfall, altitude, water quality, nitrogen deposition through air, etc.), the organic status of the land, prior use, type of greenhouse, type of glass or plastic, research design, length and exact dates of trial and other relevant information. Soil type and results from soil samples (macroand micro-nutrients) before and after the trial are also important if relevant to the research question.

Details on the weather conditions before and during the trial should also be provided and these include min/max soil and air temperature, sunshine hours, irradiation, humidity, wind speed. Within the greenhouse additional data on relative humidity, additional lighting type/amount, $\mathrm{CO}_{2}$ contents, heating type/source, and sun/heat screens usage are required.

For the crop cultivation as much information as possible should be recorded including, variety, rootstock, scion, source of plant, seed-treatments, seeding or planting time, type of grafting, plant density, planting date and further cultivation operations such as leaf pruning, weeding or pest control. Fertiliser additions should be recorded and the source, amount and method of application should be clearly documented. This also includes type of irrigation water used, any fertigation (supply of nutrients in the irrigation water), $\mathrm{CO}_{2}$ enrichments or climate control to enrich $\mathrm{CO}_{2}$.

\subsubsection{Recording information}

Plant records can be made by weighing, measuring heights or lengths, counting (e.g. number of stems of fruits per $\mathrm{m}^{2}$ or per plant). They can also be done by rating against an agreed scale (e.g. pest per percentage of leaf area, or percentage leaf area with symptoms). Rating is often done on a scale of 1 - 9 (or 1 -5). Measurements and ratings for a specific record should always be done by the same person for the whole trial, as this reduces the overall measurement error. 
In ratings 1 is usually used for the lowest intensity of a trait and 9 for the highest. The optimal rating and the scale used (e.g. if shortened to 1 - 3 - 5 - 7 - 9) must be documented. The Community Plant Variety Office (CPVO, www.cpvo.europa.eu) and the International Union for the Protection of New Varieties of Plants (UPOV, www.upov.int) describes technical protocols for all the important horticultural species that include reference to such scales for a variety of characteristics. Information from both organisations is very similar but that from UPOV is available in more languages. Further details are given in the chapters for individual crops. For statistical analysis quantitative measurements are better than ratings but both give valuable information. However ratings should not be used to record information which could easily be collected by measurement (especially in the case of crop yields. Taking pictures can also help to illustrate differences. In some trials simple assessments of physical parameters (e.g. fruit firmness, colour) or chemical parameters (e.g. sugar content measured by refractometers) are worthwhile.

\subsubsection{Missing values}

A missing value can be the loss of a plant, a plot or even a whole block of the experiment. All missing values need to be recorded and honestly reported in the research report. The reasons for missing values can be manifold and the most common ones are flooding, animals eating crops, application errors and loss of data. Crop losses due to the actual treatments are not missing values.

If there are too many missing values the statistical analysis of the data is affected and a very large amount of missing values can make the whole experiment useless for statistical analysis. Under certain circumstances border crops outside the core-plot can be used in the analysis as a substitute but this is not good practice and must be clearly documented.

\subsubsection{Harvest records}

During the growing phase and at harvest all relevant biotic and abiotic stresses and damage to the plants need to be recorded. The harvest should include total yield and marketable yield, with details of the EU or other private retail based trade classification used to make this distinction. The marketable yield depends on the market channel and usually four types of market channel are applicable to organic crops: direct sales, smallscale retail, supermarkets and processing. While for direct sales and processing no trade classification applies (total yield $=$ marketable yield) for other channels there are clear specifications and different prices for Class 1 or Class 2 produce. It is important to record these differences as it is the marketable yield which interests farmers and growers most. Normally the whole trial should be harvested at the same time. There are exceptions however, for example if the harvest date itself is part of the research question.

\subsubsection{Time measurement}

If new processes or growing techniques are being researched measuring the time needed for application (including preparation time) needs to be recorded. This can be done by using stopwatches or smartphones and data can later be expressed in labour hours per $\mathrm{m}^{2}$ or hours/ha. It is important that only one person, or one team of people, makes these measurements in all the treatments. 
Example 1: Timing tomato harvest (in a trial with different plant densities)

Measurements:

- Harvest time (seconds)

- Total number of harvested fruit

- Shoots per treatment

- Fruits per shoot

- From this data the following can be calculated:

- Harvest time per fruit (seconds)

- Harvested fruit per hour

- Harvested shoots per hour

- Labour hours per hectare or $\mathrm{m}^{2}$

Example 2: Timing for weed control treatment (in a trial to compare fleece versus uncovered soil) Measurements:

- Hand weeding time (seconds)

- Number of plants per plot

- Number of weeds per plot

- From this data the following can be calculated:

- Hand weeded plants per hour

- Removed weeds per hour

- Labour hours per hectare or $\mathrm{m}^{2}$

For further agronomic and economic calculations data from reference material such as farm management handbooks can be used to include machinery costs, fertiliser costs and labour costs for 'what-ifs', i.e. if done on a commercial scale and not in a plot scale. Further information on this can be found in the chapter on the economic evaluation of crop trials.

\subsection{Data analysis and statistics}

Data should be collected in clear record sheets (on paper or electronically) and all data must be correctly allocated to the particular treatment. Common problems are typing or reading errors, decimal points being accidently moved, double entries, missed records, rounding data or missing digits and a general lack of concentration. Human error in data recording and analysis cannot be eliminated but it can be minimised by good experimental practices.

Data cleaning and checking is best done within a spread-sheet software programme (e.g. Microsoft Excel). Some of the mistakes described above can be spotted in a data screening exercise where extreme values are crosschecked, and data can be sorted to find double entries or other unusual entries. When entering data in a spreadsheet it is useful to immediately calculate mean, median, standard deviation and standard error in predefined formulas, as this can give extra check on typing errors. This descriptive statistics can also give guidance on further statistical methods to be used during the analysis.

\subsubsection{Plot values}

Yield data from plot areas have to be converted to standard metric area units - usually $1 \mathrm{~m}^{2}, 1000 \mathrm{~m}^{2}$ or 1 ha. It is important to distinguish between the core-plot area and the total-plot area. Borders or pathways specifically associated with an experiment have to be excluded when calculating commercial yields but access ways that are normally part of the cropping system (e.g. tractor wheelings) should be included. Usually yields per ha are appropriate for field crops and some poly-tunnels and yields per $\mathrm{m}^{2}$ for greenhouses and some polytunnels. 


\subsubsection{Statistical analysis}

The data from experimental trials are usually analysed with the ANalysis Of VAriance (ANOVA) methods. This is a collection of statistical methods to differentiate between treatment means and the variation among and between treatments. The method was developed by Ronald Fisher and first published in the 1920s. The F-test, named after him, is used to find out if the variance of a treatment is different to the variance of the remainder. Other tests exist if the means are not 'normally' distributed (e.g. the Kruskal-Wallis test). It may be necessary to mathematically 'transform' some data sets to make them appropriate before analysis. Following on the F-test, further tests like the Tukey-test can be used to find means that are significantly different from each other. Those differences are marked with different letters in graphs or tables. Further statistical tests, correlation and regression analysis are also possible if the data are suitable for such analysis.

If in doubt about the correct statistical analysis method to use it is worthwhile seeking the advice of a statistician. This should be done before the experiment has been set up to confirm that the design is appropriate to generate the data needed to test the hypothesis.

\section{Further information}

Grafen A. And Hails R. (2002).

Modern Statistics for the Life Sciences. Oxford University press. ISBN 978-0-19-925231-2

Zar, J. H. (2010).

Biostatistical Analysis, 5th ed., Pearson Prentice Hall, Upper Saddle River, NJ. ISBN: 978-0-13-100846-5

\subsection{Writing up an experimental report}

Reports will vary depending on the requirements of the institution and the funding body and the size of the project; a final report of a trial running for several years will clearly contain more information than an interim report. However, most reports will include the following sections that are also usually found in academic papers.

\section{Introduction and background}

The focus of the introduction section of the report is the research question and how it is embedded in the background of existing knowledge. What is the framework of the research and which underlining assumptions have been made? What are the overall aims of the research, how can it contribute to new knowledge and who will use this knowledge (e.g. private companies, academic institutions, farmers and growers, consumers)?

\section{Materials and methods}

The report should explain the choice of methods used to assess the research question and then describe the materials and methods used in the experimental trial with sufficient detail to enable it to be repeated:

Trial design (e.g. block or Latin square), number of replications (usually called $n=4$ for 4 replications), plants per plot, plot size, plant density, boarders and size of core-plot, general background on the site in terms of location, climate, soil, cropping history, organic status.

Short but comprehensive summary of all trial details, treatments and operations including dates.

Short, but comprehensive summary of crop data like plant variety, propagation, pre-treatments, pruning, fertiliser etc. which could affect the results of the trial.

Description of all assessment methodology. This is particularly important when there is chemical analysis of soil or plant materials as different techniques will give quite different results.

\section{Results and discussion}

The interpretation of results should be written in simple readable text with useful observations and descriptive data from scoring sheets and pictures. This qualitative description should be combined with the presentation of quantitative data from the statistical analysis. It is important to report the quantitative data as un-biased first and then offer an interpretation. The reason for this is that the reader may come to a different interpretation of the data than the author of the report. Authors sometimes have a selective view towards 'good results' they are hoping for. However, any result is a 'good result' if achieved with a pre-defined research method following a rigorous procedure. Graphs and tables are appropriate tools to present results clearly and compactly. 
Appropriate and clearly labelled scales are important (e.g. logarithmic for growth functions) and graph types should be chosen to avoid optical illusions. In a discussion sections the personal view and interpretation of the authors (called 'expert knowledge') are valuable information to the reader; they should however be clearly indicated as such and separated from the pure description of the results and this includes personal value judgements in the description of results like "treatment $x$ had an 'a much more important' effect". Methods and experiments that failed should also be described.

\section{Conclusions}

Key findings or the research should be presented. This will show how the results can be made use of by growers and identify the need for any further research work.

\section{Acknowledgements}

Acknowledgements should include all staff involved, from picture credits to field and greenhouse staff, to lab, statistical and proof reading support. If farmer groups or citizens were involved in setting the research question or collecting results this should also be acknowledged.

\section{References}

All academic or 'grey' literature cited in the text should be clearly listed.

\section{Summary or abstract}

A short (one or two page) summary of the work that briefly covers what was done and the main findings is useful for people who do not have time to read the full version, especially for commercial producers for whom the results may be relevant. This may be distributed as a leaflet or made available on a website. In such a case every effort should be made to avoid unnecessary jargon. 


\section{Key Types of Experiments}

\subsection{Crop variety trials}

\subsubsection{Variety comparison experiments}

\section{By Ingrid Bender}

\section{Requirements}

The tests should be carried out under soil and environmental conditions that ensure satisfactory growth and development of the crop concerned - these are explained in the guidelines for the individual vegetable species in Chapter 4.

Make sure that all varieties are maintained under the same light, temperature and humidity conditions. The sowing and transplanting must be done at the optimum time and take case to avoid mixing the varieties. When transplanting is used make sure that uniform, strong and healthy plants are planted. If, after transplanting, a plant dies, replanting a replacement is possible during first few days. To avoid shocks for the young plants they should be hardened off before transplanting.

Operations such as the preparation of growing media, sowing or planting, harrowing, pruning, etc. should be carried out and completed, if possible, on the same day and under the same weather conditions. If this cannot be done a complete trial replication or block should be finished.

Phytosanitary measures and weed control should be done according to ordinary local practice. The irrigation should be adapted to the plant species, growth stage, soil type and climatic conditions. It is important to ensure a uniform distribution of water; preferably irrigate at night or in calm weather.
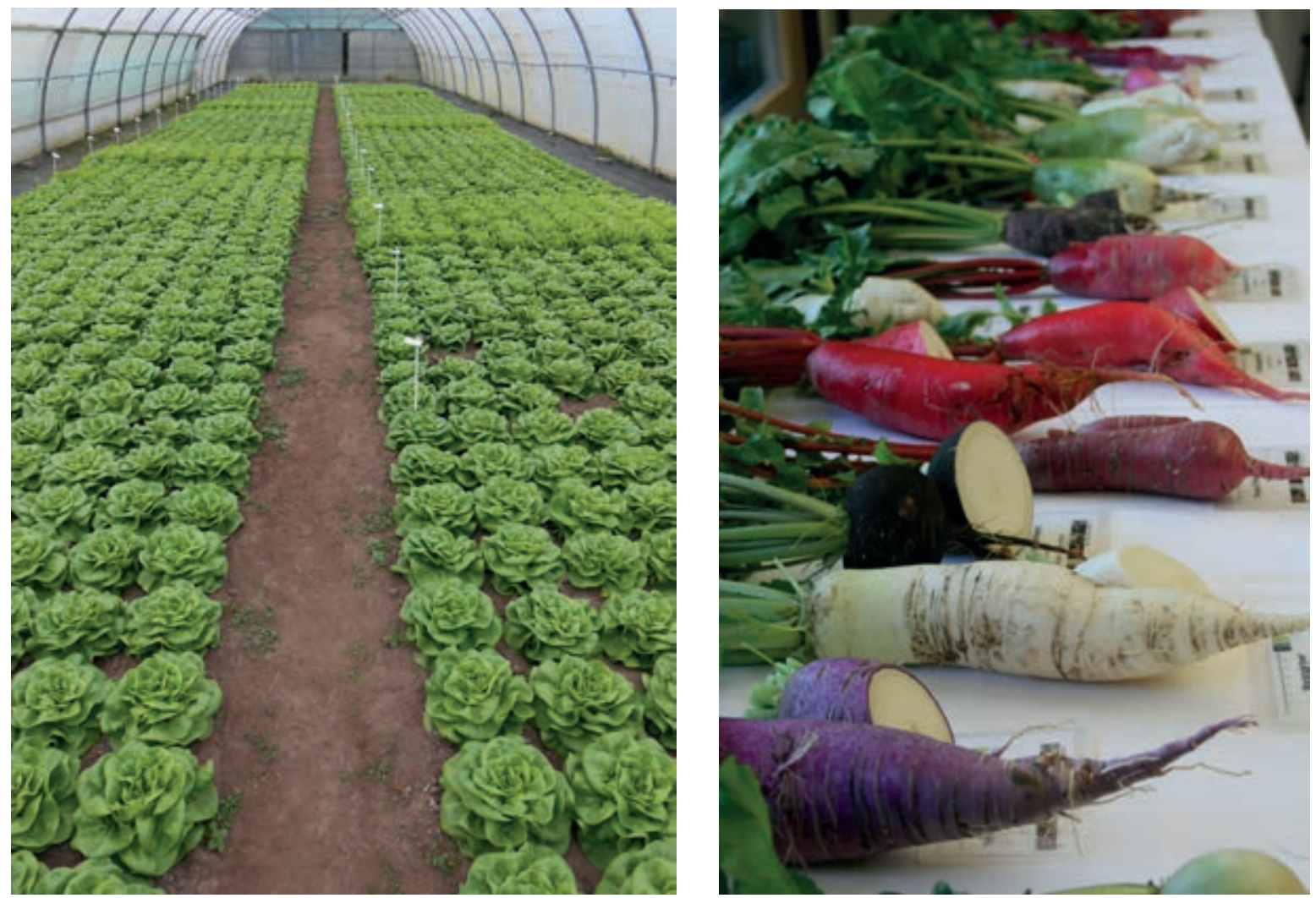

Figure 3.1 Left, a lettuce variety trial; Right, evaluation of radish characteristics. 


\section{Experimental design of variety trials}

Variety trials are usually monofactorial and set up as a block design or as a Latin square. If different harvest times are expected (e.g. for radish and salads), a buffer should be planted around the experimental plots. The desired number of plants per $\mathrm{m} / \mathrm{m}^{2}$ corresponds to the practice in commercial cultivation and is specified at the specific guidelines of the individual vegetables (see Chapter 4). At least three replications are recommended for fruit vegetables and four for leafy vegetables (as the plots for these are normally smaller and more replicates are easier to establish). The minimum number of plants per variety should be chosen according to the recommendation of CPVO (www.cpvo.europa.eu).

\section{Variety screening}

For some research questions (e.g. breeding, pre-screening), a variety trial as described above is often too time consuming or limited by the available facilities. In such cases a screening trial with less plants and less replicates could be performed. However, the results of such experiments should be interpreted carefully and the methodological constraints should be mentioned in the experimental report.

Pest and disease assessments (see section 3.4)

The assessment of infection of any pests and diseases should be carried out at what is likely to be the time of their maximum severity. If the problem subsequently increases the assessment should be repeated.

\section{Observations before harvest}

To record the results of the scoring and harvesting the forms of the Community Plant Variety Office (CPVO) or the International Union for the Protection of New Varieties of Plants (UPOV) should be used. These recommend that two independent cropping cycles (normally repeated in the same place) are grown and monitored before any conclusions can be drawn.

Monitoring during the period of crop growth provides a reliable, in-depth evaluation of the varieties and supplements the yield measurements. The assessments that are appropriate will vary and are given in the guidelines for each plant species. Plant features and characteristics are usually scored, at strategic dates, on a scale 1 to 9 as quantitative measurements are often difficult. Assessments are always carried out on all in the whole trial. The date of strategic events in the life of the crop (e.g. flowering, fruit set) should be recorded. If making colour assessments this is best done under an overcast sky.

\section{Harvest observations}

The determination of harvesting time depends on the developmental state of the plant and should not be impeded by external factors such as market conditions, lack of time, etc. The harvest information, as well as criteria for the optimum harvest maturity, are given in the guidelines for each plant species in Chapter 4 . Each harvest should usually be made at the optimum time for each variety. With only a few species will all varieties be ready for harvest at the same time. In many case the time taken from planting to harvest is an important piece of information.

To avoid mistakes the plot treatment and replication number should be clearly marked on any crates or sample bags. The weight should not be determined on wet or heavily contaminated crops. The harvested crop should be classified as marketable or non-marketable by national trade classes or EU quality standards. Detailed information on this is given in the guidelines for each plant species.

For further analyses a representative sub-sample of the harvest should be used:

- Ingredient research and taste testing may complement and complete the variety trials. As a basis for investigations are methods of biochemical and food analysis (Boehringer, Mannheim, 1989).

- Sensory tests can be carried out using two different approaches:

1. Working with trained panel. This type of testing is concerned with obtaining objective facts about products due to the general principles of the Standards Committee for Food and Agricultural Products (e.g. DIN 10 950, Sensory analysis Basic principles STANDARD by Deutsches Institut Fur Normung E.V. (German National Standard), 10/01/2012) http://www.nal.din.de/).

2. Consumer testing. This type of testing is concerned with obtaining subjective data, or how well products are likely to be accepted. Usually large panels (50 or more) of untrained personnel are recruited for this type of testing. 
For some types of vegetables a storage test can be carried out. The crop for storage must be undamaged and free from pests and diseases. The storage conditions (duration, temperature, humidity and the storage facilities) have to be carefully described. After completion of storage, the crop is first weighed to determine the respiration and evaporation losses, then cleaned and sorted into marketable and non-marketable produce.

\section{References and further information}

Boehringer Mannheim GmbH. 1989.

Methods of biochemical and food analysis. Mannheim

www.cpvo.europa.eu/main/en/home/technical-examinations/technical-protocols

www.upov.int/de/publications/tg_rom/tg_index_numerical.html

www.bioversityinternational.org/e-library/publications/categories/descriptors/

\subsubsection{Grafting experiments}

\section{By Justine Dewitte (In cooperation with COST Action FA 1204 "Vegetable Grafting")}

\section{Requirements}

Rootstock trials are carried out on a similar way to variety trials so the requirements are almost the same. However, there are some particular points to pay attention to:

- Make sure that the growing medium is the best one for the rootstock of that crop

- Make sure that the rootstock and the variety (scion) are sown at the optimal time so you can graft under the best conditions. This can be different for every combination, so it is best to check with the seed company in advance concerning the germination rate and growth speed. Depending on the crop and the time of sowing, the difference in sowing time can vary from a few days to a few weeks earlier or later.

- It is very important that each rootstock and variety is maintained in exactly the same way (the same light, temperature and humidity conditions). These should follow the general needs of the crop as listed in Chapter 4. It is not permitted to create conditions that favour one specific rootstock.

- If transplanting is necessary, it has to be done under uniform conditions. This is also the case when grafting the plants.

- Mixing different rootstocks is not permitted. Make sure that the different plants are clearly labelled.

- Each operation has to be completed on the same day under the same conditions.

- The planting material should be hardened off (acclimatised) in a uniform way before planting out.

\section{Experimental design}

Rootstock trials are usually set up with a monofactorial block design. All borders of the greenhouse have to be planted up but these plants should not be part of the trial - they are a buffer for external factors. The desired number of plants per $\mathrm{m}^{2}$ should correspond to the practice in commercial cultivation and this is specified in the guidelines for the individual vegetables in CPVO protocols. At least three, or if possible four, replications are recommended. It is advantageous to have a history of the soil conditions of the greenhouse or polytunnel so that the pest and disease pressure of a particular soil can be taken into account. Controls are important - these can either be ungrafted or self- grafted plants or both. 


\section{Plant health assessments}

To score above ground infections of pests and diseases on the plants the same assessments can be used as for variety trials. However, one of the most important aims of rootstock trials concerns the health of the roots. Soil borne pests or diseases, as well as damage caused by physiological problems, can be evaluated by estimating the percentage of infected root area. Scores (1-9) can be transformed by a logarithmic scale to \%. Logarithmic evaluation:

1 = absent $0 \%$

2 = very low to low $>0$ to $2.5 \%$

$3=$ low $>2.5$ to $5 \%$

$4=$ low to medium $>5-10 \%$

$5=$ medium $>10-15 \%$

$6=$ medium to strong $>15-25 \%$

$7=$ strong $>25-35 \%$

8 = strong to very strong $>35$ to $67.5 \%$

$9=$ very strong 67.5 to $100 \%$

Roots should be evaluated immediately after the end of the growing period - they still have to be fresh. It is important to avoid damaging the roots while taking them out of the soil. It is also possible to make additional assessments during the growing period but this necessitates destruction of the plants and so larger plots are required in order to have some remaining at harvest.

Root knot nematodes are a common pest in fruit vegetables, especially in heated greenhouses. The main reason for this is the rather limited crop rotations that are used for economic reasons. Therefore, a specific measurement method is carried out, called "rootknotindex" (Figure 3.2). The pictures can be used for all species of Meloidogyne. A score of 0 to 3 will not have much influence on the growth of the plant, but higher scores (4 to10) can cause large harvest losses.

\section{Observations during vegetative period}

The growth assessments of rootstock trials are very similar to those of variety trials (see section 3.1.1, Variety Trials).

\section{Harvest and observation on crop}

The harvest measurements and monitoring of rootstock trials are similar to those of variety trials (see section 3.1.1, Variety Trials). 


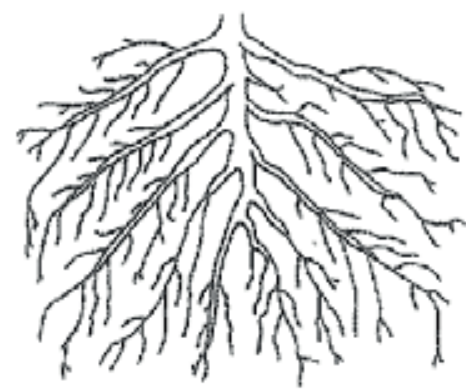

Score 0 (undamaged plant)

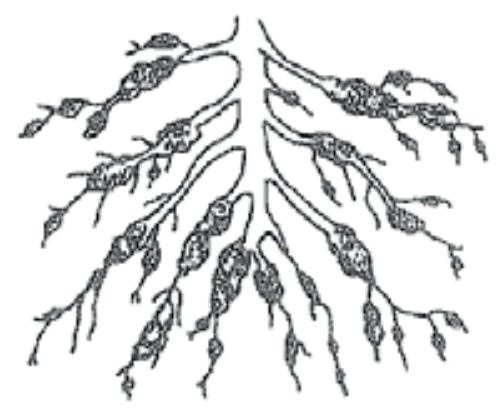

Score 6 (50\% of roots affected)

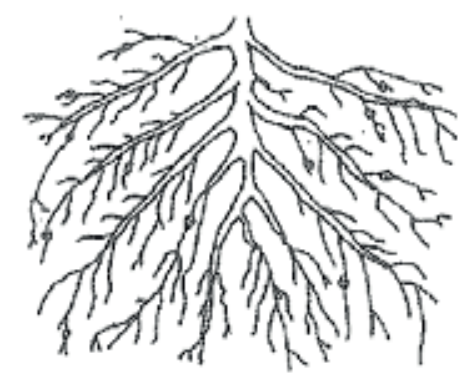

Score 2

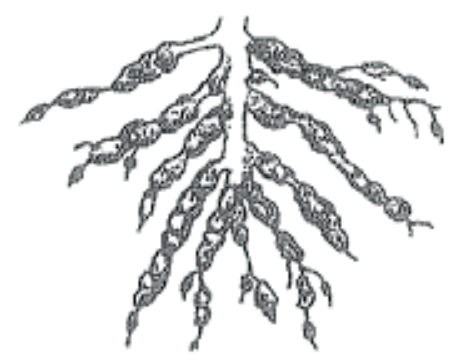

Score 7 (75\% roots affected)

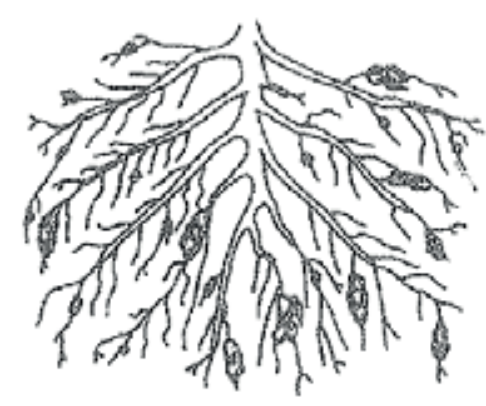

Score 4

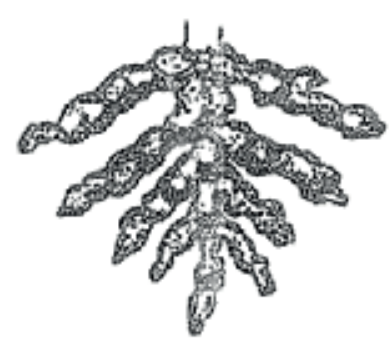

Score 9 (100\% roots affected)

Figure 3.2 Scoring system to assess root knot nematode damage (from Cuijpers and Janmaat, 2012).

References and further information

\section{COST Action FA1204}

(Vegetable Grafting to Improve Yield and Fruit Quality under Biotic and Abiotic Stress Conditions http://www. cost.eu/COST_Actions/fa/FA1204

Cuijpers, Willemijn and Janmaat, Leen (2012)

Biowisselkas: Bredere vruchtwisseling voor een gezondere bodem. [Organic greenhouse intercropping:

Broadening crop rotations for a healthier soil.] Louis Bolk Instituut, Driebergen. www.orgprints.org/20824 


\subsection{Fertilisation experiments}

\section{By Wim Voogt}

Fertilisation experiments in organic farming are quite complicated as one has to deal with some important constraints as well as multiple parameters which are very much entangled. One of the constraints is that the majority of the $\mathrm{N}$ in manures, composts and supplemental fertilisers is in an organic form; plants take up $\mathrm{N}$ in mineral form $\left(\mathrm{NH}_{4}{ }^{+}\right.$and $\mathrm{NO}_{3}^{-}$) and these ions only become available as a result of the decay of organic matter (mineralisation). Furthermore, organic fertilisers comprise of a mixture of several nutrients. For example, consider a quantitative $\mathrm{N}$-trial using chicken manure. Application rates will not only affect the intended range of $\mathrm{N}$ supply but also other nutrients $(\mathrm{K}, \mathrm{P})$, salinity $(\mathrm{EC}, \mathrm{Na}, \mathrm{Cl})$ as well as the quantity of organic matter. Each of these parameters will, or may, have an effect on the soil chemical, physical and biological conditions and hence contribute to the result. Setting up simple one-dimensional experiments - as in conventional horticulture with mineral fertilisers - is really impossible, or at least would require large trial set-ups. Instead a more general approach is needed whereby it will be crucial to define the research question and the aim of the trial and adjust the design accordingly. In many cases it also requires the monitoring of additional parameters to interpret the results.

Fertilisation trials can be conducted with the aims of:

- Quantification of nutrient availability (including mineralisation trials)

- Determining the effect on crop development in relation to plant requirements

\subsubsection{Experiments with solid fertilisers, manures and commercial products}

\section{By Wim Voogt}

\section{QUANTIFICATION TRIALS}

The aim of these is to estimate the pattern of the availability of nutrients after application of a fertiliser.

\section{Requirements}

To determine nitrogen availability these trials should preferably be done as incubation trials, in pots under controlled conditions of temperature and water content, to make extrapolation of the results possible. Containers of at least 1 litre should be used. Preferably a standard soil mixture should be prepared, which than can be used in all other parallel and consecutive trials. This standard soil must resemble the soil or growing media used in the commercial practice that these tests are intended to reflect. The best approach is to take a large amount of this soil, thoroughly mix, sieve, air dry and store in a cool and dry place; each time soil is needed for a trial it can be taken from this stock.

A more practical way is to designate a homogeneous plot - not necessarily a greenhouse plot - as the standard soil source. This should be kept under permanent crop cover or a continuous rotation. If either of these approaches is impossible, then other soil can be used but this is less satisfactory and the results cannot so easily be extrapolated. Pre testing of the soil is needed to estimate the bulk weight of pots filled with air dry soil, considering a maximum filling rate of $75 \%$. This weight will be the standard for all pots. The data on specific weight of soil per pot and water quantity needed will be used for all incubation tests to be performed with this standard.

\section{Experimental design of incubation trials}

The fertiliser to be tested must be analysed and characterised. All organic fertilisers contain a mixture of nutrients which complicates the application and the testing. All incubation trials need a range of applications, including a zero control. The range should resemble an expected total supply of the nutrient under investigation. For $\mathrm{N}$ this can be $0,25,50,75,100 \mathrm{~kg} \mathrm{~N} / \mathrm{ha}$. For $\mathrm{K}$, the range is likely to be $0,50,100,150,200 \mathrm{~kg} \mathrm{~K} / \mathrm{ha}$ and for $\mathrm{P}$ the range can be $0.5,10,15,20,25 \mathrm{~kg} \mathrm{P} / \mathrm{ha}$. 
The incubation trial should be set up with at least four replicates. Before starting, the required application must be determined, based on the weight of soil at field capacity and filling rate of the pots. The required portion of air-dry soil will be taken from storage and for each treatment the total quantity of soil should be thoroughly mixed with the fertiliser under investigation. After mixing the soil must be divided in equal portions between the pots. A cement mixer is ideal for mixing the soil. During the mixing process half of the required water quantity will be added and thoroughly mixed. Then pots will be filled with equal quantities of the soil-fertiliser mixture. After the pots are put in place, the remaining water will be added to each pot. Pots should preferably be placed in a room with controlled environmental conditions.

In some experiments the results may show an initial decrease in the mineral $\mathrm{N}$ concentration. This is due to immobilisation of $\mathrm{N}$ by microorganisms, caused by a low availability from the organic matter (low $\mathrm{C} / \mathrm{N}$ ratio). This is related to properties of the fertiliser and is a true outcome of the test. However, this might be undesirable for the purpose of interpretation and application of the data so it is better to avoid this immobilisation effect and use soil with higher mineral $\mathrm{N}$. To boost the mineral $\mathrm{N}$ in the soil, either simply base dress the bulk soil with some (conventional) urea or prepare the bulk soil by adding a rapid releasing organic fertiliser such as blood-meal. However, this preparation needs to be done with fresh field moist soil at least four weeks prior to the testing to enable the process go for some time. The air drying, as described above, is then needed before storage of this soil.

\section{Quantitification}

The quantity of fertiliser to be mixed into the soil can be calculated as follows:

$\mathrm{F}=(\mathrm{N} / 3000) *(\mathrm{Bd} / \mathrm{n}) * \mathrm{r} * \mathrm{v}$

where:

$F=g$ fertiliser to be added

$N=N \mathrm{~kg} / \mathrm{ha} N$ treatment level to be supplied

$n=N$ quantity in the fertiliser, in $\mathrm{g} / \mathrm{kg}$

$B d=$ bulk density of the air dry soil $\mathrm{g} /$ litre

$r=$ number of replicates

$V=$ filling volume of pot (in litres)

(3000 equivalent for a soil area of 1 ha to $30 \mathrm{~cm}$ rooting zone)

As the processes involved in mineralisation are strongly dependent on temperature and soil moisture the pots should ideally be placed in a climate-chamber with controlled environment i.e. constant temperature and humidity, with set-points resembling the average greenhouse environment. Alternatively the pots can be placed in a section of a greenhouse, together with continuous monitoring of the pot temperature, to make it possible to compare and extrapolate the results. During the tests, the water capacity should be kept at around field capacity. The best estimation of this will be obtained by placing some of the pots on electronic scales and refill the pots with water according to their weight. If these are not available, the moisture conditions can be checked with hand-held soil moisture sensors (FD-sensors). To protect the top layer of the pots from drying out too quickly, a cover with perforated plastic can be used. Never use closed plastic sheet as air movement for unrestricted $\mathrm{CO}_{2}$ and $\mathrm{O}_{2}$ exchange must be possible. Obviously, the water source used must be as pure as possible (e.g. rainwater, reverse osmosis or demineralized water) to avoid interactions and misinterpretation of results. 


\section{Observations and interpretation of data}

After mixing the fertilisers and before filling the pots a soil sample must be taken from each treatment (including the control). During the incubation trial soil samples must be taken at regular intervals from the pots to enable calculation of a nutrient release curve. Samples can be taken by using a small auger; the boreholes must be refilled with soil from the pot. The frequency will depend on the expected release time of the fertiliser under investigation (based on expert judgement or knowledge of some components). For rapidly mineralising fertilisers a reasonable schedule is after 7, 14, 28 and 56 days. For more slowly mineralising fertilisers it can be: 10, 25, 50, 100 days. Both schedules will provide sufficient information for practical application purposes. However, if one wants to know the full release, the schedule must be prolonged to 200 days and one year respectively. If it is not known if a certain fertiliser belongs to the category of rapid or slow releasers, a short testing prior to the incubation test is required. For soil analysis, it is necessary to estimate both $\mathrm{NH}_{4}{ }^{+}$and $\mathrm{NO}_{3}{ }^{-}$concentrations as well as the quantity of soil solution. Therefore the $1: 10 \mathrm{CaCl}_{2}$ (Houba et al. 2000) or 1:2 extract (Sonneveld et al. 1990), then using $\mathrm{CaCl}_{2}$ instead of demineralised-water (modification after Sonneveld et al. 1990) are the most appropriate. For a scientific approach, all four replicates must be sampled individually to enable statistical analysis. For pragmatic approaches, the sampled soil of the four replicates can be put together rather than being analysed separately although this will reduce the opportunity for statistical analysis. The results can be expressed relative to the total supplied $\mathrm{N}$.

\section{CROP DEMAND TRIALS}

The aim of these is to assess the effect of fertilisers on crop development and determination of plant requirements. The approach can be either a response trial with base dressing only, with top dressing only, or a mixed design.

Crop: When selecting a test crop it is important to verify that this is likely to show the expected impact of the treatments; some crops are more nutrient demanding than others.

Soil Type: It is recommended to do parallel tests on contrasting sandy and clay soils. The soil should not have been fertilised too heavily in previous years.

Location: The trial should be established in a homogeneous area with regard to factors such as soil and water management. No trial should have been laid out there before as there may be after effects of the treatments. Differences can partly be corrected in statistical analysis of the results but this does reduce the accuracy of the work.

Size: In greenhouses plots of at least $10 \mathrm{~m}^{2}$ should be considered. For practical reasons it is recommendable to use the span-width as the measure for width and a length of 3 meters.

Additional fertilisation: For a trial is focused on a particular nutrient it should be ensured that all other nutrients are sufficiently available or will be supplied.

Irrigation and soil moisture: Nutrient availability depends strongly on the moisture content of the soil. Wet and dry conditions will disturb microbial processes such as mineralisation and cause heterogeneities. Therefore drip irrigation is not a favourite system for fertiliser trials as, by definition, they will cause horizontal heterogeneity and dry zones in the topsoil. Some sprinkler type systems, on the other hand, have disadvantages as well. The least disturbing system is probably a combination of drip and sprinkler. Soil moisture content should be monitored and ideally controlled by soil moisture sensors or tensiometers.

Crop-husbandry: It is important to do as much as possible to minimise the occurrence of pests and diseases and weed growth. 


\section{Experimental design}

Important guidelines are:

- Always include an unfertilised control plot. This will give information on the extent of the background nutrient availability by the soil.

- When comparing fertilisers systems a treatment with the relevant nutrient supplied at a suboptimal level must be incorporated.

- There should be at least four rates of application including the control. If the goal is to establish the crop need (for example, updating fertilizing advice) then both sub and supra-optimal levels must be used.

\section{Specifically for trials aiming at base dressings:}

Prior to the testing, soil analysis must be made to estimate the background mineral content at the start.

- Decisions about application rates of the fertilisers must be based on data concerning the expected release of nutrients, either obtained from literature or the supplier. If not available, incubation trials are required prior to the crops response trials.

- For very long season crops (e.g. tomatoes grown for longer than six months) $\mathrm{N}$-and K-supply solely by base dressings is inappropriate, due to too high inputs needed at the start. For these crops, a mix of base- and top dressings is required, taking into account the fact that that the total $\mathrm{N}, \mathrm{K}$ or EC level in the soil must not surpass certain maxima, as described in Sonneveld and Voogt, (2009). Hence the top dressings must also be part of the design.

- The choice for the different levels to be applied must be based on profound estimations of crop demand and rate of mineral release. A good principle to begin with is that halfway through the growing period, half of the required nutrient should become available.

- For comparison trials (e.g. alternatives to established organic fertilisers) a reference treatment with the "standard" should be incorporated. The supposed 'optimal' should get the same quantity of N (or K or P) as the reference plot.

\section{Specifically for trials aiming at top dressing}

- Prior to the testing, soil analysis must be made to estimate the background mineral content at the start.

- Use a standard base dressing using fertilisers for nutrients not under investigation.

Overlap and interference with the nutrient/fertiliser under investigation cannot be avoided completely, but use minimal inputs to keep at least the EC between boundary values.

- The choice for the different levels to be applied must be based on profound estimations of crop demand and mineral release. The determination of timing and splitting of the applications must be set and based on realistic expectations.

- Applications must be carefully supplied, in case of solid fertilisers, these cannot be combined with drip irrigation, as unequal wetting of the fertilisers will be a risk.

- For comparison trials (e.g. alternatives to established organic fertilisers) a reference treatment with the "standard" should be incorporated. The supposed 'optimal' should get the same quantity of N (or K or P) as the reference plot.

Fertiliser trials are usually laid out as a block design. In a greenhouse the plots are laid out span-wide, each treatment plot then can follow one after the other. A border area of at least $1 \mathrm{~m}$ width is usually left on both sides of the trial. At least four replications are recommended.

\section{Observations}

Crop: Yield and quality should be monitored, the exact parameters depending on the crop type (see Chapter 4). Particular attention should be paid to nutritional disorder symptoms (leaf colour etc.) during crop growth. Total biomass should be assessed, either at crop harvest or, in the case of long term crops with prunings, also during the growth period. Biomass should be dried and the nutrient content determined to calculate total crop uptake.

Soil: At least before planting or sowing, after 4 weeks and at final crop harvest, soil samples must be taken from the rooting zone (0-25 cm depth). Cores should be taken randomly in the plant rows. If drip irrigation is used cores should be taken equally from spots close by and in between the dripping zone. Samples should be analysed for $\mathrm{N}$-min, $\mathrm{K}$ and $\mathrm{P}$, using appropriate analytical methods like the $\mathrm{CaCl}$ extraction method or the 1:2 volume extract (Houba et al. 2000; Sonneveld et al. 1990). 


\section{References and further information}

Houba VJG., Temminghoff EJM., Gaikhorst GJ, Van Vark, W. 2000.

Soil analysis procedures using $0.01 \mathrm{~m}$ Calcium Chloride as extraction reagent. Commun. Soil Sci. Plant Anal., 31(9\&10), 1299-1396.

Sonneveld C Van den Ende J and De Bes S S. 1990.

Estimating the chemical composition of soil solutions by obtaining saturation extracts or specific $1: 2$ by volume extracts. Plant Soil 122, 169-175.

\subsubsection{Experiments with liquid fertilisers}

\section{By Martin Koller}

\section{General requirements}

The plots must have been fertilized equally in the previous years. If this is not the case the crop and soil management should have be the same at least within each experimental block. If there is any doubt about the homogeneity of the trial site a nitrogen demanding green manure could be established prior to the experiment (e.g. oil radish). The biomass of this green manure has to be removed before the experiment begins.

An appropriate buffer around each core plot has to be established. In most cases $1 \mathrm{~m}$ along the row and one row between the plots is sufficient to separate different fertigation treatments (liquid fertilisers mixed in the irrigation water). However the minimum distance between core plots depend on the irrigation system. With drip irrigation systems, at least the length of 3 drip holes between the core plot and the border of the plot should be reserved as a buffer. With sprinkler irrigation systems the border around the core plot has to be at least 1.5 times the irrigation radius of the sprinkler.

\section{Fertilisers}

All the fertilisers to be tested have to be characterized carefully. In most cases it is best to determine the nitrogen (and carbon) content of each batch to be used before the experiment begins. For liquid organic fertilisers the density and the viscosity has to be measured (in the case of viscosity this can most easily be described by comparing it to well known fertilisers).

Fertilisers should be applied according to their total nitrogen content. If it is suspected that their rates of nitrogen availability are very different a preliminary incubation experiment should be carried out to determine availability ratio of each one. This enables them to be applied according to "available nitrogen " instead of total nitrogen.

\section{Fertiliser application}

For experimental use it is possible to mix the fertiliser with water and to spread it with watering cans. However this is very unlike true farm practice so it is therefore advisable to use drip irrigation hose for each treatment separately and mix the fertilisers and the irrigation water with proportional dosing pumps (e.g. Dosatron). If dosing pumps are used, it is important to confirm that they work properly, e.g. by measuring the nitrogen content of the fertigation solution. Especially with very viscous fertilisers dosing pumps do not always run properly. In such cases some water should first be added to the fertiliser (20-50\% of the volume of the fertiliser is usually sufficient) and the dosing pump then adjusted accordingly. Alternatively the fertilisers can be mixed manually. Some fertilisers will cause clogging. They should, therefore first be tested on a small scale and after every fertigation run the system should be rinsed with clean water. 

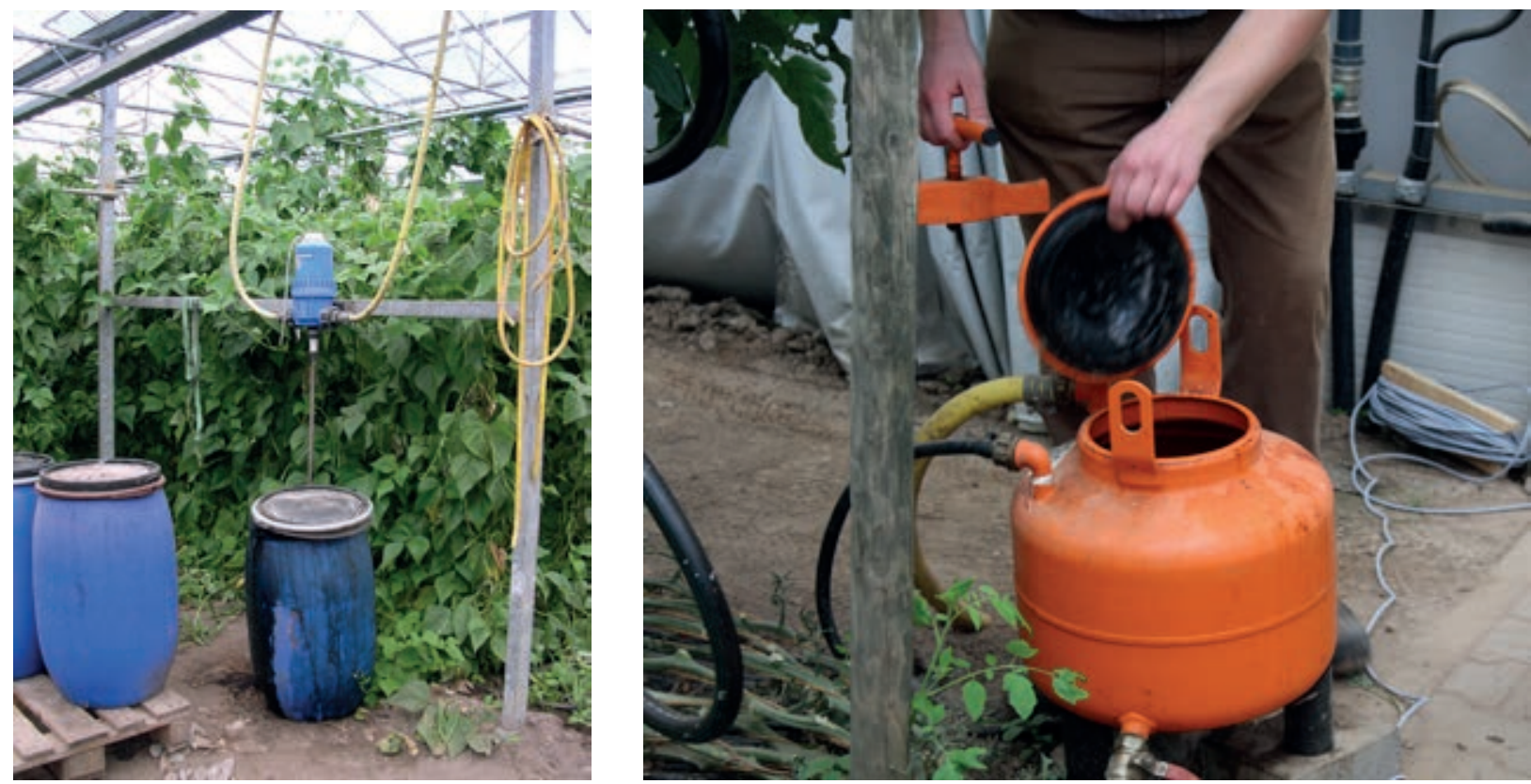

Figure 3.3 Equipment used for fertigation of greenhouse crops, mixing nutrients into the irrigation water.

\section{Soil and plant samples}

Before the start of the experiment soil samples should be collected from all plots. For fruiting vegetables samples should be taken down to $60 \mathrm{~cm}$ depth; in lettuce and other more shallow rooting crops $30 \mathrm{~cm}$ might be sufficient. During the cropping period additional soil sampling could be conducted although mineral nitrogen analysis will not show if plants have already taken up the available nitrogen or if the fertiliser is not yet completely mineralized; interpretation or the results is not straightforward.

A more direct approach is to measure nutrients in plant sap (e.g. using portable ion meters such as LAQUAtwin, www.horiba.com) or to measure the colour of the leaves (e.g. using Minolta SPAD 502 chlorophyll meter).

Soil samples should also be collected at the end of experiment. Measurements should also be made of the vegetative plant material, harvested fruits (at a representative number of harvests) and any leaves or side shoots that are removed. The nutrients in these components should be determined and the data can be used to calculate a nutrient budget for the crop.

In the following example, for nitrogen, the apparent effectiveness of an organic fertiliser could be calculated according to:

$$
\text { apparent effectivness }(\%)=\frac{\left(N_{\text {tot }}+N_{\text {min }}\right)_{\text {treatment } A}-\left(N_{\text {tot }}+N_{\text {min }}\right)_{\text {unfertilised control }}}{\text { applied nitrogen in treatment } A}
$$

$\mathrm{N}_{\text {tot }}=$ Sum of nitrogen in plants

$\mathrm{N}_{\min }=$ Mineralised nitrogen in the soil at the end of experiment

\section{Evaluation}

In most cases a comparison of the yield is sufficient to compare the effectiveness of different fertilisers. Yield determination has to be carried out according to the recommendation for the different vegetables (see Chapter 4). In fruit crops such as tomatoes, some quality parameters such as total soluble solids, titratable acidity and firmness on at least at three harvest dates could complete the assessment. With leafy vegetables, produce should be sampled for nitrate, at least if grown during winter time, because of concerns of its effects on human health. 


\subsubsection{Experiments with compost}

\section{By Jacques Fuchs}

\section{Aims of compost experiments}

Depending on the situation there can be various aims of compost experiments. For example to study the influence of compost on soil structure, on water holding capacity, on plant nutrition, on plant health, to compare of the effect of different compost types (different inputs, different maturity etc.), or to compare different strategies of compost use (e.g. distribution over the whole field or only in the crop rows, rates and timing of compost application etc.).

Before beginning a compost experiment, the specific question to be answered has to be clearly defined as this will influence the design. For example, if the primary aim is to study/demonstrate the influence of the compost on the soil structure, the experiment has to have a minimum duration of five years but if the aim of the experiment is to investigate the effect of compost against diseases then a duration of only one or two crops may be sufficient.

\section{General requirements}

The site on which the experiment will be done has to be homogenous. The choice of the site should be in relation to the question we want to investigate (e.g. using land with, or at risk of, soil structural problems if we want to investigate the influence of compost on soil structure).

The composts used have to be well characterized in order to compare the results of different experiments. When analysis results are stated it is important to be clear about the methods used and if the results are expressed relative to compost volume or compost weight (fresh or dried). Different countries each have normally accepted methods (that may be related to compost quality standards e.g. BundesgütegemeinschaftKompost, VKS-ASIC 2010). The concentration of some elements is often expressed in terms of their oxides (e.g. $P_{2} O_{5}$ rather than $P$ ). This may be a legal requirement for the declaration of fertiliser composition but it can easily lead to confusion. The information needed includes:

Information about the composting process:

- Quantitative and qualitative characterisation of input materials (in percentage terms).

- Composting system (e.g. open windrow or in vessel).

- Profile of temperature and moisture content during process.

- Information on the intensity and method of compost turning.

- Duration of the process.

- Storage conditions.

Physical and chemical and biological analysis of the compost:

- Sieving size (in $\mathrm{mm}$ ).

- Bulk density of fresh compost (weight per volume).

- Dry matter (in as a percentage by weight of fresh compost).

- Organic matter (usually as a percentage of dry matter).

- Ph (in water or in a specific salt solution).

- Electrical conductivity and salt content.

- Total element content of major nutrients (including nitrogen, phosphorus, potassium magnesium, calcium).

- Available or extractable nutrient content (e.g. $\mathrm{NH}_{4}-\mathrm{N}, \mathrm{NO}_{2}-\mathrm{N}$ and $\mathrm{NO}_{3}-\mathrm{N}$ ).

- $\mathrm{C} / \mathrm{N}$ ratio.

- Total potentially toxic elements (e.G. Mercury, cadmium and zinc).

- Contamination with inert materials (stones, glass, metal and plastic).

- Occurrence of viable weed seeds.

- Occurrence of human pathogens.

Depending of the aim of the experiment, knowledge of other characteristics of the compost can also be important (Fuchs et al. 2008). For example suppressivity potential against Pythium and Rhizoctonia or phytotoxicity effects. 
The soil where the experiment is performed also has to be analysed (type of soil, texture, organic matter content, N, P, K, Mg, Ca etc.). It is very important to describe exactly the methods used for the determination of the compost and soil parameters (especially the extraction medium used) as a number of techniques are available that may give quite different results.

\section{Quantity of compost used}

The maximum quantity of compost used is determined by the balance of fertiliser. The nitrogen is usually in a very unavailable form and so in some countries (e.g. Switzerland) only $10 \%$ of the total amount is considered in the balance. However there may be other limits of application (e.g. in Switzerland a maximum of 25 tonnes dry matter per ha can be applied in any three year period). As the compost cannot offer to the plant all the nutrients in sufficient quantity additional inputs may also be needed (e.g. of nitrogen).

\section{Reference plots}

If not only fertilisation questions have to be answered by the experiment, it is important to have, in addition to an untreated reference plot, also a standard treatment (a N, P, K, Mg control). The quantity of fertiliser in this plot has to represent the fertiliser content in the compost, and the availability of the fertilisers also has to be similar. For $\mathrm{K}$ and $\mathrm{Mg}$, 'Patentkali' can be recommended - this is a mixture of potassium sulphate and magnesium sulphate. $\mathrm{P}$ can be added as rock phosphate. For nitrogen, it is recommended to add horn shavings to balance the soil $\mathrm{N}_{\min }$ content as a result of compost addition.

\section{Experimental design}

For experiments with a duration of only one season, a standard design with four replications can be used. The plots have to be of a sufficient size to avoid border effects in the evaluation of the results (e.g. plots with a minimum width of 4 crop rows and length of 10 meters; the middle two rows are evaluated between meters 2 and 8). For experiments with a duration of several years (e.g. to evaluate the effect of compost on soil structure) the plots have to be larger in order to avoid the mixing of soil from the various treatments. The buffer zones, in which no measurements are done, are more important than in the short time experiments. For experiments running for several years, soil samples from all the plots should be collected and analysed before the work begins in order to establish base line values.

\section{References and further information}

Fuchs J.G., Berner A., Mayer J.,Smidt E., Schleiss K. 2008

Influence of compost and digestates on plant growth and health: potentials and limits. Proceedings of the international congress CODIS 2008.p. 101-110.www.orgprints.org/17977/

Bundesgütegemeinschaft Kompost e.V.Methodenbuch (in German). www.kompost.de VKS-ASIC 2010. Schweizerische Qualitätsrichtlinien (in German). Directive Suisse de la branche sur la qualité du compost et du digestat (in French). www.vks-asic.ch

\subsubsection{Experiments with green manures}

\section{By Francis Rayns}

\section{Background}

Green manures are crops grown for the benefit of the soil rather than for harvest and sale. They can have a number of effects in protected cropping that include:

- Adding nitrogen to the soil by nitrogen fixation (legumes only).

- Modifying the availability of other plant nutrients.

- Adding organic matter to the soil.

- Stimulating biological activity.

- Contributing to the control of weeds, pests and diseases. 
A huge range of species can be used as green manures; many of these are also important as animal forage (e.g. clovers) or can be grown as crops in their own right (e.g. buckwheat). They may be grown for several years or just a few weeks. Mixtures are commonly used (e.g. rye and vetch). Green manures are at the heart of most organic crop rotations in as they greatly reduce the reliance on external inputs. Their use is easier to justify in more extensive growing systems than in protected cropping where the infrastructure costs are high and there is greater pressure to grow as many cash crops as possible. However they certainly have a role in some glasshouse situations and more research is needed to evaluate their potential that could include:

- Screening of different species (and varieties) of green manures. This could include determining appropriate sowing dates in various regions, duration of growth, accumulation of biomass and nutrient composition at different growth stages, suppression of weeds, temperature tolerance (high and low limits), tolerance of soil conditions (e.g. of pH), suitability for use in mixtures or intercropped with cash crops, susceptibility to pests and diseases.

- Management techniques. This could include determining the best seed rate and sowing method (e.g. broadcast or drilled), the value of inoculation with Rhizobium bacteria, possible mowing regimes, incorporation or mulching techniques.

- Effect on soil quality. This could include studies of the pattern of release of nutrients from green manures after incorporation. This is particularly relevant for nitrogen but also for other elements (some species, e.g. buckwheat, are known to have a specific ability to mobilise phosphorus in the soil). Additions of organic matter can improve soil structure (e.g. resulting in better water holding capacity and workability).

- Effects on growth of following crops. This could include measurements of crop yield and quality, ideally for more than one subsequent crop in the rotation.

- Effects on pests, diseases and weeds. Some green manures (e.g. certain mustards) have a biofumigating effect on the soil - to achieve the full potential of this specific incorporation techniques are required. Others (e.g. vetch) have an allelopathic effect that may help with weed control. Conversely the use of green manures may create a 'green bridge' allowing some pests or diseases to persist during an otherwise fallow period.

\section{Trial design}

This is more likely to be constrained than in green manure experiments for field vegetable crops as space can be at a premium in a greenhouse situation. There will also be less flexibility of layout and plot size because of pathways and other infrastructure. The effect of proximity of the edges of the building must be considered. There may only be room to have a single set of treatments in one structure - the replicates may need to be in other greenhouses on the same site. It is possible to use the growers holding as a whole as the statistical 'block' and replicate the experiment on other sites but there is likely to be more variation with this approach and so a need to have more replication in order to obtain a robust result.
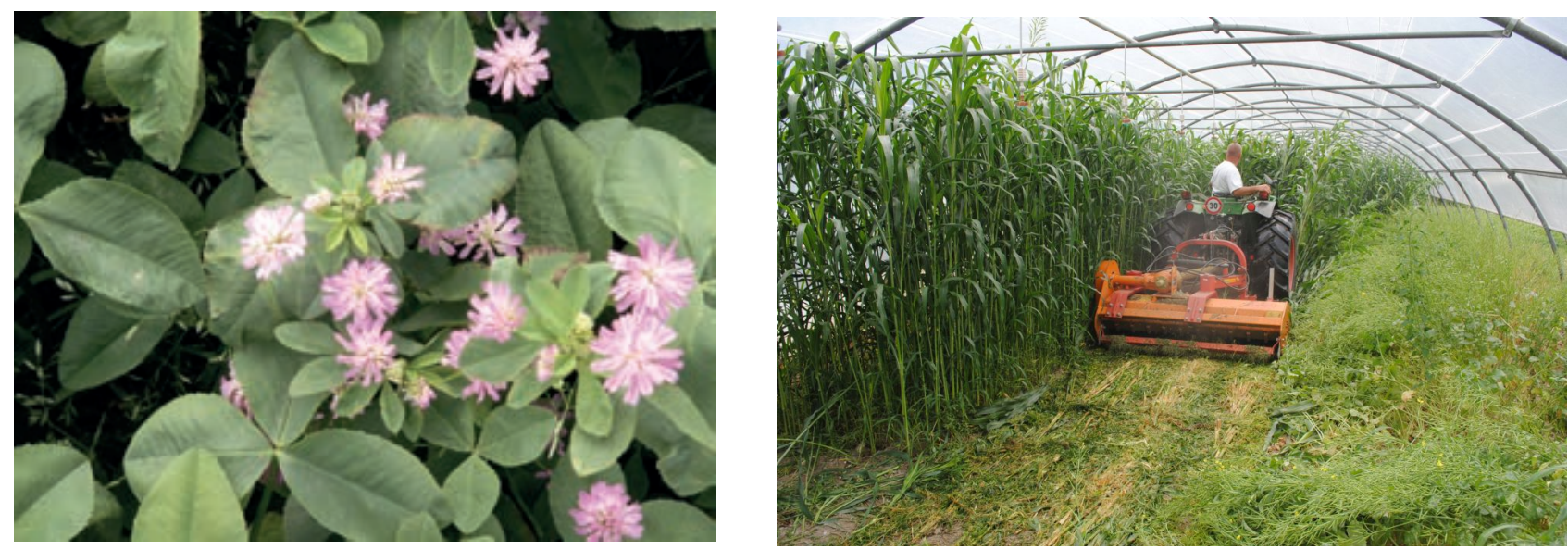

Figure 3.4 Green manures: Red clover (left) and Sudan grass and brown mustard being mown in a polytunnel in Switzerland (right, picture by Agroscope Conthey, Switzerland). 


\section{Crop husbandry}

Whenever possibility all operations should be done in as similar manner as possible to what would be commercial practice. In some cases, however, sowing etc. may need to be done by hand rather than machine if a number of different species are being compared. If the performance of a green manure crop in a region is completely unknown then it may be worthwhile to conduct some small, unreplicated, tests in the season before the main experiment is set up. This will ensure that there is a basic understanding of a crops requirements so that a promising idea is not dismissed as a failure when, with slightly different management, it could be grown to advantage.

\section{Measurements}

All trials should include at least some measurements of green manure performance but the degree of detail to which this is done does depend on the aim of the work and, to some extent, the time available. Measurements could include:

- Crop germination. Counts of seedling emergence can be done every few days in the weeks after sowing. If a mixture of species has been sown then the different species should be identified and recorded separately. It is best done by counting the numbers in several meter lengths of row (these can be marked out and the same rows used for each successive count) or in a square quadrat if the seeds have been broadcast.

- Crop growth and development. Crop heights give a simple, non-destructive yet numerical way of assessing growth. However, it can be misleading in comparisons between different species as some will tend to have a more upright habit than others and this is not necessarily related to biomass production. Estimates of ground cover are useful (these can be categorised into bare ground, green manure and weeds) and, if regularly done, can show development over time. Quadrats can be used or estimates of whole plot performance can be made. Monitoring of growth stage is important as the effects of a green manure will change as it matures; they generally become more lignified and slower to decompose. Seed set is also an issue as there is a potential for green manures to become weeds in following crops. Some researchers have used cameras installed in tubes ('minirhizotrons') to follow root development but this is a very specialist area.

- Nitrogen fixation. For leguminous green manures an estimate of input of atmospheric nitrogen is likely to be relevant. Unfortunately measuring fixation accurately is not easy and can be expensive. There are a number of methods available, for example using ${ }^{15} \mathrm{~N}$ labelling, using natural ${ }^{15} \mathrm{~N}$ abundance and comparing nitrogen uptake with a non-legume green manure Many researchers use estimates from the literature (for example to construct nutrient budgets) but it may not be appropriate to extrapolate from field to glasshouse conditions. At the very least there should be observations to see if nodules are present and if they are pink to show that they are active.

- Weed, pest and disease problems. Particular issues should always be noted. If control of these problems is a focus of the trial then more detailed monitoring may be worthwhile (eg scoring of damage at regular intervals to show the spread of a disease). Excessive weeds may interfere with some antagonistic green manure effects (e.g. the inhibition of nematodes by Tagetes)

- Biomass. If the crop is mown during its growth (common for longer tem green manures outside but perhaps less relevant in a greenhouse situation) then the amount cut should be measured. This is best done by cutting a quadrat with sheers at the same height as the mower used for the whole trial. The amount and nature of plant material actually incorporated is perhaps the most important measurement of all but measurements of biomass may also be made as the green manure crop grows - this information may be useful for modelling growth. Biomass is best measured by sampling one or more quadrats per plot. Ideally the plants are carefully dug up, the roots washed and the roots and shoots weighed separately. Weeds can also be separated from the crop, and a green manure mixture separated into its component species. It is impossible to extract all the roots so this measurement will only be 'recoverable roots' and an underestimate of the full root biomass. As an alternative the shoots can just be cut off 'at ground level'. This is much quicker but does result in an underestimate of the above ground biomass because many of the stem bases will not be included. If more information about root growth is really needed then it is possible to extract large (say $10 \mathrm{~cm}$ diameter) soil cores and wash out the roots from them over sieves. There is likely to be a lot of variability so preliminary wok may be needed to ensure that there is enough replication to make the results statistically robust. In small plots there needs to be a compromise between the gathering of data and disruption to the plot (trampling causing compaction, removal of samples etc.). This is a particular issue in the case of a long term trial where the growth of following crops can be affected. 
- Biomass quality. Fresh weight of the sampled material is readily measured and is usually expressed as tonnes per ha although $\mathrm{kg}$ per square meter may be more appropriate. It is best to also use a subsample to determine the dry matter content of each crop fraction (roots, shoots, weeds etc.) by drying in an oven at $60^{\circ} \mathrm{C}$ until a constant weight is achieved. Chemical characterisation may be useful; this can mean analysis of major nutrients $(\mathrm{C}, \mathrm{N}, \mathrm{P}$ and $\mathrm{K}$ ) or of the cellulose/lignin content. The $\mathrm{C}: \mathrm{N}$ ratio is particularly important for predicting the mineralisation patterns of a green manure. Analysis of a large number of samples is expensive so it may be necessary, although not ideal, to pool the replicates or to use standard values from the literature in order to calculate the inputs to the soil.

- Soil information. Basic soil parameters (e.g. pH, available nutrients, organic matter levels etc.) should be determined at the time the experiment is set up so that the results can better be compared with those from other sites. It may be necessary to make other measurements as the green manures are growing or at the time of incorporation if soil effects are a focus of the work. Whenever soil samples are taken it is important that they are representative of each plot (adequate cores must be taken to provide a pooled sample of sufficient size for the analyses needed) and are taken with clean tools to a known depth. They must be treated appropriately before analysis (if mineral nitrogen is required they must be stored cool but not frozen although air drying is acceptable before certain determinations).

- Environmental information. Records of temperature, light levels etc. should be kept, together with information about watering (rainfall will probably be irrelevant but may influence the moisture levels in the subsoil beneath the greenhouse). It is also useful to record the previous cropping.

\section{Effects after incorporation - soil}

Regular soil sampling will show the pattern of release of nutrients as a result of incorporation of the green manures. This is of particular relevance in the case of nitrogen which, in its mineral forms, exists only transiently and yet is so important for crop nutrition; its availability is usually greatly affected by green manures. Quantifying soil physical and biological changes is more difficult. In situ measurements can be made of, for example, bulk density, soil hardness (using a penetrometer), water infiltration etc. In some cases diversity and abundance of various types of soil life can be assessed - this may be of particular relevance in monitoring the effects of green manures on soil borne diseases.

\section{Effects after incorporation -crops}

Performance of the following crops should be measured according to the protocols suggested in other chapters in this book. Depending on the focus of the work particular attention may be paid to various effects (e.g. competition with weeds, disease incidence, crop yield or quality). In some cases it may be desirable to continue to measure the performance of crops throughout a whole rotation.

\section{Economic evaluation}

All trials should include some calculation of the costs and benefits of the various treatments. This is to enable any potential yield benefits to be set in a commercial context. Ideally there should be a comparison with 'standard farm practice'. Suggestions for how this can be accomplished are covered in section 3.6 of these guidelines.

\section{Anecdotal information}

This is particularly relevant for on-farm 'participatory' trials. The grower's view on the practicality of adopting a particular strategy has a value in addition to the agronomic measurements. They may be able to show that something may be very difficult or easy to adopt. They may be able to comment on something (e.g. an improvement in soil workability) that has not been quantified but is nevertheless important.

\subsubsection{Fertilising experiments in growing media used for transplant production, potted herbs or ornamentals}

\section{By Martin Koller}

See also section 3.2.6 and 4.5.1 
The amount of nutrients and fertilisers in growing media are usually expressed in $\mathrm{mg}$ or $\mathrm{g}$ per litre of growing media (i.e. by volume rather than by weight). It is therefore crucial to use an easy and accurate laboratory method to measure bulk density. The ISHS method (Verdonck and Gabriels, 1992) or the EN 13041:2011 (CEN 2011) method are usually considered to be too time consuming. It is therefore recommended to use one of the following methods:

EN 13040:2007 Filling a one-litre test cylinder with sample "as received", static compaction (with a (CEN 2007) plunger) and weighing the contents of the cylinder.

VDLUFA (A 13.2) Filling a $250 \mathrm{ml}$ cylinder with sample "as received" (respectively rewetted to "pot condition" - i.e. when tightly compacted in a fist it must be moist but no moisture may exude), compaction by dropping 10 times from $10 \mathrm{~cm}$ height and weighing of the contents of the cylinder.

\section{Setting up experiments}

Different fertilisers should be added to the growing media to supply the same amount of the element in question (in terms of $\mathrm{mg}$ per litre). All the other elements (especially micro-elements, which are not the subject of the experiment but may also be in the fertilisers) should be equilibrated (e.g. with appropriate additions of rock phosphate and potassium sulphate).

Changes to available nutrient levels are likely to occur during growing media storage. It is therefore recommended, as well as conducting experiments using freshly mixed growing media to store samples in closed plastic bags at least for 4 weeks and then test again with the same setup. This procedure can simulate the handling and use of most commercial growing media.

At least 4 replicates should be used. In most cases it is useful to use more than one test species to assess any possible phytotoxic effects of the fertilisers (e.g. Chinese cabbage is a plant sensitive to some phytotoxic compounds).

\section{Evaluation of experiments}

Experiments should continue at least to the normal transplanting stage of the crop. There should be assessments of:

- Fresh weight of the shoot at transplanting stage.

- Nutrients in the shoot.

- Growth after transplanting.

- Analysis of the growing media for $\mathrm{pH}, \mathrm{EC}$ (salinity) and nutrients such as $\mathrm{N}_{\min }$ at least at start and at the end of the experiment.

\section{Determination of $\mathrm{pH}, \mathrm{EC}$ and nutrients in growing media:}

Either of the following methods can be recommended (Sonneveld and Voogt 2009):

$1: 1.5$ volume water extract (e.g. national standard method in the Netherlands)

1 : 5 volume water extract, according to the recommendation CEN/TC 223 or VDLUFA (national standard method in Germany)

Instead of water, stronger solutions such as CAT $\left(\mathrm{CaCl}_{2}+\right.$ DTPA) can be used as these can give more meaningful results, especially in growing media containing compost and clay products. The presence of a chelate such as DTPA will extract higher amounts of metallic elements. Whatever method is chosen it should be clearly stated in any report of the results.

\section{References and further information}

Cees Sonneveld, Wim Voogt. 2009.

Plant Nutrition of Greenhouse Crops. Chapter 4: Soil and Substrate Testing to Estimate Nutrient Availability and Salinity Status. https://books.google.ch/books?isbn $=9048125324$

CEN - European Committee for Standardization. 2007.

EN 13040:2007: Soil improvers and growing media - Sample preparation for chemical and physical tests, determination of dry matter content, moisture content and laboratory compacted bulk density. 
CEN - European Committee for Standardization. 2011. EN 13041:2011:

Soil improvers and growing media - Determination of physical properties - Dry bulk density, air volume, water volume, shrinkage value and total pore space. http://standards.cen.eu/

Wever G. and van Winkel A. 2004.

Interlaboratory Study CEN-Methods for the Analysis of Growing Media and Soil Improvers. Acta Hort. 644, 597-603. http://www.actahort.org/books/644/644_80.htm

VDLUFA 1991.

VDLUFA Methodenbuch Band I Die Untersuchung von Böden (in German). 4. edition. 19911570 p. ISBN

978-3-941273-13-9

Verdonck O. and Gabriels R. 1992.

Reference method for the determination of Physical and Chemical Properties of Plant Substrates. Acta Hort. 302, 169-179.

\subsubsection{Evaluation of container growing media}

\section{By Yuksel Tüzel}

Growing media are used in the production of potted herbs, ornamentals and vegetable transplants. For use in certified organic production transplants have to be organically propagated and so only substrates permitted by the regulations should be used. A successful growing medium must have good physical (porosity, water and air capacity), chemical ( $\mathrm{pH}$, electrical conductivity, nutrient content) and biological (organic matter, microorganisms) characteristics.

If different mixtures are to be compared the growing media should all be characterized carefully according to their water holding capacity, bulk density, pore volume and nutrient content. Mixtures should be made on a volume ratio $(\% \mathrm{v} / \mathrm{v})$ rather than by weight $(\% \mathrm{w} / \mathrm{w})$. However in some cases it is easier to determine the bulk density of each component beforehand and then compose the mixtures by weight. Fertilisers are also applied by a volume ratio (e.g. $300 \mathrm{mg} \mathrm{N}$ per litre substrate). Each tray (or even better each cell of the tray or each press pot) should contain the same amount of substrate. This can be checked by weighing once the bulk density has been established.

Growing media containing organic components will change significantly during storage. Therefore it is best, if resources permit this, to conduct a series experiments with growing media sored for different periods (e.g. in plastic bags) in order to evaluate organic growing media in a way that is relevant to on-farm practice.

\section{Watering regime}

Different growing media mixtures can hold different amounts of water. It is therefore crucial irrigate all treatments separately or to correct irrigation amounts individually several times. In an ideal case, all treatments will be irrigated regularly until a given water holding capacity is reached (between 50 and $80 \%$ ).
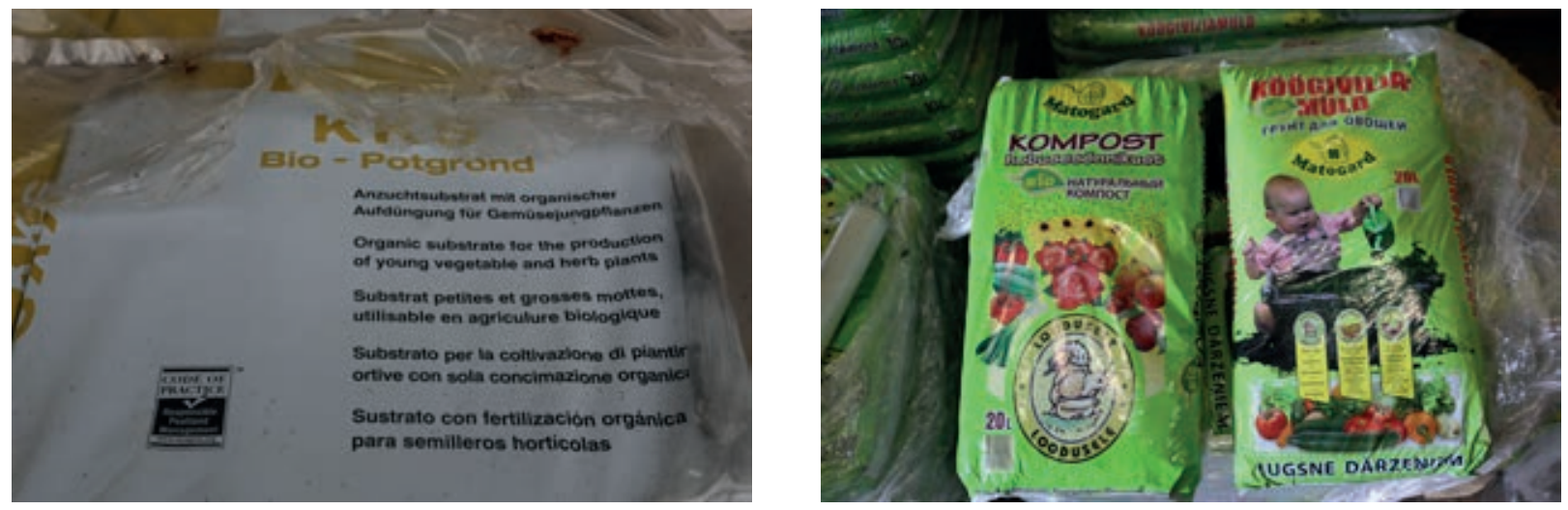

Figure 3.5 Examples of commercial growing media that may be used in trials 


\section{Experimental design}

Recommended replicates: at least 4.

Minimum number of plants per treatment: one tray per replication; this should be of a standard size used in commercial production e.g. containing 308 cells/plants.

\section{Assessments}

$\mathrm{pH}, \mathrm{EC}$ and $\mathrm{N}$ min should be measured at least at the start and the end of the experiment

Fresh matter (and dry matter) of the seedling shoots

Nutrient content (e.g. of $\mathrm{N}$ ) of the shoot (do not dry the shoot above $60^{\circ} \mathrm{C}$ )

Colour of the seedling leaves (e.g. using Chlorophyll Meter Minolta SPAD 502)

Establishment of the seedlings, by planting out seedlings and assessing their performance after a period of growth ('take off trials')

\section{References and further information}

Kuepper, G., 2010.

Potting Mixes for Certified Organic Production. Horticulture Technical Note. https://attra.ncat.org

\subsection{Experiments on weed control}

\subsubsection{Weed control}

\section{By Justine Dewitte}

\section{Requirements}

Before weed control experiments are carried out, it is advisable to learn to identify the different weeds at the seedling stage. To recognise them is crucial for the observations. Before a trial can be done an appropriate site must be selected. It is important to consider the history and the rotation stage of the field, because this will influence the process and the results of the trial. The plots must have been equally treated in previous years. An appropriate buffer around the trial has to be established.

Weed control trials can be done in different situations, for example:

- While the greenhouse is empty between two crops (for example, to assess the benefits of a green manure like Japanese oats (Avena strigose) or phacelia (Phacelia tanacetifolia), using a mulch, stale seedbed or a fallow period).

- While a crop is growing (for example, during a weed sensitive crop like baby leaf salads using flame weeding, mechanical weeding or planting through a mulch).

In both cases it is important to assess the immediate effects of these measures but also to examine the weed problems in the following crops.

\section{Experimental design}

Weed control trials are usually done using four replications, set up as a mono-factorial block design. The plots have to be of a sufficient size to prevent neighbouring plots affecting the results and to allow for the natural patchiness in weed populations. The size of the plots will depend on the aim of the trial but the work involved should not be underestimated. If a replicated trial is not possible then a 'demonstration' trial would be an alternative. In this case it is recommended to repeat the trial in subsequent seasons or at multiple locations to confirm the results. A control should be included; this is normally un-weeded but sometimes an area kept completely weed free (e.g. by hand weeding) is also appropriate. 


\section{Observations}

On each assessment date, information about the crop as well as the weeds should be recorded - this can include crop development stage (e.g. using a formalized BBCH scale), height of canopy, estimation of vigour and any pest or disease problems. The weeds on a plot can be expressed in population numbers, as a percentage of ground cover or as biomass. This can be determined in absolute figures or an estimation can be made. Information should also be recorded concerning the level of weed population on the untreated (control) plots.

Absolute assessment: Individual weed plants are counted for each species or the biomass of each species is determined by weighing. These evaluations have to be made on full plots or on randomly selected marked squares within each plot. For example, weeds could be counted in 8 randomly selected $35.3 \times 35.3 \mathrm{~cm}$ quadrats in each plot (i.e. with a total of $1 \mathrm{~m}^{2}$.)

Estimation: All treated plots have to be compared to the untreated (control or reference) plot. The relative weed population has to be estimated. The assessment includes an overall estimate of the total weed population and / or the individual weed species. It is possible to summarise in one figure an estimation of the number of weeds, the field coverage, the height and the vigour of growth ('virtual weed volume') of the weeds. In principle this is a fast and simple method. The result can be expressed as a percentage (that is to say on a linear scale of $0 \%=$ no weeds to $100 \%=$ same weed pressure as in the control plot). A similar inverse scale may be used to express the percentage of weed control $(0 \%=$ no weed control, $100 \%=$ complete weed control).

It can be important to identify the different weeds on each plot as some control measures will be effective against some and not others. The time needed to control the weeds for each treatment is also an important issue for the farmer as this is linked to the cost of production. Assessments should also be made at different times e.g. before and after specific control measures in order to assess regrowth.

\section{References and further information}

Meier, U. (ed.). 2001.

Growth stages of mono-and dicotyledonous plants. BBCH Monograph. 2. Edition German Federal Biological

Research Centre for Agriculture and Forestry. http://pub.jki.bund.de/index.php/BBCH

\subsubsection{Evaluation of mulching materials}

\section{By Samih Abu Baker}

A common agricultural practice for vegetable growers is mulching. This practice has been well documented to improve growth and yield. Mulches go back to early agriculture when they were primarily organic in nature and mainly used to conserve moisture. They can be defined as substances spread over the ground to protect soil and plant roots from undesirable environmental factors, including temperature, moisture, weed competition, soil structure, and biological activity.

The advantages of mulching include the following:

- Water conservation; mulches can greatly reduce evaporation from the soil surface and can reduce irrigation needs.

- Weed control; mulches can prevent weed growth, thus reducing competition with the crop for light, water and nutrients.

- Reduced labour requirement; much less labour is expended in weed removal and in applying water to properly mulched crops.

- Temperature modification; as a general rule, organic mulches tend to cool soil, whereas clear and black plastic mulches may be used to warm the soil mulches also generally reduce soil temperature fluctuations.

- Soil structure improvement; soil structure is improved when the lower layer of an organic mulch decays or following incorporation of organic mulches into the soil.

- Reduced insect numbers; certain organic mulches (such as cedar chips) are reputed to repel insects.

- Reduced nutrient and water losses.

- Keeping crops clean from soil contamination. 
A wide range of material can be used as mulch material; these may be organic (e.g. straw) or synthetic (usually a plastic film). Once an organic mulching material has been incorporated into the soil and has decomposed it will improve soil structure, especially in the case of "heavy" soils such as clays, clay loams, and silty soils. This improves drainage, and thus aeration of the root zone. The water-holding ability of more well drained soil will also be improved by increased organic matter. Synthetic mulches may also be biodegradable.

Available nitrogen in the soil can be reduced when incorporating organic materials from mulches into the soil. This 'nitrogen robbery' can occur because the bacteria and fungi involved in the decomposition process will utilize large amounts of nitrogen as they multiply rapidly during the break-down of the organic matter. One of the most important reasons for organic mulches is weed control by placing them directly on top of small weeds; a layer of $10 \mathrm{~cm}$ of organic mulch will block light and the photosynthesis will be prevented.

\section{Experimental layouts}

Experiments with mulches can help to quantify the benefits and costs of using them. Measurements can be made of crop yield (including its earliness and quality), effects on soil water and interactions with irrigation requirements, effects on the soil (mineralisation patterns under the mulch and the supply of nutrients as an organic mulch breaks down) and the costs of using them (in terms of labour hours and materials).

If commercial scale machines are used to lay down the mulches then the plots will need to be quite large which may limit the number of replicates and treatments. Although organic mulches can be simply applied to small scale plots by hand it may be difficult to simulate commercial use of synthetic mulches on a plot scale. A strip of about 50 to $80 \mathrm{~cm}$ is required between rows covered by mulches, regardless of type, to prevent cross movements of soil between adjacent plots.

\section{References and further information}

Decoteau, D. 2000.

Vegetable Crops. Prentice Hall. Upper Saddle River, New Hersey.

Preece, J. and P. Read. 2005.

The Biology of Horticulture: an Introductory Textbook. Second Edition. John Wiley \& Sons.

Mulches for the vegetable garden. Colorado State University Extension. The website is: http://www.ext. colostate.edu/mg/Gardennotes/715.html

\subsection{Plant protection experiments}

\subsubsection{Evaluation of fungicides and insecticides in organic cropping}

By Martin Koller and Ellen Richter (based on Martin Hommes, 2006)

\section{Preconditions and site selection}

Before plant protection experiments are carried out it is advisable to understand the biology of the pest or the pathogen concerned and to collect information regarding its incidence in the experimental region. Appreciating the route of infection of a pathogen, for example, is crucial for determining the experimental procedure. For soilborne pathogens, such as the clubroot disease of Brassica species, a uniform contamination of the experimental side is of great importance. For exclusively seed borne pathogens, it is important that each seed batch is uniformly treated and the origin of the seed is recorded.

For pests or diseases which invade the experimental plots actively there is often a clear gradation of infestation from an edge towards the field centre. The Latin square is a suitable experimental design to deal with these border effects. If they are transported by the wind and infestation is regularly distributed within the field, other designs such as a randomised block design are as most suitable. 
Experiments with plant protection products, plant 'strengtheners', or 'tonics' suitable for organic production require particularly stringent design and implementation. The effects of these products may not be very strong and therefore sample size and number of replicates should be increased in order to demonstrate statistically significant differences between the treatments. If products have only a preventive but no curative effect they must be applied before infection and on a regular schedule as long as disease pressure persists. It has to be taken into account that most plant diseases have an incubation period between infection and outbreak of symptoms.

Moreover, it is important to know the mode of action and the physical and chemical characteristics of a product under test. For example, the bacterium Bacillus thuringiensis has to be taken up actively before it becomes effective in the gut of caterpillars. In addition, temperature affects larval feeding activity and bacterial growth, older instars show reduced susceptibility and the microorganism is inactivated very quickly by UV radiation or washed off by rainfall.

\section{Application technology and water requirement}

The application technique can have a considerable impact on the efficacy of a product. Therefore, it is important to record the exact application parameters, such as spraying equipment, nozzle type, application technique, amount of water, application rate, additives etc. In order to check the application technique, water sensitive paper can be attached to different parts of the canopy to record the degree of wetting. Additionally, the weather conditions should be noted during and after application.

The amount of water needed for water based applications of fungicides and insecticides depends on the crop development and the mode of action. In Germany, for example, the following amounts of water are generally recommended for typical vertical greenhouse crops such as tomato or cucumber:

Plant height $<0.5 \mathrm{~m}=6$ litres $/ 100 \mathrm{~m}^{2}$.

Plant height $0.5-1.25 \mathrm{~m}=9$ litres $/ 100 \mathrm{~m}^{2}$.

Plant height $>1.25 \mathrm{~m}=12$ litres $/ 100 \mathrm{~m}^{2}$.

If a thorough wetting of all plant parts is recommended (as it is for products with contact effect only such as insecticidal soaps or rape seed oil) the amount of water amount may be somewhat higher but excessive use of water will just drip off the plants and thereby reduce efficacy. More accurate methods to estimate the amount of water needed are currently under development (e.g. Rueegg et al. 2012).

\section{Assessments and artificial inoculation}

Counting, estimating and measurements of disease and pest infestation levels are better suited for an appropriate statistical evaluation than using scales. However, a scale from 1 to 9 may be appropriate if no statistical evaluation is planned.

At low infestation levels $(<10)$ pest numbers can easily be counted and with some experience high numbers may be estimated. The incidence and expression of disease and pest symptoms can be expressed in percentages (e.g. as disease incidence and disease severity). If assessments are conducted by several people, it is best to harmonize the estimation of pest numbers or disease severity beforehand and to make sure that each person evaluates all treatments in one replicate. This ensures that personal effects will not distort the results of the treatments. Inexpensive and accurate methods are also available today for measuring the leaf area damage through digital image analysis (e.g. Bock et al. 2010).

If pest infestation is very heterogeneous within the plots then it may be useful to mark certain plants and to follow pest development on these plants. In this case it is particularly important that the assessments do not compromise the development of the pest.

If the natural pest or pathogen incidence is very low artificial inoculation can be considered. Sometimes it may be sufficient to place artificially inoculated plants into to the different plots. However, it is important to distribute these plants equally to all replicates and treatments. 


\section{Efficacy evaluation}

Four main formulas are available to calculate the corrected efficacy in pesticide trials. The selection of the appropriate formula will depend on the trial conditions which means considering infestation or population stability and homogeneity as well as on the data available. When dealing with infestation levels or live individuals in uniform pest or disease populations the formula according to Abbott (1925) is convenient. For non-uniform populations, the Henderson and Tilton (1955) formula is suited which allows us to judge differences in the population development. In this formula the mortality ratio is corrected on the control mortality. If mortality is assessed as such, the formulas after Sun-Shepard or Schneider-Orelli should be used (Püntener 1981).

a) Efficacy formula according to Abbott (1925)

$$
\text { Efficacy } \%=\left(1-\frac{\mathrm{n} \text { in treated plot after treatment }}{\mathrm{n} \text { in control plot after treatment }}\right) \times 100
$$

b) Efficacy formula according to Henderson and Tilton (1955)

Efficacy $\%=\left(1-\frac{\mathrm{n} \text { in control before treatment } \times \mathrm{n} \text { in treated after treatment }}{\mathrm{n} \text { in control after treatment } \times \mathrm{n} \text { in treated before treatment }}\right) \times 100$

\section{References and further information}

General information on trials for efficacy evaluation of plant protection products can be found in two general EPPO guidelines: PP1/152(4) Design and analysis of efficacy evaluation trials and PP1/181(4) Conduct and reporting of efficacy evaluation trials, including Good Experimental Practice. Many general (for phytotoxicity assessment, minimum effective dose, etc.) and specific EPPO standards are available at http://pp1.eppo.int/ Abbott, W.S. 1925.

A method of computing the effectiveness of an insecticide. J. Econ. Entomol., 18:265-267.

Bock, H., G. H. Poole, P. E. Parker and T. R. Gottwald. 2010.

Plant Disease Severity Estimated Visually, by Digital Photography and Image Analysis, and by Hyperspectral Imaging. Critical Reviews in Plant Sciences 29(2):59-107. DOI:10.1080/07352681003617285C.

Henderson, C.F. and E. W. Tilton. 1955. Tests with acaricides against the brow wheat mite, J. Econ. Entomol. 48:157-161.

Hommes. 2006.

Chapter 2.5. Besonders bei Pflanzenschutzversuchen (in German). In: Lindner and Billmann. Planning, Setup and Evaluation of Trials on Organic Vegetable Cultivation. An Experimental Design Manual

Püntener W. 1981. Manual for field trials in plant protection second edition. Agricultural Division, Ciba-Geigy Limited.

Rueegg J., M. Jermini, R. Total and S. Scettriniet. 2012.

Leaf wall area and leaf area in cucumber, eggplant, sweet pepper and tomato grown in greenhouses in Switzerland. Bulletin OEPP/EPPO Bulletin 12/2012, 42(3): 552-559. DOI: 10.1111/epp.12003

\subsubsection{Evaluation of bio control agents and natural enemies}

\section{By Gerben Messelink}

\section{Introduction}

Biological control of greenhouse pests with natural enemies has been applied successfully in greenhouse crops for decades (Pilkington et al. 2010). However, there are still serious problems as some pest species are difficult to control with currently available natural enemies (Messelink 2014). The efficacy of natural enemies may strongly depend on the type of crop; existing species therefore need to be evaluated in different cropping systems. In this chapter, some practical advice is provided for evaluation experiments with natural enemies in greenhouse crops. 


\section{Criteria for selecting natural enemies}

The selection of natural enemies for biological control was traditionally focused on specialist enemies that were released to obtain rapid control of the pests (Hussey and Bravenboer 1971), (van Lenteren and Woets 1988). Well-known examples are the spider mite predator Phytoseiulus persimilis, the whitefly parasitoid Encarsia formosa, and aphid parasitoids of the genus Aphidius, which are still successfully used in many crops and countries (van Lenteren 2012). These natural enemies are released as soon as the pests are observed, the socalled augmentative biological control. Criteria for selecting the most effective natural enemies for augmentative biological control according to van Lenteren and Woets (1988) were:

- Internal synchronization with the pest (able to develop to the adult stage).

- Adaptation to the greenhouse climate.

- No negative effects on other natural enemies.

- Mass production is possible.

- High pest kill rate.

- Good searching ability.

Although specialists are well adapted to their host and can be very effective, they often disappear when prey densities have been reduced and need to be released whenever pests resurge. As they are used mainly to obtain rapid control of specific pests, their efficacy requires high quantities and quality and intensive monitoring to assure accurate timing of the intervention.

Currently, biological control of pests is increasingly based on generalist predators combined with methods to conserve and augment them (Messelink et al. 2014a). For this approach, different criteria for evaluation are needed. These could be:

- Ability to establish on alternative or plant-provided food sources.

- Behaviour in food webs with multiple prey and food sources.

- Adaptation to the greenhouse climate.

Other criteria such as the development on the target pest are less important as generalists can complement their diets with supplemental food sources. However, negative effects on other insects can often not be excluded, as most generalist predators not only feed on pests, but also on other natural enemies. This is not necessarily bad for biological control (Janssen et al. 2006, Messelink et al. 2012). Mass production is still important, but released densities of generalist predators can be rather low when crops are "inoculated" with natural enemies, thus generalists predators can even be interesting with a suboptimal mass production system. The high pest kill rate and good searching ability are also less relevant, as these criteria can be compensated by a good establishment and high predator densities.

For evaluation experiments with natural enemies, these different criteria need to be considered. A common mistake is that natural enemies are mostly judged on their efficacy when applied curatively or on their predation capacities per individual, thereby underestimating the effects on a population level. For example, generalist predatory mirid bugs were not effective in controlling aphids when released curatively, but preventive releases was very effective (Messelink et al. 2014b).

\section{Quality control of natural enemies before trials begin}

Natural enemies obtained from commercial producers should always be checked for their quality. Quality control criteria include, for instance, the number of enemies delivered, their emergence rate, fitness, fecundity, sex ratio etc. Some practical guidelines are provided by the International Organization for Biological Control (IOBC) (van Lenteren 2003), which can be used in research. The natural enemies supplied by producers are not always of good quality and this may become worse during transport. Moreover, the age and storage conditions of natural enemy products are often unknown and this can significantly affect their performance. For these reasons it is highly recommended to rear natural enemies for at least one generation for trial purposes in order to know the exact age, and to get the right stage and "fit" natural enemies. The same may count for the pest species that are released to test natural enemies. It is finally important to realize that some pest stages are invulnerable to their natural enemies. Thereby, multiple releases of the pests and predators may be required to obtain a stable stage distribution. 


\section{Setting up a greenhouse trial to test the efficacy of a natural enemy}

Greenhouse trials for evaluating natural enemies can be complex, as many factors may influence the outcome of the trial. Firstly, the plants and the soil or growing media used should be free from pesticide residues. This is less of an issue in a dedicated organic research facility but organically acceptable chemicals will have effects on beneficial organisms. Even when pesticides are not applied, they could still unintentionally be added to plants or soil when low levels are present in, for example, the watering system. This should be checked carefully before starting an experiment. Secondly, vapours of earlier applied pesticides in greenhouse compartments can affect pests and natural enemies afterwards. Thirdly, pesticide applications used to control other organisms should be avoided as much as possible as these can strongly affects the results of the experiments. For example, sulphur used against powdery mildew will also affects predatory mites and bugs.

The setup of a greenhouse trial needs to take into account deviations in temperature, humidity, watering and light. Randomized block designs are often required to correct differences in greenhouse climate and sunlight within greenhouse compartments. Also the watering and nutrient supply should be homogenized. Fluctuations in the watering systems which may strongly affect the behaviour of certain pests such as aphids should be prevented. Experimental units need to be separated, particularly when natural enemies and pests are able to fly or migrate. This can be achieved with separated greenhouse units. As budgets and facilities are often a limiting factor, scientists may choose cages for the experiments. Then the mesh size of the insect gauze needs to be suitable to prevent insects from escaping. However, this also needs to be in balance with the ventilation capacity and light transmission. Finally, the number of plants per experimental unit should be high enough to handle a population increase (i.e. the carrying capacity). More plants are often also needed to get higher humidity levels. Plants should also be old enough to represent a real crop situation. For example, sweet pepper plants that have started flowering may give totally different results than non-flowering plants, as the pollen and nectar can be alternative food sources for both the pests and natural enemies.

\section{Methods for observations}

Populations of pests and natural enemies can be followed by direct observations on the plants, but often samples need to be taken to do observations under a binocular microscope. Leaves or other plant parts can be cut from the plants and transported in separate bags to the laboratory. At low densities more samples should be taken; it is important to have enough plant material in each experimental unit to be able to do this. Some samples can be stored at about $10^{\circ} \mathrm{C}$ when it is not possible to do all observations on one day. This works well for predatory mites, thrips, and whiteflies, but less so for aphids that start to walk around. The observed natural enemies and pest should always be identified to species level. This is particularly important for small species that are difficult to distinguish, such as predatory mites or thrips. It often happens that species of natural enemies are found in experiments other than those that were released through invasions of naturally occurring species - even in cages that you would expect to keep out unwanted organisms. Such organisms always need to be mounted in microscopic slides and identified under a microscope.

\section{Summary of tips and tricks}

Selection criteria of natural enemies depend on the species and intended application:

- Always check the quality of products with natural enemies, but preferably produce your own natural enemies and pests for experiment.

- Check the planting material, soil and facilities for pesticide residues.

- Homogenize your greenhouse set-up for effects of light, temperature, humidity, and water and correct with block designs.

- Use the right insect cages to separate units.

- Adapt the sampling to the insect/mite densities.

- Always check the identity of the observed species. 


\section{References and further information}

Hussey, N. W., and L. Bravenboer. 1971.

Control of pests in glasshouse culture by the introduction of natural enemies Pages 195-216 in C. B.

Huffaker, editor. Biological Control. Plenum Press, New York-London.

Janssen, A., M. Montserrat, R. HilleRisLambers, A. M. d. Roos, A. Pallini, and M. W. Sabelis. 2006. Intraguild Predation Usually does not Disrupt Biological Control. Pages 21-44 in J. Brodeur and G. Boivin, editors. Trophic and Guild Interactions in Biological Control. Springer Netherlands, Dordrecht.

Messelink, G. J. 2014.

Persistent and emerging pests in greenhouse crops: Is there a need for new natural enemies? IOBC/wprs Bulletin 102:143-150.

Messelink, G. J., J. Bennison, O. Alomar, B. L. Ingegno, L. Tavella, L. Shipp, E. Palevsky, and F. L. Wäckers. 2014a.

Approaches to conserving natural enemy populations in greenhouse crops: current methods and future prospects. BioControl 59:377-393.

Messelink, G. J., C. M. J. Bloemhard, H. Hoogerbrugge, J. van Schelt, B. L. Ingegno, and L. Tavella. 2014 b. Evaluation of mirid predatory bugs and release strategy for aphid control in sweet pepper. Journal of applied entomology:n/a-n/a.

Messelink, G. J., M. W. Sabelis, and A. Janssen. 2012.

Generalist predators, food web complexities and biological pest control in greenhouse crops. Pages 191-214 in M. L. Larramendy and S. Soloneski, editors. Integrated pest management and pest control - current and future tactics. InTech, Rijeka.

Pilkington, L. J., G. Messelink, J. C. van Lenteren, and K. Le Mottee. 2010.

"Protected Biological Control" - Biological pest management in the greenhouse industry. Biological Control 52:216-220.

van Lenteren, J. C. 2003.

Quality control and production of biological control agents : theory and testing procedures. CABI, Wallingford.

van Lenteren, J. C. 2012.

The state of commercial augmentative biological control: plenty of natural enemies, but a frustrating lack of uptake. BioControl 57:1-20.

van Lenteren, J. C., and J. Woets. 1988.

Biological and integrated pest control in greenhouses. Annual Review of Entomology 33:239-269.

\subsubsection{Enhancements to biodiversity using flower strips}

\section{By Jérôme Lambion}

Habitat management by agro-ecological infrastructures (such as flowers strips) aims at enhancing the presence of indigenous predators and parasitoids and thus conserving natural enemies close to the crop which is to be protected. The ultimate goal is to provide natural enemies to the crop, preferably early in cropping season at low cost and with high populations.

\section{Plant species choice}

When choosing host-plant species, attention should be paid to the following requirements:

- The crop should offer good ability to host the enemies.

- The risk of hosting pests and diseases that may later move into the crop should be low.

- The host plants should have good resilience (low requirements for water etc.).

- Seed should be available commercially at a reasonable price.

- The annual or perennial cycle of the plants should be able to develop the agro-ecological infrastructure (AEI). 


\section{Setting up the experiments}

As many natural enemies are susceptible to insecticides, a non-treated crop should be selected. The AEI should be established (by sowing or transplanting) outside or inside the protected cropping structure or shelter, in a place where it would not interfere with the grower (e.g. on a field margin, at the foot of the glass wall, etc.). The supply of water, nutrients, and light should be sufficient for a good growth and development. If the AEI is set up outside the shelter, no insect-proof mesh should separate the crop from the outside.

Either a plant mixture with potentially interesting species or pure plots of these species may be tested. The host-plants can be grown among or around the crop. Movement of the enemies from the AEI to the crop at the right time (when the crop needs these enemies) can be studied; pro-active strategies can be employed (e.g. aspiration, destruction of the flower strip etc.).

\section{Experimental design}

Several AEI treatments can be tested in the same trial. Interactions between treatments should be reduced as much as possible by choosing different shelters (one treatment per shelter), by subdividing a shelter with insects-proof walls, or by spacing out the different AEI in the same plot. A more dynamic approach is to evaluate the populations of pests and enemies at several distances from the AEI, or to follow insect populations in the crop before/after a modification of the AEI management. However, the experimental design must be adapted to the biology (life cycle, dispersion) of the enemies, the production constraints, and the time available to the scientist.

\section{Evaluating the experiments}

The growth and development of the AEI (particularly its flowering period) and its competition with weeds should be checked. The entomofauna in the AEI has to be characterized to ensure it enhances the presence of enemies without encouraging crop pests. Samples should be taken at several places in the AEI, to face the natural heterogeneity of insect populations. To be successful, the transfer to the crop must occur at the right time, early enough in the crop life. It is also very important to have a dynamic vision of the populations of enemies over a longer period. The effect of the AEI in the commercial crop should also be evaluated, through population counts of pests and enemies in the crop and assessments of crop damage. For further information to sampling see section 3.4.2 'Evaluation of bio control agents and natural enemies', paragraph on Methods for Observation.)
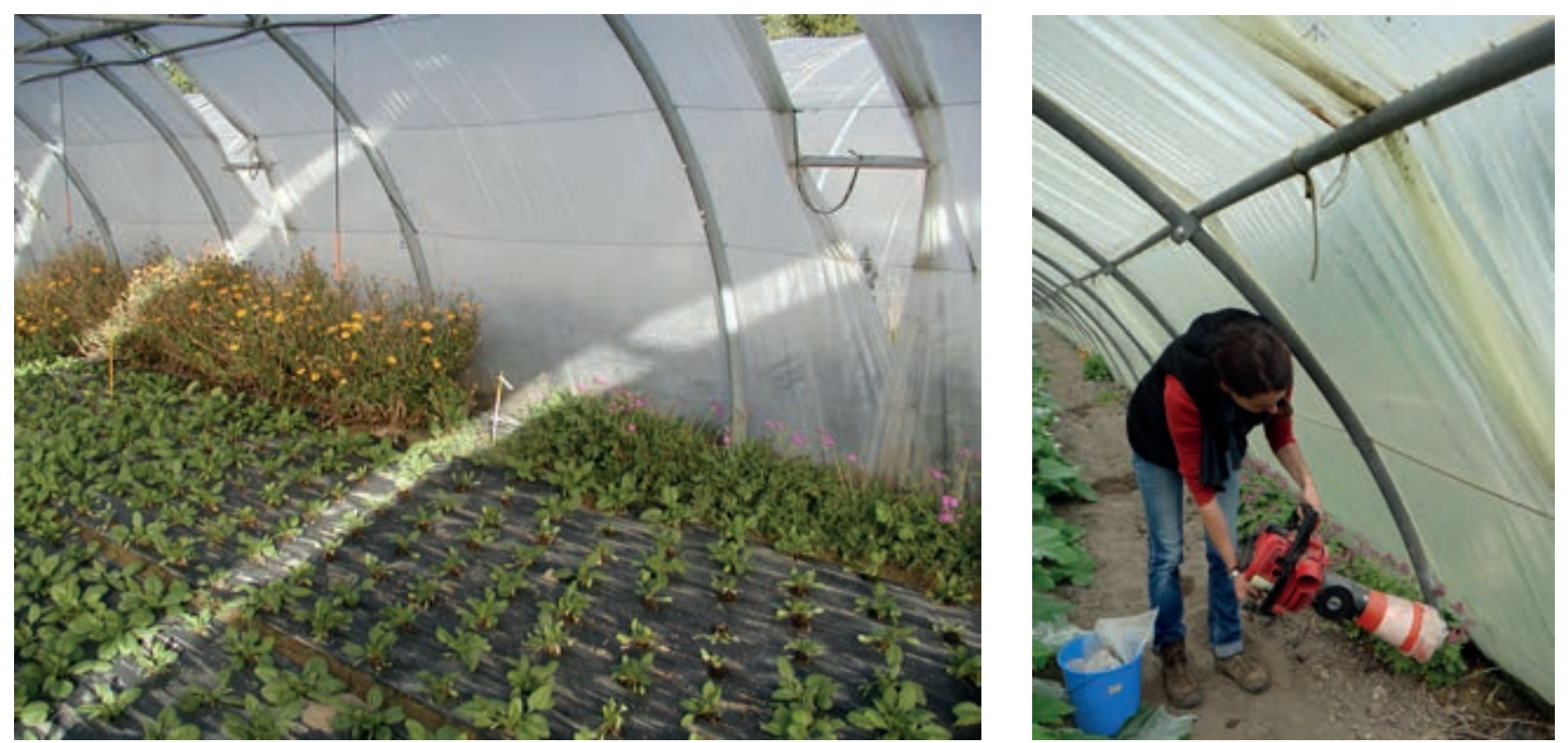

Figure 3.6 Left, a border of host plants for beneficial insects; Right, sampling insects using a vacuum collector. 


\title{
3.5 Other types of experiments
}

\author{
3.5.1 Evaluation of greenhouse infrastructure
}

\section{By Frank Kempkes}

The type of covering material of a protected cropping structure can have a huge effect on the indoor climate. Two main types of material are currently in use: glass and plastic. In principle the approach for an experimental setup does not differ between these two basic materials. The most important consideration regarding to the setup of the experiment is the greenhouse plot area. This can depend on location and season of the experiment. Sunlight can be diffuse or direct. If we have a fully clouded sky we can assume the light is diffuse. If we have a clear sky up to $90 \%$ of the light can be direct but always at least a small fraction of the light is diffuse. Whether you have a cover with a diffusing effect (as most plastics partially have) or no diffusing effect at all as for ordinary glass, the plot size for the experiment can differ substantially if we consider multispan greenhouses.

Figure 3.7 Shows how transmissivity of light through four contrasting materials depends on its wavelength. Some materials have a complete block of the UV light that can have negative effects on insects. For example, it is known that bumblebees need UV light for their orientation. If the covering material is made of polycarbonate then bumblebees are not able to fly and pollinate crops. In contrast PMMA transmits almost all UV light which can have negative effect on the life time of used plastics in the greenhouse. Glass is a kind of average between no UV transmittance and complete UV transmittance. For insects the UV A light with a wavelength between 315 and $400 \mathrm{~nm}$ is of most importance. Some crops (e.g. red lettuce) need some UV-B to develop their colour.

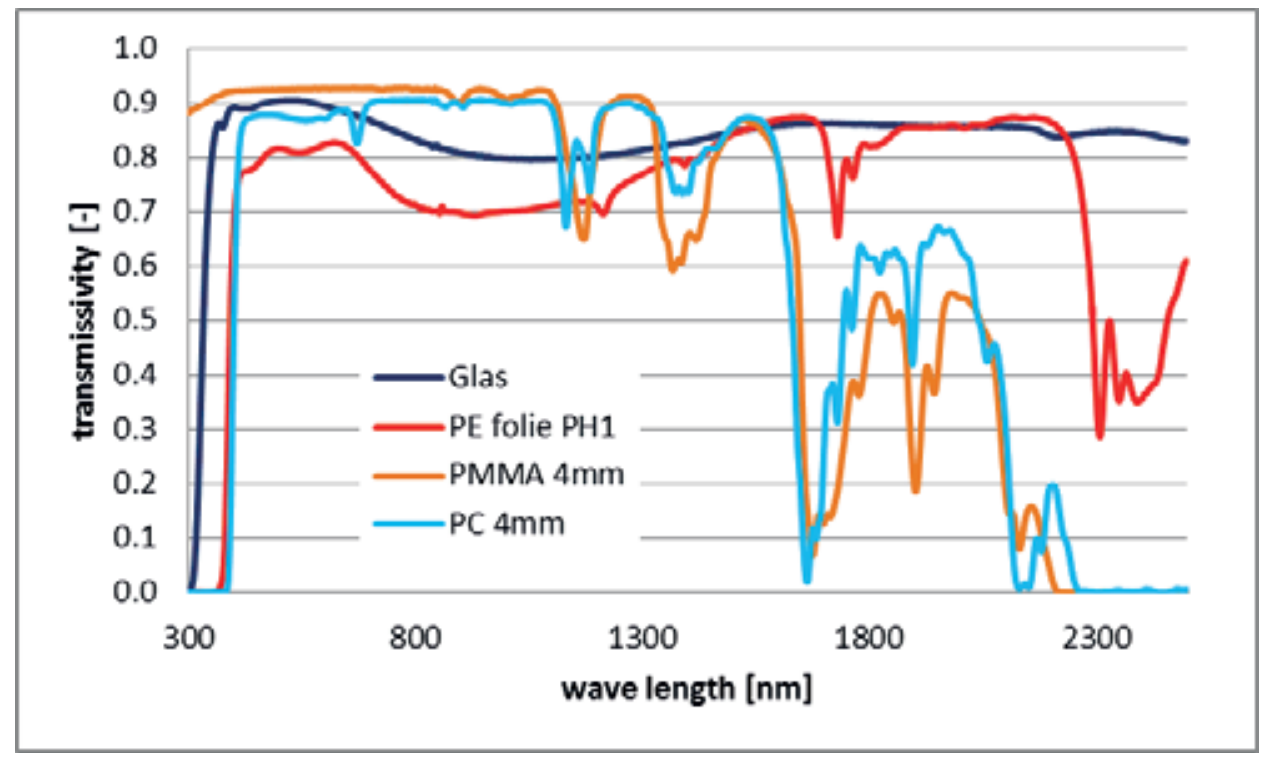

Figure 3.7 Transmissivity of different materials: Glass, PE film, PMMA and PC. (Figure provided by Wageningen UR LightLab).

The transmission of light through a material is also dependent on the angle of incidence of the (direct) light (Figure 3.8). But what is the angle of incidence? In Figure 3.9 the maximum elevation of the sun for the longest and shortest day are shown, in the case of the Netherlands, for a typical 'Venlo' type greenhouse cover. The direct light of the sun never enters the greenhouse perpendicular through this cover at this location. 


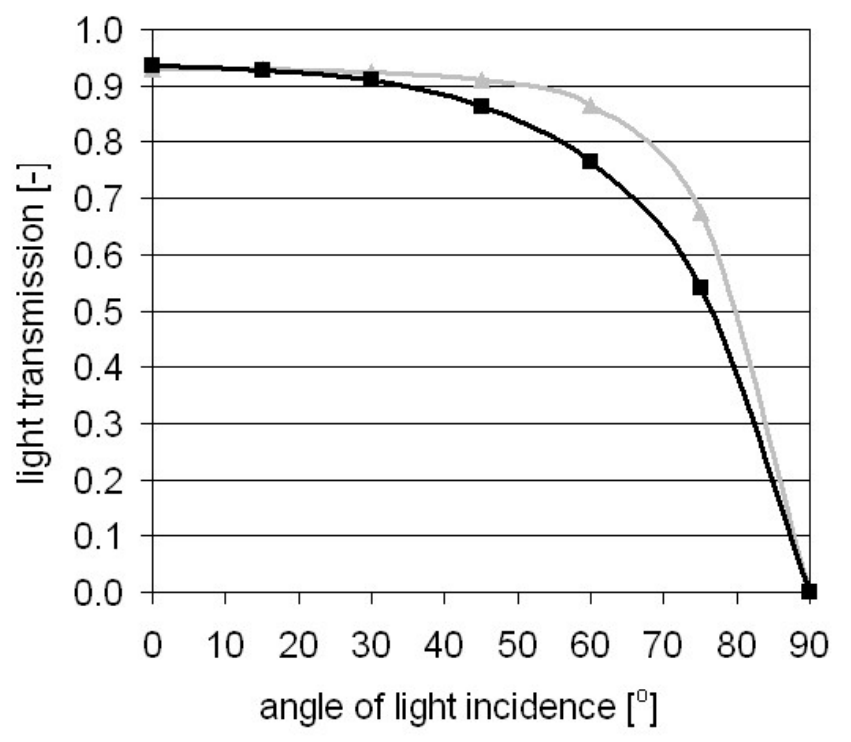

- AGC F-Clean clear $\quad \rightarrow$ AGC F-Clean diffuse

Figure 3.8 The relationship between the angle of light incidence ( $0^{\circ}$ means perpendicular and $90^{\circ}$ means parallel to the material) and the proportion of light transmission from two different glasses from the Asahi glass company (AGC). (Figure provided by Wageningen UR LightLab).

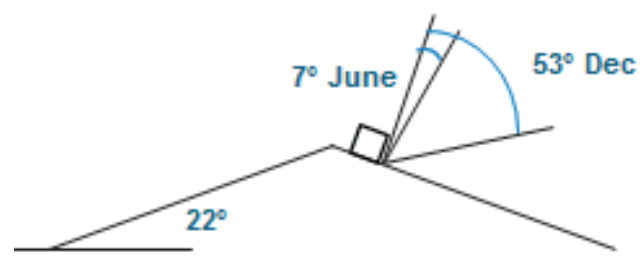

Figure 3.9 The angle of incidence of sunlight falling on a typical $22^{\circ}$ greenhouse roof in the Netherlands on the longest and shortest day of the year. (Figure provided by Wageningen UR LightLab).

If the light is diffuse (sky fully overcast) this is of less importance but remember that most light (in terms of energy sum) is at most locations direct. Even if the cover has diffusing properties these are never perfect. In case of compartments within a bigger greenhouse it is even important to consider what is being grown in the compartments which are not in use for your experiment. Think of different temperature or day length regimes. Also the crop height has to be taken into account. What if your experimental crop is radish and in the south facing compartment is a full grown sweet pepper with a height of 3.5 meters?

These effects as shown in Figure 3.10. In this example the effects of the direct part of the sunlight can only be measured at the left side of the compartment. Also, even in diffuse light the area beside the high crop will have a low light intensity. 


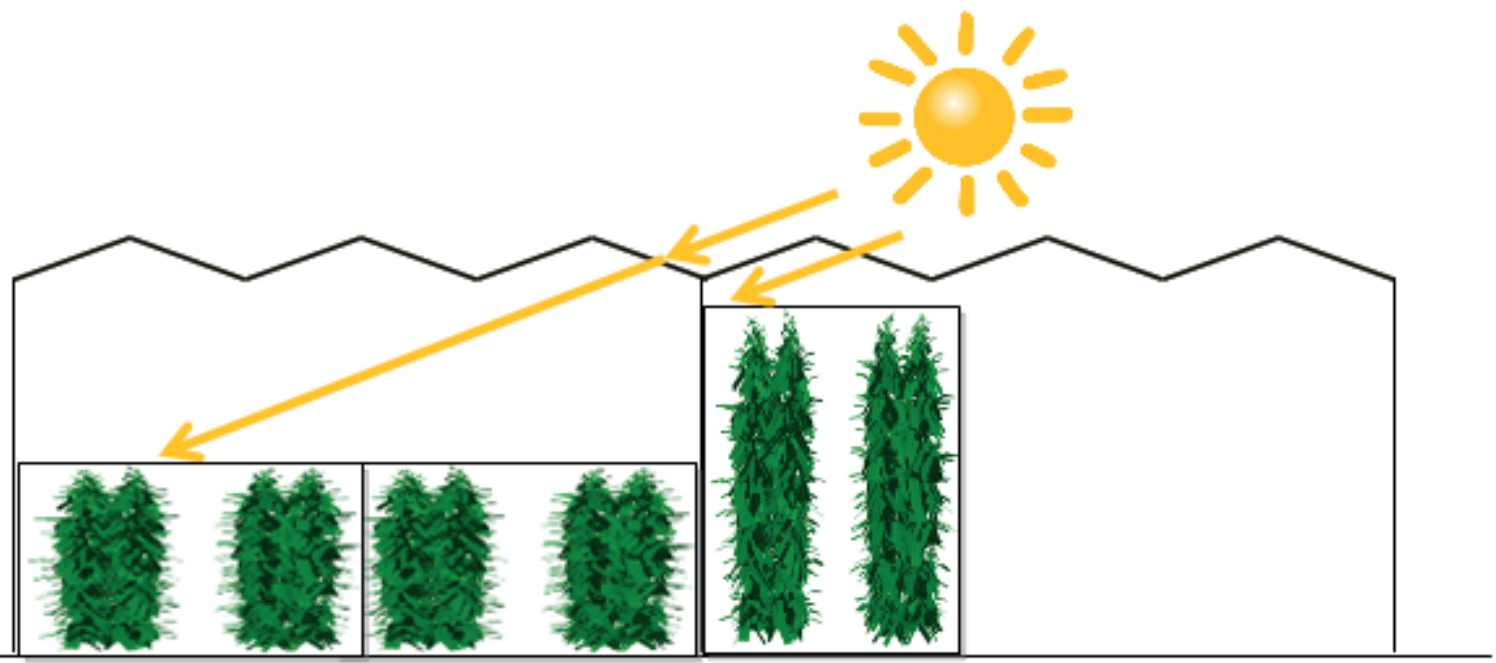

Figure 3.10 An example of the effect of crop height in adjacent greenhouse compartments on the direct light reaching a crop. (Figure provided by Wageningen UR LightLab).

It is clear that the height of the greenhouse will also have an effect on the appropriate plot size. It is best to make a simple drawing of the location and greenhouse(s). Do you have single greenhouses with the whole greenhouse with one covering material or do you have compartments within a bigger greenhouse? In general the roof orientation of all experimental greenhouses/compartments must be the same. Depending on time of the year the roof orientation has an effect on the overall light transmission. In general east-west orientation of the ridge has a higher transmission in winter time at higher latitudes but in summer the north-south orientation shows higher transmissions.

In case of the single greenhouse set up all greenhouses should have the same size, height and ventilation capacity. Do all greenhouses have the same "free" space towards the direction of the sun? Be aware the effect of shade of trees and buildings on part of the greenhouse(s). Make in the drawing of the layout the lowest and highest elevation of the sun during the experiment. Be aware in case you make this layout in mid-summer and the experiment is in winter - the elevation of the sun will be significantly different. Materials in the side walls have, in principle, the same properties as the material in the roof so do not under estimate the effect of the side walls.

It is very difficult to combine several covering materials within one greenhouse/compartment. If effects on climate are expected (which is generally the case) each experimental compartment should have its own controls for at least heating and ventilation and maybe even for irrigation if different levels of crop transpiration are expected. If so the humidity can also be affected which can influence $\mathrm{CO}_{2}$ levels and the need for ventilation. What will be the effect on condensation of moisture on the cover of the greenhouse? Each material will have different condensation properties with different effects on light transmission; is the material hydrophobic or hydrophilic?

The light measured inside a greenhouse will be very different depending on the time of year and the time of day - mainly caused by shading effects from construction components. An array of light sensors to measure photosynthetically active radiation (PAR), in $\mu \mathrm{mol} / \mathrm{m}^{2} / \mathrm{s}$, located high in the greenhouse (above the crop) which can be averaged gives a reasonable measure but require regular maintenance - it is important to keep them free from dust and dirt. The sensors need to be levelled horizontally as a few degrees angle can disturb the measurement by more than $5 \%$. 


\subsubsection{Irrigation systems}

\section{By Martine Dorais}

\section{Background}

According to the growing system (e.g. crops grown in soil or in containerised growing media) the irrigation management of organic greenhouse experiments should consider different factors such as soil characteristics (in terms of soil texture and structure, soil total and air-filled porosity, soil heterogeneity and salinity) and water quality. A good water management of organic crops will:

- Fulfil plant water requirements in real-time.

- Optimize microbial soil activity and nitrogen mineralization rate.

- Prevent anaerobic conditions that reduce root respiration, mineral uptake and water movement in roots, and consequently have a negative impact on plant growth and productivity that can increase plant susceptibility to disease.

Smart water management practices are generally achieved by means of root zone or plant sensors in addition to evapotranspiration and water-uptake models adapted to organic crops. The fine tuning of irrigation for organic crops is much more complex than for conventional crops. This is due to plant heterogeneity, ion imbalances and possible build-up of salinity when unbalanced amendments and fertilisers are used. The optimization of soil biological activity is particularly important as this is a main factor in plant productivity and plant health. From a sustainability point of view, over-irrigation to control soil salinity should be limited to prevent nutrient losses into the environment. Although crop effluent recycling is difficult with soil-grown organic greenhouse crops, because collecting drains have to be installed with minimal soil disturbance and contamination from other nearby agricultural or industrial activities, recycling runoff from potted plants can be a successful management practice. Multiple technological approaches that integrate biological processes (e.g. sand filter, wetland, passive bioreactor), membrane filtration, ozonation, UV treatment, and thermal treatment may also be used to recycle crop effluents from organic crops.

\section{Water quality}

Water quality is defined by its chemical, physical, and biological attributes. It is closely linked to the native soil components, the surrounding environment and land use. Irrigation water for organic crops should have a low concentration of salts (e.g. $\mathrm{Na}, \mathrm{Cl}, \mathrm{SO}_{4}$ ) and sodicity, be low in dissolved organic compounds, free of plant and human pathogens, heavy metals (e.g. $\mathrm{Zn}, \mathrm{Cu}, \mathrm{Cd}, \mathrm{Pb}$ etc) and contaminants (e.g. pesticides, hormones, antibiotics) and not contain any prohibited compounds listed by organic certification bodies. Low water quality can also result in drip irrigation clogging problems. Neutralizing high water $\mathrm{HCO}_{3}$ content by adding citric or acetic acids to the irrigation water promotes biofilm development, and causes clogging of drip irrigation systems. High concentrations of iron compounds in the irrigation water may also block the irrigation system by precipitation. Dissolved organic compounds in the irrigation water constitute a driving force for microbial growth in the distributed water and irrigation system which then compete for the oxygen and can provide a potential energy source for some plant pathogens. The use of rain water should be the first source of water for organic crops due to its sustainability; its use is strongly encouraged by the organic certification bodies.

\section{Water requirement}

Plant water requirements depend on the crops, soil characteristics and water quality. They involve the concepts of the "3Rs": water should be provided at the right moment, in the right amount, and in the right location. In regions threatened by water scarcity, agricultural water management should also be based on reduced, reused and recycled water use. Irrigation management should thus limit runoff from the surface, deep percolation beneath the root zone and soil water evaporation after irrigation. In practice, for organic greenhouse crops, the amount of water given to a crop is based on its evapotranspiration rate, which depends on incident solar radiation and greenhouse air temperature and humidity. For organic crops, irrigation practices should also consider the soil microbial activity, the water needs of cover crops (if present, to reduce water competition between both crops), and the air humidity and soil temperature control. In order to avoid any significant accumulation of salt at the soil surface, more water is required when the EC of the irrigation water is greater than $0.5 \mathrm{dS} / \mathrm{m}$. 
Weighing lysimeters are a direct, scientifically based method used to estimate greenhouse crop evapotranspiration. This measurement technique is, however, limited in use due to the high cost of equipment. On the other hand, evapotranspiration models (e.g. the Penman-Monteith equation) involving environmental parameters and reference crops are widely used. Several evapotranspiration or physiological models have been proposed for greenhouse crops (e.g. Jolliet \& Bailey, 1992; Baille et al. 1994; Gijzen, 1994; Carmassi et al. 2007a; Elings and Voogt, 2008; Bacci et al. 2011; Ehret et al. 2011) to help achieve good water management in terms of crop performance, product quality, and resource use.

For experimental purposes, irrigation management is often based on intercepted solar radiation (e.g. 1-3 mL/ joule/ $\mathrm{cm}^{2}$ for tomato). Even though there is a close relationship between light and plant evapotranspiration, and consequently their water need, a time lag may be observed between the root water supply and uptake and the physiological water need under some growing conditions. Therefore, soil water content and soil matric potential measurements constitute useful tools to monitor and control the irrigation. For the specific type of soil under study, a water retention curve (i.e. the relationship between soil matric potential in $\mathrm{kPa}$ and volumetric water content in $\mathrm{cm}^{3} / \mathrm{cm}^{3}$ ) can be easily determined by measuring the water content using time domain reflectometry (TDR) readings taken at mid-height of soil samples placed on a tension table (Lemay et al. 2012). This water retention curve is then used to define the appropriate irrigation threshold. In fact, relationships between plant physiological parameters such as photosynthetic parameters, stomatal conductance or plant transpiration rate and the soil water content or matric potential have been established for different growing media and plants (e.g. Lemay et al. 2012; Dorais et al. 2005). For greenhouse vegetables, the canopy temperature is a poor indicator of the matric potential but a good indicator of the substrate water content during spring (Dorais et al. 2005). Furthermore, measurements with time domain reflectometry probes (TDR) and load cells have shown good correlations with the rate of $\mathrm{CO}_{2}$ assimilation and Chlorophyll a fluorescence $\mathrm{Fv} / \mathrm{Fm}$ ratio of crop plants (Lemay et al. 2012; Dorais et al. 2005). However, the relationships between measurements of soil water content or matric potential, and physiological parameters usually vary with the growing media and season. Water requirement based on monitoring various plant stress characteristics such as trunk or branch diameter change, leaf water potential and sap flow are also useful methods (e.g. De Swaef and Steppe, 2010), but need more sophisticated apparatus.

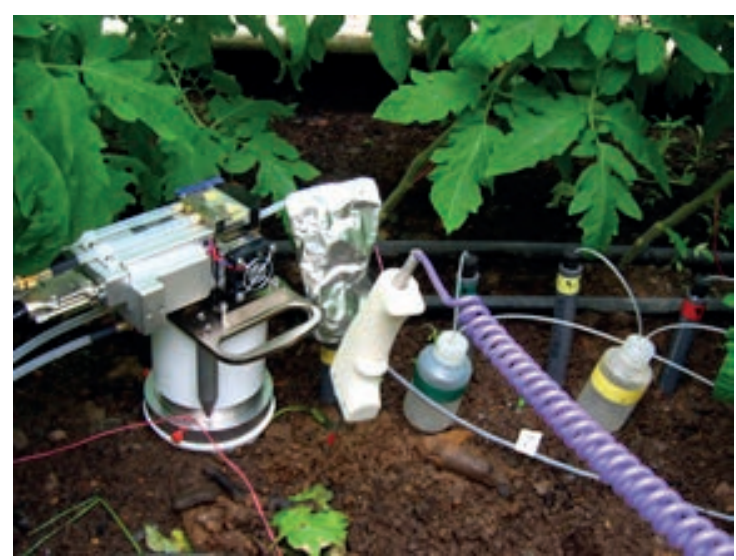

Figure 3.11 Soil $\mathrm{CO}_{2}$ flux measurement varies according to soil temperature and moisture content. 


\section{Water distribution}

Depending on the growing systems (e.g. soil grown crops or potted plants), different water distribution can be used. For an experimental set-up, the selected irrigation systems should ensure uniform water distribution within the experimental plots. Each plant should receive the same amount of water per day. Drip irrigation, by using pressure-compensating drippers, is largely used for potted plants. For soil grown plants, this distribution system leaves dry areas between drippers or emitters (drip tape), reducing soil microbial activity and mineralization rate and limiting root growth in dryer zones. On the other hand, irrigation methods that use micro sprinklers, which wet a large root zone, can result in greater $\mathrm{N}$ mineralization in comparison with drip irrigation. Thus, strip irrigation with small sprinklers provides a more uniformly irrigated soil, although dry zones between plant rows still occur. In order to reduce any dry zone, several irrigation lines with emitters, drippers or sprinklers are used (e.g. 4 lines per vegetable crop bed). For leafy vegetables, low crops or seedlings, high level sprinkler irrigation or beam sprinkler irrigation can be used. This distribution system ensures uniform soil humidity but may increase the crop susceptibility to disease as the foliage gets wet.

\section{Experimental design for irrigation study}

Depending on the crop population heterogeneity and expected study effect, a representative number of plants per experimental unit and replicates should be used to get an acceptable statistical power, which is the chance that a study will detect an effect when there is an effect there to be detected. Thus, as the power increases, the likelihood of getting a false negative (Type II error) decreases. Power analysis can be used to calculate the minimum sample size required. For greenhouse experimental design, a minimum of 10 degree of freedom at the error is generally used, with a minimum of 6 to 8 plants per experimental unit. However, when a large number of replicates is used, one plant per experimental unit can be enough to detect an effect (e.g. in a potted plant experiment). In order to minimize uncontrolled greenhouse variability (e.g. light, temperature gradient, and soil heterogeneity), completely randomized block and Latin square experimental designs are often used.

When comparing different irrigation treatments, each experimental plot should be well delimited in order to limit any water or nutrient transfer between studied treatments. Plant guard rows are often used between each experimental plot when the greenhouse experimental area is large enough. In a situation where the greenhouse area is limited experimental plots can be delimited by inserting stiff plastic sheet (at least $30 \mathrm{~cm}$ deep) between experimental plots. Only plants in the middle of the experimental plot should be sampled for experimental measurements as border plants can be affected by the physical soil barrier and soil disturbance.

\section{Measuring water in soil}

Soil water content should be measured by methods that are accurate and provide measurements in real-time at specific depths, with minimal soil disturbance and acceptable spatial representativeness. The water balance method, used to schedule the irrigation event of potted plants, measures the change in soil moisture over a time period, e.g. the weight difference between the water provided by the irrigation event and the losses due to crop evapotranspiration and drainage/runoff. Crop water requirement is then estimated from the available water in the root zone, allowable water deficit of the crop species (e.g. 40 to $60 \%$ of the available water) and daily soil water balance. For organic soil grown crops, weighing lysimeters can be used with high accuracy as described previously, but do require costly equipment. 


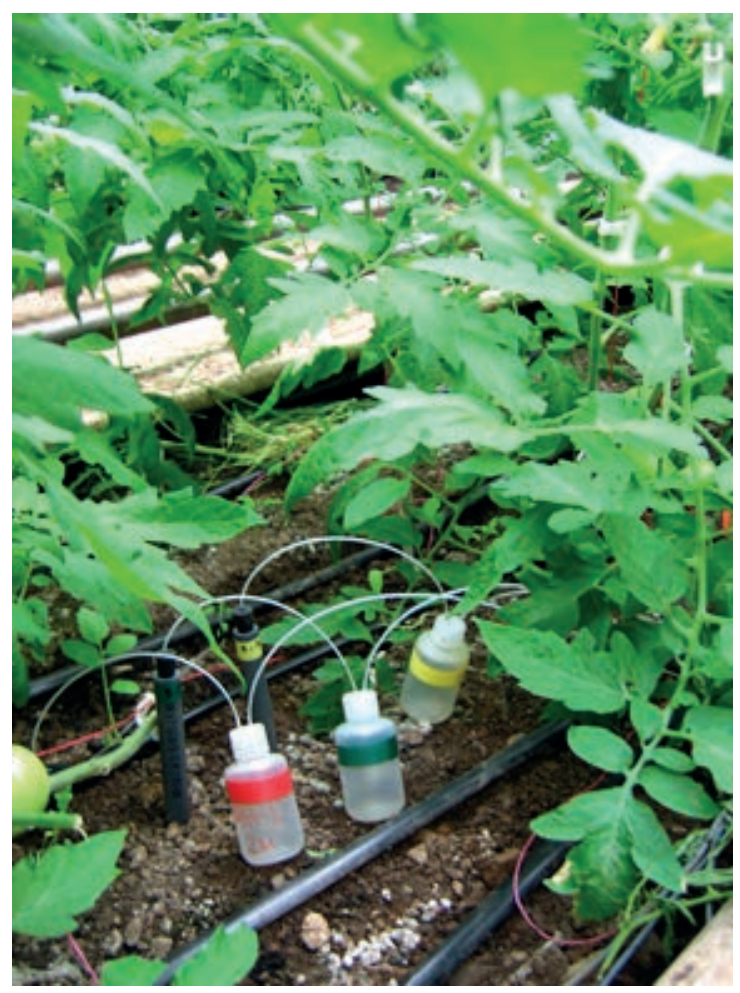

Figure 3.12 Suction lysimeters are used to collect soil nutrient solution at 15, 30 and $50 \mathrm{~cm}$ depth

Suction tensiometers are an indirect method to measure soil water content, since the matric potential has to be converted to a volumetric water content using a water retention curve specific to a defined type of soil or growing media. Because this curve changes whether under a wetting or drying cycle (i.e. soil water hysteresis), the estimation of soil water content based on measurements of matric potential may vary. Consequently, tensiometers are generally used to estimate plant water flux, and not the soil water content per se. Irrigation thresholds based on soil matric potential or soil moisture content have been established for different greenhouse crops. For example, a matric potential ranging from -22 to -15 mbar relative to a container capacity of -6 mbar was beneficial for improving the photosynthetic activity and yield of greenhouse tomato plants grown in containers filled with organic growing media (Lemay et al. 2012). Based on soil activity, physiological parameters, yield, and fruit quality, matric potential thresholds of -40 to -100 mbar were proposed for organic greenhouse tomato grown in a sandy loam soil, although similar mineralization rates were observed for organic soils at -35 and -250 mbar, while maintaining a higher potential (<-30 mbar) resulted in a lower soil mineral content (Pepin et al. 2008).

Electronic water content probes are quite commonly used to monitor and control the irrigation of experimental plots. Sensors can be connected to a control system showing the minute to minute daily soil water status in response to irrigation events. For each studied treatment, at least one probe per experimental unit should be installed to get a representative mean value of its soil water status. The cost of these probes can be substantial but a minimum number of three probes per treatment (e.g. one probe per replicate within three randomized replicates) should be used to control the irrigation. If the soil or plant heterogeneity is too high (i.e. a large variability between the three probes), additional probes should be used to minimize this variability and increase the power of the experimental design. The location of the probes within the experimental unit should be representative of the whole plot (experimental unit). For soil grown plants, the moisture probes or suction tensiometers should be located within the first 10 to $25 \mathrm{~cm}$ depth, where most of the root system is located. For organic potted plants, probes should be located at the mid substrate height. Prior the tensiometer installation, a hole must be made in the soil with a hand auger to limit any soil disturbance and air formation around the probe, which can significantly bias the reading. 


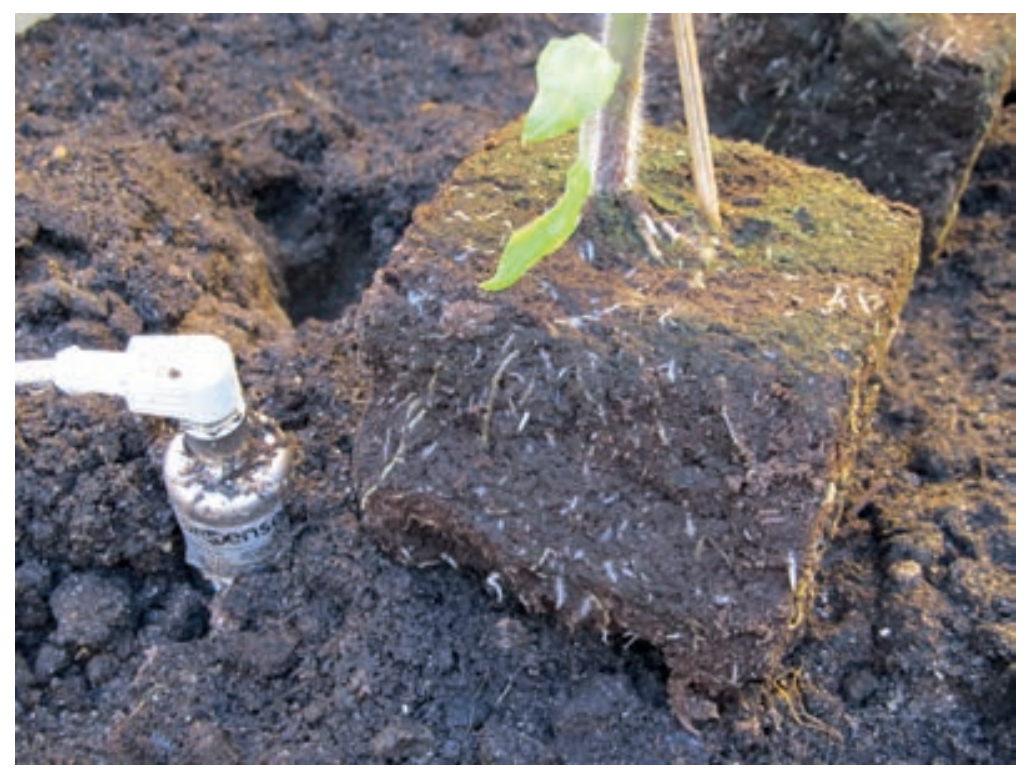

Figure 3.13 Tensiometer installed at $15 \mathrm{~cm}$ deep to control the irrigation of tomato.

The TDR system, developed in the 1970's, consists of a 2-rod or 3-rod probe connected via a coaxial cable to a digital oscilloscope coupled to a pulse generator. The TDR principle is based on changes in the apparent dielectric permittivity of the soil, which are determined by measuring the propagation speed of an electrical pulse along a TDR probe inserted into the ground (Topp et al. 2003). For each type of soil under study, a calibration curve is required as the soil texture (e.g. clay content), structure, porosity and organic matter may influence the dielectric permittivity. Depending on the goal of the study, TDR probes can be installed vertically (integration of the water content over the whole soil depth profile e.g. 0-20 cm) or horizontally (at a specific depth e.g. at 20 $\mathrm{cm}$ ) into the soil. TDR probes of different lengths may be installed vertically to estimate the water content at different depth profiles. Horizontally installed TDR probes provide a better spatial resolution compared to the vertical ones, but their installation may disturb the soil (requiring pit digging) and should be put in place several months before the beginning of the experiment. Depending of the size of the TDR rods, pre-holes can be made (e.g. for $12.7 \mathrm{~mm}$ diameter rods) or not (e.g. for 3 to $6 \mathrm{~mm}$ rods) to limit soil disruption and the development of air pockets around the probe which can significantly affect the reading.

Other real-time methods can also be used to measure soil water content for experimental purposes such as capacitance probes, which measure changes in dielectric permittivity that can be directly correlated with a change in water content. Similarly, several capacitance probes should be installed for an appropriate spatial representativeness. In general, they are less accurate than TDR probes for the measurement of soil water content, but in contrast to TDR, give a good accuracy for monitoring soil salinity.

The water content of the soil can also be measured gravimetrically (a destructive method) by comparing the fresh and dry weights of soil samples (oven-dried at $105^{\circ} \mathrm{C}$ for 48 hours). The volumetric water content can then be calculated using the soil bulk density, thus providing information about the soil water saturation status. Several samples should be collected in the experimental unit in order to minimize the spatial variability. For stony soil, this method may not be accurate enough and the technique does not provide real time data, requiring time replicate samples, which make the data acquisition long and tedious. 


\section{Measured parameters for irrigation study}

When conducting an irrigation study, a range of parameters should be measured (in addition to the effects on crop growth and yield):

- The greenhouse climatic conditions (solar radiation, air and soil temperatures, humidity e.g. as Vapour Pressure Deficit) should be continuously monitored to ensure that the irrigation treatments are well adapted to the prevailing growing season. All probes should be regularly checked and maintained to ensure an accurate daily reading.

- The daily water volume supplied per plant, the number of irrigation events and the uniformity of water distribution should be carefully recorded. Variation in the water supply by drip and sprinkle irrigation systems can be as high as $20 \%$. This variation can be much higher when dripper and nozzle clogging occur due to poor water quality, fertilisation precipitation and biofilm formation.

- Drainage water should be measured for each treatment. Suction lysimeters can be installed in each experimental unit to monitor the soil nutrient content, electrical conductivity and $\mathrm{pH}$ of the soil solution. Collecting runoff water will also help to control soil salinity and improve water management to reduce nutrient losses to the underground water.

- Soil biological activity should also be measured on a regular basis to ensure good mineralization rate, for example by using the fluorescein diacetate hydrolysis (FDA) method of Adam and Duncan (2001) or soil $\mathrm{CO}_{2}$ flux.

\section{References and further information}

Adam, G. and Duncan, H. 2001.

Development of a sensitive and rapid method for the measurement of total microbial activity using fluorescein diacetate (FDA) in a range of soils. Soil Biol. Biochem. 33:943-951.

Bacci, L., Battista, P., Cardarelli, M., Carmassi, G., Rouphael, Y., Incrocci, L., Malorgio, F., Pardossi, A., Rapi, B. and Colla, G., 2011,

Modelling Evapotranspiration of Container Crops for Irrigation Scheduling, Evapotranspiration - From Measurements to Agricultural and Environmental Applications, Dr. Giacomo Gerosa (Ed.), ISBN: 978-953307-512-9.

Baille, M., Baille, A. and Laury, J.C., 1994, A simplified model for predicting evapotranspiration rate of nine ornamental species vs climate factors and leaf area, Scientia Horticulturae, Vol.59, 217-232. Carmassi, G.,

Dorais M., Caron, J., Bégin, G., Gosselin, A., Gaudreau L. and Ménard, C.

Equipment performance for determining water needs of tomato plants grown in sawdust based substrates and rockwool. 2005. Acta Hort. 691:293-304.

Incrocci, L., Maggini, R., Malorgio, F., Tognoni, F. and Pardossi, A., 2007, An aggregated model for water requirements of greenhouse tomato grown in closed rockwoll culture with saline water, Agricultural water management, Vol.88, 73-82. De Swaef T., Steppe K., 2010. Linking stem diameter variations to sap flow, turgor and water potential in tomato. Functional Plant Biology. 37, 429-438.

Ehret D.L., Hill B.D., Helmer T., Edwards D.R. 2011. Neural network modelling of greenhouse tomato yield, growth and water use from automated crop monitoring data. Computers and Electronics in Agriculture 79:82-89.

Elings, A., Voogt, W., 2008. Management of greenhouse crop transpiration: the way forward. Acta Horticulturae 801, 1221-1228.

Gijzen, H., 1994. Development of a simulation model for transpiration and water uptake, and of an integral crop model. Report 18, AB-DLO, Wageningen.

Jolliet, O. and Bailey, B.J., 1992.

The effect of climate on tomato transpiration in greenhouse: measurements and models comparison. Agr. Forest Meteorol. 58, 43-62.

Lemay, I., Caron, J., Dorais, M., and Pepin, S. (2012) Defining irrigation set points based on substrate properties for variable irrigation and constant matric potential devices in greenhouse tomato. HortScience 47, 1141-1152. 
Pepin, S., Dorais, M., Gruyer, N. and Ménard, C. (2008).

Changes in mineral content and $\mathrm{CO}_{2}$ release from organic greenhouse soils incubated under two different temperatures and moisture conditions (poster). In: Cultivating the Future Based on Science, Vol. 1, Organic Crop Production, Proceedings of the 2nd Scientific Conference of the International Society of Organic Agriculture Research. ISOFAR, Modena, Italy, pp. 648-651.

Topp G.C., Davis J.L., Annan A.P. 2003.

The early development of TDR for soil measurements. Vadose Zone Journal 2:492-499.

\subsubsection{Pollination}

\section{By Yüksel Tüzel}

The yield of most fruit-bearing greenhouse vegetables depends on the success of fruit set which is linked to pollination. Pollination is the transfer of pollen grains to the stigma. Pollen grains are released from the anthers and usually fall onto the stigma but in greenhouses, in contrast to open field production, pollination needs assistance due to the limited air movement and high humidity. Pollination can be assisted either by using mechanical vibration or by bees and other insects. However, pollen viability and the amount of pollen, both of which are dependent particularly on temperature, are also important for successful pollination.

\section{Mechanical vibration}

Vibrators, generally battery powered ones, are used in tomato crops by holding them against the stalk of each truss for a few seconds. This should be done at least three times a week between 10.00 am and 3.00 pm due to the lower humidity and higher amount of pollen available during this period (Hochmuth, 2011). Although this method is good practice, it is time-consuming.

\section{Example of experimental design:}

Recommended replicates: at least 3

Minimum number of plants per treatment: 20 (fruit set should be checked 2 to 3 days after pollination)

\section{Bumble bees}

Many different bee species can be used as pollinators e.g. hornfaced bees (Osmia cornut) the, honey bee (Apis mellifera) and different bumble bees species (Bombus sp.). The large earth bumble bee (Bombus terrestris) has proved to be most efficient and is currently used as an excellent pollination agent in greenhouses worldwide. Bumble bees are placed in the greenhouse within the hives and are then active for about 6-8 weeks. The use of bumble bees increases the yield and fruit quality due to their effects on fruit number and mean fruit weight (Dasgan et al. 2004).

The hives are introduced to the greenhouse when the flowers are open. The approximate pollination range per hive is different with different greenhouse vegetable crops (Table 3.1).

\section{Table 3.1}

The number of hives needed for effective pollination in different vegetable crops (Tuzel, 2013).

\begin{tabular}{ll} 
Crop & Pollination range per hive $\left(\mathrm{m}^{2}\right)$ \\
Tomato & 2000 \\
\hline Pepper & 1000 \\
\hline Eggplant & 1000 \\
\hline Melon & 1000 \\
\hline Courgette & 1000 \\
\hline Strawberry & 1000
\end{tabular}


The hives are placed between 0.5 and 1 metre above the ground. They should be protected against sun and condensation of water and efforts should be made to prevent ants or other insects from entering the hives. After placing the hive in a greenhouse, the bumble bees need some time ( $1 / 2-1$ hour) to settle down before the flight hole is opened. Their activity depends on the flowering of the crop and tiny brown spots on the stamens show when they have visited the flowers.

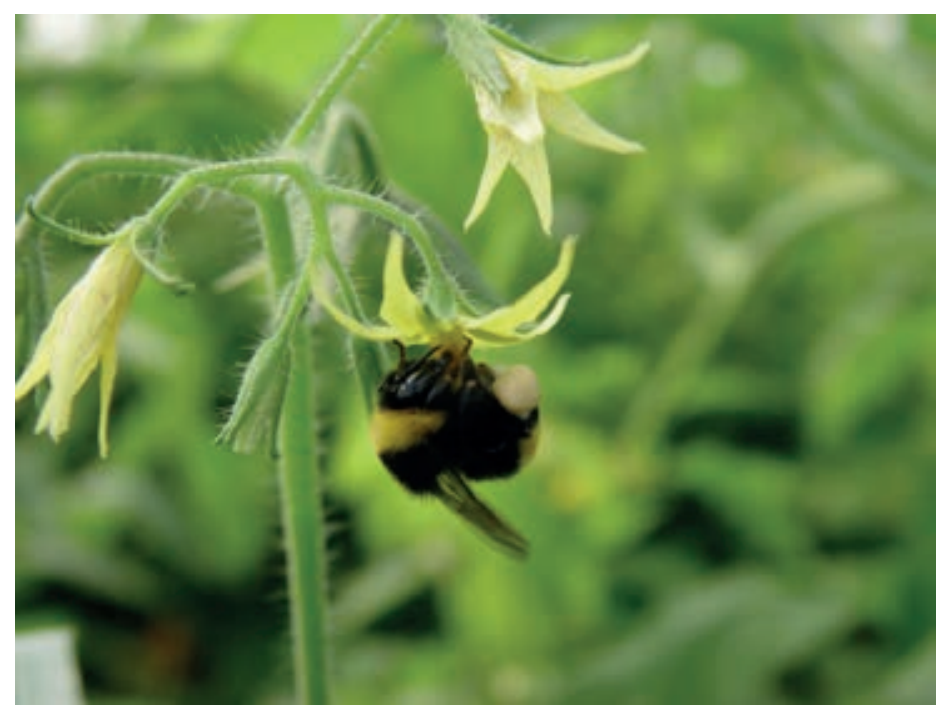

Figure 3.14 Bobus terrestris pollinating a tomato flower.

\section{Example of experimental design:}

The bee treatment should ideally be in a different greenhouse or compartment to a control having the same environmental conditions. If it has to be in the same greenhouse then the flowers of non-bee treatments should be enclosed with paper or fine muslin for a short period until the fruit has set.

Recommended replicates: at least 3 in the greenhouse (randomly placed).

Minimum number of plants per treatment: 20.

Flowers should be checked to see if there are brown, bruised spots on the anther cones (a symptom of too much activity/density). Bumble bee activity can be monitored 3 times per week by examining these marks on the anther cones of senescing flowers in 20 plants that are spread through the greenhouse (Dogterom et al. 1998; Vergara and Fonseca-Buendía, 2012).

\section{Assessments can include:}

- Fruit set: number of regularly grown fruits on a previously marked truss on 20 separate plants.

- Fruit size: Average weight of fruits ( $g /$ fruit).

- Fruit diameter: Fruits can be classified into groups (e.g. $1^{\text {st }}$ class/ $2^{\text {nd }}$ class).

- Fruit shape: Having the correct variety characteristics (not misshapen).

- Seed number: Seed number of each fruit (number/fruit).

\section{References and further information}

Hochmuth, G.J., 2011.

Production of Greenhouse Tomatoes - Florida Greenhouse Vegetable Production Handbook. HS 788. Vol 3. Hort. Sci. Dept., Florida Cooperative Extension Service, Inst. of Food and Agric. Sciences, Univ. of Florida. http://edis.ifas.ufl.edu/cv266.

Dasgan, H.Y., Ozdoğan, A.O., Kaftanoglu, O. and Abak, K., 2004.

Effectiveness of bumblebee polination in anti-frost heated tomato greenhouses in the Mediterranean Basin. Turk J. Agric. and For., 28; 73-82.

Dogterom, M.H., Matteoni, J.A., Plowright, R.C., 1998.

Pollination of Greenhouse Tomatoes by the North American Bombus vosnesenskii (Hymenoptera: Apidae). Apiculture and social Insects J. Econ. Entomol. 91(1): 71-75. http://www.entsoc.org/PDF/Pubs/Periodicals/ JEE/JEETOCS/PDF/ec019800071.pdf 
Tuzel, Y., 2013.

Cultural practices (Chapter 14). In Good Agricultural Practices for greenhouse Vegetable crops. FAO Plant Production and Protection Paper 217:379-398.

Vergara, C.H., Fonseca-Buendía, P., 2012.

Pollination of greenhouse tomatoes by the Mexican bumblebee Bombus ephippiatus (Hymenoptera: Apidae).

Journal of Pollination Ecology, 7(4): 27-30.

\subsection{Economic evaluation of crop trials}

\section{By UIrich Schmutz}

\section{Background}

Organic greenhouse horticulture is an economic activity so an economic (and socio-economic) assessment of it is important. Trials to test different varieties or other aspects such as green manures, composts, or biological pest control therefore also require an economic assessment of the measured physical differences in any trial. For example, a statistically significant difference in a treatment also will make an economic difference but this difference may have only a very minor economic impact compared to other factors. On the other hand, there may be effects which are not significantly different at a $10 \%, 5 \%$ or $1 \%$ error level, but that nevertheless could have a sizable economic or social outcome. Careful interpretation is needed to ensure that any conclusions that are drawn are valid. In general variety trials follow the standards of natural science while economics, as a social science, adds different assessment methods (models, risk assessments, probabilities, proxy values) which can be added (interdisciplinary) or combined (transdisciplinary) into the research design.

For an economic analysis no specific changes to a trial are needed. Any experimental design applied to measure physical change can also be used as a basis for an add-on economic analysis.

\section{Experimental design - the gross margin method}

A basic method to assess horticultural crops is the gross margin method (Brandao et al. 2005). This is a production economics method to measure the outputs (yield multiplied by price; $\mathrm{Y} \times \mathrm{P}$ ) and the inputs which vary directly with the level of production. For example doubling the plants grown means doubling the seed number and the costs for those seeds vary directly (they also double) with the higher production. One could argue that buying or producing seeds in very large quantities can reduce unit costs as a lower price may be negotiated, but this level of detail is not usually considered as it only applies to much larger numbers. All the variable inputs into a crop have costs and they are added together and called 'variable costs'. The gross margin (GM) is the subtraction of variable costs (VC) from output (O) values (crop yields or other by-products).

$\mathrm{GM}=\mathrm{O}-\mathrm{VC}$ with $(\mathrm{O}=\mathrm{Y} \times \mathrm{P})$

The gross margin method is adopted in both the conventional and organic farm management literature (Nix, 2015 and Lampkin et al. 2014) in the English language and e.g. with some minor changes also as 'Deckungsbeitrag' in the German language in the KTBL farm business literature (Redelberger, 2004).

Besides variable costs there are further costs which cannot be directly allocated to the crop grown and among those in protected horticulture are infrastructure costs (glasshouse and machinery) rent, depreciation, certification, office costs and others. These costs are called fixed costs (FC) or overhead costs.

If the business has only one enterprise with one simple output like milk or tomatoes they are often added in a full-cost calculation and give full-cost per unit of production (e.g. $€ /$ litre milk or $€ / \mathrm{kg}$ tomato) and a break-even cost, showing at what price the enterprise breaks even and starts making a profit. For the purpose of organic research trials this method is, however, not very useful as an organic business should have at least several crop enterprises or green manure crops in a rotation. In addition, it is more difficult to source fixed and overhead costs as they are not published in farm management handbooks. Other farm accountancy publications are needed (or farm specific data, which is often confidential). 


\section{Partial budgeting method}

A more appropriate method for trials is the partial budget analysis method used in combination with the gross margin method described before. The partial budgeting method assumes that the effect of a change in one input is the only cause for any change in output. It is therefore a partial budget - assuming that all other inputs stay the same and the change in output is only caused by the change input.

We can study this in more detail by using an example of a compost application trial. The trial has four different treatments of compost e.g. control (no compost) low, medium, and high application rate. We record the cost of the compost and the cost of application. The cost of the compost increases with application rate while the application cost (time) is remains the same for all rates. The partial budget method now assumes that all changes measured in yield are only due to the compost directly (and not due to effects of compost on, for example, possibly reduced pest-control costs).

Table 3.2 shows the example results of this type of trial with 4 replications showing the average yields. These are all significantly different at a $5 \%$ error level and this is indicated by marking with different letters. It can therefore be concluded that the best treatment is the high compost application because it delivers significantly the highest yield of $18 \mathrm{~kg} / \mathrm{m}^{2}$.

Table 3.2

An example of economic evaluation from a compost trial with high compost costs.

\begin{tabular}{lllcrrr} 
& Short & Unit & Control & Low & Medium & High \\
Compost costs & & Euro $/ \mathrm{m}^{2}$ & 0 & 10 & 20 & 30 \\
\hline Compost application costs & & Euro $/ \mathrm{m}^{2}$ & 0 & 10 & 10 & 10 \\
\hline All other variable costs & & Euro $/ \mathrm{m}^{2}$ & 30 & 30 & 30 & 30 \\
\hline Total variable costs & $\mathrm{VC}$ & Euro $/ \mathrm{m}^{2}$ & 30 & 50 & 60 & 70 \\
\hline Yield & $\mathrm{Y}$ & $\mathrm{kg} / \mathrm{m}^{2}$ & $10^{\mathrm{a}}$ & 16 & $16^{\mathrm{c}}$ & $18^{\mathrm{c}}$ \\
\hline Price & $\mathrm{P}$ & Euro $/ \mathrm{kg}$ & 4 & 4 & 4 & 4 \\
\hline Output & $\mathrm{O}$ & Euro $/ \mathrm{m}^{2}$ & 40 & 64 & 68 & 72 \\
\hline Gross margin & $\mathrm{GM}$ & Euro $/ \mathrm{m}^{2}$ & 10 & 14 & 8 & 2
\end{tabular}

However, looking at the gross margin derived by the partial budget this conclusion may be premature. The highest gross margin $\left(14 \mathrm{Euro} / \mathrm{m}^{2}\right)$ is achieved with the low compost treatment. Analysis of variance is here not applicable as these are modelled figures from a trial although other methods (e.g. sensitivity analysis or Monte Carlo simulation) may be used. It may even be concluded, by some growers, that compost applications are not worth the risk at all at the high compost costs assumed in this example because the increase of gross margin from 10 to $14 \mathrm{Euro} / \mathrm{m}^{2}$ is not enough to compensate for the higher costs and the potentially not so much higher yield. From a grower's perspective the cost for the inputs are certain at the beginning of the crop while the yield increase is uncertain and high costs at the beginning of a crop without secured higher yield are a burden on cash-flow.

In Table 3.3 we have calculated the different situation with lower compost cost (at which compost costs 3, 6 and $9 \mathrm{Euro} / \mathrm{m}^{2}$ for the low, medium and high treatments respectively). Now the highest yielding treatment would also be the most profitable one. 
Table 3.3

An example of economic evaluation from a compost trial with low compost costs.

\begin{tabular}{lllrrrr} 
& Short & Unit & Control & Low & Medium & High \\
Compost costs & & Euro $/ \mathrm{m}^{2}$ & 0 & 3 & 6 & 9 \\
\hline Compost application costs & & Euro $/ \mathrm{m}^{2}$ & 0 & 10 & 10 & 10 \\
\hline All other variable costs & & Euro $/ \mathrm{m}^{2}$ & 30 & 30 & 30 & 30 \\
\hline Total variable costs & $\mathrm{VC}$ & Euro $/ \mathrm{m}^{2}$ & 30 & 43 & 46 & 49 \\
\hline Yield & $\mathrm{Y}$ & $\mathrm{kg} / \mathrm{m}^{2}$ & $10^{\mathrm{a}}$ & $16^{\mathrm{b}}$ & $17^{\mathrm{c}}$ & $18^{\mathrm{d}}$ \\
\hline Price & $\mathrm{P}$ & Euro $/ \mathrm{kg}$ & 4 & 4 & 4 & 4 \\
\hline Output & $\mathrm{O}$ & Euro $/ \mathrm{m}^{2}$ & 40 & 64 & 68 & 72 \\
\hline Gross margin & $\mathrm{GM}$ & Euro $/ \mathrm{m}^{2}$ & 10 & 21 & 22 & 23 \\
\hline
\end{tabular}

One could also assume that due to a higher crop quality as a result of compost application the crop can achieve a higher average price (e.g. a higher proportion is Class 1 ). There could also be longer-term benefits of the compost and the yield of the next two crops may be increased by a certain percentage. This percentage is best measured in trials again but as the economic assessment is based on modelling one could also use figures from the literature or other expert knowledge to estimate the longer-term effects of compost on different crop yields.

The last two arguments show that the partial budget method becomes limited at this point as it assumes no add-on effects (such as crop quality or long-term benefits) of a specific treatment. With a complex material like compost this is clearly not the case. However, it becomes more difficult to economically assess the benefits compost may have on pest and disease control, weed population, reduced leaching, carbon sequestration, general soil fertility or even on the worker's wellbeing when applying the compost or a bio-dynamic application. Although economic methods to capture such effects exist in environmental and ecological economics, they are not suitable as a quick and easy add-on to a crop or variety trial. There is, however, one further important step to scale up the economic measurements from the trial scale to a practical average farm, greenhouse or polytunnel scale for which the trials are intended.

Scaling up from trial-scale to farm or greenhouse scale

The current example uses costs at a trial scale and not on a farm or greenhouse scale. For the full economic assessment (especially if the trial results are to be used for farm business consulting or crop advice) it is important to make an assessment with farm-scale costs. For example, the costs could be assumed for a 0.2 ha or 1 ha greenhouse or 1 ha or 10 ha field. From the published data in farm management handbooks (e.g. Nix 2015, Lampkin et al. 2014, Redelberger 2004) the cost of compost application on such a field scale are extracted and those costs are used in the calculation.

For our example the farm-scale calculation would look different (Table 3.4). The treatment with the significantly highest yield would also produce the highest gross margin. The compost application costs increase with amount of compost applied (because of the fuel cost and longer time used to apply it). Overall the compost costs are, however, dwarfed by all other variable costs (5,000 Euro/ha) and the economic effect of compost on yield is not reduced by its costs. In the farm scale model compost costs, including application, are about $1 \%$ of the total variable costs while in the trial scale model they are about $50 \%$ of the variable cost. 
Table 3.4

An Example of economic evaluation of on farm compost use.

\begin{tabular}{lllrrrr} 
Farm-scale & Short & Unit & Control & Low & Medium & High \\
Compost costs & & Euro/ha & 0 & 10 & 20 & 30 \\
\hline Compost application costs & & Euro/ha & 0 & 10 & 15 & 20 \\
\hline All other variable costs & & Euro/ha & 5,000 & 5,000 & 5,000 & 5,000 \\
\hline Total variable costs & VC & Euro/ha & 5,000 & 5,020 & 5,035 & 5,050 \\
\hline Yield & Y & t/ha & 100 & 160 & 170 & 180 \\
\hline Price & P & Euro/t & 400 & 400 & 400 & 400 \\
\hline Output & O & Euro/ha & 40,000 & 64,000 & 68,000 & 72,000 \\
\hline Gross margin & GM & Euro/ha & 35,000 & 58,980 & 62,965 & 66,950
\end{tabular}

\section{Modelling novel treatment costs and sensitivity analysis}

Sometimes products tested in a trial are not available on a large scale. For example in recent trials in Southern England with lavender extracts as biofumigants in organic strawberry polytunnels an economic farm-scale model was used to assess which price and application costs an input needs to have to increase the growth margin. A novel input with significant effects on a trial scale, can then be produced and sourced on a larger scale and the modelled cost from the trial can guide the development of the product.

The farm-scale modelling can also be used for a sensitivity analysis and this is usually done by changing key factors like treatment costs, other variable costs, yields and prices by a certain percentage. The sensitivity analysis then calculates the effect on gross margins. This can be expanded to include other outputs like environmental (e.g. leaching or carbon sequestration) or social outcome (e.g. worker wellbeing, increased skills). For the farm-scale example a $20 \%$ increase in compost cost would reduce the gross margin by $0.01 \%$, while a decrease in yield by $20 \%$ would reduce gross margin by 21 to $23 \%$.

\section{References and further information}

Brandao, M., U. Schmutz and C. Firth (2005)

Farm economics and business planning. Chapter 11, p.208-225 In: Davies, G. and M. Lennartsson 2005. Organic Vegetable Production: A Complete Guide. Henry Doubleday Research Association, Crowood Press Ltd., Marlborough, UK.

Lampkin, N., Measures, M. and S. Padel (2014)

Organic Farm Management Handbook .10th edition Organic Research Centre Elm Farm, Newbury, UK.

Nix (2015) John Nix - farm management pocketbook. 45th edition Melton Mowbray, UK www.thepocketbook. co.uk [accessed Sep 2014)

Redelberger, H. (2004)

Management-Handbuch für die ökologische Landwirtschaft - Betriebswirtschaftliche Instrumente. KTBLSchrift Landwirtschaftsverlag Münster, Germany ISBN 3-7843-2167-4

Schmutz, U., P. Sumption and M. Lennartsson (2011).

Economics of UK organic protected cropping. Acta Hort. (ISHS) 915:39-46 


\subsection{Participative experiments and on farm research}

\section{By Ulrich Schmutz and Francis Rayns}

\section{Participatory action research (PAR)}

This is an approach to conduct research in association with communities and stakeholders involving participation and practical action. PAR seeks to understand the world by trying to change it, collaboratively and following reflection. It has been used in many different parts of the world and works equally well with farmers and gardeners as stakeholders. PAR addresses the research questions important for those who participate as coresearchers. The participants are included in identifying the research question, the research design, practical field research, and in the analysis and interpretation of the results. PAR emerged in the 1950s, especially in rural and community development in the Global South. An online description of participatory research methods is given by Bergold and Thomas (2012), and a leading handbook of Action Research is published by Reason and Bradbury (2006).

The term 'citizen science' is a recently coined term and entered the Oxford English Dictionary in 2014. Citizen science can be defined as scientific work undertaken by members of the public, often in collaboration with, or under the direction of, scientific institutions. As such it can be seen as a sub-type of PAR. However, citizen science is only participative and action based when citizens are included into the research process at every stage. If citizens are only used to collect data from a large sample under instruction from an institution this cannot be called PAR.

A useful background document on citizen science is the EU Commission's green paper (Socientze, 2013) and white paper (Socientze, 2014). These publications aim to foster the interaction between the citizen science stakeholders and the EU policy institutions, reinforcing the culture of consultation and dialogue in the EU. This white paper defines citizen science, as "broad networks of people collaborating where participants provide experimental data and facilities for researchers, raise new questions and co-create a new scientific culture". This new co-created scientific culture can be similar to the one to which PAR aspires. A practical guide to citizen science, specifically to study biodiversity and the environment, can be downloaded from the UK Environmental Observation Framework (Tweddle et al. 2012).

\section{Example of PAR and citizen science}

There are many good PAR examples, however one of the most long-running is that of the UK charity Henry Doubleday Research Association (HDRA, current working name Garden Organic), which has conducted citizen science experiments for more than 50 years. They are known as "Members' Experiments" and the idea was (and still is) that citizens interested in organic horticulture and agriculture form a membership organisation which then co-develops research into organic horticulture "among farmers, gardeners and schools" (HDRA, 1960; Dehnen-Schmutz et al. 2014). Each year three to ten experiments have been organised with between 50 and 400 participants per experiment. They are provided with background information, methodology/instructions, recording forms, seeds and any specialist materials required. Recurring topics have included soil fertility (especially the use of comfrey), pest and disease control, novel crops and varieties, and biodiversity surveys. 
Results are shared with all the charities' members and the wider public (i.e. not only those taking part in the research). Detailed results are published in a member magazine and many of the now well-known techniques of organic horticulture were supported by results from these experiments. Some findings have also made their way into the peer-reviewed academic literature but most of them are not open-access and hence remain rather inaccessible.

A recent example of a Member's Experiment was the use of biochar as a soil amendment. For this more than 300

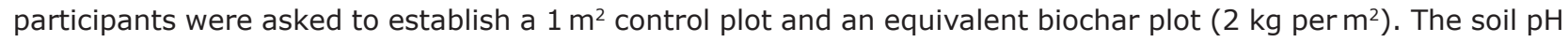
and soil structure were assessed by the participants. Participants were given seeds and asked to use the same date, time and sowing method for control and treatment plots. Crop management, watering, and weeding also had to be similar. Measurements were made on crop yield by separating above ground fresh biomass from below ground and weighing separately. Photographs of the produce were taken for a visual comparison and they also recorded harvest time and exact location. An experiment webpage was maintained with guidance, feedback and discussion boards.

What to consider when planning PAR and citizen science?

Before you start:

- Include participants in planning the research and framing the research questions as much as possible.

- Create a non-hierarchical atmosphere where all knowledge (e.g. practical experience, artistic knowledge, scientific expertise) is equally valid.

- Used simple clear words rather than scientific jargon.

- Build a long-standing research network - not short-term, early exit research.

During the experiment:

- In the research design use simple but effective questions, don't overload participants with data recording.

- Provide good guidance on the research background and material and methods used.

- Provide seeds and any other materials needed for the research, together with clear instructions.

- Aim for a large as possible participation as this will make the results more robust.

- Interact with participants regularly (e.g. through a website) not just when the project is finished.

- Include other social and environmental aspects like economics, biodiversity, health and wellbeing.

- Ask for feedback, including social and environmental aspects, even if this more difficult to analyse and capture and incorporate the feed-back into next year's research design.

After the experiment:

- Use good understandable graphics, pictures and visual aids to communicate results with the citizen science community.

- Use statistical analysis wherever appropriate.

- Publish in applied journals and user magazines read by your audience. Use internet, smart technology and social media as appropriate.

- Also publish in peer-reviewed journals, however only if these have open-access to citizen scientists.

- Build a long-standing research network, use lessons learned for next year's experiments. 


\section{References and further information}

Bergold, J. and S. Thomas (2012).

Participatory Research Methods: A Methodological Approach in Motion. Forum: Qualitative Social Research, 13 (1). Art. 30, www.qualitative-research.net/index.php/fqs/article/view/1801/3334

Dehnen-Schmutz, K., G. Foster, S. Persello and F. Rayns (2014):

Garden Organic Members' Experiments: A 50 year history of citizen science in the garden. Wildlife Gardening Conference: Citizen Science and Biological Recording in the Garden. Natural History Museum, London, Nov2014, http://bit.ly/1GdVum ${ }^{6}$

Henry Doubleday Research Association - HDRA (1960)

Memorandum: About the association. www.gardenorganic.org.uk

Reason, P. and H. Bradbury Editors (2006)

Handbook of action research. Sage Publications, London, UK, ISBN 978-1-4129-2030-8.

Socientize / EU Commission (2013)

Green paper on citizen science. Citizen science for Europe. Towards a better society of empowered citizens and enhanced research. Socientize project. www.socientize.eu

Socientize / EU Commission (2014)

White paper on citizen science for Europe. Socientize project. www.socientize.eu

Tweddle, J., L. Robinson, M. Pocock, and H. Roy (2012).

Guide to citizen science: developing, implementing and evaluating citizen science to study biodiversity and the environment in the UK. Natural History Museum and NERC Centre for Ecology \& Hydrology for UK-EOF. www.ukeof.org.uk/resources/citizen-science-resources 
68 | Guidelines for Experimental Practice 


\section{$4 \quad$ Guidelines for Selected Crops}

\subsection{Introduction}

\section{By Francis Rayns}

This chapter provides specific information for the major greenhouse crops grown in Europe and is intended to support Chapters 2 and 3. It is arranged by crop type (fruit vegetables, leafy vegetables, other vegetables, transplants, herbs, perennial fruit and ornamentals). Not every possible crop is included; if the one you intend to use is missing then read though the sections that cover the most similar ones. To avoid too much repetition the most important crops (e.g. tomatoes) are covered in most detail.

\section{General crop requirements}

This section describes the characteristics of the crop, the maximum and minimum temperatures that it can be grown under and other factors such as any need for pollinating insects.

\section{Experimental guidelines}

Here we suggest the minimum plot size/minimum number of test plants and the number of replicates that are needed. To some extent this will depend on the purpose of the experiment; as discussed earlier it is possible to conduct variety screening trials with only two replicates but at least four are needed for pest and disease control trials. For trials of soil amendments, especially if these are to run for several years, then larger border areas are needed around the experimental plots. Ideally the same experiment should be repeated in several locations and in successive seasons before the results are published to make sure that the findings are repeatable. Sometimes the standard farm practice with regard to the density of planting varies across Europe and may depend on whether the greenhouse is heated or not. The tables therefore contain several columns for the typical spacing in the various situations. We have divided Europe into 'Northern ', 'Central' and 'Mediterranean ' Zones but these are obviously generalisations and it is advisable to check on local practice as altitude and proximity to the sea with also have an effect. If in doubt follow the CPVO protocols (e.g. TP-117/1 for eggplant, TP-44/4 for tomatoes).

\section{Sowing and planting}

The information in this section is again divided into geographical zones and according to the heating regime of the greenhouses. Suggested sowing/planting/harvest times are suggested although these are more relevant to some crops than others - short term salad crops are often sown successively for year round production.

\section{Plant nutrition}

The tables in this section are a guide to the nutrient demand of each crop NOT a fertiliser requirement. The numbers given are a compilation of different sources (see Appendix B). The nutrients are usually supplied from the mineralisation of soil organic matter in combination with soil amendments brought into the greenhouse. For some crops it is sufficient for these to be added to the soil before planting but long-term fruit crops, e.g. tomatoes, are normally fed, in addition, during the growing period itself. Under ideal growing conditions of temperature and water availability etc. crops will require more nutrients from the soil in order to attain maximum yield. Remember that only a proportion of the total nutrient content of any organic soil amendment will be available to plants in the first year after application. Moreover, there may further restrictions from your local authorities or organic growing associations in amount and kind of fertilisers which are acceptable.

For some crops tissue analysis can be used as a guide to appropriate nutrient supply. Typical concentrations are listed in Appendix C.

\section{Crop management}

Some crops require pruning and training on support wires etc. This section outlines the main considerations but wherever possible it is best to check that what is suggested conforms to local standard farming practice. 


\section{Diseases, pests and physiological disorders}

The main problems arising from bacteria, fungi, viruses, insects, mites, and nutritional imbalances are outlined here.

\section{Observations and assessment of growth}

This section is concerned with the usually non-destructive assessments that can be made as the plants grow. These are particularly important in the characterisation of different varieties.

\section{Harvest and yield assessments}

Methods are suggested for the quantification of total and marketable yield. Some specifications are suggested with regard to acceptable size categories etc. but these will differ depending on market channels. Specifications for supermarkets will be much more stringent than for box schemes, resulting in a lower proportion of the crop being considered marketable; this will have an effect on any subsequent economic assessment.

\section{References and further information}

These guidelines are not intended to be a textbook on crop husbandry. It is always worthwhile referring to textbooks and information provided by seed companies etc. Trials should be relevant to real farming conditions and so it is always worthwhile making contacts with local commercial growers and visiting them whenever possible.

The following websites provide guidelines on assessments, particularly with regard to the characterisation of crop varieties:

www.eppo.int (European \& Mediterranean Plant Protection Organization - EPPO).

www.cpvo.europa.eu (Community Plant Variety Office - CPVO).

www.upov.int (International Union for the Protection of New Varieties of Plants). 


\section{$4.2 \quad$ Fruit vegetables}

\subsubsection{Tomatoes}

\section{By Ingrid Bender}

\section{Botanical name: Solanum lycopersicum}

\section{General crop requirements}

The tomato is a light-demanding crop but needs shading in Southern latitudes during late spring. Day length may have an effect on fruit yield in Northern countries, above the 60th parallel (Jones, 2007). The plants need significant quantities of water, but not to excess. Under ideal conditions, plants are fully turgid all the time. As warmth-demanding plants they cannot tolerate frost. Air temperatures of $10^{\circ} \mathrm{C}$ or below will inhibit vegetative development, reduce fruit set and impair fruit ripening. High air temperatures (above $35^{\circ} \mathrm{C}$ ) reduce fruit set and inhibit development of normal fruit colour. Pollination occurs when the night-time temperature is between $13-$ $24^{\circ} \mathrm{C}$ and daytime temperature between $15.5-33^{\circ} \mathrm{C}$. Tomato plants prefer well-drained, fertile, slightly acid ( $\mathrm{pH}$ 5.8 - 6.5) loam and sandy loam type soils, but they will grow in almost all soil type except heavy clay. They have some tolerance to soil salinity.
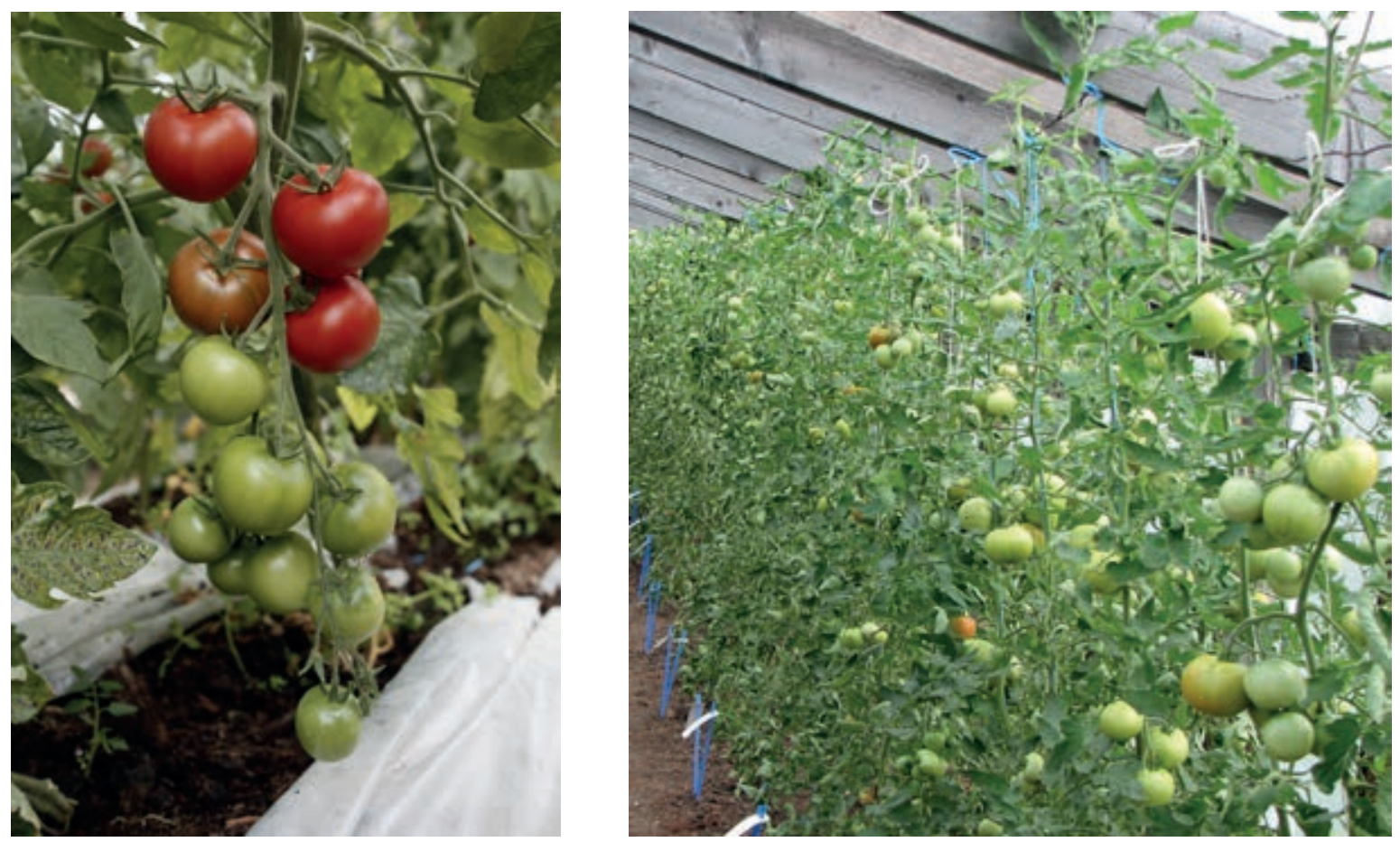

Figure 4.1 Tomato crop trials in Estonia.

\section{Experimental design}

The minimum duration of tests should normally be two independent growing cycles.

Recommended replicates: at least three.

Tomatoes (and many other crops) may be planted in either single or double rows. The latter is often preferable as it permits a high plant density whilst leaving sufficient space for access for harvest and pruning/training (see Figure 4.2).

Production season and the length of crop cycle depend on local climatic conditions (e.g. temperature, light etc.) and availability of climate control (e.g. heating) in the greenhouse. 

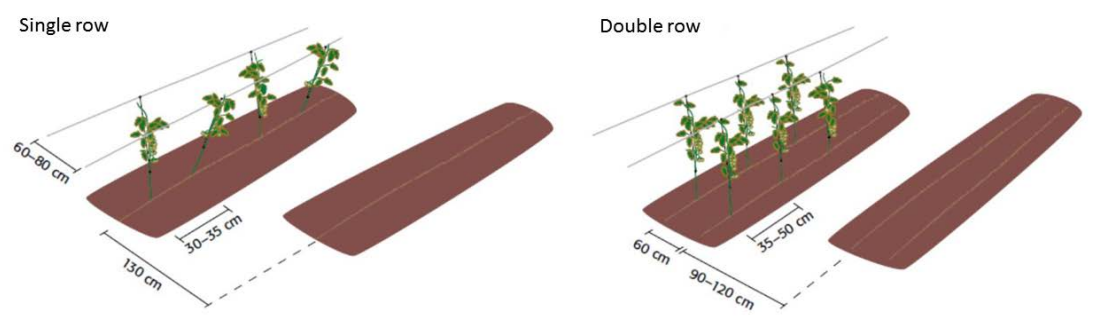

Figure 4.2 Diagram showing the layout of tomato plants using single or double rows (diagram provided by FiBL).

\section{Table 4.1}

Typical tomato plant spacing and number of plants required for trials.

\begin{tabular}{llll} 
& $\begin{array}{l}\text { North \& Central } \\
\text { Unheated }\end{array}$ & $\begin{array}{l}\text { North \& Central } \\
\text { Heated }\end{array}$ & $\begin{array}{l}\text { Mediterranean } \\
\text { Unheated } \\
\text { frost-free) }\end{array}$ \\
\hline Minimum number of plants / core plot & 8 & 8 & 8 \\
\hline Minimum size core plot $\left(\mathrm{m}^{2}\right)$ & 3.5 & 3.5 & 3.5 \\
\hline Plant density / $\mathrm{m}^{2}$ & $2.5-3$ & $2.5-3$ & up to 4 \\
\hline Row distance $(\mathrm{cm})$ double rows & e.g. $50 / 100 *$ & e.g. $60 / 120 *$ & e.g. $50 / 170 *$ \\
\hline Distance within the row $(\mathrm{cm})$ & $30-50$ & $30-50$ & $30-50$
\end{tabular}

*double rows - see Figure 4.2

Table 4.2

Typical tomato sowing and harvesting dates.

\begin{tabular}{|c|c|c|c|c|c|}
\hline $\begin{array}{l}\text { Region } \\
\text { - Production type }\end{array}$ & Sowing & Planting & $\begin{array}{l}\text { Start of } \\
\text { harvest }\end{array}$ & End of harvest & Remarks \\
\hline $\begin{array}{l}\text { North \& Central } \\
\text { - Unheated }\end{array}$ & March & Apr - May & June & October & $\begin{array}{l}\text { Ungrafted or } \\
\text { grafted crops }\end{array}$ \\
\hline - Seasonal Heated & December & March & May & October & Grafted crops \\
\hline - Long cycle Heated & November & January & April & November & Grafted crops \\
\hline $\begin{array}{l}\text { Mediterranean } \\
\text { - Long cycle }\end{array}$ & July & September & November & July & Grafted crops \\
\hline - Short cycle Spring & December & February & April & July & Grafted crops \\
\hline - Short cycle Autumn & July & September & November & January & Grafted crops \\
\hline
\end{tabular}




\section{Table 4.3}

Temperatures required for the production of tomato seedlings and plants.

\begin{tabular}{llll}
$\begin{array}{l}\text { Germination temperature } \\
\text { day/ night }\end{array}$ & Days until germination & $\begin{array}{l}\text { Temperature for seedlings } \\
\text { day / night }\end{array}$ & Weeks until planting \\
$25 / 20^{\circ} \mathrm{C}$ & $6-8$ & $21 / 19^{\circ} \mathrm{C}$ & $4-7$ \\
Ventilation from $26^{\circ} \mathrm{C}$ & & Ventilation from $24^{\circ} \mathrm{C}$ & \\
\hline
\end{tabular}

Table 4.4

Optimal temperatures for tomato growth and fruit production.

\begin{tabular}{llll} 
& Day & Night & Ventilation from \\
After planting: & $22-24^{\circ} \mathrm{C}$ & $20-18^{\circ} \mathrm{C}$ & $25^{\circ} \mathrm{C}$ \\
\hline For fruit production & $19-22^{\circ} \mathrm{C}$ & $17-19^{\circ} \mathrm{C}$ & $20-24^{\circ} \mathrm{C}$
\end{tabular}

\section{Plant nutrition}

Tomatoes are nutrient demanding plants because of their long growing season (especially when grown in heated greenhouses). Adequate potassium is particularly important for good fruit development.

Table 4.5

Tomato plant nutrient requirements.

\begin{tabular}{lllll} 
Yield expectation $\left(\mathrm{kg} / \mathrm{m}^{2}\right)$ & $\mathrm{N} \mathrm{g} / \mathrm{m}^{2}$ & $\mathrm{P} \mathrm{g} / \mathrm{m}^{2}$ & $\mathrm{~K} \mathrm{~g} / \mathrm{m}^{2}$ & $\mathrm{Mg} \mathrm{g} / \mathrm{m}^{2}$ \\
10 & 32 & 4 & 52 & 5 \\
\hline 25 & 70 & 10 & 114 & 12 \\
\hline 40 & 92 & 16 & 148 & 20 \\
\hline
\end{tabular}

* adapted from various sources, see Appendix B. Leaf nutrient content given in Appendix C.

\section{Transplant production}

A good transplant is one that is as wide as it is tall and is not yet flowering (Heuvelink, 2005).

\section{Pruning and training}

De-leafing is required to remove old leaves from the lower part of the plant to improve air movement under the plants and to make the growing plants easier to manage. Shortly before the first harvest, the lower leaves can be removed up to the first fruit truss. It is then continuously defoliated until the next harvestable truss. At least 16 leaves must be left on the plant. Ungrafted tomatoes are grown with one shoot. Grafted plants can also be cultivated with two shoots. The plants must be regularly pruned by removing all lateral (side) shoots. In normal culture the plants are pruned after reaching the tension wire. In longer culture duration with greenhouses of sufficient height the plants can also be considered as a 'layer crop'. Here, when the shoot reaches the tension wire more cord is let down to allow the base of the stem to lie along the ground. If the oldest fruit is misshapen ('bunker fruit') it is removed. The optimal fruit number per truss is 14 for cherry tomatoes, 12 for cocktail tomatoes, 6 to 8 for regularly-sized fruits and 4 for beefsteak types.

\section{Pollination}

For pollination, the flowers must be mechanically vibrated two or three times per week or bumblebees used as pollinators. One hive is recommended for $2000 \mathrm{~m}^{2}$. The optimum temperature for pollen tube growth is $21^{\circ} \mathrm{C}$. Above or below this temperature the germination and growth of the pollen tube is reduced, with very poor results below $10^{\circ} \mathrm{C}$ or above $35^{\circ} \mathrm{C}$. 


\section{Irrigation}

Greenhouse tomatoes require large amounts of water. A mature tomato crop uses 2-3 litres of water per plant per day. A greenhouse irrigation system should be able to provide at least 8 litres per $\mathrm{m}^{2}$ per day. Plants should be watered immediately after planting. One week after planting has taken place it is possible to withhold water until flowering begins - this encourages good root growth as the roots begin to seek moisture deeper in the ground. During flowering the demand for water increases. Water is best applied to the base of the plant (without getting foliage wet) where the entire root area should be thoroughly moistened.

\section{Mulching}

When a mulch is used the moisture is retained for longer, soil temperature is increased and yield improved. Before mulching it is necessary to wait until the plants are rooted and the soil has warmed - about two weeks after setting plants in the greenhouse. Suitable mulch materials include organic mulches such as leaves, grass clippings, several types of straw, pine needles, shredded bark etc. as well as the woven plastic types.

\section{Disease and pest infestation, physiological disorders and other abiotic damage}

Since there are hardly any effective means for direct control of fungal diseases in organic tomato production, optimal climate control is critical - especially sufficient ventilation and the reduction of humidity. Pests and diseases may be assessed once or more depending on the length of cultivation. Disease incidence, disease severity and date of assessment (growth stage) should be recorded. For a detailed description of diseases and pests see the European and Mediterranean Plant Protection Organization website: http://www.eppo.int

\section{Diseases (with references to available EPPO Guidelines)}

- Powdery mildew - Oidium lycopersicum, (PP 1/57 (3): Powdery mildew of cucurbits and other vegetables).

- Grey mold - Botrytis cinerea, (PP 1/54 (3): Botrytis spp. and Sclerotinia spp. on vegetables).

- Late blight - Phytophthora infestans.

- Didymella stem and fruit rot - Didymella Iycopersici.

- Leaf mould - Fulvia fulva.

- Fusarium wilt - Fusarium oxysporum f sp. Lycopersici.

- Bacterial wilt - Clavibacter michiganense subsp. Michiganensis.

\section{Viruses}

- Tomato mosaic virus (ToMV).

- Potato virus Y (PVY).

- Spotted wilt disease (SWV).

- Double streak (TMV+PVX - potato virus X or CMV).

- Pepino mosaic virus.

\section{Pests}

- Spider mites (PP 1/37 (2) Tetranychus urticae on vegetables).

- Whitefly - Trialeurodes vaporariorum EPPO reference (PP 1/36 (2).

- Sweet potato whitefly - Bemisia tabaci.

- Leaf miners - Tuta absoluta. Liriomyza bryoniae EPPO reference: (PP 1/177 (2) Leaf miners on vegetables)

- Tomato russet mite - Aculops lycopersici.

- Root knot nematodes - e.g. Meloidogyne incognita, M. arenaria and M. hapla. 


\section{Abiotic damage}

- Blossom end rot (blackening of fruit due to problems with calcium transport).

- Cracking (is the splitting of the epidermis when the internal expansion is faster than the expansion of the epidermis).

- Catface (misshapen fruit caused by something internal or external that occurs during the formation of the flower).

- Internal white tissue (white hard areas in vascular region caused by high temperatures and too much exposure to sun light). Greenback, green shoulder, yellow eye and yellow shoulder are all names for the same condition but with different severities).

- Gold spots (calcium oxalate deposition under the skin).

- Puffiness (open cavities between the seed gel area and outer wall caused by too low or too high temperatures during fruit set).

\section{Assessments made during crop growth}

- Overall vigour (1 to 9 scale).

- Uniformity of structure (1 to 9 scale).

- Side shoot formation (1 to 9 scale).

- Leaf mass (leaf size and number, 1 to 9 scale).

- Inter-node length (measured on three plants per plot between the 1st and 4th inflorescence, each three times to specify the average).

- Number of inflorescences (the number of fruit clusters is counted on five plants per plot).

- Missing plants (counted before harvest begins).

\section{Assessments made at harvest}

- The time of harvest is reached with the first fruit ripening. The crop yield will need to be assessed on repeated dates during the life of the crop.

- The crop is sorted, weighed and counted according to recognised quality standards (marketable and nonmarketable).

- The non-marketable crop is divided into main reasons for rejection e.g. diseased fruits, insect damage and fruits with physiological disorders.

- Taste testing.

- Nutritional analysis.

\section{Overall value score}

This is particularly appropriate for variety trials. It takes into account all the criteria for the cultivation and marketing of the variety, based on expert opinion as evaluated by researchers based on information from farmers, wholesalers and consumers $(1=$ very low, $3=$ low, $5=$ medium, $7=$ high, $9=$ very high $)$.

\section{References and further information}

Jones, J.,B., 2007.

Tomato Plant Culture: In the Field, Greenhouse, and Home Garden, Second Edition. CRC Press, 404 p.

Lattuschke G. 2004.

Anbau von Gewächshausgemüse. Hinweise zum umweltgerechten Anbau. Sächsische Landesanstalt für Landwirtschaft, Dresden, Germany. (in german). 219 p.

Scharpf and Weier, 1994.

Düngung von Unterglasgemüse in Bodenkulturen, Gemüse 11/94 623-626

Heuvelink, E. (Editor), 2005.

Tomatoes. E. CABI Publishing, London, UK, $341 \mathrm{p}$.

http://www2.ca.uky.edu/entomology/entomology.php

http://www7.inra.fr

http://www.rhs.org.uk

http://www.eppo.int

http://www.cpvo.europa.eu/main/en

UPOV Guidelines for the conduct of tests for distinctness, uniformity and stability. Tomatoes (TP/44/4). http:// www.upov.int 


\subsubsection{Eggplant}

\section{By Yüksel Tüzel}

Botanical name: Solanum melongena

Common names: Eggplant, aubergine, melanzana, brinjal, garden egg, guinea squash

\section{General crop requirements}

Eggplant is a perennial crop in warm climates. However, it is cultivated as an annual crop under moderate climatic conditions. Plants require high temperatures. The optimum growing temperature range is $21^{\circ}-30^{\circ} \mathrm{C}$. Temperatures above $35^{\circ} \mathrm{C}$ and below $15^{\circ} \mathrm{C}$ reduce fruit set. High light intensity from 12 to 14 hours per day is important for plant growth. It is grown in greenhouse conditions in the Mediterranean region while its culture is rare in Northern climatic conditions. Pollination with bumble bees has a positive effect on fruit setting and fruit size.
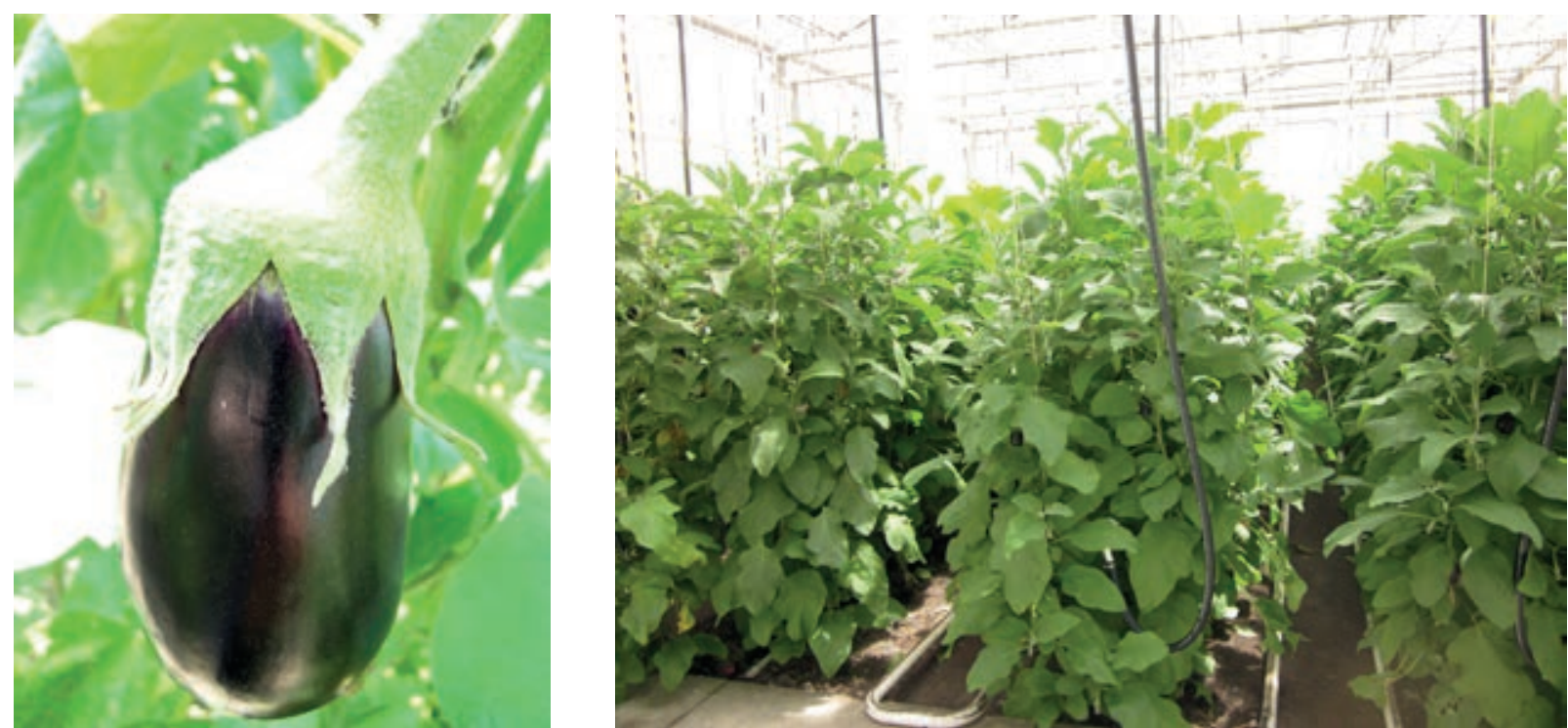

Figure 4.3 Eggplant crop trials in Belgium.

\section{Experimental design}

Recommended replicates: A minimum of three.

\section{Sowing and planting: temperature requirements}

Production season and the length of crop cycle depend on local climatic conditions (e.g. temperature, light) and availability of climate control (e.g. heating) in the greenhouses. Growing season and length of cycle affects plant density. Lower plant densities are recommended for longer seasons. If grafted plants are used, the plant density could be lower. 
Table 4.6

Typical eggplant plant spacing and number of plants required for trials.

\begin{tabular}{llll} 
& $\begin{array}{l}\text { North \& Central } \\
\text { Unheated }\end{array}$ & $\begin{array}{l}\text { North \& Central } \\
\text { Heated }\end{array}$ & $\begin{array}{l}\text { Mediterranean } \\
\text { Unheated } \\
\text { (frost-free) }\end{array}$ \\
Minimum number of plants / core plot & 12 & 12 & 12 \\
\hline Minimum size core plot $\left(\mathrm{m}^{2}\right)$ & 6 & 6 & 6 \\
\hline Plant density / $\mathrm{m}^{2}$ & $1.8-2$ & $2-3$ & 2 \\
\hline Stem density / $\mathrm{m}^{2}$ & $5-6$ & $4-6$ & 4 \\
\hline Row distance $(\mathrm{cm})$ & 80 & $120 / 80 *$ & $90-100$ \\
\hline Distance within the row $(\mathrm{cm})$ & $60-70$ & 50 & $50-60$ \\
\hline
\end{tabular}

* double rows - see Figure 4.2

Table 4.7

Typical eggplant sowing and harvesting dates.

\begin{tabular}{llllll}
$\begin{array}{l}\text { Region } \\
\text { - Production type }\end{array}$ & Sowing at & Planting at & $\begin{array}{l}\text { Start of } \\
\text { harvest }\end{array}$ & End of harvest & Remarks \\
$\begin{array}{l}\text { North \& Central } \\
\text { - Unheated }\end{array}$ & Feb-Mar & Apr-May & June-July & October & $\begin{array}{l}\text { Rarely grown in } \\
\text { Northern Europe }\end{array}$ \\
\hline $\begin{array}{l}\text { - Seasonal Heated } \\
\text { Mediterranean }\end{array}$ & Jan-Feb & Mar-Apr & May-June & October & Unheated \\
- Long cycle & August & Sept-Oct & Jan-Feb & July & greenhouses \\
\hline $\begin{array}{l}\text { - Short cycle Spring } \\
\text { Oct-Dec }\end{array}$ & February & May & July & Unheated \\
greenhouses
\end{tabular}

Sowing is carried out in multipots into appropriate growing medium. Temperature demand for germination and seedling growth is high. The seedlings are grown in the nurseries. For grafted seedlings, the seeds of rootstocks are sown three days after the scion seeds. Seedlings are planted when $30 \mathrm{~cm}$ tall in Northern countries. However, those having developed only two true leaves are transferred to the greenhouse in Mediterranean countries.

\section{Table 4.8}

Temperatures required for the production of eggplant seedlings and plants.

\begin{tabular}{lllll} 
Region & $\begin{array}{l}\text { Germination } \\
\text { temperature } \\
\text { day/ night }\end{array}$ & $\begin{array}{l}\text { Days until } \\
\text { germination }\end{array}$ & $\begin{array}{l}\text { Temperature for seedlings } \\
\text { in }{ }^{\circ} \mathrm{C} \text { day / night }\end{array}$ & $\begin{array}{l}\text { Weeks before planting } \\
\text { out }\end{array}$ \\
\hline $\begin{array}{l}\text { North \& } \\
\text { Central }\end{array}$ & $24-25$ & $3-5$ & $\begin{array}{l}1^{\text {st }} \text { stage } 22 / 20, \\
\text { later on } 20 / 18 \\
\text { Vent at } 25^{\circ} \mathrm{C}\end{array}$ & $7-9$ \\
\hline Mediterranean & $24-25$ & $3-5$ & $\begin{array}{l}24-26 / 20 \\
\text { Vent at } 28^{\circ} \mathrm{C}\end{array}$ & 4 \\
\hline
\end{tabular}


Table 4.9

Temperature requirement for eggplant growth and cropping

\begin{tabular}{llll} 
Growing cycle temperature & Day & Night & Ventilation from \\
\hline North \& Central & $20-22^{\circ} \mathrm{C}$ & $16-18^{\circ} \mathrm{C}$ & $\begin{array}{l}25^{\circ} \mathrm{C} \text { (depending on } \\
\text { humidity }\end{array}$ \\
\hline Mediterranean & $24-26^{\circ} \mathrm{C}$ & $16-18^{\circ} \mathrm{C}$ & $28^{\circ} \mathrm{C}$ \\
\hline
\end{tabular}

The soil temperature should be warm at the time of planting (at least $16^{\circ} \mathrm{C}$ ). During the growing period the temperatures should not exceed $35^{\circ} \mathrm{C}$ or drop below $15^{\circ} \mathrm{C}$. The optimum temperature for pollen germination is 20 to $27^{\circ} \mathrm{C}$.

\section{Plant nutrition}

Table 4.10

Eggplant nutrient requirements

\begin{tabular}{lcccc} 
Yield expectation $\left(\mathrm{kg} / \mathrm{m}^{2}\right)$ & $\mathrm{N} \mathrm{g} / \mathrm{m}^{2}$ & $\mathrm{P} \mathrm{g} / \mathrm{m}^{2}$ & $\mathrm{~K} \mathrm{~g} / \mathrm{m}^{2}$ & $\mathrm{Mg} \mathrm{g} / \mathrm{m}^{2}$ \\
10 & 32 & 4 & 52 & 5 \\
\hline 25 & 70 & 10 & 114 & 12 \\
\hline 40 & 92 & 16 & 148 & 20 \\
\hline
\end{tabular}

* adapted from various sources, see Appendix B. Leaf nutrient content is given in Appendix C.

\section{Pruning and training}

The plants are pruned to form a plant with two to four main stems (similar to pepper - see section 4.2.3) Yields increase with increasing number of branches up to a certain threshold which depends also on plant density. However, a very high stem density may negatively affect mean fruit size and thus marketable yield and fruit quality, although the overall yield may still increase. Strong lateral branches are allowed to grow above the point of the first flower, while all lateral shoots below that height are removed. Side shoots on the stems are pruned after the first fruit set, in particular in long cycle production (shown in Figure 4.4).

(a)

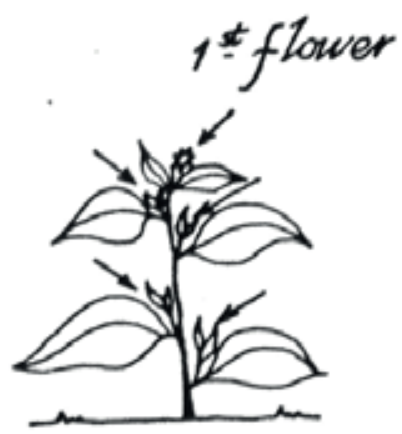

(b)

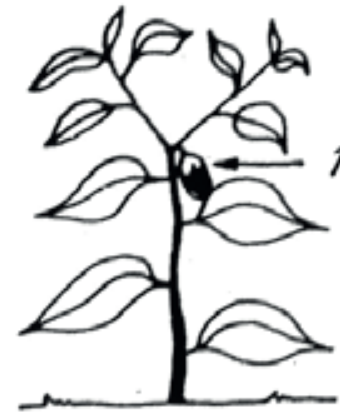

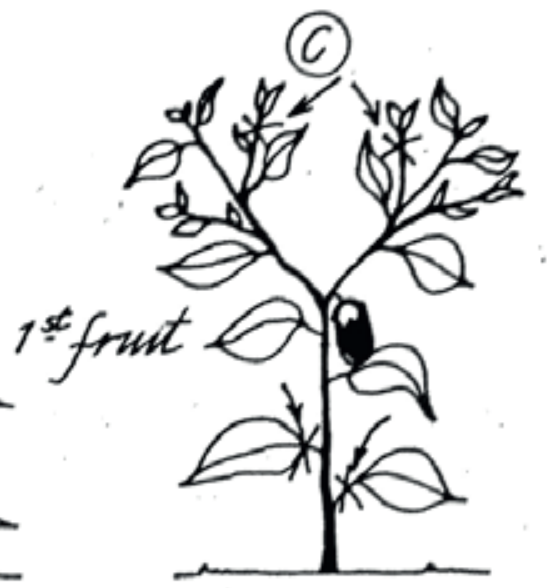

Figure 4.4 Pruning eggplants (a-removal of side shoots below the first flower, $b$-training to two stems, c-removal of inner shoots and old leaves) (FAO, 1990).

It is also possible to grow eggplant as a bush without pruning any shoots. The plants are vertically supported by a structure of poles and horizontal twines extended on both sides of the plant rows. Grafted plants are always grown on high wire systems. 


\section{Pollination}

One bumble bee hive is recommended for every $1000 \mathrm{~m}^{2}$.

\section{Irrigation}

At each irrigation event it is important to ensure that soil is moistened sufficiently. Eggplant is moderately sensitive to salinity.

\section{Mulching and weeding}

Mulching is useful to prevent evaporation and for weed control. Poultry can be useful for weed control too if the plants are not too small and vulnerable.

\section{Disease and pest problems and physiological disorders}

More information can be found at www.eppo.int - the European and Mediterranean Plant Protection Organization. Particular problems include:

- Powdery mildew: (Oidium longipes). See EPPO reference (PP 1/57(3) Powdery mildew of cucurbits and other vegetables).

- Grey mould: Botrytis spp. See EPPO reference (PP 1/54(3) Botrytis spp. and Sclerotinia spp. on vegetables).

- Verticillium wilt: Verticillium albo- atrum and V. dahliae.

- Viral diseases: Cucumber mosaic virus and eggplant special strains of tobamovirus. There are varieties with resistance to both viruses.

- Insect and mite pests (Shirinivasan, 2009; (more information can be found at www.avrdc.org. AVRDC Publication: 09-729. ISBN 92-9058-176-X).

- Calcium deficiency: This leads to the formation of uneven fruit. The fruit is then prone to splitting open, especially when growth and water uptake occurs quickly.

\section{Assessments made during crop growth}

- Vigour.

- Missing plants.

- Growth habit (1, Very upright; 3, Upright; 5, Intermediate; 7, Prostrate; 9, Very prostrate.

- Plant height (1, very short; 3, short; 5, medium; 7, tall; 9, very tall).

\section{Assessments made at harvest}

Yield Eggplants are harvested unripe when the fruits reach market size and before seeds become large and turn brown in colour. The fruit surface should be glossy. If the outer skin is dull and brown seeds are inside then the optimal harvest time has been exceeded. In a variety trial, harvesting is carried out once a week.

The crop is classified according to the quality standards for marketable and non-marketable produce, and the fruits in each fraction are weighed and counted. The exact sizes specified will depend on the location and the market channel but they would typically be:

Elongated fruit shape: Minimum diameter $40 \mathrm{~mm}$, minimum length $80 \mathrm{~mm}$.

Rounded fruit shape: No guidelines for minimum diameter, but minimum length should be 70 mm, minimum weight $100 \mathrm{~g}$.

Average fruit weight is mostly around $300 \mathrm{~g}$, depending on the type of fruit. If it is relevant to the question of the experiment, the marketable fruit, by weight, can be further sorted (e.g. 100-300 g; 300-500 g; $500 \mathrm{~g}$ and above). The non-marketable fruits can be subdivided into the following categories: small fruits, rotten and diseased fruits, other non-marketable fruits.

Fruit shape and colour Sample at least ten marketable fruits per plot on three separate occasions during harvest time to assess fruit shape and colour intensity, distribution of colour (stripes etc.), firmness, lustre and spininess of the calyx. This can be done using 1 to 9 scales (for example Figure 4.5). Fruit length and diameter can also be measured. See CPVO guidelines for more information on how to assess the crop. 
Shelf life in days At harvest time, 20 marketable fruits are stored at the same time at room temperature for each variety (mixed sample of the plots). Every 2-3 days each individual fruit is assessed for marketability. Record how long (in number of days) it takes for $50 \%$ of the eggplants to become unmarketable - this gives an indication of shelf-life.

\section{Overall value score}

This takes into account all the criteria for cultivation and marketing (it is particularly appropriate for variety trials). It can be an aggregate of other scores or more subjective and based on based on 'expert opinion'. It is normally described on a 1 to 9 scale ( $1=$ very low, $3=$ low, $5=$ medium, $7=$ high, $9=$ very high $)$.

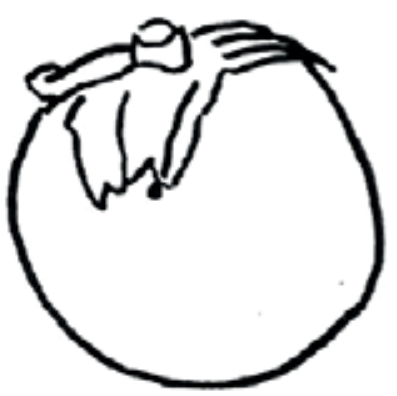

1

globular

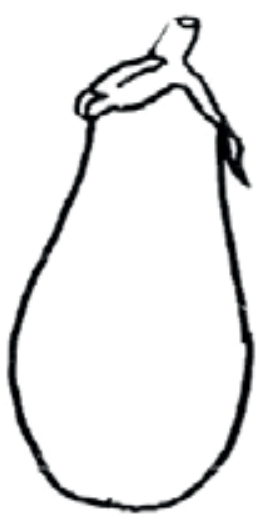

4

pear shaped

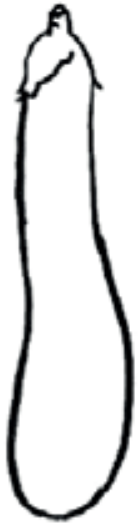

5

club shaped

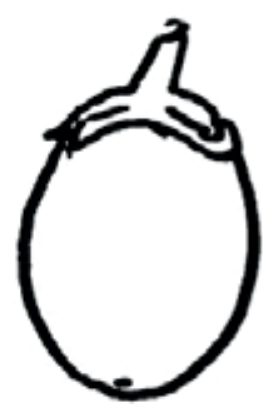

2

ovoid

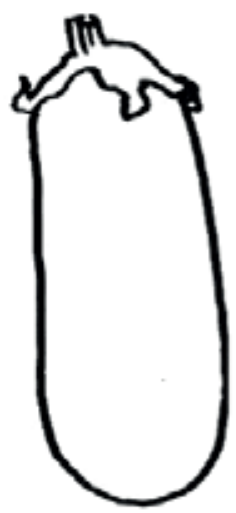

6

ellipsoid

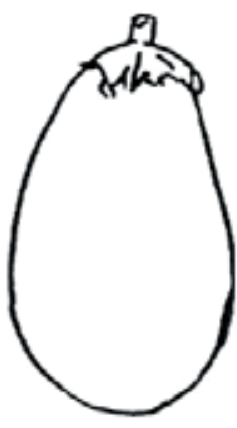

3

obovate

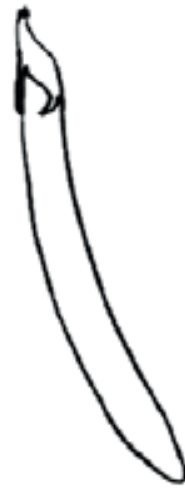

7

cylindrical

Figure 4.5 Fruit shape classification of eggplant (source UPOV, TP117/1). 


\section{References and further information}

Anon., 2008.

Minimum descriptors for eggplant, Capsicum (sweet and hot pepper) and tomato. ECPGR Working Group on Solanaceae. (www.ecpgr.cgiar.org)

FAO, 1990.

Protected Cultivation in the Mediterranean Climate. FAO Plant Production and Protection paper 90. 313 p.

Gianquinto, G., Munoz, P., Pardossi, A., Ramazzotti, S., Savvas, D., 2013.

Soil fertility and plant nutrition. In Good Agricultural Practices for greenhouse Vegetable crops. FAO Plant Production and Protection Paper 217:215-270.

Maas, E.V. 1990. MAAS E.V., 1990.

Crop salt tolerance. In: Tanji K.K. (ed.), Agricultural salinity assessment and management. ASCE Manual Reports on Engineering Practices, 71: 262-304.

Shirinivasan, R.,2009.

Insects and Mite Pests on Eggplant. A field guide for identification and Management: (www.avrdc.org. AVRDC Publication: 09-729. ISBN 92-9058-176-X).

UPOV, 2002.

Guidelines for the conduct of tests for distinctness, uniformity and stability. Eggplant (Solanum melongena).

TP 117/1. http://www.upov.int

http://www.eppo.int

http://www.cpvo.europa.eu/main/en 


\subsubsection{Peppers}

\section{By Justine Dewitte}

Botanical name: Capsicum annuum

Common names: Bell pepper, Sweet pepper

\section{General crop requirements}

Peppers are a perennial crop in warm climates. However, they are cultivated as an annual crop under moderate climatic conditions. The growth conditions for peppers require rather high temperatures $\left(20^{\circ}-28^{\circ}\right)$ and high light intensity. The soil has to be warmed up before planting. There must be a rotation of at least four years; if they are grown more intensively, grafting is recommended because of pressure from soil borne diseases and pests such as root knot nematodes and Verticillium. However the yield of grafted pepper plants is usually less than ungrafted plants. They are grown in greenhouse conditions in the Mediterranean region but their culture is less common in Northern climatic conditions. Pollination with bumblebees is not necessary, but is commonly used to reduce pollen concentrations in the greenhouse. Pepper pollen is known to frequently induce allergies in humans.
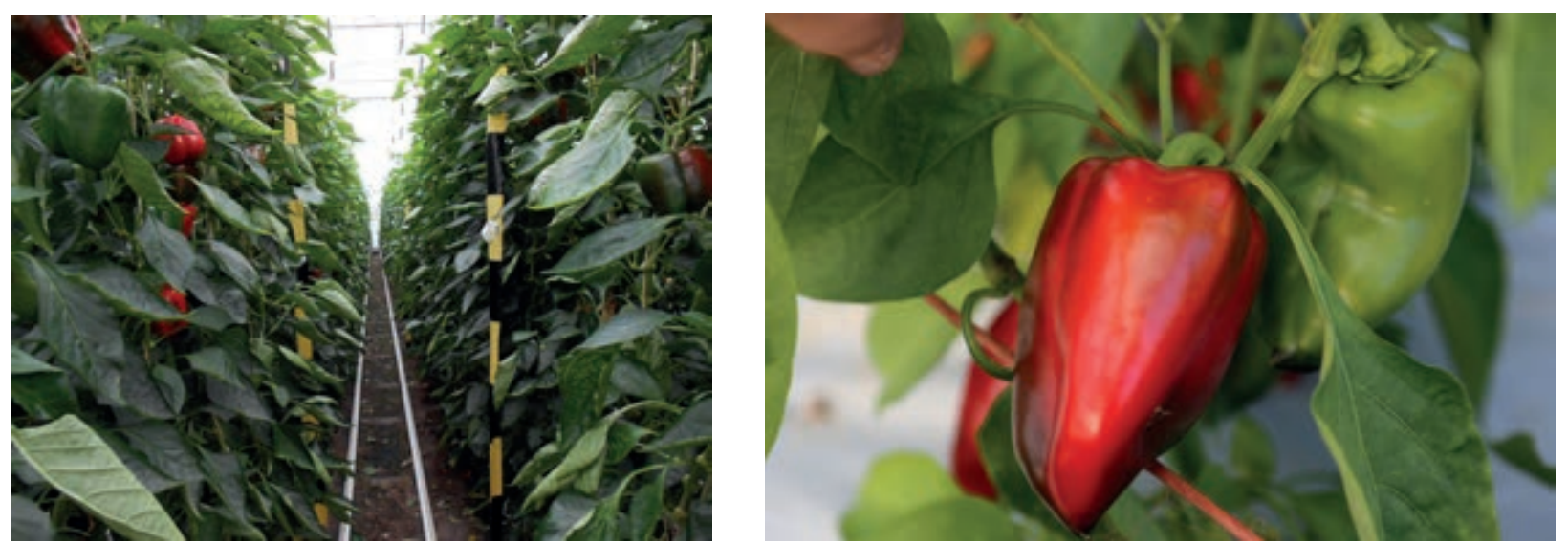

Figure 4.6 Pepper trials in Belgium.

\section{Experimental design}

Recommended replicates: at least three.

See UPOV/CPVO protocols for details. Growth density depends on growing conditions (heated greenhouse or polytunnel), growing season and the length of growing cycle.

\section{Table 4.11}

Typical pepper plant spacing and number of plants required for trials.

\begin{tabular}{llll} 
& $\begin{array}{l}\text { North \& Central } \\
\text { Unheated }\end{array}$ & $\begin{array}{l}\text { North \& Central } \\
\text { Heated }\end{array}$ & $\begin{array}{l}\text { Mediterranean } \\
\text { Unheated } \\
\text { (frost-free) }\end{array}$ \\
Minimum number of plants / core plot & 12 & 12 & 12 \\
\hline Minimum size core plot $\left(\mathrm{m}^{2}\right)$ & $4.0-3.5$ & $4.0-3.5$ & $3.5-4.0$ \\
\hline Plant density / $\mathrm{m}^{2}$ & $3.0-3.4$ & $3.0-3.4$ & $2.5-4$ \\
\hline Stem density $/ \mathrm{m}^{2}$ & $6.5-7.0$ & $6.5-7.0$ & $6-7$ \\
\hline Row distance $(\mathrm{cm})$ & $0.6-1.00$ & $0.6-1.00$ & $0.9-1.00$ \\
\hline Distance within the row $(\mathrm{cm})$ & $35-40$ & $35-40$ & $35-40$ \\
\hline
\end{tabular}




\section{Sowing and planting}

Production season and the length of crop cycle depend on local climate conditions (e.g. temperature, light) and availability of climate control (e.g. heating) in the greenhouse.

\section{Table 4.12}

Pepper sowing and harvesting dates.

\begin{tabular}{|c|c|c|c|c|c|}
\hline $\begin{array}{l}\text { Region } \\
\text { - Production type }\end{array}$ & Sowing at & Planting at & Start of harvest & End of harvest & Remarks \\
\hline $\begin{array}{l}\text { North \& Central } \\
\text { - Unheated }\end{array}$ & $\begin{array}{l}\text { Feb - Mar (heat } \\
\text { required at this } \\
\text { stage ) }\end{array}$ & April - May & June & October & Ungrafted crops \\
\hline $\begin{array}{l}\text { - Seasonal } \\
\text { Heated }\end{array}$ & January & March & May & October & $\begin{array}{l}\text { Ungrafted or } \\
\text { grafted crops }\end{array}$ \\
\hline - Long cycle Heated & November & January & April & November & Grafted crops \\
\hline $\begin{array}{l}\text { Mediterranean } \\
\text { - Long cycle }\end{array}$ & July & August & November & June & $\begin{array}{l}\text { Ungrafted or } \\
\text { grafted crops }\end{array}$ \\
\hline - Short cycle Spring & Oct - Nov & Jan - Feb & May & June & $\begin{array}{l}\text { Ungrafted or } \\
\text { grafted crops }\end{array}$ \\
\hline
\end{tabular}

Sowing is carried out in trays or pots. The temperature demand of the crop is high during germination and seedling growth so the seedlings are grown in heated nurseries. After 2-3 weeks, transplanting or grafting is carried out. The sowing date of the rootstock and the scion can differ by three to five days, depending on the vigour of the varieties.

Table 4.13

Conditions required for the production of pepper seedlings.

\begin{tabular}{|c|c|c|c|c|}
\hline $\begin{array}{l}\text { Germination } \\
\text { temperature }{ }^{\circ} \mathrm{C} \\
\text { Day/ Night }\end{array}$ & $\begin{array}{l}\text { Days until } \\
\text { germination }\end{array}$ & $\begin{array}{l}\text { Temperature for } \\
\text { seedlings in }{ }^{\circ} \mathrm{C} \\
\text { Day/ Night }\end{array}$ & Pot size & Weeks until planting \\
\hline $\begin{array}{l}26^{\circ} / 24^{\circ} \\
\text { Ventilation from } 28^{\circ}\end{array}$ & $10-15$ & $\begin{array}{l}20^{\circ} / 20^{\circ} \\
\text { Ventilation from } 28^{\circ}\end{array}$ & $\begin{array}{l}5-10 \mathrm{~cm} \\
\text { pot }\end{array}$ & $7-10$ \\
\hline
\end{tabular}

When the seedlings are $20 \mathrm{~cm}$ high they are planted into warm soil. They should have 4-6 leaves. Grafted plants should not be planted too deeply to avoid adventitious roots developing from the scion. Temperatures should be $22-24^{\circ} \mathrm{C}$ during the day and $18-20^{\circ} \mathrm{C}$ during the night. The crop should be ventilated when temperatures reach $26-28^{\circ} \mathrm{C}$.

\section{Plant nutrition}

Peppers are nutrient-demanding crops. Before planting, a basic soil amendment such as green compost or composted manure should be added to the soil. During the growing season an additional dressing of organic commercial fertiliser will be needed. Several organic fertilisers are suitable such as blood meal, soy scrap, horn shavings, maltaflor, vinasse, etc. It is recommended to use partial slow-release fertilisers. 
Table 4.1

Pepper plant nutrient requirements

\begin{tabular}{llcll}
$\begin{array}{l}\text { Yield expectation } \\
\left(\mathrm{kg} / \mathrm{m}^{2}\right)\end{array}$ & $\mathrm{N} \mathrm{g} / \mathrm{m}^{2}$ & $\mathrm{P} \mathrm{g} / \mathrm{m}^{2}$ & $\mathrm{~K} \mathrm{~g} / \mathrm{m}^{2}$ & $\mathrm{Mg} \mathrm{g} / \mathrm{m}^{2}$ \\
10 & 36 & 5 & 43 & 4 \\
\hline 25 & 59 & 8 & 70 & 7 \\
\hline 40 & 81 & 11 & 97 & 9
\end{tabular}

* adapted from various sources, see Appendix B. Leaf nutrient contents are given in Appendix C.

\section{Pruning and training}

Shortly after planting, when growth commences, the first flower should be removed. The subsequent first flower(s) of each stalk should also be removed. Thinning out the flowers is necessary to avoid too much fruit setting. Early vegetative growth of the plant is necessary to have robust plants for the rest of the season. The plants are pruned to form a plant with two to three main stems. Yield depends on plant density in relation to the number of branches. Of course, other factors also influence the yield such as variety, temperature, water, etc. When the stem density is too high the mean fruit size will be negatively affected. Strong lateral branches are allowed to grow after the formation of the first flower, while all lateral shoots below that height are removed. Side shoots on the stems are pruned after the first fruit set, in particular in long cycle production (See Figure 4.7).

It is also possible to grow peppers using bush culture without pruning any shoots. The plants are vertically supported by a structure of poles and horizontal twines extended on both sides of the plant rows. Grafted plants are always grown on a high wire system. Broken shoots and leaves need to be removed because of the risk of Botrytis.

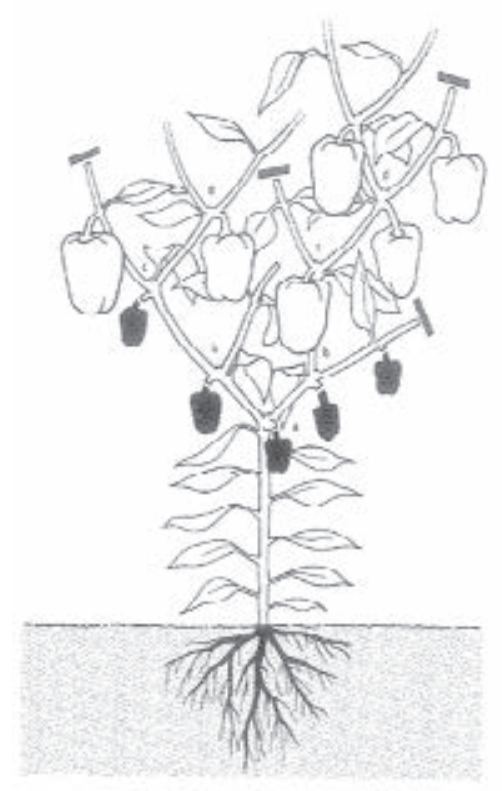

Figure 4.7 Pruning pepper plants; pruning side shoots after the formation of the first fruits. The small fruits, shown as the black little peppers at the base of the plant, have to be removed.

\section{Pollination}

Pepper plants are self-pollinators and bumblebees are not generally necessary, although, if used, they will improve pollination and increase fruit weight. 


\section{Irrigation}

Irrigation is necessary directly after planting. The week after planting, when plants are a little more established, the soil can be kept dry until fruit setting commences. The moment that fruit setting has started, the water demand increases.

\section{Mulching and weeding}

Covering the soil with mulch material during cultivation can be useful because of the advantageous effect on mineralisation. It is not recommended directly after planting, because the soil stays too cold. Weeding can be done by using poultry (when the plants are big enough), or by hand.

\section{Disease and pest problems}

- Grey mould and grey-brown spots: Botrytis cinerea (infection takes place primarily on wounds).

- Fusarium and Verticilium wilts.

- Sclerotinia sclerotiorum (white cotton-like mycelium with black sclerotia).

- Virus diseases such as Tomato Mosaic Virus (ToMV) and Cucumber Mosaic Virus (CMV).

- Aphids are the main pest of peppers. This leads to yield losses and less photosynthesis because of sooty mould. The most common species are Myzus persicae, Aphis Frangulae ssp. Gossypii and the two potato aphids Macrosiphum euphorbiae and Aulacorthum solani. Beneficial insects prevent or control attacks of aphids, whiteflies, spider mites and thrips.

- Root knot nematodes: Meloidogyne spp. Meloidogyne occur mostly when there is insufficient crop rotation.

Further information can be obtained from the European and Mediterranean Plant Protection Organization: http:// archives.eppo.int

\section{Assessments made during crop growth}

- Missing plants.

- Uniformity of the plants.

- Vigour.

- Colour of the leaves.

\section{Assessments made at harvest}

The time of harvest depends on the type of fruit you want to harvest, i.e. coloured green yellow or red. The peppers have to reach their marketable size and to be firm. Green fruits are the first to be harvested, followed by coloured fruits. Fruits are harvested with a little of the stalk attached. The harvest of the peppers in a greenhouse has to be done every week, in a polytunnel it is less frequent and depends on the climate

Evaluation of the following characteristics should be determined on 10 fruits, three times during the growing season:

Fruit shape There are several forms of peppers (see Fig 4.8)

Fruit colour ( 1 = very pale, $3=$ pale, $5=$ medium, 7 = dark, $9=$ very dark)

Length and diameter

Wall thickness of the fruits ( 1 = very thin, $3=$ low, $5=$ medium, $7=$ high, $9=$ very thick)

Shelf-life in days The durability of peppers is tested under optimal conditions. For each plot, five fruits are stored and assessed regularly to monitor their deterioration to an unmarketable state. 
Marketable and unmarketable yield This will need to be done repeatedly throughout the productive phase of the crop. The fruits are sorted (and counted) according to recognised quality standards. There may be a subsequent division into Class 1 and Class 2 produce. The non-marketable crop is divided into main reasons for rejection:

- Fruit size too small.

- Rotten fruits.

- Distorted fruits.

- Fruits damaged by pests or diseases.

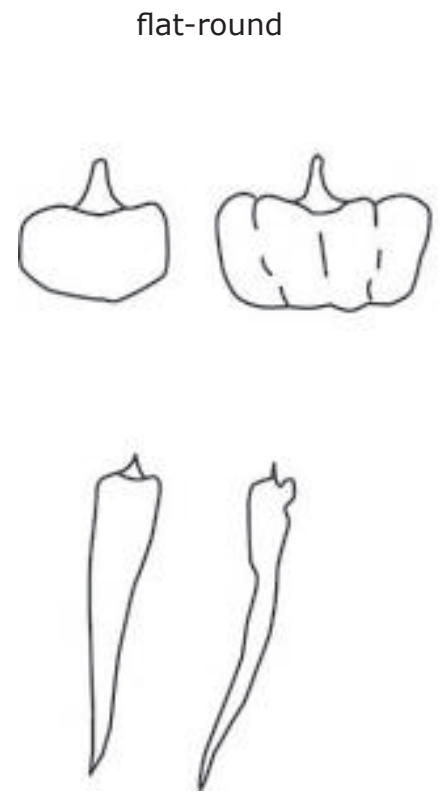

small triangular

$$
\text { round }
$$
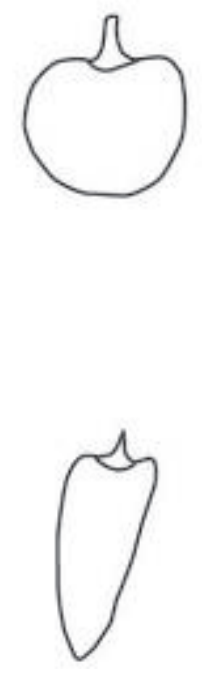

triangular broad blocky
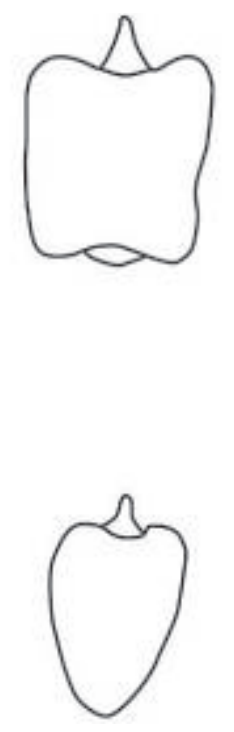

cordate small blocky
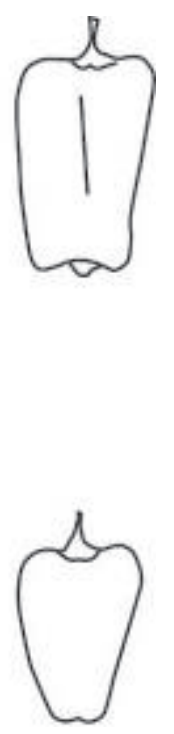

trapezoidal

Figure 4.8. Classification of pepper fruit shapes (source UPOV TG/76/8).

\section{Overall value score}

This takes into account all the criteria for cultivation and marketing (it is particularly appropriate for variety trials). It can be an aggregate of other scores or more subjective and based on 'expert opinion'. It is normally described on a 1 to 9 scale ( $1=$ very low, $3=$ low, $5=$ medium, $7=$ high, $9=$ very high $)$.

\section{References and further information}

Anon., 2008.

Minimum descriptors for eggplant, Capsicum (sweet and hot pepper) and tomato. ECPGR Working Group on Solanaceae. (www.ecpgr.cgiar.org)

UPOV, 2002.

Guidelines for the conduct of tests for distinctness, uniformity and stability. Peppers (TG/76/8). http://www. upov.int

Dedeene, L., De Kinder, G. Groente \& Fruit Encyclopedie (2009), Kosmos, p.131. Van Boxem, H., Buysse, G., Maes, B., Robinet, P., Williame, F. Handboek Ecologisch Tuinieren (2006), Velt vzw. P561. Malais, M.H., Ravensberg, W.J.

Kennen en herkennen: Levenswijzen van kasplagen en hun natuurlijke vijanden http://www.eppo.int http://www.cpvo.europa.eu/main/en 


\subsubsection{Courgette}

\section{By Pedro Gomez}

Botanical name: Cucurbita pepo

Common names: zapallito, zucchini

\section{General crop requirements}

Courgettes are herbaceous, annual plants with a bushy growth habit. They are cultivated under warm climatic conditions with an optimal temperature of $18-24^{\circ} \mathrm{C}\left(16^{\circ} \mathrm{C}\right.$ at night with ventilation from $\left.24^{\circ} \mathrm{C}\right)$. They do not tolerate frost. Nowadays, most varieties are hybrids harvested before fruit maturation. In the Mediterranean region, greenhouse plants are grown in soil with a sand mulch. Fruit shape is usually long and skin colour green, but there are also round-shaped, white and yellow coloured varieties. Fresh courgettes must feel firm and have an undamaged skin. The flesh colour is white and has a delicate flavour.

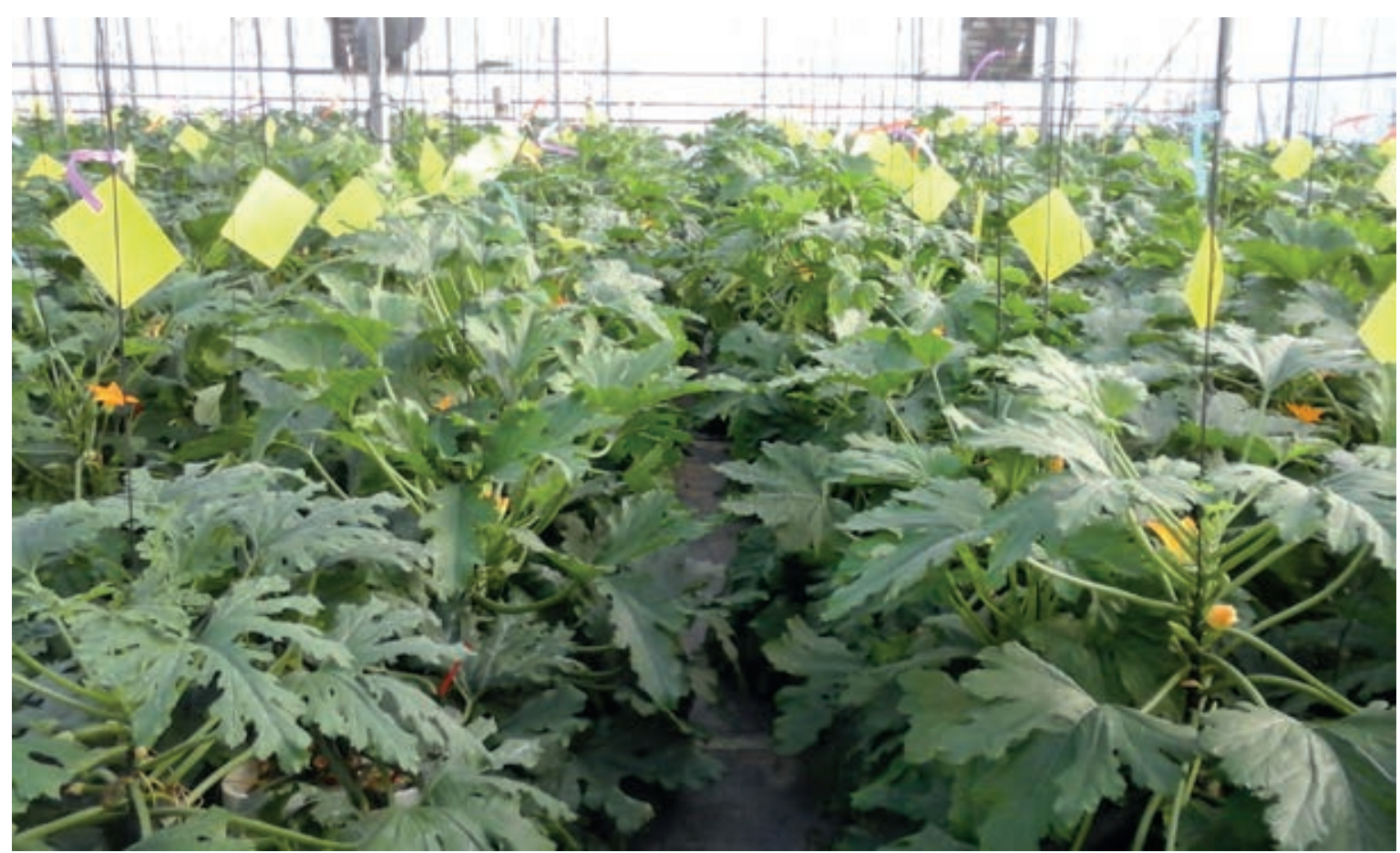

Figure 4.9 Courgette trial in Spain.

\section{Experimental design}

Recommended replicates: at least three.

The plants require plenty of space to grow. Depending on the heterogeneity of the group to be tested, the core size can be increased in order to avoid differences of variation. 
Table 4.15

Typical courgette plant spacing and number of plants required for trials.

\begin{tabular}{llll} 
& $\begin{array}{l}\text { North \& Central } \\
\text { Unheated }\end{array}$ & $\begin{array}{l}\text { North \& Central } \\
\text { Heated }\end{array}$ & $\begin{array}{c}\text { Mediterranean } \\
\text { unheated } \\
\text { (frost-free) }\end{array}$ \\
\hline Minimum number of plants / core plot & 5 & 5 & $4-5$ \\
\hline Minimum size core plot $\left(\mathrm{m}^{2}\right)$ & 5 & 3.5 & 4 \\
\hline Plant density / $\mathrm{m}^{2}$ & $1-1.5$ & 1.5 & 1 \\
\hline Row distance $(\mathrm{cm})$ & $50-100$ & 50 & $50-100$ \\
\hline Distance within the row $(\mathrm{cm})$ & $100-150$ & 130 & $100-150$
\end{tabular}

\section{Table 4.16}

Typical courgette sowing and harvesting dates.

\begin{tabular}{|c|c|c|c|c|c|}
\hline $\begin{array}{l}\text { Region } \\
\text { - Production type }\end{array}$ & Sowing at & Planting at & Start of harvest & End of harvest & Remarks \\
\hline $\begin{array}{l}\text { North \& Central } \\
\text { - Unheated }\end{array}$ & March & April & May & August & $\begin{array}{l}\text { Additional frost } \\
\text { protecting with } \\
\text { floating row cover } \\
\text { may be necessary }\end{array}$ \\
\hline $\begin{array}{l}\text { - Seasonal } \\
\text { Heated }\end{array}$ & February & March & April & June & $\begin{array}{l}\text { Bumble bees for } \\
\text { pollination or use } \\
\text { parthenocarpic } \\
\text { varieties }\end{array}$ \\
\hline $\begin{array}{l}\text { Mediterranean } \\
\text { - Long cycle }\end{array}$ & September & September & November & March & \\
\hline $\begin{array}{l}\text { - Short cycle } \\
\text { Spring }\end{array}$ & December & January & February & May & \\
\hline $\begin{array}{l}\text { - Short cycle } \\
\text { Autumn }\end{array}$ & August & September & October & December & \\
\hline
\end{tabular}

\section{Table 4.17}

Temperatures required for the production of courgette transplants.

\begin{tabular}{llllll} 
Region & $\begin{array}{l}\text { Germination } \\
\text { temperature }{ }^{\circ} \mathrm{C} \\
\text { Day / Night }\end{array}$ & $\begin{array}{l}\text { Days until } \\
\text { germination }\end{array}$ & $\begin{array}{l}\text { Temperature for } \\
\text { seedlings in }{ }^{\circ} \mathrm{C} \\
\text { Day / Night }\end{array}$ & Pot size & $\begin{array}{l}\text { Weeks until } \\
\text { planting }\end{array}$ \\
\hline North \& Central & $20-25 / 20$ & $5-10$ & $18-25 / 16-20$ & $8-10 \mathrm{~cm} *$ & $2-4$ \\
\hline Mediterranean & $20-25 / 12$ & $5-10$ & $25-30 / 15$ & $8-10 \mathrm{~cm}$ & $2-4$
\end{tabular}

*For early planting in cold soil larger pots $(10-11 \mathrm{~cm})$ are recommended 
Table 4.18

Courgette plant nutrient requirements.

\begin{tabular}{lllll}
$\begin{array}{l}\text { Yield expectation } \\
\left(\mathrm{kg} / \mathrm{m}^{2}\right)\end{array}$ & $\mathrm{N} \mathrm{g} / \mathrm{m}^{2}$ & $\mathrm{P} \mathrm{g} / \mathrm{m}^{2}$ & $\mathrm{~K} \mathrm{~g} / \mathrm{m}^{2}$ & $\mathrm{Mg} \mathrm{g} / \mathrm{m}^{2}$ \\
4 & 16 & 3 & 26 & 2 \\
\hline 8 & 32 & 6 & 52 & 4 \\
\hline
\end{tabular}

Source: adapted from various sources, see Appendix B

\section{Growing requirements}

Pruning is not required. Courgettes are grown both outdoors and under glass. In greenhouses, the plants are sometimes tied up, just like tomato plants. When grown outdoors, courgette plants tend to be fairly compact. One courgette plant can produce up to 30 courgettes. Courgettes can reach a length of up to $30 \mathrm{~cm}$.

Pollination by Bombus terrestris is recommended, introducing 10 hives / ha.

Irrigation at $2.5-3 \mathrm{l} / \mathrm{m}^{2}$ a day is recommended.

\section{Disease and pest problems and physiological disorders}

\section{Diseases}

- Powdery mildew - Sphaerotheca fuliginea.

- Gummy Stem Blight - Didymella bryoniae.

- Botrytis - Botrytis cinerea.

- ZYMV (Zucchini Yellow Mosaic Virus).

- WMV-2 (Watermelon Mosaic Virus-2).

- CMV (Cucumber Mosaic Virus).

- CVYV (Cucumber vein yellowing virus).

- ToLCNDV (Tomato Leaf Curl New Delhi Virus).

- CYSDV (Cucumber Yellow Stunt Disorder Virus).

\section{Pests}

- Thrips - Frankliniella occidentalis.

- Whitefly - Trialeurodes vaporariorum, Bemisia tabaci.

- Aphids - Aphis gossypii, Myzus persicae.

- Red mite - Tetranychus spp.

- Leaf miner - Liriomyza trifolii), Liriomyza strigata, Lyriomyza bryoniae

- Green worm - Spodoptera exigua.

\section{Physiological disorders}

- Silver leaf (associated with some cultivars).

- Fruits abort (caused by insufficient pollination or plant autoregulation).

- Fruit torsion - malformation (caused by insufficient pollination).

\section{Assessments during growth}

Missing plants, uniformity of crop, vigour, number of faults, proportion of female flowers per plant, number of fruits per stem, leaf size, virus resistance, resistance of roots to Fusarium and nematodes. When quantification is difficult a scoring system can be used ( 1 = very low, $3=$ low, $5=$ medium, $7=$ high, $9=$ very large/high). 


\section{Assessments at harvest}

Courgettes are non-climacteric fruit and should be harvested before maturity (before they become marrows) when fruits reach 20-30 cm. Harvest periodically every 2 - 3 days. The crop should be sorted according to recognised quality standards into non-marketable fractions (rejecting twisted fruit, aborted etc.). The acceptable size depends on the cultivar. Factors to assess specifically (often using a 1 to 9 scale) include:

- Colour and brightness of the skin.

- Flesh texture and firmness.

- Flesh colour.

- Diameter.

- Shape.

\section{Overall value score}

This takes into account all the criteria for the cultivation and marketing of a variety, based on expert opinion as evaluated by researchers using information from farmers, wholesalers and consumers ( $1=$ very low, $3=$ low, 5 = medium, 7 = high, 9 = very high).

\section{References and further information}

Maynard, D. N. and G. J. Hochmuth. 2007.

Knott's Handbook for Vegetable Growers. Hoboken, NJ, John Wiley \& Sons, Inc

UPOV Guidelines for the conduct of tests for distinctness, uniformity and stability. Courgette (TP/119/1). http:// www.upov.int

Reche J. 1997

Cultivo de Calabacín en Invernadero (Spanish). Ed Colegio Oficial de Ingenieros Técnicos Agrícolas 


\subsubsection{Cucumbers}

\section{By Wolfgang Palme}

Botanical name: Cucumis sativus

\section{General crop requirements}

Cucumbers need warm, light, free-draining soils that are rich in nutrients and humus. They should be grown with rotation breaks of 4 years. If a closer crop rotation is chosen then it is preferable to use grafted plants.
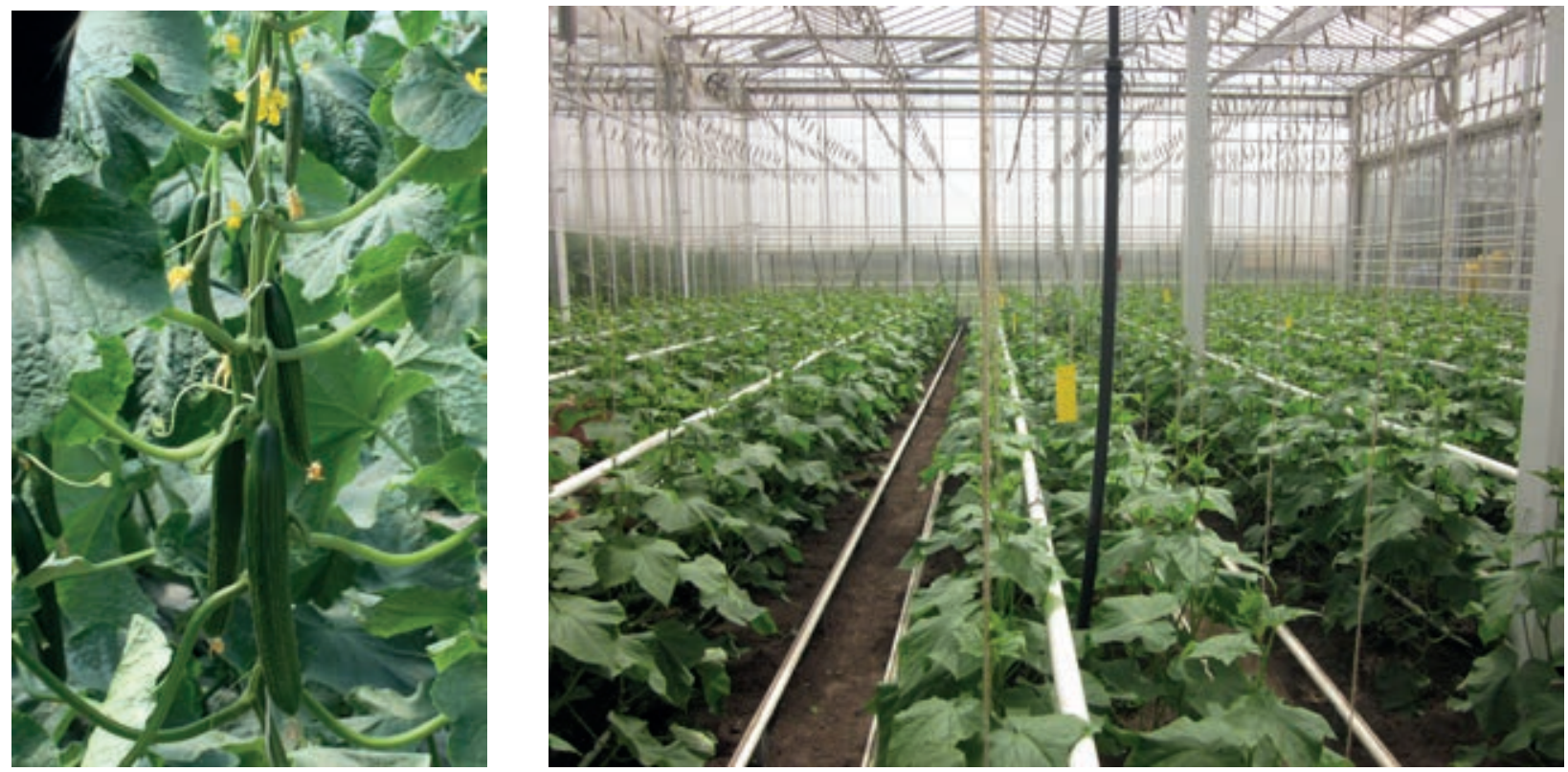

Figure 4.10 Cucumber trials; on the right showing commercial scale production.

\section{Experimental design}

Recommended replicates: at least three.

Cucumber plants can take up a lot of room (depending on variety and fruit length). It is therefore often best to use a 'double row' system (staggering the plants) as a way of saving space - as illustrated in Figure 4.2. See also recommendations made by CPVO for cultivation according to variety.

Table 4.19

Typical cucumber plant spacing and numbers of plants required for trials.

\begin{tabular}{llll} 
& $\begin{array}{l}\text { North \& Central } \\
\text { Unheated }\end{array}$ & $\begin{array}{l}\text { North \& Central } \\
\text { Heated }\end{array}$ & $\begin{array}{l}\text { Mediterranean } \\
\text { Unheated } \\
\text { (frost-free) }\end{array}$ \\
\hline Minimum number of plants / core plot & 12 & 12 & 12 \\
\hline Minimum size core plot $\left(\mathrm{m}^{2}\right)$ & 10 & 10 & 10 \\
\hline Plant density $/ \mathrm{m}^{2}$ & $1.2-1.8$ & $1.2-1.8$ & $2-3.3$ \\
\hline Steams density $/ \mathrm{m}^{2}$ & $1.2-1.8$ & $1.2-1.8$ & 1 \\
\hline Row distance $(\mathrm{cm})$ & 1 row: $120-150$ & 1 row: $120-150$ & 1 row: 100 \\
& $\begin{array}{l}\text { Double rows: } \\
\text { Double rows: }\end{array}$ & Double rows: $50 / 100$ \\
\hline Distance within the row $(\mathrm{cm})$ & $45-55-100 / 200$ & $60 / 120-100 / 200$ & $45-50$
\end{tabular}




\section{Sowing and planting}

Production season and the length of crop cycle depend on local climatic conditions (e.g. temperature, light etc.) and availability of climate control (e.g. heating) in the greenhouse. If the soil temperature drops below $14-16^{\circ} \mathrm{C}$ for a prolonged period of time the plants will wilt and die. If the temperature rises too high and there is not enough humidity the main shoots can show leaf burn. High temperatures with high humidity are not conducive to development either - if this happens the crops should be shaded.

\section{Table 4.20}

Typical cucumber sowing and harvesting dates.

\begin{tabular}{|c|c|c|c|c|c|}
\hline $\begin{array}{l}\text { Region } \\
\text { - Production type }\end{array}$ & Sowing at & Planting at & Start of harvest & End of harvest & Remarks \\
\hline $\begin{array}{l}\text { North \& Central } \\
\text { - Unheated }\end{array}$ & April & May & June & September & \\
\hline - Seasonal Heated & February & March & May & September & \\
\hline - Long cycle Heated & $\begin{array}{l}\text { December } \\
\text { June }\end{array}$ & $\begin{array}{l}\text { February } \\
\text { July }\end{array}$ & $\begin{array}{l}\text { March } \\
\text { July }\end{array}$ & $\begin{array}{l}\text { July } \\
\text { October }\end{array}$ & $\begin{array}{l}2 \text { Sets, grafted } \\
\text { plants }\end{array}$ \\
\hline $\begin{array}{l}\text { Mediterranean } \\
\text { - Long cycle }\end{array}$ & October & November & December & July & \\
\hline - Short cycle Spring & January & February & March & July & \\
\hline - Short cycle Autumn & August & September & October & February & \\
\hline
\end{tabular}

Table 4.21. Temperatures required for the production of cucumber seedlings and plants.

$\begin{array}{lllll}\begin{array}{l}\text { Germination temperature }{ }^{\circ} \mathrm{C} \\ \text { Day/ Night }\end{array} & \begin{array}{l}\text { Days until } \\ \text { germination }\end{array} & \begin{array}{l}\text { Temperature for seedlings in }{ }^{\circ} \mathrm{C} \\ \text { (Day/ Night) }\end{array} & \begin{array}{l}\text { Pot size } \\ \text { planting }\end{array} \\ \begin{array}{llll}25 / 20 & 8-14 & 20-25 / 18-20 & 8-13 \mathrm{~cm}\end{array} \\ \begin{array}{l}\text { Ventilation from 26 } \\ \hline\end{array}\end{array}$

Table 4.22

Optimal temperatures for cucumber growth and fruit production.

\begin{tabular}{llll} 
& Day & Night & Ventilation from \\
Immediately after planting & $22-24^{\circ} \mathrm{C}$ & $16-18^{\circ} \mathrm{C}$ & $25^{\circ} \mathrm{C}$ \\
\hline Later in the growing season & $20^{\circ} \mathrm{C}$ & $15^{\circ} \mathrm{C}$ & $22^{\circ} \mathrm{C}$ \\
\hline
\end{tabular}

\section{Plant nutrition and irrigation}

Table.4.23

Cucumber plant nutrient requirements.

\begin{tabular}{lllll}
$\begin{array}{l}\text { Yield expectation } \\
\left(\mathrm{kg} / \mathrm{m}^{2}\right)\end{array}$ & $\mathrm{N}\left(\mathrm{g} / \mathrm{m}^{2}\right)$ & $\mathrm{P}\left(\mathrm{g} / \mathrm{m}^{2}\right)$ & $\mathrm{Kg}\left(\mathrm{g} / \mathrm{m}^{2}\right)$ & 7 \\
\hline 15 & 25 & 6 & 44 & 13 \\
\hline 25 & 38 & 10 & 65 & 20
\end{tabular}

Source: adapted from various sources, see Appendix B. Leaf nutrient contents are given in Appendix C.

The crops need $5-6.5 \mathrm{l} / \mathrm{m}^{2}$ of water each day from May onwards. 


\section{Training and pruning}

Cucumbers can be grown via two methods using cords (vertical strings tied to a horizontal top wire). Side shoots, tendrils and fruits are removed up to a height of $0.75 \mathrm{~m}$.

For the first method (see Figure 4.11), only tendrils and side shoots are removed from a height of $0.30 \mathrm{~m}$ $0.75 \mathrm{~m}$. One fruit per axil should be left. The main shoot has to be cut when it reaches the top wire. The last 2-3 side shoots are allowed to hang down from the top wire. This way of pruning the cucumber crop is called "Kringmethod".

For the second method (termed 'high cord culture'), all the side shoots have to be removed. One fruit in every two is also removed. In this case one axil will be empty, another will have just one fruit. The main shoot does not have to be cut, but grows along the cords. When it reaches the top wire, its cord has to be let down to allow the base of the stem to lie along the ground.

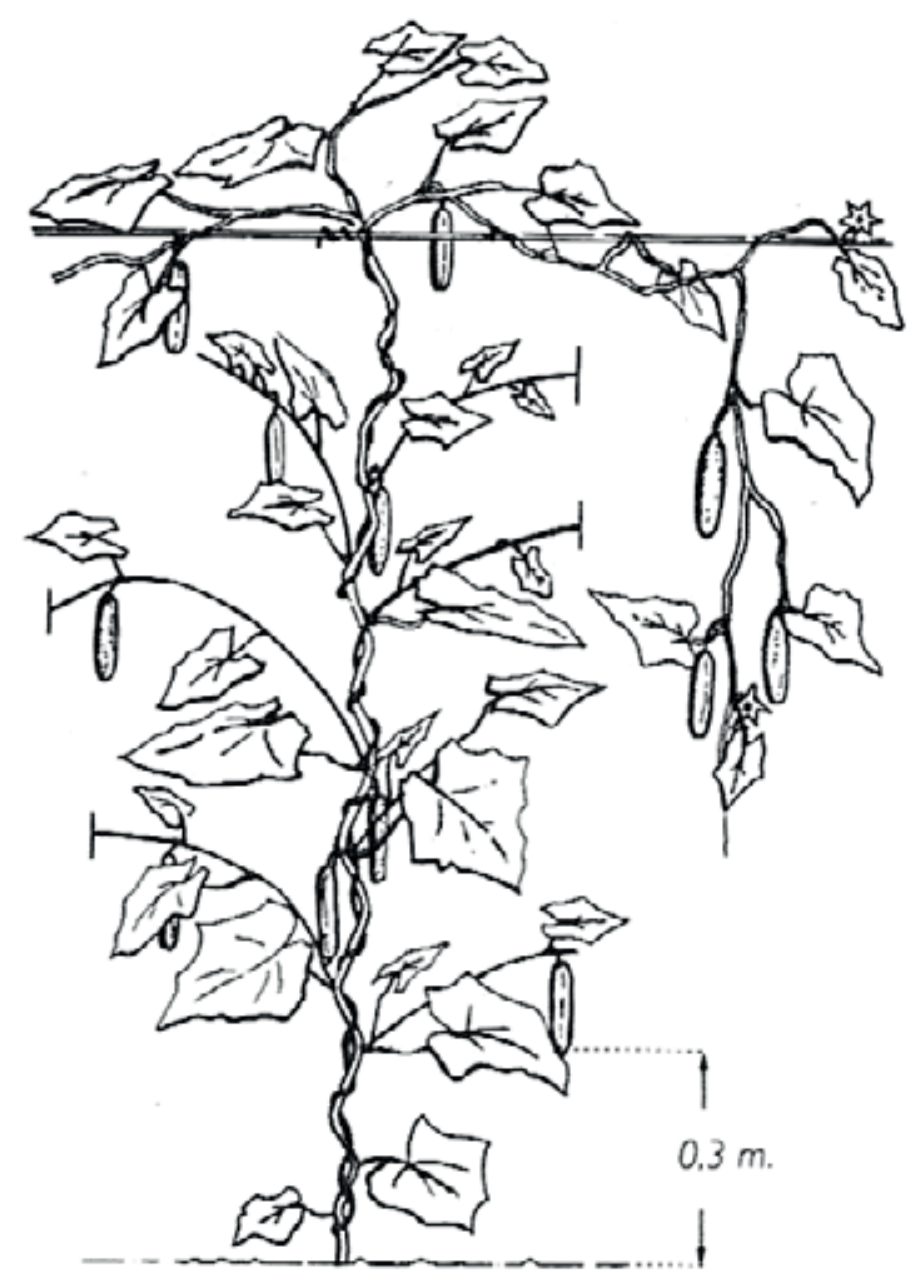

Figure 4.11 Training and pruning of cucumbers according to the Kring method.

\section{Disease and pest infestation, physiological disorders and other abiotic damage}

- Downy mildew - also affecting lettuce and other vegetables (Pseudoperonospora cubensis).

- Powdery mildew of cucurbits and other vegetables (Sphaerotheca fuliginea and Erysiphe cichoracearum).

- Leafspots of vegetables (Didymella bryoniae).

- Sclerontinia sclerotiorum.

- Other diseases such as Colletotrichum, Verticillium, Fusarium. 
- Thrips on greenhouse crops.

- Spider mites (Tetranychus urticae).

- Aphids, white flies, leaf miners etc.

\section{Assessments made during growth}

Many parameters can be assessed using a 1 to 9 scale ( $1=$ very low, $3=$ low, $5=$ medium, $7=$ high, $9=$ very large / high) but quantitative measurements are preferable whenever possible.

- Number of missing plants.

- Uniformity of crop.

- Vigour/density of the crop.

- Regeneration capacity after harvesting.

- Internode length.

- Leaf size.

- Colour of the leaves.

- Total length of the plant (at the end of cultivation).

\section{Assessments made at harvest}

Harvesting should usually begin when fruits have an average weight of more than $400 \mathrm{~g}$ (later in the year they should reach more than $500 \mathrm{~g}$ ). However, in Northern and Central Europe early fruits of more than $300 \mathrm{~g}$ are permitted. Harvesting should be done regularly (three times a week). The crop should be sorted according to EU quality standards. Crops are divided into marketable and non-marketable (undersized, rotten, odd-shaped or yellow). Fruits are counted and weighed.

Length and diameter of the fruit should be recorded. At least three times per year ten marketable fruits from the main stem and ten from the side shoots are measured. Diameter is determined at the thickest point.

Evaluation of the following quality parameters are assessed for ten fruits, three times a year:

- Ridged fruits.

- Colour of the fruits.

- Relationship between flesh and seed construction.

- Shelf-life in days.

\section{Overall value score}

This is particularly appropriate for variety trials. It takes into account all the criteria for the cultivation and marketing of the variety based on expert opinion as evaluated by researchers using information from farmers, wholesalers and consumers ( $1=$ very low, $3=$ low, $5=$ medium, $7=$ high, $9=$ very high $)$.

\section{References and further information}

UPOV Guidelines for the conduct of tests for distinctness, uniformity and stability. Cucumber (TP/61/2). www.upov.int 


\subsubsection{Watermelon}

\section{By Pedro Gomez}

Botanical name: Citrullus lannatus

Common names: Watermelon

\section{General crop requirements}

Watermelon is a herbaceous, annual plant with a prostrate growth habit. It is cultivated as an annual crop under climatic conditions warmer than $20^{\circ} \mathrm{C}$. Nowadays, most varieties are triploids producing seedless fruit, without pollen, and need to be grown together with diploid varieties with fertile pollen. In the Mediterranean region, greenhouse plants are grown in soil with sand as a mulch. The fruit has a smooth hard rind, usually green with dark green stripes or yellow spots, and a juicy, sweet interior flesh, often deep red to pink.

Experimental design

Recommended replicates: at least three. For trial purposes it is best to erect barriers to stop the foliage form adjacent plots becoming mixed. If conditions in the greenhouse are homogenous it is possible to use only 2 replicates but with more plants per replicate. This minimizes the expense on plot separation (see Figure 4.12). Where triploid varieties are grown a diploid pollinator is needed in the row is one after every three plants.
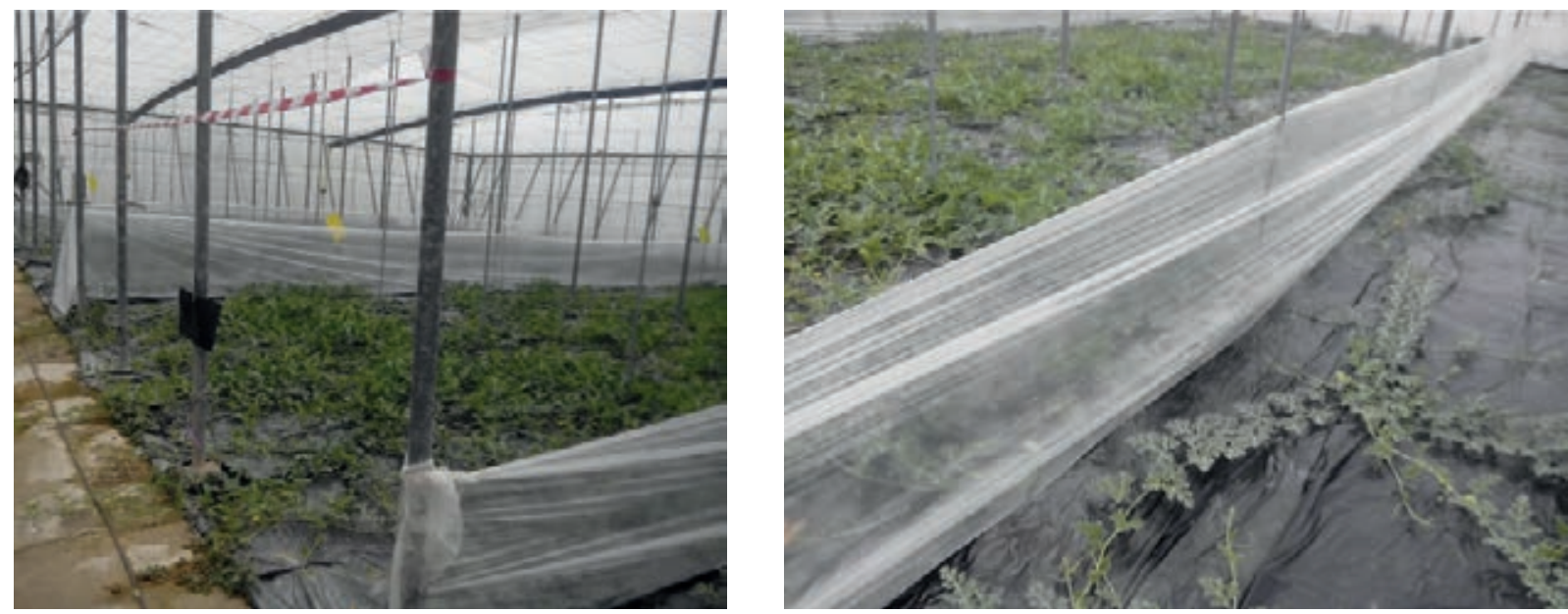

Figure 4.12 Watermelon trial - showing the separation system between cultivars.

Table. 4.24

Typical watermelon plant spacing and number of plants needed for trials.

\begin{tabular}{|c|c|c|}
\hline & $\begin{array}{l}\text { North \& Central } \\
\text { Unheated }\end{array}$ & $\begin{array}{l}\text { Mediterranean } \\
\text { Unheated } \\
\text { (frost-free) }\end{array}$ \\
\hline Minimum number of plants/ core plot & 5 & $5-20 *$ \\
\hline Minimum size core plot $\left(\mathrm{m}^{2}\right)$ & 5 & $5 *$ \\
\hline Plant density / m² & 1 & 1 \\
\hline Row distance $(\mathrm{cm})$ & 200 & 200 \\
\hline Distance within the row $(\mathrm{cm})$ & 50 & 50 \\
\hline
\end{tabular}

*The plants require plenty of space to grow. Depending on the heterogeneity of the group to be tested, the core size can be increased in order to avoid differences of variation. 
Table 4.25

Typical watermelon sowing and harvesting dates.

\begin{tabular}{|c|c|c|c|c|c|}
\hline $\begin{array}{l}\text { Region } \\
\text { - Production type* }\end{array}$ & Sowing at & Planting at & $\begin{array}{l}\text { Start of } \\
\text { Harvest }\end{array}$ & End of harvest & Remarks \\
\hline $\begin{array}{l}\text { North \& Central } \\
\text { - Unheated }\end{array}$ & April & May & July & September & \\
\hline $\begin{array}{l}\text { Mediterranean } \\
\text { - Short cycle Spring }\end{array}$ & Dec & Jan & Apr & May & Grafted crops \\
\hline $\begin{array}{l}\text { Mediterranean } \\
\text { - Short cycle Autumn }\end{array}$ & Feb & Feb & May & Jun & Grafted crops \\
\hline
\end{tabular}

*Watermelons are not usually grown using heated production (seasonal) or in Mediterranean long cycle production.

Table 4.26

Temperatures required for the production of watermelon seedlings and

\begin{tabular}{llllll} 
Region & $\begin{array}{l}\text { Germination } \\
\text { temperature }{ }^{\circ} \mathrm{C} \\
\text { Day / Night }\end{array}$ & $\begin{array}{l}\text { Days until } \\
\text { germination }\end{array}$ & $\begin{array}{l}\text { Temperature for Pot size } \\
\text { seedlings in }{ }^{\circ} \mathrm{C} \\
\text { Day / Night }\end{array}$ & $\begin{array}{l}\text { Weeks until } \\
\text { planting }\end{array}$ \\
North \& Central & $20-25 / 20$ & $5-10$ & $18-25 / 16-20$ & $10 \mathrm{~cm}$ & $2-4$ \\
\hline Mediterranean & $17-30 / 15$ & $7-15$ & $\begin{array}{l}17-30 / 10 \\
\text { Ventilation from } \\
20-25\end{array}$ & & \\
\end{tabular}

Table 4.27

Optimal temperatures for watermelon growth and fruit production in the Mediterranean.

\begin{tabular}{lccc} 
& Day $\left({ }^{\circ} \mathrm{C}\right)$ & Night $\left({ }^{\circ} \mathrm{C}\right)$ & $\begin{array}{c}\text { Ventilation } \\
\text { from }\left({ }^{\circ} \mathrm{C}\right)\end{array}$ \\
Planting in February / harvest end April & $18-27$ & $10-14$ & $20-25$ \\
\hline
\end{tabular}

Table.4.28

Watermelon plant nutrient requirements.

\begin{tabular}{lllll}
$\begin{array}{l}\text { Yield expectation } \\
\left(\mathrm{kg} / \mathrm{m}^{2}\right)\end{array}$ & $\mathrm{N}\left(\mathrm{g} / \mathrm{m}^{2}\right)$ & $\mathrm{P}\left(\mathrm{g} / \mathrm{m}^{2}\right)$ & $\mathrm{K}\left(\mathrm{g} / \mathrm{m}^{2}\right)$ & $\mathrm{Mg}\left(\mathrm{g} / \mathrm{m}^{2}\right)$ \\
\hline 5 & 12 & 3 & 15 & 3 \\
\hline 10 & 17 & 6 & 23 & 5
\end{tabular}

Source: adapted from various sources, see Appendix B. Leaf nutrient contents are given in Appendix C.

\section{Crop management}

Pruning is advisable in order to control the architecture of the plant. The main shoot is cut before growth exceeds 5 - 6 leaves, to encourage 4 - 5 secondary shoots.

Pollination by Apis mellifera, is recommended, introducing 2 - 4 beehives / ha. Triploid watermelons need diploid watermelons with viable pollen as pollinators. It is important to establish a ratio of $25-30 \%$ pollinator diploid cultivars amongst triploid cultivars.

Irrigation at $2.5-3 \mathrm{l} / \mathrm{m}^{2}$ a day is recommended.

96 | Guidelines for Experimental Practice 


\section{Disease and pest infestation, physiological disorders and other abiotic damage}

\section{Diseases:}

- Powdery mildew - Sphaerotheca fuliginea.

- Gummy Stem Blight - Didymella bryoniae.

- Fusarium - Fusarium oxysporum.

- MNSV (Melon Necrotic Spot Virus).

- ZYMV (Zucchini Yellow Mosaic Virus).

- WMV-2 (Watermelon Mosaic Virus-2).

- CMV (Cucumber Mosaic Virus).

- CVYV (Cucumber vein yellowing virus).

\section{Pests:}

- Red mite - Tetranychus spp.

- Whitefly - Trialeurodes vaporariorum, Bemisia tabaci.

- Aphids - Aphis gossypii, Myzus persicae.

- Thrips - Frankliniella occidentalis.

- Leaf miner - Liriomyza trifolii, Liriomyza strigata, Lyriomyza bryoniae.

- Green worm - Spodoptera exigua.

- Nematodes - Meloidogyne spp. (roots nodules), M. javanica, M. arenaria, M. incognita.

\section{Physiological disorders}

- Fruit breakage (caused by excess relative humidity and temperature changes, conductivity changes, poor ventilation etc.).

- Fruits abort (caused by excessive vigour or plant auto-regulation).

- Root anoxia, resulting in adventitious roots and wilting with high soil water content (caused by a lack of oxygen in the soil).

\section{Assessments made during growth}

These include: Missing plants, number of pollinator plants, uniformity of crop, number of stems and vigour, regeneration capacity, number of fruits per stem, leaf size, root resistance: (Fusarium and nematodes), physiological damage caused by salininty. Many of these can best be assessed on a 1 to 9 scale when measurements are not possible ( $1=$ very low, $3=$ low, $5=$ medium, $7=$ high, $9=$ very large $/$ high $)$.

\section{Assessments made at harvest}

Watermelons are non-climacteric fruit, harvested in maturity, when fruits have developed at least $12^{\circ}$ Brix sugar content. After harvest, plants can be left to regenerate a second crop. Fruits should be sorted into marketable and unmarketable categories according to recognised quality standards. Unmarketable fruits should be categorised according to the reasons for rejection. The acceptable size depends on the cultivar.

Quality parameters include:

- Total soluble solids ( ${ }^{\circ}$ Brix).

- Fruit size (diameter).

- Width of stripes (very narrow to very broad).

- Skin ground colour (yellow to very dark green) - based on UPOV watermelon DUS guidelines.

- Colour of flesh (white to dark red) - based on UPOV watermelon DUS guidelines.

- Seediness.

- Flesh texture and firmness.

- Symmetry. 


\section{Overall value}

This takes into account all the criteria for the cultivation and marketing of a variety, based on expert opinion as evaluated by researchers using information from farmers, wholesalers and consumers ( $1=$ very low, $3=$ low, 5

= medium, 7 = high , 9 = very high).

\section{References and further information}

UPOV Guidelines for the conduct of tests for distinctness, uniformity and stability. Watermelon (TP/142/2). www.upov.int

Reche J. 1997

Cultivo de Sandia en Invernadero (Spanish). Ed Colegio Oficial de Ingenieros Técnicos Agrícolas 


\subsubsection{Melons}

\section{By Pedro Gomez}

Botanical name: Cucumis melo

Common names: muskmelon, honeydew melon, cantaloupe melon.

\section{General crop requirements}

Melon plants are herbaceous, annual plants, with a prostrate habit. The crop is grown under warm climatic conditions with optimal temperatures higher than $20^{\circ} \mathrm{C}$. Nowadays, most varieties are hybrids, harvested when they reach maturity, and usually very sweet. In Mediterranean greenhouses plants are grown in soil with sand as a mulch. In experimental crops of melon, where varieties are being evaluated, the most productive method of growing is to stake plants. Fruit shape depends of cultivar, from long to round and skin colour can vary from green, yellow or white. Fruit skin is strong, and flesh acquires variable colour from white to orange.

\section{Experimental design}

Recommended replicates: at least three.

\section{Table 4.29}

Typical melon plant spacing and number of plants required for trials.

\begin{tabular}{lll} 
& $\begin{array}{l}\text { North \& Central } \\
\text { Heated }\end{array}$ & $\begin{array}{l}\text { Mediterranean Unheated } \\
\text { (frost-free) }\end{array}$ \\
Minimum number of plants / core plot & 7 & $6 *$ \\
\hline Minimum size core plot $\left(\mathrm{m}^{2}\right)$ & 5 & $3 *$ \\
\hline Plant density / $\mathrm{m}^{2}$ & 1.3 & 2 \\
\hline Stem density / $\mathrm{m}^{2}$ & $1.3-2.6$ & 4 \\
\hline Row distance $(\mathrm{cm})$ & 150 & $150-200$ \\
\hline Distance within the row $(\mathrm{cm})$ & 50 & $50-100$
\end{tabular}

*The plants require plenty of space to grow. Depending on the heterogeneity of the group to be tested, the core plot size can be increased in order to avoid too much variation.

\section{Table 4.30}

Typical melon sowing and harvesting dates.

\begin{tabular}{|c|c|c|c|c|c|}
\hline $\begin{array}{l}\text { Region } \\
\text { - Production type }\end{array}$ & Sowing at & Planting at & $\begin{array}{l}\text { Start of } \\
\text { harvest }\end{array}$ & $\begin{array}{l}\text { End of } \\
\text { harvest }\end{array}$ & Remarks \\
\hline $\begin{array}{l}\text { North \& Central* } \\
\text { - Unheated }\end{array}$ & April & May & July & September & $\begin{array}{l}\text { Vertical string trained } \\
\text { (recommended) or along the soil. }\end{array}$ \\
\hline $\begin{array}{l}\text { Mediterranean } \\
\text { - Long cycle }\end{array}$ & November & December & April & May & \\
\hline $\begin{array}{l}\text { - Short cycle } \\
\text { Spring }\end{array}$ & December & January & May & June & \\
\hline
\end{tabular}

*Melons are not usually grown in heated greenhouses in the North and Central region. 
Table 4.31

Conditions required for the production of melon seedlings and plants.

\begin{tabular}{lllll} 
Region & $\begin{array}{l}\text { Germination } \\
\text { temperature }{ }^{\circ} \mathrm{C}\end{array}$ & $\begin{array}{l}\text { Days until } \\
\text { germination }\end{array}$ & $\begin{array}{l}\text { Temperature for } \\
\text { seedlings in }{ }^{\circ} \mathrm{C} \text { Day } \\
\text { / Night }\end{array}$ & Weeks until planting \\
\hline North \& Central & $20-25 / 20$ & $5-10$ & $18-25 / 16-20$ & \\
\hline Mediterranean & $20-25 / 12$ & $5-10$ & $25-30 / 15$ & $1.5-2$
\end{tabular}

Table 4.32

Melon plant nutrient requirements.

\begin{tabular}{lllll} 
Yield expectation & $\mathrm{N}\left(\mathrm{g} / \mathrm{m}^{2}\right)$ & $\mathrm{P}\left(\mathrm{g} / \mathrm{m}^{2}\right)$ & $\mathrm{K}\left(\mathrm{g} / \mathrm{m}^{2}\right)$ & $\mathrm{Mg}\left(\mathrm{g} / \mathrm{m}^{2}\right)$ \\
$\left(\mathrm{kg} / \mathrm{m}^{2}\right)$ & & 2 & 19 & 2 \\
\hline 4 & 18 & 4 & 29 & 4 \\
\hline 7 & 21 & 29 & \\
\hline
\end{tabular}

Source: adapted from various sources, see Appendix B. Leaf nutrient contents are given in Appendix C.

\section{Crop management}

Staking the plants increases productivity and improves fruit quality. Pruning is recommended to leave two stems per plant. For cultivars with prostrate growth, it is advisable to cut the primary stem to encourage several secondary stems to develop which will carry the fruit. One stem will produce 2- 4 fruits depending of the fruit size of the cultivar.

The most effective way of pollination is by Apis melliphera (2 hives/ha) and Bombus terrestris (2-4 hives/ha). If only a smaller area of melons are being grown the number of hives will need to be maintained.

\section{Disease and pest problems, physiological disorders and other abiotic damage}

Diseases:

- Powdery mildew - Sphaerotheca fuliginea.

- Gummy Stem Blight - Didymella bryoniae.

- Botrytis - Botrytis cinerea.

- ZYMV (Zucchini Yellow Mosaic Virus).

- WMV-2 (Watermelon Mosaic Virus-2).

- CMV (Cucumber Mosaic Virus).

- CVYV (Cucumber vein yellowing virus).

- ToLCNDV (Tomato Leaf Curl New Delhi Virus).

- CYSDV (Cucumber Yellow Stunt Disorder Virus).

\section{Pests:}

- Thrips - Frankliniella occidentalis.

- Whitefly - Trialeurodes vaporariorum, Bemisia tabaci.

- Aphids - Aphis gossypii, Myzus persicae.

- Red mite - Tetranychus spp.

- Leaf miner - Liriomyza trifolii, Liriomyza strigata, Lyriomyza bryoniae.

- Green worm - Spodoptera exigua.

\section{Physiological disorders}

Sudden wilt (associated to some cultivars at certain growth stages during some climatic conditions).

Excessive vegetative growth resulting in a reduction of flowering.

Fruits abort (due to insufficient pollination or plant auto-regulation).

Fruit splitting (due to imbalances of temperature and water, or uneven maturity). 


\section{Assessment during growth}

These include: Missing plants, uniformity of crop, vigour, number of faults, number of female flowers per plant, number of fruits per stem, leaf size, virus resistance and salinity responses. When counting is not possible these can be scored on a scale ( $1=$ very low, $3=$ low, $5=$ medium, $7=$ high, $9=$ very large $/$ high $)$.

\section{Assessments at harvest}

It is very important to determine the correct moment for harvest. Fruit must reach the appropriate ${ }^{\circ} \mathrm{Brix}$ level according to the type of cultivar. There are several characteristics that alter during ripening (e.g. skin colour, aroma). Cracks at the stem base as well as a sweet smell from the fruit indicate ripeness. Fruits are usually picked on a weekly basis. The crop should be harvested into marketable and unmarketable according to recognised standards and the reasons for rejection recorded (broken fruit, twisted fruit, incorrect size etc.). Scores (on a 1-9 scale) or measurements can be made of fruit parameters including:

- Colour and skin characteristics.

- Flesh texture and firmness.

- Colour of flesh.

- Diameter.

- Shape.

\section{Overall value score}

This is particularly appropriate for variety trials. It takes into account all the criteria for cultivation and marketing, based on expert opinion as evaluated by researchers using information from farmers, wholesalers and consumers ( $1=$ very low , $3=$ low, $5=$ medium, $7=$ high , $9=$ very high $)$.

\section{References and further information}

UPOV Guidelines for the conduct of tests for distinctness, uniformity and stability. Melons (TP/104/2). www.upov.int

Reche J. 1997

Cultivo de melón en Invernadero (Spanish). Ed Consejeria de Agricultura y Pesca

Maynard, D. N. and G. J. Hochmuth. 2007.

Knott's Handbook for Vegetable Growers. Hoboken, NJ, John Wiley \& Sons, Inc 


\subsection{Leafy vegetables}

\subsubsection{Lamb's lettuce}

\section{By Justine Dewitte}

Botanical name: Valerianella locusta

Other common name: Corn salad

\section{General crop requirements}

Lamb's lettuce requires a loamy and humus rich soil with good water retention. It can grow best in soils with a pH between 6 and 7. Lamb's lettuce is moderately sensitive to salinity. It has a need for a well-drained soil without compaction and is compatible with most crops in a vegetable rotation. Nutrient requirements are low. It can be grown year round but is often used as an intercrop in autumn and winter.

The crop can be sown directly in the soil but, because of weed pressure, it is more common to sown in 'pressed blocks' of growing media and then transplant it (see Section 4.5). Each block is multisown with approximately 5 seeds. The blocks are also known as 'peat pots' in some countries.

The crop is not common in the Mediterranean region.

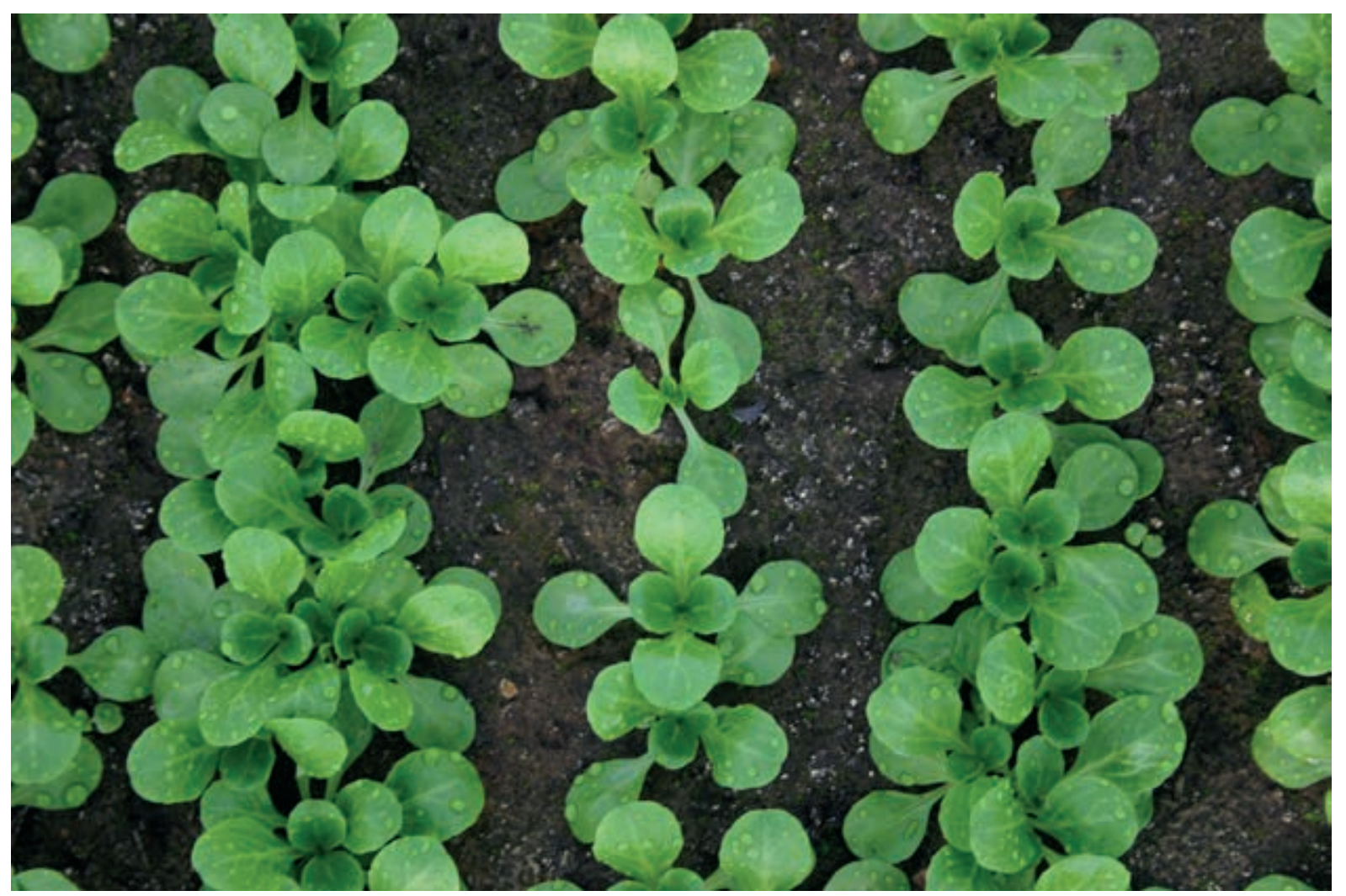

Figure 4.13 A lamb's lettuce plot.

\section{Experimental design}

Recommended replicates: at least four 
Table 4.33

Typical lamb's lettuce plant spacing and number of plants required for trials.

\begin{tabular}{ll} 
& $\begin{array}{l}\text { North \& central } \\
\text { unheated (or frost free) }\end{array}$ \\
\hline Minimum number of plants/ core plot & 240 (multisown pressed blocks) ; 200 (direct sown) \\
\hline Minimum size core plot $\left(\mathrm{m}^{2}\right)$ & 3 \\
\hline Density sown seeds $/ \mathrm{m}^{2}$ & $600-700$ \\
\hline Density of transplanted pressed blocks / $\mathrm{m}^{2}$ & 80 \\
\hline Row distance $(\mathrm{cm})$ & $8-15$ \\
\hline Distance within the row $(\mathrm{cm})$ & $8-12$ (transplanted in blocks) ; 2-3 (direct sown)
\end{tabular}

\section{Table 4.34}

Typical lamb's lettuce sowing and harvesting dates.

\begin{tabular}{|c|c|c|c|c|c|}
\hline $\begin{array}{l}\text { Region } \\
\text { - Production } \\
\text { type }\end{array}$ & Sowing at & Planting at & Start of Harvest & End of harvest & Remarks \\
\hline $\begin{array}{l}\text { North \& central } \\
\text { - Unheated }\end{array}$ & $\begin{array}{l}\text { August to } \\
\text { November }\end{array}$ & $\begin{array}{l}\text { September to } \\
\text { January }\end{array}$ & October & March & $\begin{array}{l}\text { Lamb's lettuce can be } \\
\text { grown year round, but } \\
\text { is typical during autumn } \\
\text { and winter }\end{array}$ \\
\hline
\end{tabular}

Table 4.35

Temperature requirements for lambs lettuce sowing and planting.

\begin{tabular}{llll}
$\begin{array}{l}\text { Germination } \\
\text { temperature }{ }^{\circ} \mathrm{C}\end{array}$ & $\begin{array}{l}\text { Days until } \\
\text { germination }\end{array}$ & $\begin{array}{l}\text { Temperature for } \\
\text { seedlings in }{ }^{\circ} \mathrm{C}\end{array}$ & Block size \\
Day/ Night & $\begin{array}{l}\text { Time until planting } \\
\text { (in weeks) }\end{array}$ \\
\hline $12-18$ & $7-10$ & $\begin{array}{l}10-18 / 7-18 \\
\text { Ventilation from 20 }\end{array}$ & $\begin{array}{l}3-4 \mathrm{~cm}, 5 \text { plants in } \\
\text { each }\end{array}$ \\
\hline
\end{tabular}

If the greenhouse can be slightly heated at the beginning of the cultivation period then this will accelerate germination. A soil temperature of $10^{\circ} \mathrm{C}$ is optimal. When temperature is above $21^{\circ} \mathrm{C}$ the seed will become dormant. Lamb's lettuce can withstand mild frost $\left(-5^{\circ} \mathrm{C}\right)$. The leaves can be deformed when the temperature exceeds $20^{\circ} \mathrm{C}$ (this is known as spooning).

\section{Table.4.36}

Lamb's lettuce plant nutrient requirements.

\begin{tabular}{lllll}
$\begin{array}{l}\text { Yield expectation } \\
\left(\mathrm{kg} / \mathrm{m}^{2}\right)\end{array}$ & $\mathrm{N}\left(\mathrm{g} / \mathrm{m}^{2}\right)$ & $\mathrm{P}\left(\mathrm{g} / \mathrm{m}^{2}\right)$ & $\mathrm{Kg}\left(\mathrm{g} / \mathrm{m}^{2}\right)$ & 0.2 \\
0.6 & 2.5 & 0.2 & 4 & 0.3 \\
\hline 1 & 4 & 0.3 & 6 & 0.4
\end{tabular}

Source: adapted from various sources, see Appendix B 


\section{Disease and pest infestation, physiological disorders and other abiotic damage}

Also see the relevant EPPO Guidelines: www.eppo.int.

- Acidovorax valerianellae sp.

- Botrytis.

- Powdery mildew - Golovinomyces orontii.

- Downy mildew - Peronospora valerianella.

- Phoma valerianellae.

- Pythium.

- Rhizoctonia solani.

- Sclerotinia.

\section{Assessments during growth}

A range of parameters are best assessed using a 1 to 9 scale $(1=$ very low, $3=$ low, $5=$ medium, $7=$ high, $9=$ very high):

- Germination.

- Uniformity of crop.

- Size of plants.

- Leaf size.

- Leaf shape.

- Colour of the leaves.

- Losses (from disease etc.).

\section{Assessments at harvest}

The correct time of harvest depends on light hours and temperature. The lamb's lettuce is harvested by cutting off the leaves in the soil just above the roots. The crop should be sorted according to recognised quality standards into marketable and non-marketable produce, identifying the reasons for rejection (e.g. pest or disease damage, bolted plants etc.).

\section{Overall value score}

This takes into account all the criteria for the cultivation and marketing of a variety, based on expert opinion as evaluated by researchers using information from farmers, wholesalers and consumers ( 1 = very low , $3=$ low, 5 = medium, 7 = high , 9 = very high).

\section{References and further information}

Dedeene, L., De Kinder, G.

Groente \& Fruit Encyclopedie (2009), Kosmos Uitgevers. p.86.

Van Boxem, H., Buysse, G., Maes, B., Robinet, P., Williame, F. Handboek Ecologisch Tuinieren (2006), Velt vzw. P. 419.

UPOV Guidelines for the conduct of tests for distinctness, uniformity and stability. Lamb's lettuce (TP/75/2). www.upov.int 


\subsubsection{Lettuce}

\section{By Wolfgang Palme}

Botanical name: Lactuca sativa

Subspecies: capitata; crispa, longifolia

Common types: Butterhead Lettuce, Iceberg Lettuce, Oak Leaf Lettuce, Romaine Lettuce, Baby Cos Lettuce, Battavia Lettuce

\section{General conditions}

Lettuces need loose soils with good structure. Especially suitable are sandy loams with high humus content and $\mathrm{pH}$ of 6.5-7. Head lettuce is sensitive to high salinity.

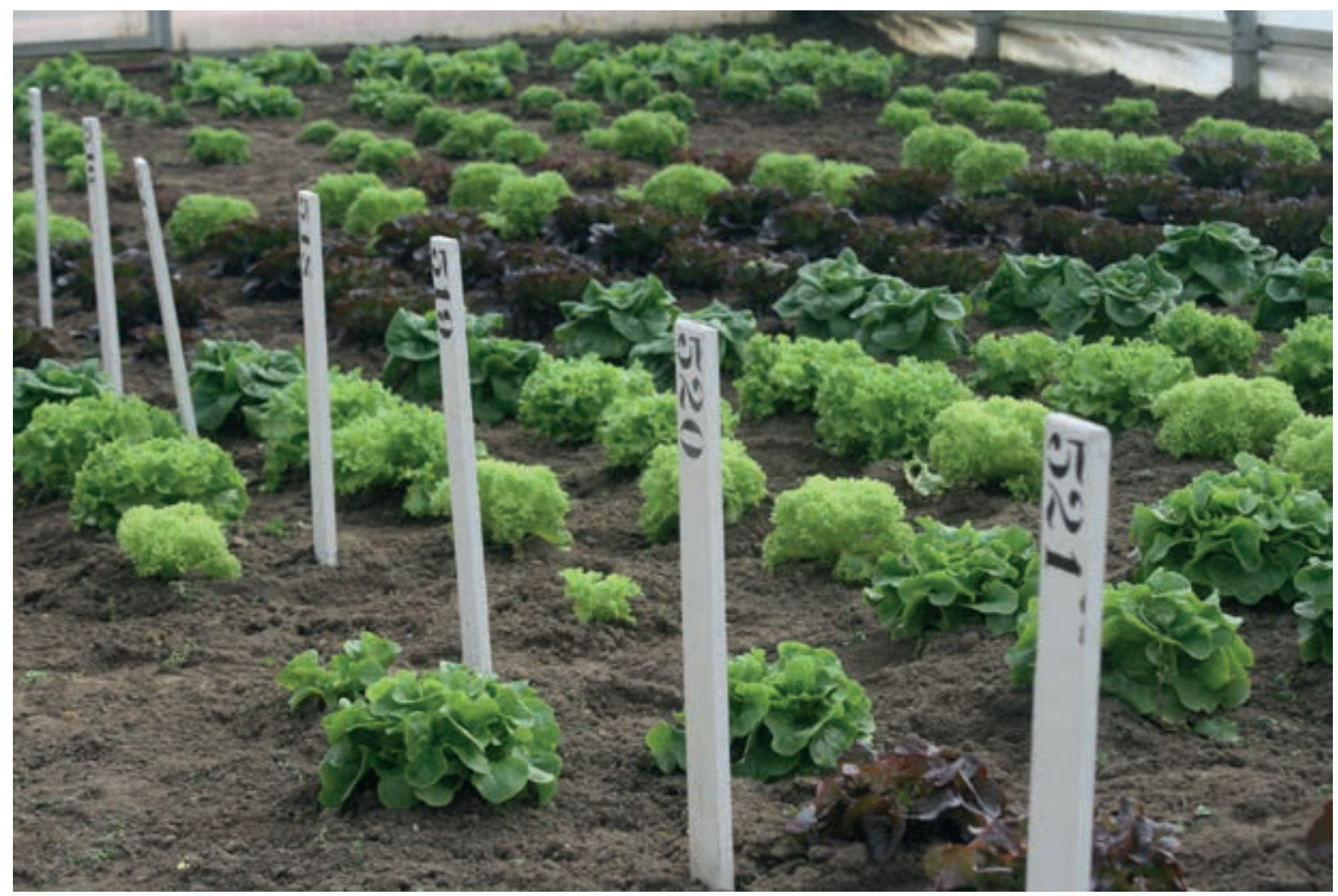

Figure 4.14 A lettuce variety trial in Austria.

\section{Experimental design}

Trial with at least four replications.

Table 4.37

Typical lettuce plant spacing and number of plants required for trials.

\begin{tabular}{ll} 
& North and Central \\
Minimum number of plants per core plot & $20-30$ \\
\hline Minimum size of core plot $\left(\mathrm{m}^{2}\right)$ & $2-3$ \\
\hline Plant density (plants $\left./ \mathrm{m}^{2}\right)$ & 11 \\
\hline Distance between plants $(\mathrm{cm})$ & $30 \times 30$ \\
\hline
\end{tabular}


Table 4.38

Typical lettuce sowing and harvesting dates.

\begin{tabular}{llll} 
Cultivation period & Sowing in & Planting in & Start of Harvest \\
Spring & December & February & April \\
\hline Autumn & August & September & November \\
\hline Winter & November & January & March \\
\hline
\end{tabular}

The optimal temperature for germination of lettuces is 12 to $20^{\circ} \mathrm{C}$. High temperatures cause secondary dormancy. In summer sow in the evening or put the seed trays in a cool place. It is advisable to cover the seed trays with Styrofoam or to cool seeds and substrates. Sow pelleted seeds in $4 \mathrm{~cm}$ soil blocks. When the seedlings have 4 leaves and are compact and strong plant them shallowly into the soil.

In greenhouses the air temperature has to be $10-18^{\circ} \mathrm{C}$ depending on the light conditions. Temperatures during night can be as low as $5-8^{\circ} \mathrm{C}$ (lettuces are frost hardy). Avoid temperatures above $20^{\circ} \mathrm{C}$.

\section{Fertilisation}

Nitrogen fertilisation has to be related to the demand of plants including the mineralized nitrogen content of the soil (measured to $0-30 \mathrm{~cm}$ or 0-60 cm depth) and the content of organic residues. Do not use animal fertilisers because of the risk of microbial contamination of the produce.

Fertilisation with phosphorus and potassium has to be done in accordance with availability in the soil and the expected plant uptake which depends on the yield..

Table.4.39

Lettuce plant nutrient requirements.

\begin{tabular}{lllll}
$\begin{array}{l}\text { Yield expectation } \\
\left(\mathrm{kg} / \mathrm{m}^{2}\right)\end{array}$ & $\mathrm{N}\left(\mathrm{g} / \mathrm{m}^{2}\right)$ & $\mathrm{P}\left(\mathrm{g} / \mathrm{m}^{2}\right)$ & $\mathrm{K}\left(\mathrm{g} / \mathrm{m}^{2}\right)$ & $\mathrm{Mg}\left(\mathrm{g} / \mathrm{m}^{2}\right)$ \\
\hline 2.5 & 5 & 1 & 8 & 0.8 \\
\hline 4 & 8 & 1.6 & 13 & 1.2 \\
\hline 6 & 12 & 2.4 & 19 & 1.8 \\
\hline
\end{tabular}

Source: adapted from various sources, see Appendix B. Leaf nutrient contents are given in Appendix C.

\section{Plant husbandry}

Prepare a good seed bed before planting by cultivation and ensure there is high soil moisture. Special treatments such as artificial lighting or $\mathrm{CO}_{2}$-enhancement have to be documented in the report.

\section{Pests and Plant diseases}

- Downy Mildew of lettuce and other vegetables - Bremia lactucae.

- Botrytis spp. and Sclerotinia spp. on vegetables - Botrytis cinerea.

- Botrytis spp. and Sclerotinia spp. on vegetables - Sclerotinia sclerotiorum.

- Aphids: esp. Nasonovia ribisnigri.

- Other diseases such as Rhizoctonia solani (lettuce rot).

- Abiotic damages such as dry edges (caused by drought, high salinity or high temperatures during night), blight of inner leaves (caused by lack of calcium).

The visual inspection and evaluation of infection has to be done at least once but probably several times. Frequency and degree of pest infestation and effect on quality and yield have to be documented. 


\section{Assessment during crop growth}

Many parameters can be assessed using a 1 to 9 scale (1, very low; 9, very high) but measurements are preferable when possible:

- Size of plants.

- Size of heads (when applicable, e.g. iceberg lettuce).

- Green Colour.

- Other colours (by anthocyanins).

- Heading.

- Firmness of heads.

- Leaf shape and leaf size.

- Losses.

- Date of bolting.

\section{Assessments at harvest}

Every cultivar has to be harvested at the optimal time. The heads have to show their characteristic weight, size and firmness. The crop should be classified according to quality standards. Marketable heads are weighed and counted:

- Minimum weight of heads (in greenhouses) of butterhead lettuce: $100 \mathrm{~g}$.

- Minimum weight of heads (in greenhouses) of iceberg lettuce: $200 \mathrm{~g}$.

\section{Non marketable lettuces are sorted into}

- Bolted plants.

- Rotten heads.

- Others.

A range of quality parameters can also be assessed (e.g. uniformity of crop, tightness/looseness of foliage, firmness of stems, blistering, amount of outer leaves, effort of cleaning etc.). This is normally done on 10 lettuces taken from each plot using a 1 to 9 scale. The number of side shoots can be counted

\section{Overall value score}

This is particularly appropriate for variety trials. The total value includes all parameters of cultivation and marketing. Give numbers from 1 (poor) to 9 (excellent).

\section{References and other information}

UPOV Guidelines for the conduct of tests for distinctness, uniformity and stability. Lettuce (TP/13/5). www.upov.int 


\subsubsection{Rocket and other baby leaf brassica salads}

\section{By Wolfgang Palme}

Botanical and common names: Eruca sativa (rocket or arugula), Diplotaxis tenuifolia (wall rocket or wild rocket), Brassica rapa (e.g. mizuna), Brassica juncea (e.g. mustard greens, brown mustard).

\section{General conditions}

Loose, well structured soils with high humus content and good water supply are needed. Adequate soil moisture levels are important to prevent bolting. During summer the growing site can be lightly shaded. Do not grow repeated crops of rocket or oriental greens or follow other Brassicas because of disease issues. Avoid following a crop which leaves high nitrogen residues.

\section{Experimental layout}

An experimental layout with four replicates should be used.

\section{Table 4.40}

Typical rocket plant spacing and number of plants required for trials.

\begin{tabular}{lll} 
& Sown directly & Planted \\
Minimum size core plot $\left(\mathrm{m}^{2}\right)$ & 2 & 2 \\
\hline Plant density $/ \mathrm{m}^{2}$ & $200-400$ & 33 substrate blocks each with 5-7 plants \\
\hline Row distance $(\mathrm{cm})$ & $10-15$ & $15-20$ \\
\hline Distance in the range/row $(\mathrm{cm})$ & & $10-15$
\end{tabular}

\section{Sowing and planting, temperature requirements}

It is possible to sow all year round although from March to April oriental greens tend to bolt. They are very frost hardy and fast growing crops.

\section{Fertilisation and Irrigation}

The nutrient requirement is low because of the short cultivation period. Avoid organic fertilisers such as manure. Ensure a regular water supply.

\section{Table.4.41}

Rocket plant nutrient requirements.

\begin{tabular}{lllll}
$\begin{array}{l}\text { Yield expectation } \\
\left(\mathrm{kg} / \mathrm{m}^{2}\right)\end{array}$ & $\mathrm{N}\left(\mathrm{g} / \mathrm{m}^{2}\right)$ & $\mathrm{P}\left(\mathrm{g} / \mathrm{m}^{2}\right)$ & $\mathrm{K}\left(\mathrm{g} / \mathrm{m}^{2}\right)$ & $\mathrm{Mg}\left(\mathrm{g} / \mathrm{m}^{2}\right)$ \\
2 & 14 & 1.2 & 10 & 1.4 \\
\hline 3 & 21 & 1.8 & 15 & 2.1 \\
\hline
\end{tabular}

Source: adapted from various sources, see Appendix B

\section{Crop management and phytosanitary measures}

Ensure the crop is kept weed free by mechanical methods. To prevent flea beetle attack cover with insect proof netting. 


\section{Disease and pest infestation}

Disease and pest infestation should be assessed one or more times during the cropping period. Disease/pest incidence, disease/pest severity, and optionally the effect on quality and yield have to be noted (see also section 2.5). Key problems include:

- Downy mildew.

- Botrytis.

- Pseudomonas.

- Xanthomonas.

- Phoma.

- Alternaria.

- Flea beetle - Phyllotreta undulata.

- Assessments during growth.

- Speed of germination (days after sowing by which $50 \%$ of seedlings have germinated).

- Uniformity of crop ( 1 = very low, 3 = low, 5 = medium, $7=$ high, $9=$ very high $)$.

- Time before bolting (days by which $10 \%$ of plants have started to bolt).

- Colour ( 1 = very light, 3 = light, 5 = medium, 7 = intense, 9 = very dark).

- Number of missing plants (counted before harvest begins).

- Time to harvest.

\section{Assessments at harvest}

The crop is normally harvested at the 'baby leaf' stage $(8-10 \mathrm{~cm})$. They should not be longer than $20 \mathrm{~cm}$. Repeated harvests are possible before the crop finally bolts. Yield of picked leaves should be recorded on each harvesting occasion - these are divided into marketable and unmarketable fractions (e.g. excluding diseased leaves).

\section{Total value}

The total value takes into account all criteria for the cultivation and marketing of the variety $(1=$ very low, $3=$ low, 5 = medium, 7 = high, $9=$ very high). It is particularly suitable for variety trials.

\section{References and other information}

UPOV Guidelines for the conduct of tests for distinctness, uniformity and stability. Wild rocket (TG/244/1). www. upov.int 


\title{
4.4 Other vegetables
}

\author{
4.4.1 Climbing beans
}

\section{by Yüksel Tüzel}

Botanical name: Phaseolus vulgaris

Common names: Common bean, climbing French bean, Haricot bean, pole bean, string bean

\section{General crop requirements}

Climbing bean is an annual leguminous crop and requires warm temperatures. It can be grown on all soil types excluding extremely light and heavy soils although it prefers deep, calcareous and sandy soils. Sites with a tendency to form surface crusts or become waterlogged should be avoided. A high content of organic matter increases crop yield. It is very intolerant of salinity in soil and water and also very sensitive to $\mathrm{pH}<6.0$. Most varieties are climbers but others (dwarf French beans) grow as low bushes. It should not be confused with the runner bean (Phaseolus coccineus).

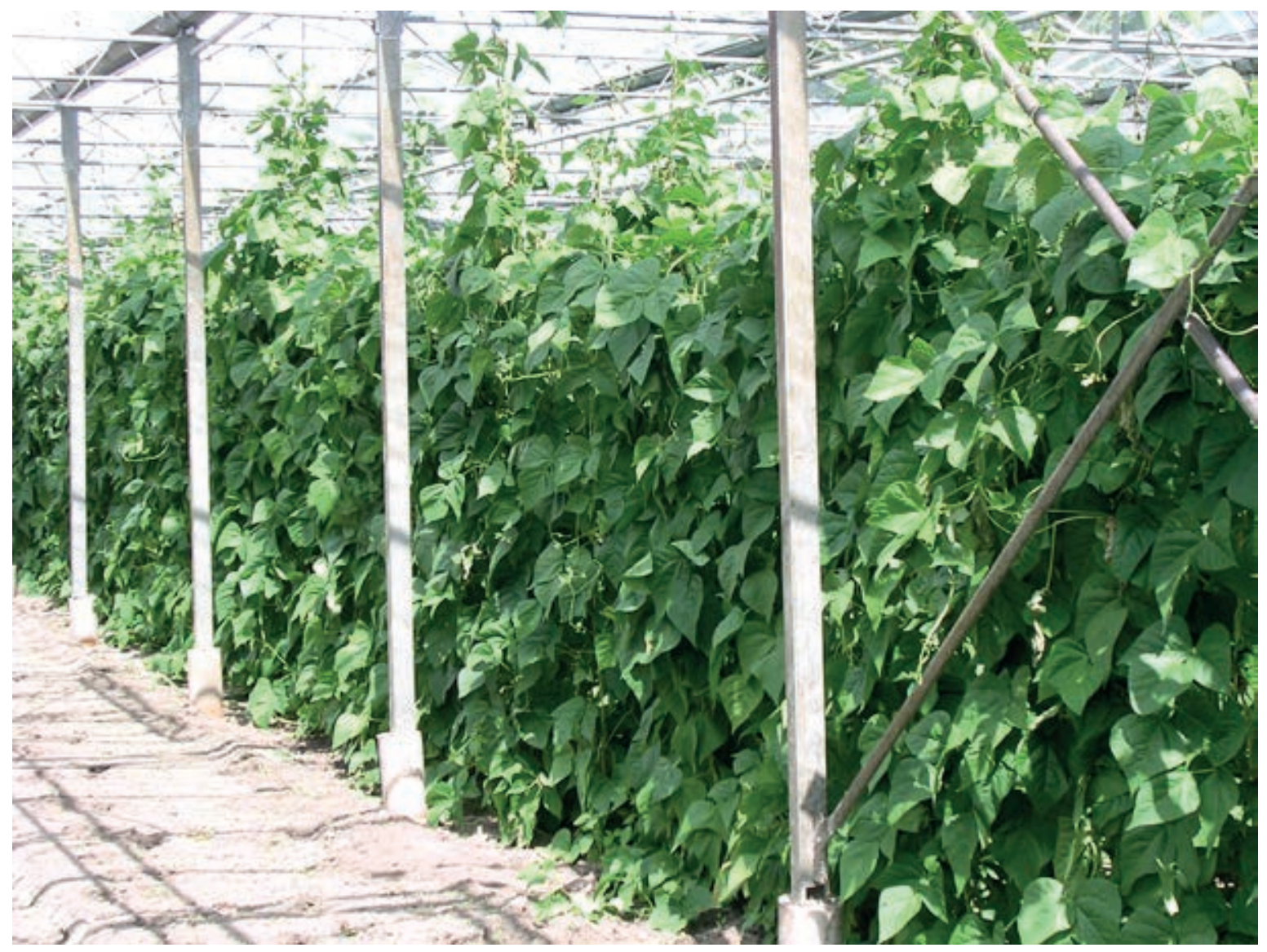

Figure 4.15 Climbing bean production in Germany.

\section{Experimental guidelines}

Block design - with at least three replicates. 
Table 4.42

Typical bean plant spacing and number of plants required for trials.

\begin{tabular}{ll} 
& All regions \\
Minimum number of plants per plot/ core & 75 (on 25 support cords) \\
\hline Minimum size core plot $\left(\mathrm{m}^{2}\right)$ & 7.5 \\
\hline Number of plants & 4 per support cord \\
\hline Row spacing $(\mathrm{cm})$ & $100-110$ \\
\hline Distance within the row $(\mathrm{cm})$ & 35
\end{tabular}

\section{Sowing and planting, temperature requirements}

Production season and the length of crop cycle depend on local climatic conditions. Beans can be grown by direct seed sowing or transplanting the seedlings. Four to six seeds are sown into each pot with a depth of approximately $3 \mathrm{~cm}$. After emergence, the weakest are thinned by pinching out. The remainder are planted about two weeks after sowing, before the shoots are about $10 \mathrm{~cm}$ long. Temperatures below $15^{\circ} \mathrm{C}$ and above $24^{\circ} \mathrm{C}$ and strong temperature fluctuations lead to increased shedding of flowers and poor fruit set.

\section{Table 4.43}

Typical bean planting and harvesting dates

\begin{tabular}{lllll}
$\begin{array}{l}\text { Region } \\
\text { - Production type }\end{array}$ & Sowing at & Start of Harvest & End of harvest & Remarks \\
$\begin{array}{l}\text { North \& central } \\
\text { - Unheated }\end{array}$ & Apr & Jun & Sept & $\begin{array}{l}\text { Planting 2 weeks } \\
\text { after sowing }\end{array}$ \\
\hline $\begin{array}{l}\text { - Seasonal Heated } \\
\text { Jan }\end{array}$ & $\begin{array}{l}\text { Mid Feb } \\
\text { to Mid Mar }\end{array}$ & May & Late May & $\begin{array}{l}\text { Planting } 2 \text { weeks } \\
\text { after sowing }\end{array}$ \\
$\begin{array}{l}\text { Mediterranean } \\
\text { - Short cycle }\end{array}$ & End Aug - Sep & Dec & Aug & Unheated \\
\hline $\begin{array}{l}\text { Autumn } \\
\text { - Short cycle Spring }\end{array}$ & Dec - Jan & Mar & Feb & greenhouses \\
\hline
\end{tabular}

\section{Table 4.44}

Temperatures $\left({ }^{\circ} \mathrm{C}\right)$ required for production of been seedlings and plants.

\begin{tabular}{lll}
$\begin{array}{l}\text { Germination } \\
\text { temperature }{ }^{\circ} \mathrm{C}\end{array}$ & Days until germination \\
Day / Night & $1-2$ & $\begin{array}{l}\text { Temperature for seedlings } \\
\text { in }{ }^{\circ} \mathrm{C} \\
\text { Day / Night }\end{array}$ \\
22 / 24 & $22 / 18$ & $\begin{array}{l}\text { Weeks before } \\
\text { transplanting }\end{array}$ \\
\hline
\end{tabular}

Table 4.45

Temperatures required for been plant growth and pod production.

\begin{tabular}{|c|c|c|c|}
\hline Growing cycle temperature & Day $^{\circ} \mathrm{C}$ & Night $^{\circ} \mathrm{C}$ & Ventilation from ${ }^{\circ} \mathrm{C}$ \\
\hline & $22-24$ & $16-18$ & 26 \\
\hline
\end{tabular}


Table.4.46

Climbing bean plant nutrient requirements.

\begin{tabular}{lllll} 
Yield expectation & $N\left(\mathrm{~g} / \mathrm{m}^{2}\right)$ & $\mathrm{P}\left(\mathrm{g} / \mathrm{m}^{2}\right)$ & $\mathrm{K}\left(\mathrm{g} / \mathrm{m}^{2}\right)$ & $\mathrm{Mg}\left(\mathrm{g} / \mathrm{m}^{2}\right)$ \\
$\left(\mathrm{kg} / \mathrm{m}^{2}\right)$ & 12 & 2 & 11 & 2 \\
\hline 3 & 20 & 4 & 18 & 3 \\
\hline 5 & 12 & & \\
\hline
\end{tabular}

Source: adapted from various sources, see Appendix B. For climbing beans there is more variation between authors than for any other vegetable!

\section{Pruning and training}

Vertical strings or cords attached to a tension wire usually support the climbing plants. Some growers use sticks (rods) rather than strings. The fast-growing shoots must first be set by hand onto the cord. Subsequent side stems are pinched out at the $3^{\text {rd }}$ or $4^{\text {th }}$ node. Some leaves are removed to improve air circulation and light conditions. The main shoot is run back down after reaching the tension wire.

\section{Pollination}

Beans are self-pollinated. Low temperatures affect pollen viability resulting in poor fruit set and curled pods.

\section{Irrigation}

In protected cultivation plants are watered by drip irrigation systems. Beans are very sensitive to excess soil moisture, therefore water supply should be limited during the growth stage although enough water should be applied before planting out. Water requirement increases after flowering. Beans are very sensitive to soil salinity.

\section{Disease and pest problems}

Disease and pest infestations are assessed one or more times depending on the growth cycle length. Disease incidence, disease severity, bean quality and yield, and the date of survey should be recorded. Some important diseases and pests include:

- Botrytis pod rot - Botrytis cinerea.

- Alternaria leaf spot - Alternaria alternata.

- Anthracnose - Glomerella lindemuthiana.

- Black root rot - Thielaviopsis basicola.

- Fusarium root rot - Fusarium solani.

- White mould (Sclerotinia rot) - Sclerotinia sclerotum.

- Bacterial brown spot - Pseudomonas syringae.

- Bacterial blight - Xanthomonas campestris (synonym Xanthomonas axonopodis).

- Halo blight - Pseudomonas syringae.

- Mosaic Bean common mosaic virus (BCMV).

- Bean common mosaic necrosis virus (BCMNV).

- Aphids (e.g. cowpea aphid - Aphis craccivor).

- Spider mites (especially two-spotted spider mite - Tetranychus urticae).

- Whitefly - Trialeurodes vaporariorum.

- Thrips - Frankliniella occidentalis.

\section{Assessments during growth}

- Time to germination (germination of $50 \%$ of the seeds sown).

- Plant vigour; if direct sown it is determined to what extent the plants are fully germinated or patchy before thinning out ( 1 = absent or very weak, $3=$ low, $5=$ medium, $7=$ strong, $9=$ very strong defects).

- Before harvesting, the number of missing plants is counted. 


\section{Assessments at harvest}

Harvest begins, for each variety, when the first pods are marketable. The pods must be 'crisp' to break and smooth and juicy internally. The seeds may be only slightly developed (soft texture, small grain marking, difficult to separate from the pod). The beans are harvested once or twice a week depending on their rate of development. The harvest is carried out with care, so that the immature pods are not damaged. The harvest period will carry on for approximately 8 weeks.

At each harvest event the pods are classified, according to recognised quality standards, into marketable and non-marketable categories and counted and weighed. In variety trials a number of different properties of the pods are often categorised (using a subsample of the harvested crop from each replicate) :

Pod colour Green: ( 1 = very light green, $3=$ light green, medium green = 5, $7=$ dark green, $9=$ very dark green). Yellow: ( $1=$ very pale yellow, $3=$ light yellow, $5=$ medium yellow, dark yellow $=7,9=$ very dark yellow). Balance of pod colour (in yellow-podded varieties) is assessed by examination of the pods for uniformity of colour ( 1 = very low, 3 = low, 5 = medium, 7 = high, $9=$ very large $)$.

Curvature of the pods This can be done using a 1 to 9 scale as illustrated in Figure 4.16
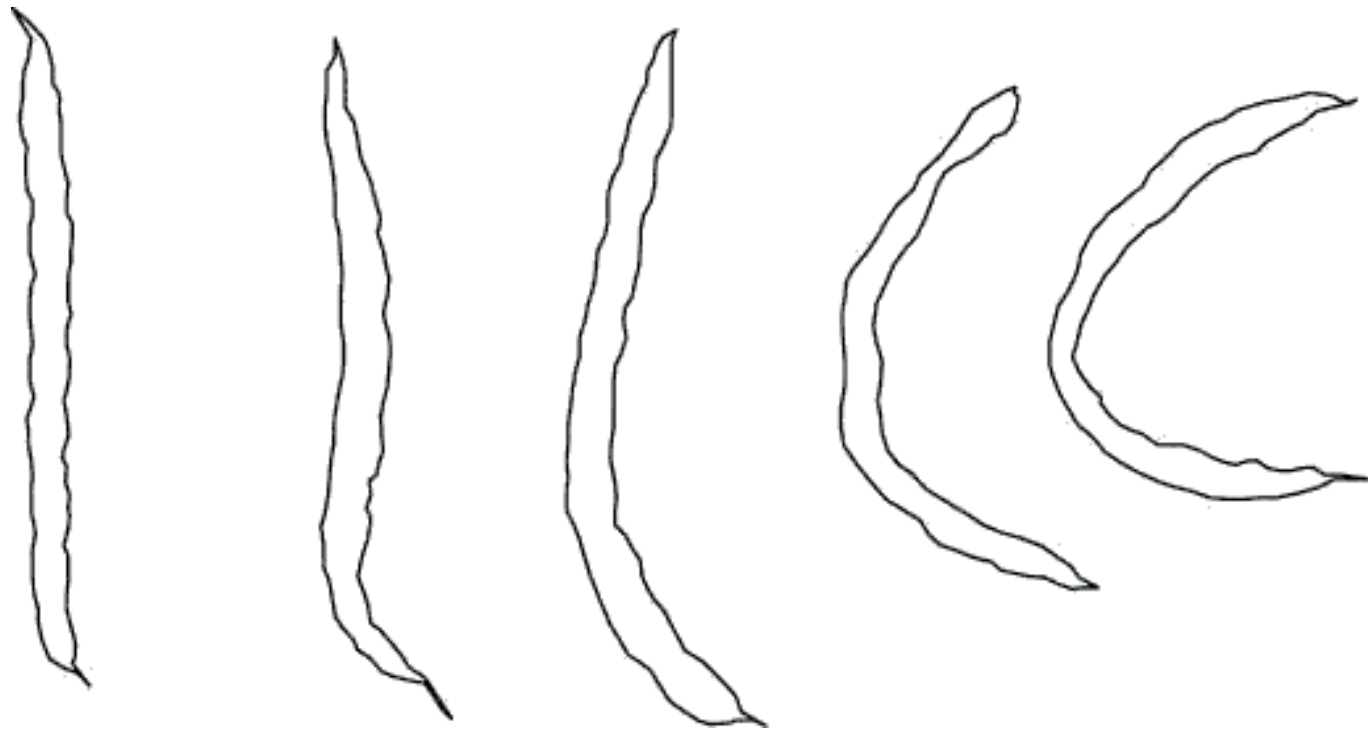

$1=$ none or very low $3=$ low

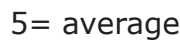

$7=$ strong

$9=$ very strong

Figure 4.16 Scale for assessing the curvature of bean pods (source UPOV, TP/12/4).

Seed marking How clearly can the seeds be seen through the pods? $(1=$ absent, $3=$ low, $5=$ medium, $7=$ strong, 9 = very strong).

Pod length, sleeve width Bean pods are measured for length (of the solid part, not the terminal spike) and width (from seam to seam in the middle of the pod). The measurements can be described using a scale for pod length ( $1=$ Very short, $3=$ short, $5=$ medium, $7=$ long, $9=$ very long) and pod thickness $(1=$ Very thin, $3=$ thin, $5=$ medium, $7=$ thick, $9=$ very thick).

Pod cross-section After measuring, pods are cut (near to a seed) and the shape of the cross section is scored ( 1 = elliptic, 3 = oval, 5 = round-oval, 7 = round, 9 = oblate) .

Stringiness Mature pods during the main harvest period are broken through and scored for stringiness ( $1=$ absent, 3 = low, 5 = medium, 7 = strong, 9 = very strong). 
Field life This is assessed using the crop from at least 2 strings per replicate. These can be in the plot border areas so as not to interfere with the yield measurements. For this purpose, refrain from harvest during the main harvest time. About a week after the last harvest the fibrousness and stringiness of mature pods is scored (using at least 10 pods per replicate).

Fibrousness begins with whitish discoloration of the initially 'glassy', juicy pod flesh in the dorsal and ventral suture (seam). A little later you can see the formation of an inner thin fleece-like pericarp skin when you open the pod. The flesh becomes increasingly dry. To assess the fibrousness, the pods are broken and opened. With increasing maturity, they break less easily ( 1 = absent or very weak, 3 = low (whitish discoloration in the area of the dorsal and ventral suture), $5=$ medium, 7 = strong, 9 = very strong - bean will no longer break).

\section{Overall value score}

This takes into account all criteria for cultivation and commercialization of the variety ( 1 = very low, $3=$ low, $5=$ medium, 7 = high, 9 = very high).

\section{References and further information}

CABI Crop Protection Compendium. (2008).

Phaseolus vulgaris datasheet. Available at: http://www.cabi.org/cpc/datasheet/40626. [Accessed 23

December 14]. Paid subscription required.

Drost, D. (2010).

Beans in the Garden. Utah State University Cooperative Extension. Available at: https://extension.usu.edu/ files/publications/publication/HG_Garden_2005-08.pdf. [Accessed 23 December 14]. Free to access.

FAO, 1990.

Protected Cultivation in the Mediterranean Climate. FAO paper 90: 249-251.

Biddle, A.J., Cattlin, N.D., 2007.

Pests, Diseases and Disorders of Peas and Beans. A colour handbook. Academic Press, USA.

Gianquinto, G., Munoz, P., Pardossi, A., Ramazzotti, S., Savvas, D., 2013.

Soil fertility and plant nutrition. In Good Agricultural Practices for greenhouse Vegetable crops. FAO Plant Production and Protection Paper 217:215-270.

Schwartz, H. F., Steadman, J. R., Hall, R. \& Forster, R. L. (2005)

Compendium of Bean Diseases. Available at: http://www.apsnet.org/apsstore/shopapspress/Pages/43275. aspx. Available for purchase from APS Press.

UPOV

Guidelines for the conduct of tests for distinctness, uniformity and stability. French beans (TP/12/4). http:// www.upov.int 


\subsubsection{Kohlrabi}

\section{By Martin Koller}

Botanical name: Brassica oleracea L. var. gongylodes (Brassicaceae)

Other common names: German turnip, turnip cabbage

With appropriate modifications the information in this section can also be used as a template for similar crops like Chinese cabbage, Pak-choi, Swiss chard or celery.

\section{General crop requirements}

Kohlrabi can be cultivated all year around with a low temperature requirement but in greenhouses, winter production is most important. Some varieties are sensitive to low temperature at the seedling stage in order to avoid leaf deformation and heartlessness. A uniform water supply prevents cracks and woodiness of the tuber. Kohlrabi in greenhouses are grown in Central and Northern Europe, but very rarely in the Mediterranean.

\section{Experimental design}

Recommended replicates: at least 4.

Table 4.47

Typical kohlrabi plant spacing and number of plants required for trials.

\begin{tabular}{lll} 
& $\begin{array}{l}\text { North \& central } \\
\text { un-heated }\end{array}$ & $\begin{array}{l}\text { North \& central } \\
\text { heated }\end{array}$ \\
Minimum number of plants/ core plot & 30 & 40 \\
\hline Minimum size core plot $\left(\mathrm{m}^{2}\right)$ & $2.5-3.5$ & 2.5 \\
\hline Plant density / $\mathrm{m}^{2}$ & $12-16$ & 16 \\
\hline Row distance $(\mathrm{cm})$ & $25-30$ & 25 \\
\hline Spacing within the row $(\mathrm{cm})$ & $25-30$ & 25
\end{tabular}

\section{Table 4.48}

Typical kohlrabi sowing and harvesting dates.

\begin{tabular}{|c|c|c|c|c|c|}
\hline $\begin{array}{l}\text { Region } \\
\text { - Production type }\end{array}$ & Sowing at & Planting at & Start of Harvest & End of harvest & Remarks \\
\hline $\begin{array}{l}\text { North \& central } \\
\text { - Unheated* }\end{array}$ & $\begin{array}{l}\text { Dec } \\
\text { Jul }\end{array}$ & $\begin{array}{l}\text { Feb } \\
\text { Aug }\end{array}$ & $\begin{array}{l}\text { Apr } \\
\text { Oct }\end{array}$ & $\begin{array}{l}\text { Apr } \\
\text { Nov }\end{array}$ & $\begin{array}{l}\text { Spring crop } \\
\text { Autumn crop }\end{array}$ \\
\hline $\begin{array}{l}\text { - Seasonal } \\
\text { heated }\end{array}$ & $\begin{array}{l}\text { Nov } \\
\text { Aug }\end{array}$ & $\begin{array}{l}\text { Jan } \\
\text { Sept }\end{array}$ & $\begin{array}{l}\text { March } \\
\text { Dec }\end{array}$ & $\begin{array}{l}\text { March } \\
\text { Dec }\end{array}$ & $\begin{array}{l}\text { Spring crop } \\
\text { Autumn crop }\end{array}$ \\
\hline
\end{tabular}

*Transplants are produced in heated greenhouses even if the production phase is unheated.

Table 4.49

Kohlrabi temperature requirements for sowing and seedling development.

\begin{tabular}{|c|c|c|c|c|}
\hline $\begin{array}{l}\text { Germination } \\
\text { temperature }{ }^{\circ} \mathrm{C} \\
\text { Day/ Night }\end{array}$ & $\begin{array}{l}\text { Days until } \\
\text { germination }\end{array}$ & $\begin{array}{l}\text { Temperature for } \\
\text { seedlings in }{ }^{\circ} \mathrm{C} \\
\text { Day/ Night }\end{array}$ & Pots & $\begin{array}{l}\text { Weeks until } \\
\text { plantation }\end{array}$ \\
\hline $\begin{array}{l}16-20 / 14 \\
\text { Ventilation from } 20-25\end{array}$ & $6-12$ & $\begin{array}{l}12-16 / 10 \\
\text { Ventilation from } 20-25\end{array}$ & $\begin{array}{l}4-5 \mathrm{~cm} \\
\text { peat pot }\end{array}$ & $4-8$ \\
\hline
\end{tabular}


Table 4.50

Optimal temperatures for plant growth after planting.

\begin{tabular}{|c|c|c|c|}
\hline & Day & Night & Ventilation from \\
\hline $\begin{array}{l}\text { Planting in late February / } \\
\text { harvest end April }\end{array}$ & $10-15^{\circ} \mathrm{C}$ & $7-8^{\circ} \mathrm{C}$ & $20-24^{\circ} \mathrm{C}$ \\
\hline
\end{tabular}

Table 4.51

Kohlrabi plant nutrient requirements.

\begin{tabular}{lllll} 
Yield expectation & $\mathrm{N}\left(\mathrm{g} / \mathrm{m}^{2}\right)$ & $\mathrm{P}\left(\mathrm{g} / \mathrm{m}^{2}\right)$ & $\mathrm{K}\left(\mathrm{g} / \mathrm{m}^{2}\right)$ & $\mathrm{Mg}\left(\mathrm{g} / \mathrm{m}^{2}\right)$ \\
$\left(\mathrm{kg} / \mathrm{m}^{2}\right)$ & 8 & 1.5 & 9 & 2 \\
\hline 2.5 & 14 & 3 & 17 & 3 \\
\hline 4.5 & 8 & 8
\end{tabular}

Source: adapted from various sources, see Appendix B

\section{Irrigation}

Regular irrigation of 15 to $20 \mathrm{~mm}$ is needed (on sandy soils). The soil must not be allowed to dry out in order to avoid cracks and woodiness.

\section{Disease and pest infestation, physiological disorders and other abiotic damage}

To help identify diseases see e.g. "Compendium of Brassica Disease" (APS, ISBN 978-0-89054-344-3). Relevant pests and diseases, with link to relevant EPPO Guidelines, include:

- Downy mildew - Peronospora parasitica (PP 1/65(3) - Downy mildews of lettuce and other vegetables). Yellow spots on the leaf surface and grey-brownish sporangia's and the underside (also on cotyledons).

- Clubroot Plasmodiophora brassicae (PP 1/39(2)).

- Black leaf spot, Alternaria brassicae and A. brassicicola (PP 1/121(2) Leafspots of vegetables) Round, black spots on the leaf surface.

- Cabbage flea beetle Phyllotreta spp. (on rape) (PP 1/218(1).

- Cabbage root fly (PP $1 / 9$ (3) Delia radicum).

- Caterpillars e.g. Plutella xylostella, Pieris sp., Mamestra brassicae: (PP 1/83(2) - Caterpillars on leaf brassicas)

- Cabbage aphids Brevicoryne brassicae: (PP 1/24(2) Aphids on potato, sugar beet, pea, broad bean and other vegetables).

\section{Assessments during growth}

See: UPOV Guidelines T/65/4

Amount and size of leaves The leaf mass is scored before the beginning of harvest ( 1 = very low, $3=$ low, $5=$ medium, 7 = high, 9 = very large).

Leaf position The leaf position of the majority of the leaves is assessed before the beginning of harvest. This scoring should be carried out in the morning. Kohlrabi with leaves in an upright position are easier to harvest and to put in boxes ( 3 = erect/upright, 5 = semi-erect/semi-upright, 7 = horizontal).

Shape of bulb (UPOV characteristic 21). Shape of bulb in longitudinal section, see UPOV page 13 ( $1=$ transverse narrow elliptic, $2=$ transverse elliptic, $3=$ transverse broad elliptic, $4=$ circular, 5 = broad elliptic).

Colour of skin (UPOV characteristic 20). 1 = white green, $2=$ green, 3 pale violet, $4=$ dark violet 
Stability of plants $1=$ very low, $3=$ low, $5=$ medium, $7=$ high, $9=$ very large

Missing plants Missing plants should be counted before harvest begins.

\section{Assessments at harvest}

Kohlrabi can be harvested as soon as a certain diameter is reached (e.g. Germany > 80 mm for spring crop, for autumn crop $70 \mathrm{~mm}$ ). Some plants develop more quickly than others and so the whole crop requires more than one harvest. The cropping of a Kohlrabi variety in greenhouses should be finished after three harvests. More harvests are considered as uneconomic. The crop is sorted and weighed according to the quality standards for marketable and non-marketable produce. The non-marketable crop is divided into main reasons for rejection:

- Bulbs with cracks.

- Bolters.

- Others (rot, diseased, misshaped, too small, cracks because of weevils).

In addition to yield a number of other parameters can be determined:

Stalk length Before removing the root, the stalk length is scored. With a too short stalk, there is a risk that the bulbs get dirty and rot. Too long stalk may have unfavourable effect on the stability of the plant in the ground (1 = very short, 3 = short, 5 = medium, 7 = long, 9 = very long).

Woodiness On the day with the biggest harvest a slice of approximately $1 \mathrm{~mm}$ thickness is cut of the middle of 10 marketable bulbs. The woodiness is determined by chewing on the slice. In addition, the bulb halves can be dried for one to two days in a warm greenhouse. The fibres will afterwards be defined more clearly ( $1=$ absent or very low, 3 = low, 5 = medium, 7 = strong, 9 = very strong).

\section{Overall value score}

This takes into account all criteria for the cultivation and marketing of the variety, based on expert opinion as evaluated by researchers using information from farmers, wholesalers and consumers ( $1=$ very low, $3=$ low, 5 = medium, 7 = high , 9 = very high).

\section{References and further information}

Rimmer S. R., Shattuck V.I. and Buchwaldt L.(Eds). 2007.

Compendium of Brassica Disease. American Phytopathological Society. (ISBN 978-0-89054-344-3)

International Union for the Protection of New Varieties of Plants (UPOV):

Kohlrabi TG/65/4 www.upov.int 


\subsubsection{Radish}

\section{By Wolfgang Palme}

Botanical name: Raphanus sativus var. sativus

\section{General crop requirements}

Radish need loose well structured soils with high humus content and good water supply. Irrigation has to be provided. Do not grow radish after another radish crop or after other Brassicas. Avoid previous crops that leave high nitrogen residues.

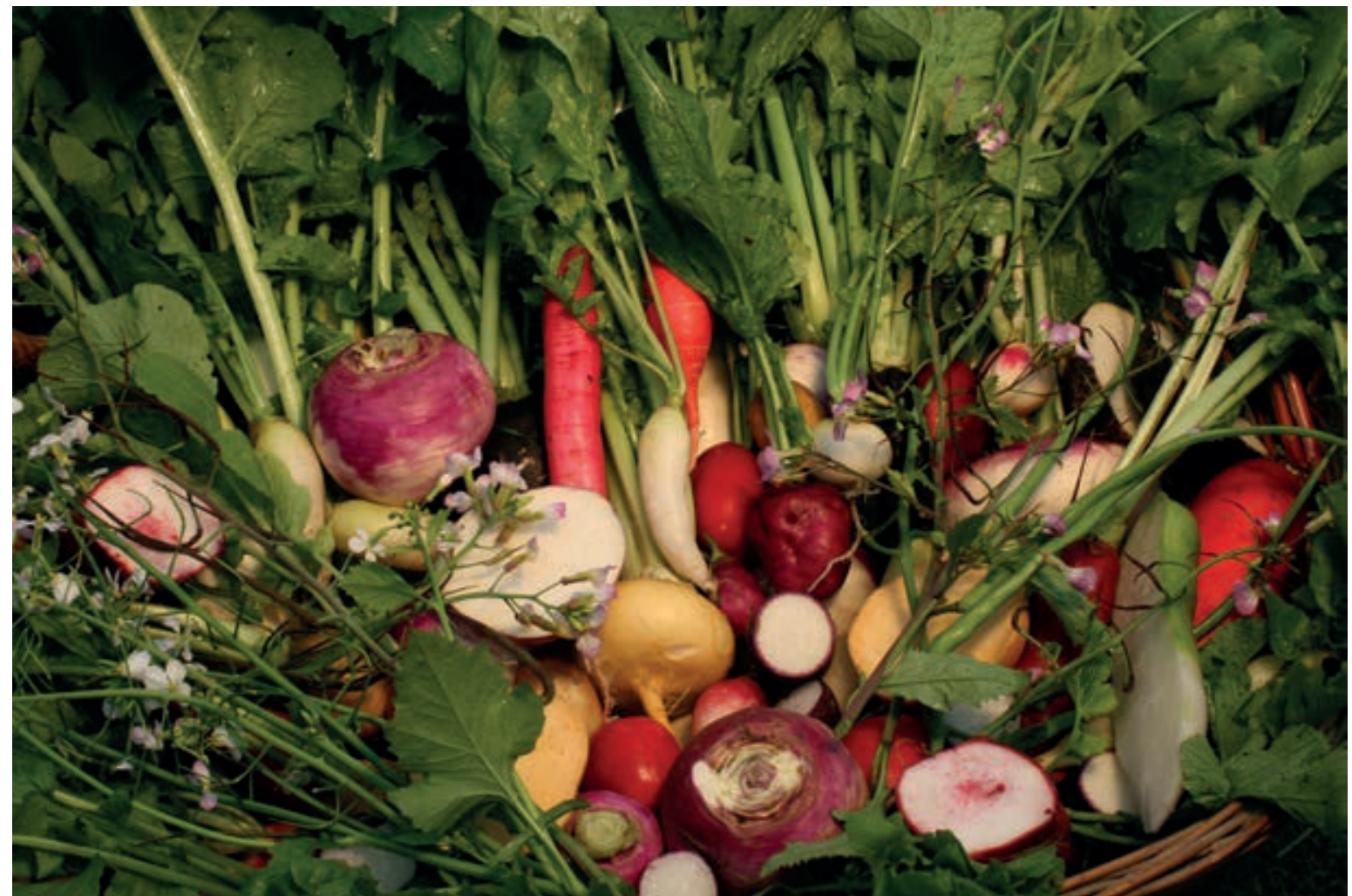

Figure 4.17 Radishes, indicating the diversity of different varieties

\section{Experimental layout}

An experimental layout with four replicates should be used

\section{Table 4.52}

Typical radish plant spacing and number of plants required for trials.

\begin{tabular}{lll} 
& $\begin{array}{l}\text { Greenhouse } \\
\text { heated }\end{array}$ & $\begin{array}{l}\text { Greenhouses } \\
\text { North of Alps } \\
\text { Not heated } \\
\text { (but free of frost) }\end{array}$ \\
\hline Minimum size core plot $\left(\mathrm{m}^{2}\right)$ & 2 & 2 \\
\hline Plant density / $\mathrm{m}^{2}$ & 250 & $250-300$ \\
\hline Row distance $(\mathrm{cm})$ & $10-15$ & $10-12$ \\
\hline Spacing with the row $(\mathrm{cm})$ & $4-8$ & $4-8$ \\
\hline
\end{tabular}




\section{Table 4.53}

Typical radish sowing dates and growing periods.

\begin{tabular}{lll} 
Region & Sowing at & Cultivation period (days) \\
- Production type & & \\
North \& central & Feb-March & $40-55$ \\
- Unheated & Sept. & $35-55$ \\
\hline North \& central & Jan-Feb & $40-70$ \\
- Seasonal heated & Sept.-Oct & $35-70$ \\
\hline
\end{tabular}

It is best, if possible, to sow using a precision seeder that sets seeds at controlled spacing. If they are sown at an excessive density the seedlings have to be singled after germination. For optimum seed placement and best germination the seedbed should be rolled. If the seeds are sown too deeply $(>1-1.5 \mathrm{~cm})$ roots can become deformed.

Conditions for germination: $12-15^{\circ} \mathrm{C}$ air temperature, ventilation $>20^{\circ} \mathrm{C}$. Soil temperature: $>10^{\circ}$. After germination: $5-6^{\circ} \mathrm{C}$, ventilation: $>15^{\circ} \mathrm{C}$.

\section{Crop nutrition}

The nutrient requirement is low because of the short cultivation period. If a contribution from crop residues of the previous crop is available no fertilisation is needed. Avoid organic fertilisers such as manure.

Table.4.54

Radish plant nutrient requirements.

\begin{tabular}{lllll}
$\begin{array}{l}\text { Yield expectation } \\
\left(\mathrm{kg} / \mathrm{m}^{2}\right)\end{array}$ & $\mathrm{N}\left(\mathrm{g} / \mathrm{m}^{2}\right)$ & $\mathrm{P}\left(\mathrm{g} / \mathrm{m}^{2}\right)$ & $\mathrm{K}\left(\mathrm{g} / \mathrm{m}^{2}\right)$ & $\mathrm{Mg}\left(\mathrm{g} / \mathrm{m}^{2}\right)$ \\
\hline 2 & 6 & 0.8 & 6 & 1 \\
\hline 4 & 12 & 1.6 & 2.4 & 12 \\
\hline 6 (e.g. Daikon- a long white Asian radish) & 18 & & 3
\end{tabular}

Source: adapted from various sources, see Appendix B

\section{Irrigation}

Ensure there is a regular water supply. Irregular irrigation causes quality defects such as cracking. A lack of water makes the roots spongy.

\section{Crop management and phytosanitary measures}

Ensure that the crop is kept weed free. Before sowing and even after germination flame weeding is possible. To be effective against flea beetles and summer cabbage flies cover with insect proof netting.

\section{Disease and pest problems}

The disease and pest infestation (incidence and severity) should be assessed one or more times during the crop growth (see also section 2.5). Key problems include:

- Downy mildew - Peronospora parasitica.

- Black scurf - Rhizoctonia solani.

- Fusarium.

- Clubroot - Plasmodiophora brassicae.

- White rust - Aphanomyces raphanin/Albugo candida.

- Flea beetle - Phyllotreta undulata.

- Cabbage root fly - Delia radium. 


\section{Observations during growth}

Date of emergence ( $90 \%$ of germinated seedling show expanded cotyledons)

Plant density (measured per running meter on a representative spot in the crop)

Missing plants (counted before harvest begins)

\section{Assessments at harvest}

The time of harvest has come when bulb diameter is $>20 \mathrm{~mm}$ (or in autumn $>25 \mathrm{~mm}$ ). Not more than two or three harvests should be carried out. The crop should be sorted according to recognised quality standards into marketable and non- marketable fractions and the reasons for rejection indentified. These could include:

- Bulbs with cracks.

- Undersized bulbs ( $<10 \mathrm{~mm})$.

- Rotten, diseased, bulbs.

- Bolters (stems $>3 \mathrm{~cm}$ ).

- Others (misshaped, miscoloured).

In addition to yield a number of other parameters can also be assessed including:

Uniformity of bulbs ( 1 = very low, 3 = low, 5 = medium, 7 = high, 9 = very high)

Size of main root Ideally the main root base should be small. ( $1=$ very small, $3=$ small, $5=$ medium, $7=$ thick, 9 = very thick).

Length of leaves 10 bulbs of marketable produce are measured concerning leaf. If the leaves are too long the storage life is reduced. If it is too short it is not easy to manage bundling.

Diameter of bulbs 10 bulbs of marketable produce are measured. Cultivars with oblong shape are also measured in length.

Sponginess On the day of harvesting 20 marketable bulbs are cut longitudinally. Sponginess is determined ( $1=$ very soft, 9 = very hard).

\section{Total value score}

The total value takes into account all criteria for the cultivation and marketing of the variety $(1=$ very low, $3=$ low, 5 = medium, 7 = high, 9 = very high).

\section{References and further information}

UPOV

Guidelines for the conduct of tests for distinctness, uniformity and stability. Radish (TP/64/2). http://www. upov.int 


\subsubsection{Spring onion}

\section{By Karin Postweiler}

Botanical name: Allium cepa and Allium fistulosum

Spring onions are divided into types with bulbs and early leaf development and types without bulbs (bunching types). These types belong to the species Allium fistulosum or are crossings between A. cepa and A. fistulosum. Both types are harvested with their leaves.

\section{General crop requirements}

Spring onions need soils with high humus content, with a pH 6.5 to 7.5. Plots with high nitrogen residues are not appropriate. Do not grow spring onions after other Allium crop. Throughout the cultivation period a regular water supply and sufficient irrigation is necessary. Spring onions can be established by direct sowing (ideally with precision seeders) or transplanted ( 3 or 4 seeds per 'pressed block'). Seeds usually take 10 to 25 days to germinate and the crop has a cultivation period of 220 to 240 days.

\section{Experimental design}

An experimental layout with four replicates should be used.

\section{Table 4.55}

Typical spring onion spacing and number of plants required for trials

\begin{tabular}{lll} 
& $\begin{array}{l}\text { Greenhouse } \\
\text { unheated (free of frost) } \\
\text { types with bulbs }\end{array}$ & $\begin{array}{l}\text { Greenhouse } \\
\text { unheated (free of frost) } \\
\text { types without bulbs }\end{array}$ \\
\hline Minimum size core plot $\left(\mathrm{m}^{2}\right)$ & 4 & 4 \\
\hline Plant density / $\mathrm{m}^{2}$ & 200 & 250 \\
\hline Row distance $(\mathrm{cm})$ & 20 & 15 \\
\hline Plant distance with the row $(\mathrm{cm})$ & 2 & 2 \\
\hline
\end{tabular}

\section{Crop nutrition and irrigation}

Sufficient irrigation is necessary to prevent drought damage. Nitrogen fertilisation should be supplied according to the residues in the soil.

\section{Table.4.56}

Spring onion plant nutrient requirements.

\begin{tabular}{lllll} 
Yield expectation & $\mathrm{N}\left(\mathrm{g} / \mathrm{m}^{2}\right)$ & $\mathrm{P}\left(\mathrm{g} / \mathrm{m}^{2}\right)$ & $\mathrm{K}\left(\mathrm{g} / \mathrm{m}^{2}\right)$ & $\mathrm{Mg}\left(\mathrm{g} / \mathrm{m}^{2}\right)$ \\
$\left(\mathrm{kg} / \mathrm{m}^{2}\right)$ & 5 & 1.2 & 5 & 1 \\
\hline 2 & 10 & 2.4 & 9 & 2 \\
\hline 4 & 5 & 9
\end{tabular}

Source: adapted from various sources, see Appendix B

\section{Crop management and phytosanitary measures}

Aim for a weed free crop. Before sowing or planting flam weeding is possible. To prevent damage by insects mesh covers can be used. 


\section{Disease and pest problems}

The disease and pest infestation should be assessed one or more times during the cropping period. Disease/pest incidence and severity should be noted. Effect of specific pests and diseases on crop quality at harvest can also recorded.

- Downy mildew - Peronospora destructor.

- Botrytis squamosa.

- Allium root rot - Sclerotium cepivorum.

- Fusarium.

Onion thrips - Thrips tabaci

Onion flies - Delia antiqua

Leek moth - Acrolepiopsis assectella

Allium leaf miner - Phytomyza gymnostoma

\section{Assessments during crop growth}

Date of emergence The number of days from sowing to $50 \%$ emergence.

Plant density Counted per running meter on a representative spot in the crop.

Position of the Foliage Before harvest the position of the leaves is determined. For better bunching upright leaves are preferable.

Number of bolters These should be counted

\section{Assessments at harvest}

The harvest of spring onions is reached when bulb diameter is about $10 \mathrm{~mm}$. The harvest should all be done on one date. The weighed yield measurement are carried out on the marketable onions per plot. The crop is sorted according to recognised quality standards. For the bulb producing species the crop can be further sorted according to size, for example with diameters of:

- $10-20 \mathrm{~mm}$.

- 20-30 mm.

- over $30 \mathrm{~mm}$.

To characterise a variety length of the plant and length of the shaft should be measured on at least 10 plants per plot.

The non-marketable crop is divided into main reasons for rejection:

- Rotten, diseased bulbs.

- Others, misshaped, to small.

\section{Overall value score}

This takes into account all criteria for the cultivation and marketing of a variety ( $1=$ very low, $3=$ low, $5=$ medium, 7 = high, 9 = very high).

\section{Other information}

UPOV

Guidelines for the conduct of tests for distinctness, uniformity and stability. Onions (TP/46/2 and TP/161/1). http://www.upov.int 


\subsection{Transplants}

\subsubsection{Vegetable transplants}

\section{By Yuksel Tüzel}

\section{Systems}

Vegetable seedlings are increasingly being raised in module systems (i.e. plug trays) which have many cells each with a small volume. Each transplant is grown in its own cell resulting in the elimination of the damage caused by tearing apart matted root systems of plants grown together (Doolan et al. 1999).

In modular systems, trays differ in terms of number, shape and size of cells (i.e. from 70 to 600). The material can be expanded polystyrene, rigid polyethylene or polypropylene. The growing media used must provide an appropriate environment for seed germination, support the plant and provide water and limited amount of nutrients. Many trials are concerned with nutrient supply and the composition of growing media (especially the use of alternatives to peat) - see Sections 3.2.5 and 3.2.6.

\section{Other systems in use are:}

- Pressed blocks; these can be made a variety of substrates and hold together without the need for a 'container'. It is considered difficult to use growing media other than peat that have the required characteristics and the use of peat is considered unethical in certain countries e.g. the UK.

- Bare root transplants (e.g. leeks, cabbage, or in some regions tomatoes and lettuce).

The appropriate system will depend on cropping season, temperature, and vegetable species.
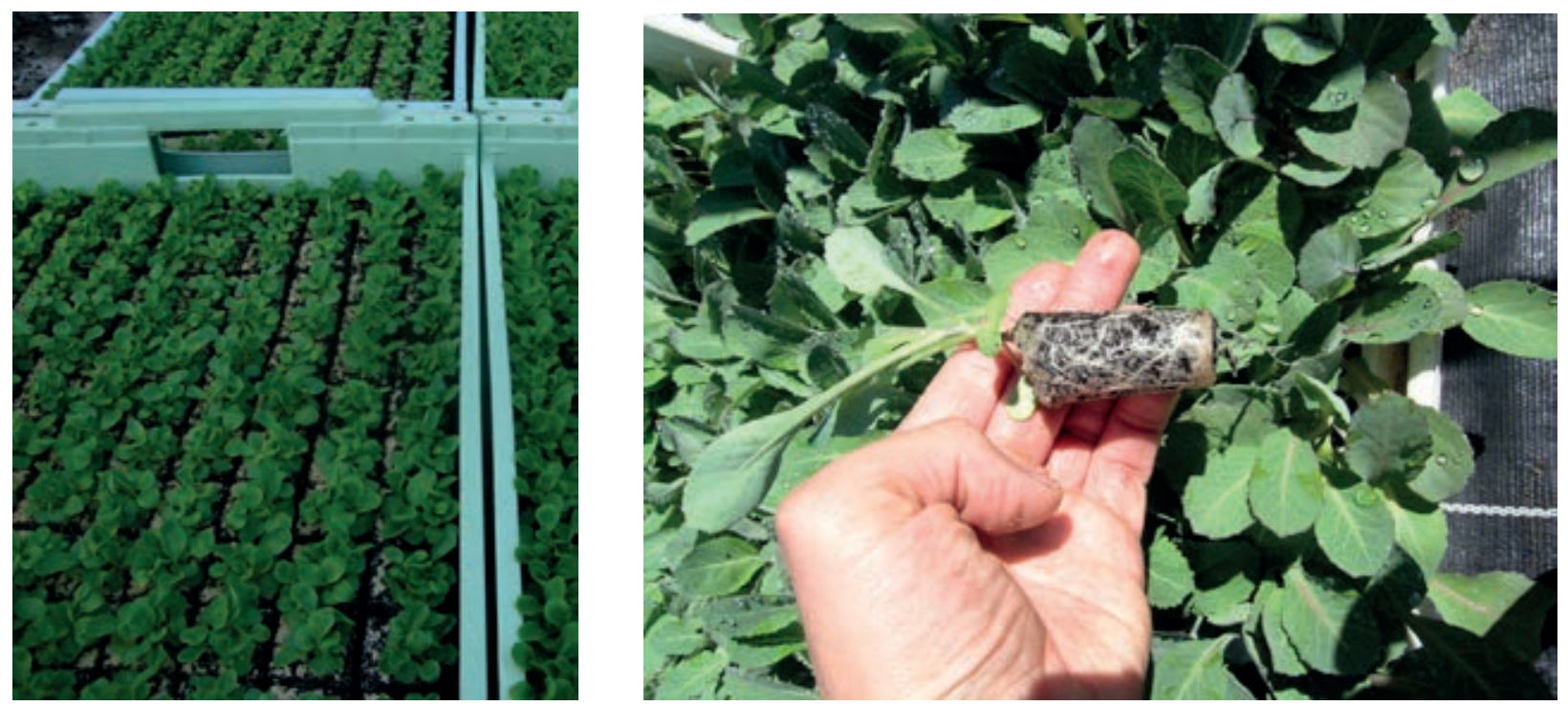

Figure 4.18 Left, Lamb's lettuce transplants grown in pressed block (70\% peat); Right, cabbage transplants ('speedy plants') grown in module trays.

\section{Experimental guidelines}

Recommended replicates: at least 4

Minimum number of plants per treatment: One tray per replication (or similar amount of bare rooted transplants) 


\section{Evaluation}

- Fresh matter (and dry matter) weight of shoot of the seedling.

- Colour of the seedling leaves (e.g. using Chlorophyll Meter Minolta SPAD 502).

- Establishment in the soil of the seedlings, by planting out seedlings and count the success within 1 and 2 weeks (biomass could easily be assessed).

- Crop yield of different methods after transplanting and earliness of yield.
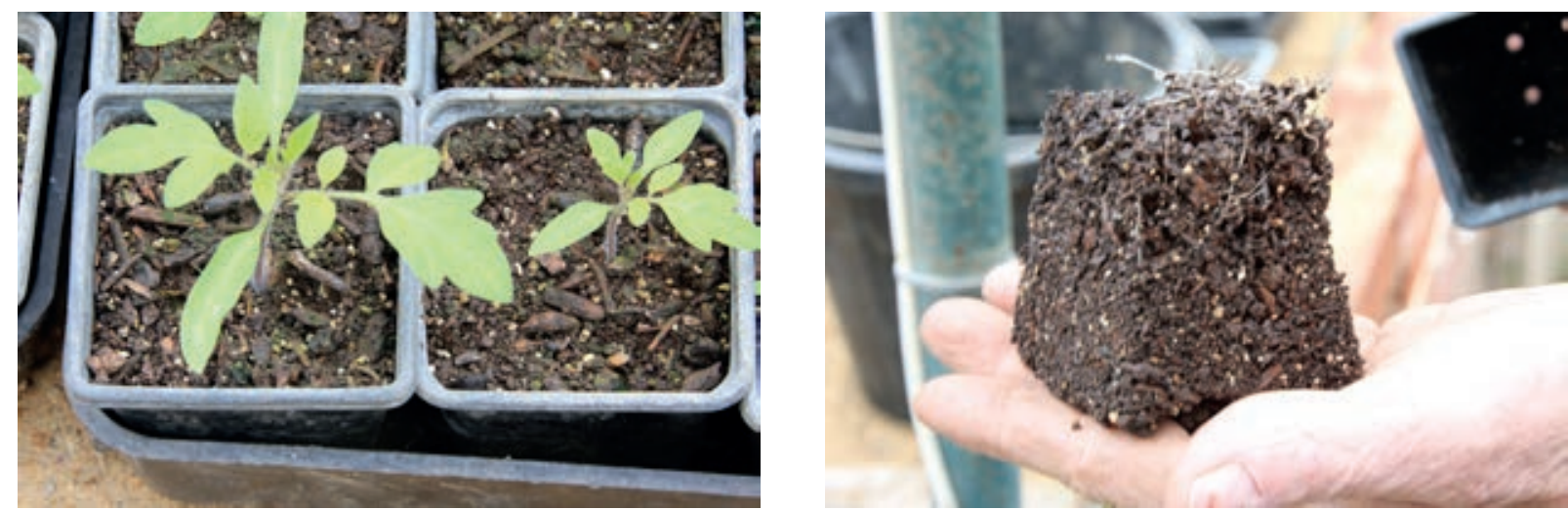

Figure 4.19 Tomato plants grown in peat-free growing media containg a high proportion of composted wood chips.

\section{References and further information}

Doolan, D.W., Leonardi, C., Baudoin, W.O., 1999.

Vegetable Seedling Production Manual. FAO Plant Production and Protection Paper 155. 


\subsection{Herbs}

Many different species of herbs can be grown in greenhouses. Out of them, parsley was chosen as a typical crop to grown in soil and basil as a typical potted herb. They can serve as 'model systems' for other herbs.

\subsubsection{Parsley}

\section{By Martin Koller and Justine Dewitte}

Botanical name: Petroselinum crispum

\section{General crop requirements}

Parsley is in the Apiaceae family and so is related to celery, carrots, fennel and dill. It is a biennial plant. The leaves tolerate only minimal freezing temperatures but the root is hardy. The first year is the vegetative phase and the second year starts the generative phase. As a herb crop it is grown for only one year.

Two types are grown:

- Curly leaf ( $P$. crispum crispum group). This can be divided in sub types, according to their leaves characteristics e.g. Curled (type perlé), Fine curled, Paramount, double/triple curled, frisé vert fonce, "Mooskrause". Unfortunately the names for different types are not used consistently.

- Italian, or flat leaf ( $P$. crispum neapolitanum group/ P. crispum ssp. latifolium).

Plants can grow 30-60 cm tall; the flat leaf parsley grows taller than the curly leaf parsley.

Parsley prefers moist, deep and rich soil. It is sensitive to dry conditions but resistant to cold. There should be a break of at least five years between two parsley crops in the rotation.

The leaves can either be cut mechanically or picked by hand - the sowing density is different in each case. Darkness is needed for germination so direct sowing has to be done at a depth of 2.5 to $3 \mathrm{~cm}$. If transplanted three to four seeds are sown in each $4 \mathrm{~cm}$ diameter pressed block. Parsley has a taproot, so the plants have to be planted at the right time because the roots do not have enough space to develop in the blocks.

The crop requires regular watering as it cannot withstand dry periods. A plastic mulch, preferably with preformed holes, can be used.

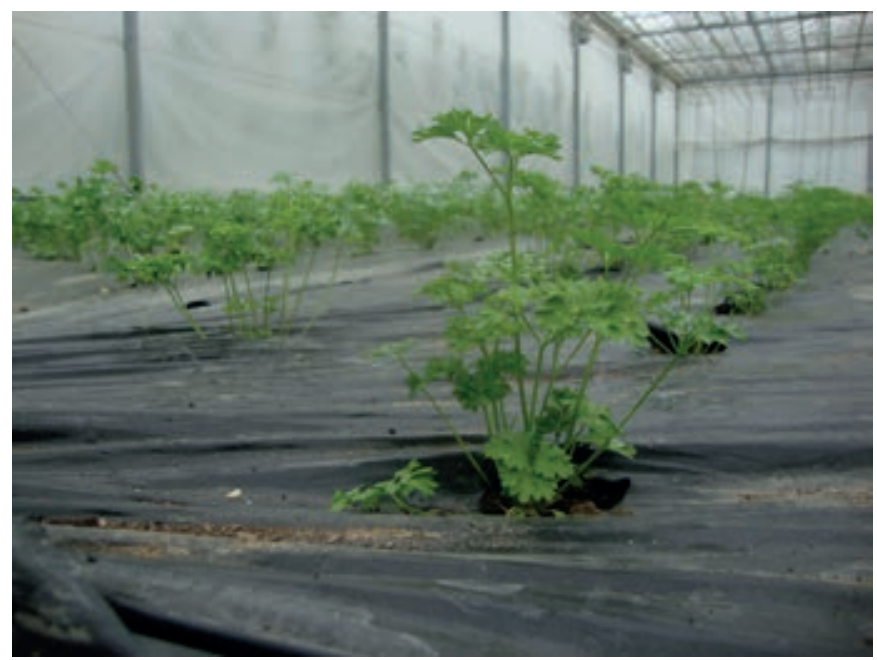

Figure 4.20 Parsley crop, plants being grown through a plastic mulch.

\section{Experimental design}

Recommended replicates: at least 3. 
Table 4.57

Typical parsley plant spacing and number of plants required for trials.

\begin{tabular}{lll} 
& Direct sown (for cutting) & Planted (for picking) \\
\hline Minimum number of plants/ core plot & $2800-3200$ & $55-135$ \\
\hline Minimum size core plot $\left(\mathrm{m}^{2}\right)$ & 10 & 5 \\
\hline Plant (or block) density / $\mathrm{m}^{2}$ & $280-320$ & $11-27$ multisown peat blocks \\
\hline Row distance $(\mathrm{cm})$ & $10-25$ & $25-30$ \\
\hline Distance between the rows $(\mathrm{cm})$ & $2-15$ & $15-25$
\end{tabular}

\section{Table 4.58}

Typical parsley sowing and harvesting dates.

\begin{tabular}{|c|c|c|c|c|c|}
\hline $\begin{array}{l}\text { Region } \\
\text { - Production } \\
\text { type }\end{array}$ & Sowing at & Planting at & $\begin{array}{l}\text { Start of } \\
\text { Harvest }\end{array}$ & $\begin{array}{l}\text { End of } \\
\text { harvest }\end{array}$ & Remarks \\
\hline $\begin{array}{l}\text { North \& } \\
\text { central } \\
\text { Winter crop }\end{array}$ & Mid Jul & Sept & Nov & Apr/May & $\begin{array}{l}\text { Unheated or Frost-free greenhouse } \\
\text { or polytunnel. In summer parsley } \\
\text { is grown in open field only. }\end{array}$ \\
\hline
\end{tabular}

Table 4.59

Temperatures required for parsley germination and seedling growth.

\begin{tabular}{|c|c|c|c|c|}
\hline $\begin{array}{l}\text { Germination } \\
\text { temperature }{ }^{\circ} \mathrm{C} \\
\text { Day/ Night }\end{array}$ & $\begin{array}{l}\text { Days until } \\
\text { germination }\end{array}$ & $\begin{array}{l}\text { Temperature for } \\
\text { seedlings in }{ }^{\circ} \mathrm{C} \\
\text { Day/ Night }\end{array}$ & Peat block size & $\begin{array}{l}\text { Time from sowing to } \\
\text { planting (weeks) }\end{array}$ \\
\hline $\begin{array}{l}20 / 18^{\circ} \\
\text { Ventilation from } 22 \\
-25\end{array}$ & $5-12$ & $\begin{array}{l}12-16 / 10 \\
\text { Ventilation from } 20 \\
-25\end{array}$ & $4-5 \mathrm{~cm}$ & $4-8$ \\
\hline
\end{tabular}

\section{Table 4.60}

Optimal temperature and critical temperature for parsley crop production

\begin{tabular}{llll} 
& Day & Night & Ventilation from \\
Winter crop (optimal) & $10-15^{\circ} \mathrm{C}$ & $7-8^{\circ} \mathrm{C}$ & $18^{\circ} \mathrm{C}$ \\
\hline Winter crop (critical) & $5-6^{\circ} \mathrm{C} *$ & $5-6^{\circ} \mathrm{C}$ & $18^{\circ} \mathrm{C}$ \\
\hline
\end{tabular}

\section{Table.4.61}

Parsley plant nutrient requirements.

\begin{tabular}{lllll}
$\begin{array}{l}\text { Yield expectation } \\
\left(\mathrm{kg} / \mathrm{m}^{2}\right)\end{array}$ & $\mathrm{N}\left(\mathrm{g} / \mathrm{m}^{2}\right)$ & $\mathrm{P}\left(\mathrm{g} / \mathrm{m}^{2}\right)$ & $\mathrm{K}\left(\mathrm{g} / \mathrm{m}^{2}\right)$ & $\mathrm{Mg}\left(\mathrm{g} / \mathrm{m}^{2}\right)$ \\
\hline 2 & 10 & 1.4 & 8 & 1 \\
\hline 3.5 & 17 & 2.5 & 14 & 1.5
\end{tabular}

Source: adapted from various sources, see Appendix B 


\section{Disease and pest infestation, physiological disorders and other abiotic damage}

The disease and pest incidence and severity should be scored several times during cropping (see also section 2.5). For the main problems the corresponding EPPO test guidelines are:

- Septoria leaf spot disease - Septoria petroselini (PP 1/121 (2) of leaf spots on vegetables).

- Downy mildew - Plasmopara crustosa (PP 1/65 (3) Downy mildews of lettuce and other vegetables).

- Powdery mildew (PP 1/57(3) Powdery mildew of cucurbits and other vegetables).

- Aphids (PP 1/24(2) Aphids on potato, sugar beet, pea, broad bean and other vegetables). Yellow dwarf virus is spread by aphids.

Other emerging diseases and pests (such as virus diseases, bacterial leaf spots, sclerotina, aphids, carrot fly, parsley weevil) should be mentioned in the trial report or recorded individually if different infestations in the treatments occur.

\section{Assessments during crop growth}

- For direct sown crops - the number of days between sowing and germination (the date by which approximately $50 \%$ of the plants have germinated).

- Crop establishment ( 1 = absent or very weak, $3=$ low, $5=$ moderate, 7 = strongly, $9=$ very strong).

- Stand density - about 4 weeks after emergence, the plant number in a $1 \mathrm{~m}$ length of row is counted in a typical area of the plot.

- $\operatorname{Colour}(1=$ pale green, 3 = light green, $5=$ medium green, $7=$ dark green, $9=$ very dark green)

- Curliness of leaves ( $1=$ absent or very weak, $3=$ low, $5=$ moderate, $7=$ strongly, $9=$ very strong)

- Yellowing of lower (older) leaves ( $1=$ absent or very weak, $3=$ low, $5=$ moderate, $7=$ strongly, $9=$ very strong)

- Canopy height - the crop height is measured at 5 locations per plot.

- Missing plants - gaps of more than $25 \mathrm{~cm}$ in length shall be measured.

\section{Assessments at harvest}

Harvesting is done three times by hand or power mower (e.g. baby leaf harvester) approximately $5 \mathrm{~cm}$ above the soil. Each treatment is harvested when both yield and quality reach an optimum (e.g. begin for curly types when canopy height is greater than $20 \mathrm{~cm}$, begin for flat leaf types when the canopy is greater than $40 \mathrm{~cm}$ or the lower leaves are turning yellow). The total harvest of the core plot should be weighed and the proportion of nonmarketable crop determined (rejecting, for example, yellowed, red and diseased leaves). The leaf / stem ratio is determined by sorting and weighing a sub sample of $1000 \mathrm{~g}$ of the crop.

Parsley may be grown for processing as dry produce. To assess this samples of each plot should be dried gently at $40-45^{\circ} \mathrm{C}$ (for about $18 \mathrm{hrs}$.). The foliage is then weighed. In some experiments it is desirable to determine the quantity of essential oil in the foliage $(\% \mathrm{v} / \mathrm{m})$.

\section{Overall value score}

This takes into account all criteria of the variety, based by on expert opinion as evaluated by researchers using information from farmers, wholesalers and consumers ( $1=$ very low, $3=$ low, $5=$ medium, $7=$ high, $9=$ very high).

\section{References and Further information.}

International Union for the Protection of New Varieties of Plants (UPOV). 2004. Parsley TG/136/5 (Draft). www.upov.int

R. M. Davis \& R. N. Raid (Eds). 2002.

Compendium of Umbelliferous Crop Diseases. American Phytopathological Society APS, Minnesota, USA. ISBN: 0-89054-287-2. 


\subsubsection{Basil - grown in pots}

\section{By Martin Koller and Robert Koch}

Botanical name: Ocimum basilicum

\section{Crop requirements}

There are many different types available, but only the big leaved Genovese type is of significant commercial interest. Beside sweet basil other varieties are cultivated, like Thai basil ( $O$. basilicum var. thyrsiflora), lemon basil (O. $x$ citriodorum) and holy basil (Ocimum tenuiflorum). Most of the basil types are annual but some can be perennial, e.g. African blue basil (Ocimum kilimandscharicum $\times$ basilicum 'Dark Opal').

Basil has a high warmth and light requirement. The crop is sensitive to wet leaves and should therefore be irrigated from below (e.g. using an ebb-flood system). If experiments are to be conducted in winter in regions with short day length then artificial lightning should be considered (e.g. in Germany an additional 7h lighting with 2000 - 3500 lux). Different types of basil (like red leaf types, small leaf) should be watered separately. This can cause complications in a trial using both types.

The cultivation period depends on the temperature and light; it can vary from 4 weeks in the summer to 9 weeks in the winter (from sowing date to point of sale). Temperatures below $16^{\circ} \mathrm{C}$ should be avoided, because red-brownish or bright yellow leaf spots may develop. Basil is grown in different pot sizes according to market demand. Smaller pot sizes ( 9 to $10 \mathrm{~cm}$ diameter) are chosen if it is intended for the consumer cut it once or to transplant it. Bigger pot sizes ( $>12 \mathrm{~cm}$ diameter) are used when it is intended that the consumer is will keep it in that pot for several weeks.

\section{Experimental design}

Recommended replicates: at least 4

The core plots should be surrounded by 'guard' pots.
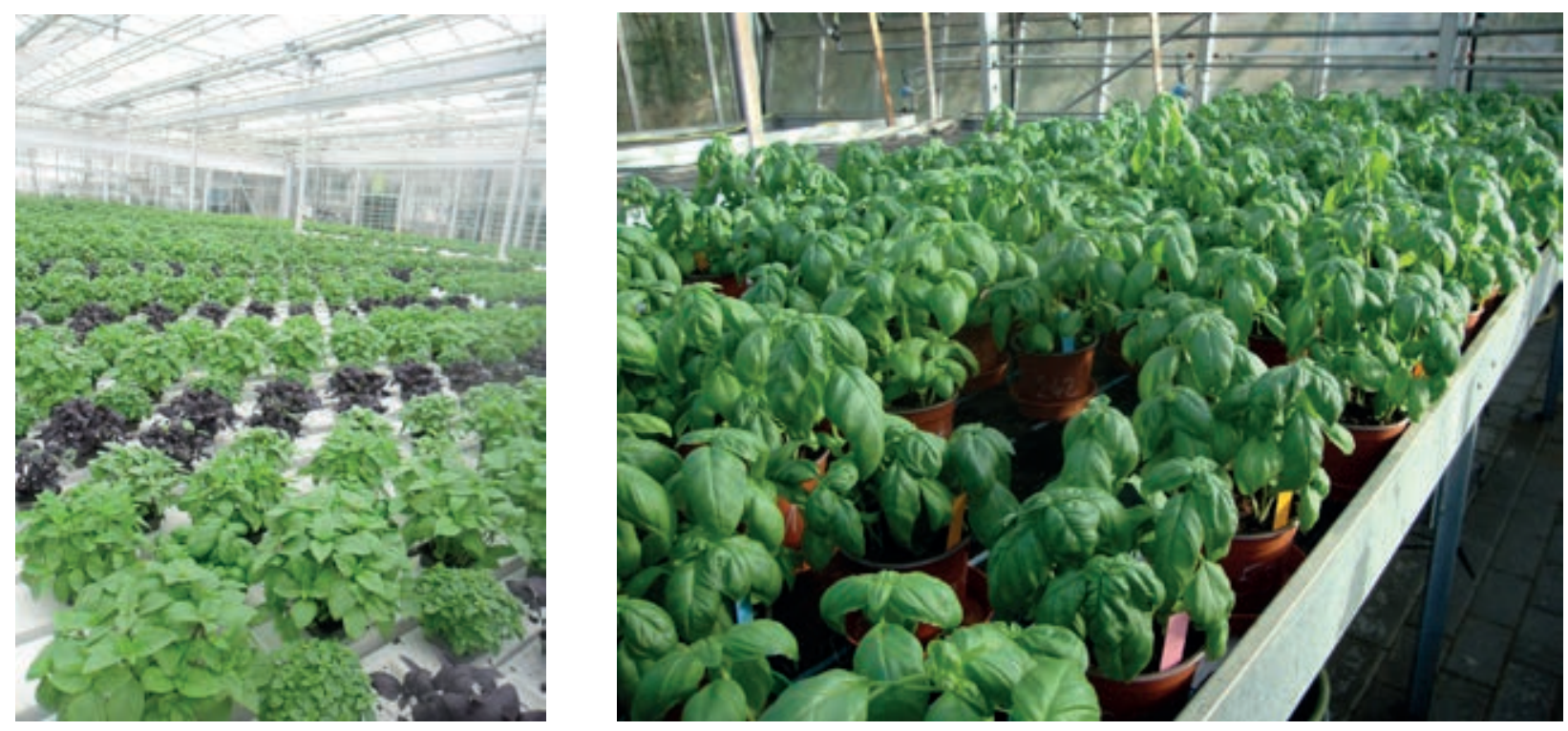

Figure 4.21 Basil grown in pots, on the greenhouse floor (left)or on benches (right). 
Table 4.61

Typical number of basil plants for trials using two pot sizes.

\begin{tabular}{lll} 
& Pots & Pots \\
Minimum number of plants/ core plot & $\varnothing 9 \mathrm{~cm}$ & $\varnothing 12 \mathrm{~cm}$ \\
\hline Minimum size core plot $\left(\mathrm{m}^{2}\right)$ & 15 & 15 \\
\hline Pot density / $\mathrm{m}^{2}$ & 0.5 & 0.6 \\
\hline Plants per pot & $30-35$ & 25 \\
\hline
\end{tabular}

\section{Table 4.63}

Temperature requirements for germination and growth of basil.

$\begin{array}{lll}\begin{array}{l}\text { Germination temperature }{ }^{\circ} \mathrm{C} \\ \text { Day/ Night }\end{array} & \text { Days until germination } & \begin{array}{l}\text { Optimal heating temperature for } \\ \text { Cultivation in }{ }^{\circ} \mathrm{C} \\ \text { Day/ Night }\end{array} \\ \begin{array}{lll}20 / 18^{\circ} \mathrm{C} \\ \text { Ventilation from } 22^{\circ} \mathrm{C}\end{array} & 5-8 & 18 / 16^{\circ} \mathrm{C} \\ \text { Ventilation from } 22-25^{\circ} \mathrm{C}\end{array}$

\section{Crop nutrition}

Table 4.64

Basil plant nutrient requirements.

\begin{tabular}{lllll} 
Pot size & $\mathrm{N}(\mathrm{mg} / \mathrm{pot})$ & $\mathrm{P}(\mathrm{mg} / \mathrm{pot})$ & $\mathrm{K}(\mathrm{mg} / \mathrm{pot})$ & $\mathrm{Mg}(\mathrm{mg} / \mathrm{pot})$ \\
$9 \mathrm{~cm}$ & 320 & 50 & 200 & 50 \\
\hline $12 \mathrm{~cm}$ & 750 & 100 & 300 & 100 \\
\hline
\end{tabular}

The nutrient requirement is dependent on the pot size and the number of plants per plot. If growing media with $20 \%$ compost is used additional phosphorus and potassium fertilisation is usually not needed. If necessary granulated organic fertiliser can be added. It should be noted that the nitrogen availability rate for organic fertilisers is estimated to be only about $60 \%\left(\mathrm{~N}_{\text {available }} / \mathrm{N}_{\text {total }}\right)$. If the growing period is longer than five weeks it is best to apply a supplementary feed of organic fertiliser (either in liquid or solid form).

\section{Crop management}

Pruning of shoots is not common (with the exception of perennial types) but it will prolong the cultivation time. Basil is sensitive to excessive water application.

\section{Disease and pest infestation, physiological disorders and other abiotic damage}

This list includes links to relevant EPPO Guidelines:

Colletotrichum leaf spots - Colletotrichum gloeosporioides (PP 1/121(2) Leafspots of vegetables)

Downy mildew - Peronospora behlbarii (PP 1/65(3) - Downy mildews of lettuce and other vegetables)

Sciarid flys (fungus gnat, Bradysia sp.) are common in basil crop:

Natural enemies, like Steinernema feltiae or bio control agents (Bacillus thuringiensis israelensis) should be applied preventively (drench application). Hypoaspis miles may useful in perennial basil.

The occurrence of other diseases and pests, like Fusarium, Botrytis, Rhizoctonia or pests like aphids or white flies should be recorded in the report. 


\section{Assessments during growth}

- Leaf colour ( 1 = very light green, $3=$ light green, $5=$ medium green, $7=$ dark green, $9=$ very dark green).

- Anthocyanin - in red-leafed varieties ( $1=$ absent or very weak, $3=$ low, $5=$ moderate, $7=$ strongly, $9=$ very strong).

- Leaf size - $(1=$ very small, $3=$ small, $5=$ moderate, $7=$ large, $9=$ very large $)$.

- Leaf blistering ( $1=$ absent or very weak, $3=$ low, $5=$ moderate, $7=$ strongly, $9=$ very strong $)$.

- Uniformity of crop ( $1=$ very poor, $3=$ low, $5=$ moderate, $7=$ strongly, $9=$ very uniform).

- Growth habit ( $1=$ very erect, $3=$ erect, $5=$ moderate, $7=$ compact, $9=$ very compact).

- Number of plants per pot (the number of plants should be counted in 5 pots of each treatment).

\section{Assessments at harvest}

The crop is usually harvested with a plant height of 12 to $15 \mathrm{~cm}$ (although this may vary depending on local requirements). Shoots are cut $0.5 \mathrm{~cm}$ above the growing media, from at least 10 pots. Plant height, fresh weight and dry weight should be measured. The leaves are very sensitive to pressure.

If intended for processing into a herbal drug then extra assessments may be carried out. According to the European Pharmacopoeia:

- Leaves without stems will be dried at maximum of $30^{\circ} \mathrm{C}$.

- Content of essential oil in $\mathrm{ml} / 100 \mathrm{~g}(\% \mathrm{v} / \mathrm{m})$.

- Content of estragol (in \% of essential oil).

\section{Overall value score}

This takes into account all criteria for the cultivation and marketing of a variety, based on expert opinion as evaluated by researchers using information from farmers, wholesalers and consumers ( $1=$ very low, $3=$ low, 5 $=$ medium, $7=$ high, 9 = very high).

\section{References and further information}

International Union for the Protection of New Varieties of Plants (UPOV). 2004.

Basil TG/200/1. www.upov.int 


\subsection{Perennial fruits}

\subsubsection{Strawberries}

\section{By Stella Cubison}

Botanical name: Fragaria sp., Fragaria $x$ ananassa

\section{General crop requirements}

Strawberries can be grown in the open field in most European climates, but they are also increasingly grown under protective structures. In most cases this will be a polytunnel. These are either permanent structures (they can last 3-10 years) or they are dismantled after every season in order to comply with planning regulations, as they are unpopular structures in certain rural settings. In some cases strawberries may also be grown in greenhouses under glass, but this is not common. Strawberry production is highly intensive due to the high input of labour required. Whilst most EU countries are capable of producing their own spring and summer crops, Spain is the principal Mediterranean country supplying strawberries to other countries during the winter months, but Portugal is also a relatively large producer. In Spain, over $90 \%$ of this production takes place in the SW corner of the country (Huelva region), which has a Mediterranean climate and high light levels. Similarly, most of the production in Portugal is concentrated in the South of the country, which includes the Ribatejo, Oeste, Alentejo and Algarve regions. However, only a small percentage of this production is organic.

Under UK conditions, June-bearing (short-day) rather than Ever-bearing varieties are more suited to trials work since there are more cultivars available, a greater choice of planting material and a quick turn-around is possible from planting to harvest. Harvest is also condensed into a shorter period of time (2-4 weeks). Flowering and harvest are also relatively unaffected by high temperatures. Such cultivars are equally suited to trials in other European and Mediterranean countries, and are often grown on an annual basis commercially during the winter months in countries with warm Mediterranean climates (such as Spain).

\section{Site and soil}

Strawberries require a medium sand- or silt-loam soil with high humus content for optimum performance, but can be grown successfully on a range of soil types, provided they are not poorly-drained and compacted. A soil $\mathrm{pH}$ of 6.0-6.5 is ideal. Strawberries require high levels of potassium. Low levels of phosphate and nitrogen can be tolerated, except during establishment. An application of bulky organic manure applied in early spring before planting should provide most nutrients required. Even under protected production, the most favourable site is on a gentle south-facing slope which is sheltered from strong winds and away from frost pockets.

\section{Experimental design}

It is best to use a trial with at least 3 replications. CPVO protocols recommend using at least two trials which will give satisfactory crops of fruit.

Strawberries grown under protection (in tunnels) commercially are usually grown on raised beds. Two rows per raised bed is best practice in organic systems, though higher densities (three-row-beds) are used in conventional production, using staggered planting. It is generally uneconomical to use raised beds for single rows. In intensive conventional systems, plants are also frequently grown in substrate in 'table top' systems where plants are grown in grow-bags on structures positioned at a convenient height for picking. Planting density tends to be higher in such systems (10 plants / $\mathrm{m}^{2}$ ).

A standard-sized polytunnel bay of about 8 metres will span five raised beds. Plants can also be grown as single rows on flat beds, but whilst this is fine for outdoor production it is obviously less economical for protected cropping. 

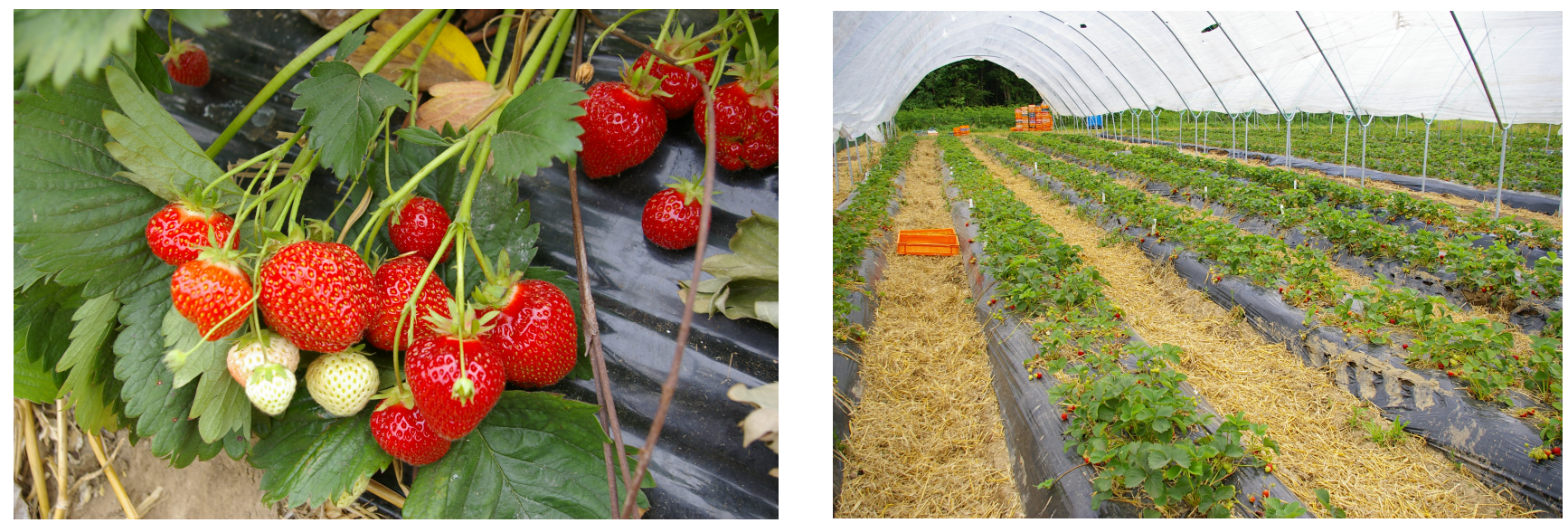

Figure 4.22 Strawberry production, on the right showing the use of raised mulched beds in England.

Table 4.65

Typical strawberry plant spacing and number of plants required for trials.

\begin{tabular}{ll} 
& $\begin{array}{l}\text { North \& Central / Mediterranean } \\
\text { Unheated }\end{array}$ \\
Minimum number of plants / core plot & 20 \\
\hline Minimum size of core plot $\left(\mathrm{m}^{2}\right)$ & 4 \\
\hline Plant density $\left(\right.$ plants $\left./ \mathrm{m}^{2}\right)$ & $4-5$ \\
\hline Row distance $(\mathrm{cm})$ & $\begin{array}{l}\text { Single rows: } 50-75 \mathrm{~cm} \\
\text { Double rows: } 30-35 \mathrm{~cm}^{*}\end{array}$ \\
\hline Triple rows: $20-25 \mathrm{~cm}^{*}$
\end{tabular}

*Usually grown on raised beds

Table 4.66

Typical strawberry planting and harvesting dates.

\begin{tabular}{llll}
$\begin{array}{l}\text { Region - } \\
\text { Production type }\end{array}$ & Planting material & Planting at & $\begin{array}{l}\text { Start of Harvest (Harvest } \\
\text { lasts 2-4 weeks) }\end{array}$ \\
$\begin{array}{l}\text { North \& Central } \\
\text { Unheated }\end{array}$ & $\begin{array}{l}\text { Fresh dug runners } \\
\text { Cold-stored runners }\end{array}$ & $\begin{array}{l}\text { February - April* } \\
\text { February - April }\end{array}$ & $\begin{array}{l}\text { May-June (year 2) } \\
\text { May-June ('60 day') }\end{array}$ \\
\hline $\begin{array}{l}\text { Long cycle (unheated) } \\
\text { Mediterranean }\end{array}$ & $\begin{array}{l}\text { Fresh dug runners } \\
\text { Cold-stored runners }\end{array}$ & $\begin{array}{l}\text { August - November } \\
\text { June-July* }\end{array}$ & $\begin{array}{l}\text { May-June } \\
\text { April-June }\end{array}$ \\
\hline $\begin{array}{l}\text { Spring cycle } \\
\text { Tray (fresh green) plants } \\
\text { Mediterranean }\end{array}$ & January & April-May \\
- Autumn cycle & $\begin{array}{l}\text { Tray (fresh green) plants } \\
\text { or fresh-dug runners }\end{array}$ & September-December & December-April \\
\hline
\end{tabular}

* Remove blossoms after planting in first year

June-bearing (short-day) varieties of strawberry are less affected by extremes of temperature than ever-bearing varieties, but tunnels and glasshouses should still be vented once temperatures exceed $26^{\circ} \mathrm{C}$ during the day. The optimum temperature range is between $15-25^{\circ} \mathrm{C}$ during flowering, for optimum pollination and between $21-26^{\circ}$ $\mathrm{C}$ for growth. Vents and covers should be rolled back to allow access by pollinating insects during warm weather at flowering. If there are no naturally-occurring pollinating insects around, it is advisable to use an artificial hive (one hive should be sufficient for a 1.5 ha area). 


\section{Fertilisation}

Depending on soil analysis, strawberries will benefit from a high nitrogen fertiliser during establishment (this can be applied through the irrigation system), switching to a high potassium feed thereafter, dependant on the needs of the crop. Little additional feed may be necessary during the growing season following manure applied to the soil before planting, but if the plants are to remain (and crop) in place for more than a year, supplementary feeding will be required the following year(s) in the form of permitted organic fertilisers or foliar feed.

Table.4.67

Strawberry plant nutrient requirements.

\begin{tabular}{lllll}
$\begin{array}{l}\text { Yield expectation } \\
\left(\mathrm{kg} / \mathrm{m}^{2}\right)\end{array}$ & $\mathrm{N}\left(\mathrm{g} / \mathrm{m}^{2}\right)$ & $\mathrm{P}\left(\mathrm{g} / \mathrm{m}^{2}\right)$ & $\mathrm{K}\left(\mathrm{g} / \mathrm{m}^{2}\right)$ & $\mathrm{Mg}\left(\mathrm{g} / \mathrm{m}^{2}\right)$ \\
\hline 1.8 & 6 & 2 & 10 & 1 \\
\hline 4 & 14 & 4.5 & 22 & 2 \\
\hline
\end{tabular}

Source: adapted from various sources, see Annex B. Leaf nutrient content is given in Appendix C.

\section{Irrigation}

It is usual practice to use a trickle irrigation system beneath plastic mulch, along the crop rows. Overhead irrigation may be used during plant establishment, but after this trickle irrigation is preferred in order to avoid botrytis (grey mould) infection. Plants should be kept irrigated in hot weather and also after fruiting, if the plants are to be allowed to remain in the ground to fruit the following year.

\section{Harvest}

Straw (preferably organic or untreated) is used to keep the rows clean and to keep fruit away from contact with the soil. Straw is laid just prior to fruit ripening. Once ripe, the berries will need picking over regularly (daily in hot weather) and the fruit cooled as quickly as possible after harvest to remove field heat. Fruit is best picked early in the morning. After harvest, the foliage above the crowns of the plant should be mown off $(2.5 \mathrm{~cm}$ above the crown) to reduce the incidence of disease and to encourage the plants to produce fresh leaves and to build reserves for the following year's crop. Runners should also be removed. If the plants are at the end of their cropping life, they can be removed or incorporated deep into the soil, to prevent regrowth.

\section{Diseases and pests}

- Powdery mildew (Sphaerotheca macularis).

- Grey mould (Botrytis cinerea).

- Post-harvest rots (e.g. Mucor spp., Cladosporium spp., Rhizopus spp.,).

- Verticillium wilt (Verticillium dahliae).

- Phytophthora spp: red core (Phytophthora fragariae var. fragariae) \& crown and leather rot (Phytophthora cactorum).

- Spider mites (Tetranychus urticae, Phytonemus pallidus fragariae).

- Slugs / Snails.

- Aphids spp. (e.g. Chaetosiphon fragaefolii, Myzus ascalonicus, Macrosiphum euphorbiae, Aphis gossypii).

- Blossom weevil (Anthonomus rubi).

- Spotted wing drosophila (Drosophila suzukii).

- European Tarnished plant bug (Lygus rugulipennis).

- Common Green Capsid (Lygocoris pabulinus).

- Vine weevil (Otiorhynchus sulcatus).

- Western flower thrip (Frankliniella occidentalis).

- Nematodes spp. (Longidorus, Xiphenema, Ditylenchus, Aphelenchoides).

A comprehensive database of strawberry pests and diseases is available from www.eppo.int (European \& Mediterranean Plant Protection Organization). UK-specific information on strawberry pests and diseases is also available in the 'Strawberry Crop Walker's Guide' (available from the HDC). 


\section{Assessments during crop growth}

Plant growth assessments could be carried out soon after planting, during flowering and just before or at harvest by measuring the plant diameter (two ways across each plant). Other parameters to be recorded may include:

- Plant height, vigour and growth habit, health and number of leaves (foliage density).

- Runner (stolon) production.

- Inflorescence (number of flowers).

- Leaf mineral analysis (and possibly soil analysis) might be desirable at flowering and/ or harvest.

- Visual estimation of Verticillium wilt and Powdery mildew can be carried out by counting the number of plants showing disease symptoms. Other pests and diseases are likely to be more localised and could just be noted if seen, unless a full assessment of pest / disease infestation and effect on quality and yield is desirable.

\section{Assessments at harvest}

Evaluating the yield of a strawberry harvest requires much manual labour. Plants need to be hand-picked every 2-3 days (minimum) for approximately four weeks, until harvest ceases. It is generally easier to record the yield of Class $1 \& 2$ fruits from each plot, taking sub-samples from a smaller number of plants to examine fruit quality in more detail (e.g. fruit number, weight and reasons for pest/disease damage). At each picking, it is easier to remove everything other than unripe fruit. Rotten/diseased/damaged fruit must be removed to avoid contaminating ripening berries. Scales and punnets will need to be on-site during harvest. Fruit size, shape, colour, firmness and sugars/soluble solids ( ${ }^{\circ}$ Brix) can be recorded for a detailed variety trial, otherwise this is often done by eye by the farm's pickers, who pick and grade simultaneously. Further information on what to assess can be found in the CPVO protocols for the evaluation of strawberry crops; (www.cpvo.europa.eu).

\section{References and further information}

http://www.eppo.int (European \& Mediterranean Plant Protection Organization - EPPO)

http://cpvo.europa.eu (Community Plant Variety Office - CPVO)

Alford, D.V. 1999,

'A Colour Atlas of Fruit Pests' (Manson Publishing Ltd). ISBN 0723408165

HDC / AHDB (2013):

Crop Walkers' Guide - 'Strawberry,' available from www.hdr.org.uk.

Berry Yearbook \& Buyers Guide - Published annually in UK by ACT Publishing (www.actpub.co.uk)

International Union for the Protection of New Varieties of Plants (UPOV). 2004.

Strawberry TG/22/10. www.upov.int 


\subsubsection{Raspberries}

\section{By Carolyn Mitchell and Nikki Jennings}

Botanical name: Rubus idaeus

\section{General crop requirements}

Organic raspberries are typically grown under polytunnels in the UK and Europe. Open field production is also possible (without covers) for small-scale growers supplying local markets and pick-your-own enterprises, although use of temporary tunnels ensures better fruit quality and season extension. As with strawberry production, Spain and Portugal are the largest producers of conventionally-grown raspberries in a Mediterranean climate. Much of this fruit is exported to supply 'off-season' fruit to North and Central European countries between autumn and spring from annual cropping using long-cane planting material, but this practise is not carried out to any great extent for organic crops.

Production costs of raspberries are high since they are labour intensive in terms of harvesting and general husbandry and a trellis system is required to support the plants. Floricanes and primocanes are both suited to trial work but they should be assessed independently. Floricane (Summer-fruiting) varieties produce vegetative canes in their first year of growth, before flowering and fruiting on two-year-old canes. The fruited canes are then cut down after harvest, leaving the new canes to be tied in to the supporting wires. Primocane (Autumnfruiting) varieties produce new canes which flower and fruit within the same year. They crop in late summer - autumn, but the canes can also be pruned to encourage a second flush of early fruit the following spring - a technique known as 'double cropping' (although this is rarely carried out in organic production). If not 'double cropped' the cane is cut down during late winter - early spring following cropping. This helps to stimulate the production of new canes almost immediately. These guidelines have been written primarily for floricane production. Harvest time is very dependent on variety chosen and this should be taken into consideration. The plants must be sourced from known healthy stocks e.g. certified stock.

\section{Site and soil}

Raspberries require a sandy loam soil with good drainage. A soil pH of 5.6-6.2 is required. Raspberries require $\mathrm{N} 3: \mathrm{P} 2: \mathrm{K} 9$ during establishment with additional potassium during fruiting. It is preferred that the ground has not previously been used for raspberry production to reduce the possibility of soil-borne pathogens. The most favourable site is a gentle south-facing slope which is sheltered from the wind. In conventional production there is a move towards using coir-based substrate in the UK and Europe to reduce the infection by soil borne pathogens, especially Phytophthora root rot, but organic growers are not permitted to use this soil-less growing method.

\section{Experimental design}

\section{Table 4.69}

Typical raspberry plant spacing and number of plants required for trials.

\begin{tabular}{ll} 
& $\begin{array}{l}\text { North \& Central } \\
\text { Unheated }\end{array}$ \\
Minimum number of plants per trial plot & $5-10$ \\
\hline Number of replicates & 4 \\
\hline Cane density (plants $\left./ \mathrm{m}^{2}\right)$ & $6-8$ \\
\hline Distance between plants $(\mathrm{cm})$ & 60 \\
\hline
\end{tabular}


Raspberries are grown on raised beds to maintain good drainage. For experimental purposes, the use of mulch is discouraged to ensure that adjacent genotypes remain physically distinct. A distance of $120 \mathrm{~cm}$ is left between genotypes, also preventing potential mixing of genotypes. An eight metre polytunnel will span three rows with 2.5 metres between rows.

\section{Planting and temperature requirements}

\section{Table 4.70}

Typical raspberry planting and harvest dates.

\begin{tabular}{lllll} 
Cultivation period & Planting material & Planting at & Start of Harvest & Pruning \\
$\begin{array}{l}\text { North \& Central } \\
\text { Spring-Summer }\end{array}$ & $\begin{array}{l}\text { Floricanes - short } \\
\text { cane (bare root) or } \\
\text { potted short cane }\end{array}$ & $\begin{array}{l}\text { Nov - March } \\
\text { (uncovered until }\end{array}$ & $\begin{array}{l}\text { Jeb) } \\
\text { June - August (year }\end{array}$ & $\begin{array}{l}\text { Fruited canes cut } \\
\text { after harvest }\end{array}$ \\
\hline $\begin{array}{l}\text { North \& Central } \\
\text { Spring-Autumn }\end{array}$ & $\begin{array}{l}\text { Short cane } \\
\text { (primocane } \\
\text { varieties) }\end{array}$ & $\begin{array}{l}\text { Nov - March } \\
\text { (uncovered until } \\
\text { Feb) }\end{array}$ & August onwards* & $\begin{array}{l}\text { All canes cut in late } \\
\text { winter - early spring }\end{array}$ \\
\hline
\end{tabular}

*Light crop only to be expected in establishment year/s

Tunnels should be vented once temperatures exceed $28^{\circ} \mathrm{C}$ during the day. The optimum temperature range is between $15-25^{\circ} \mathrm{C}$ during flowering, for optimum pollination and between $21-26^{\circ} \mathrm{C}$ for growth. Pollination usually involves introduced hives of bumble bees which have been sourced responsibly. This is particularly important in cooler climates where the doors on the tunnels must be closed during the flowering period.

\section{Fertilisation and Irrigation}

Having been planted into a well-prepared bed (incorporating the use of compost or manure if appropriate), it is advisable to continue to provide raspberry canes with a N3:P2:K9 fertiliser during the critical period of establishment. This can be applied when required as a liquid feed through the irrigation system. During the fruiting year the plants are fed with a N3:P2:K9 fertiliser between May-August with additional potassium fertiliser during flowering. Additional feeds may be necessary depending on the needs of the crop. Any deficiencies require addition of micronutrients in the form of foliar feeds. All fertilisers and foliar feeds used must be permitted for organic production and will usually consist of products derived from seaweed, vegetable waste or chicken manure (sourced from non-intensive farms).

It is usual practice to use a trickle irrigation system at soil level. Soil moisture levels must be monitored and irrigated accordingly. Too much moisture results in unhealthy roots and poor fruit quality (especially concerning flavour).

\section{Harvest}

Once ripe, the berries are required to be picked every 2-3 days and the fruit cooled as quickly as possible after harvest to retain freshness. After harvest is complete, old fruiting canes from floricane varieties should be removed and new canes selected for cropping the following year. Approximately 6-8 canes per metre are selected, ensuring any which are damaged, diseased or have excessively large or small diameters are removed. The selected canes must be tied into the support system during winter. Once the plants are established in the spring of year two, the first flush of primocane growth may be removed (up to a height of $15 \mathrm{~cm}$ ) to balance resources between fruiting and vegetative canes. Old, fruited canes from primocane (autumn fruiting) varieties are cut down to soil level in late winter / early spring following fruiting to stimulate the production of new canes which will carry the next crop. 


\section{Diseases and pests}

- Powdery mildew - Sphaerotheca macularis

- Cane botrytis - Botrytis cinerea

- Spur blight - Didymella applanata

- Cane blight - Leptosphaeria coniothyrium

- Raspberry root rot - Phytophthora rubi

- Verticillium wilt - Verticillium spp.

- Raspberry yellow rust - Phragmidium rubi-idaei

- Crown gall - Agrobacterium spp.

- Post-harvest rots e.g. Cladosporium spp., Mucor spp., Rhizopus spp., Botrytis spp.

- Aphid species - Amphorophora idaei, Aphis idaei, Macrosiphum euphorbiae

- Black vine weevil - Otiorhynchus sulcatus

- Spotted wing drosophila - Drosophila suzukii

- Raspberry leaf and bud mite - Phyllocoptes gracilis

- Two spotted spider mite - Tetranychus urticae

- Raspberry beetle - Byturus tomentosus

- Earwigs - Forficula auricularia

- Cane midge - Resseliela theobaldi

\section{Assessments during crop growth}

The following plant growth assessments can be carried out throughout the year.

- Plant habit - vigour, primocane number and height

- Presentation of fruit - lateral length and strength

- Cane spine density or absence

- Cane splitting

- Crop development - date of bud break and first flower

- Visual estimation of any serious pest or disease incidence

\section{Assessments at harvest}

Plants need to be hand-picked every 2-3 days for the duration of fruit production. Assessments are made once a week on fruit size (weight), total yield and ${ }^{\circ}$ Brix level (soluble solids). An arbitrary score is used to record firmness, flavour and colour. Shelf life can be assessed through the season by picking a small sample which is stored at $4^{\circ} \mathrm{C}$ and assessed for post-harvest appearance, firmness and rot after 4-7 days.

\section{References and further information}

International Union for the Protection of New Varieties of Plants (UPOV). 2004.

Raspberry TG/43/7. www.upov.int
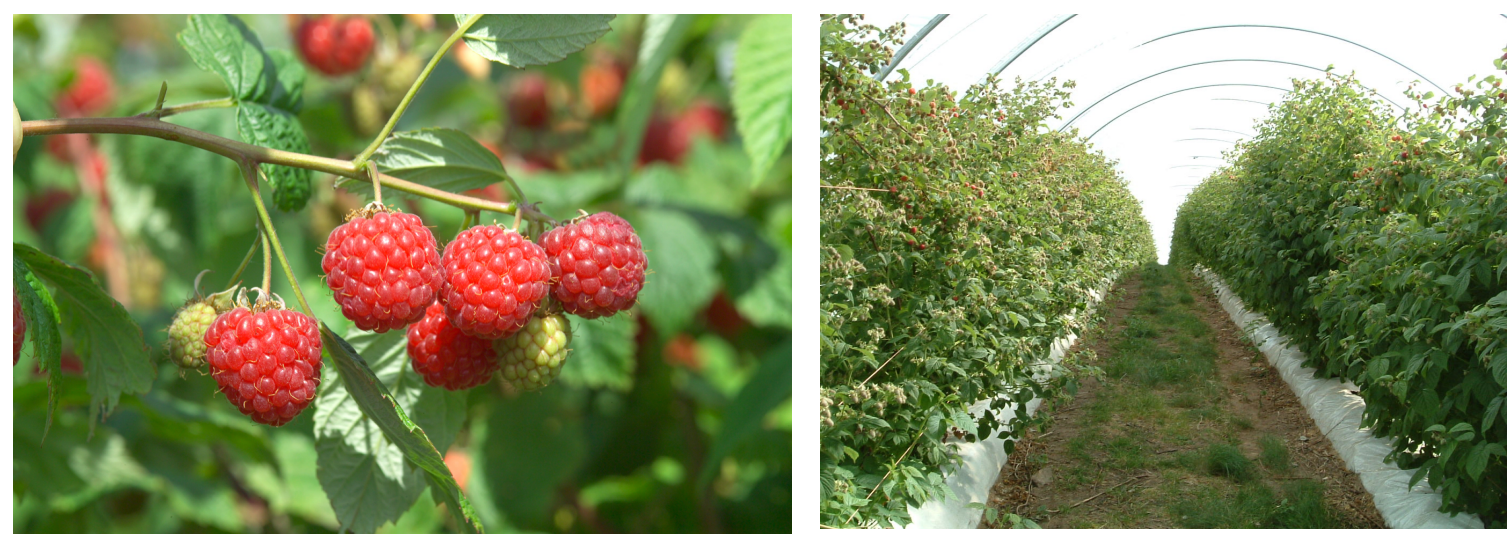

Figure 4.23 Raspberry fruit (left) and commercial production in polytunnels in Scotland (right). 


\subsubsection{Table grapes}

\section{By Samih Abu Baker}

European grapes: Vitis vinifera

American grapes: Vitis labrusca

\section{General crop requirements}

Grapes can grow and survive in areas where the temperature goes well below freezing in the winter; some grape species can survive temperatures as low as $-40^{\circ} \mathrm{C}$. However, Vitis vinifera is much more tender and cannot withstand temperatures below $-15^{\circ} \mathrm{C}$. The threshold of $10^{\circ} \mathrm{C}$ is used for grapevines to calculate growing degree day (GDD) because there is little biological activity in plants below this temperature. Grapes prefer a sunny site with well-drained soil. Clay soils should be amended with organic matter (compost or manure).

\section{Experimental design}

For field experiments, a randomized complete block design is used with a minimum number of blocks with a predetermined number of vines for each block. Pot experiments are also utilized for salinity research.

\section{Planting and cultural practices}

Common ways to plant vines are with a mechanical furrow planter, an auger, or by hand with a spade. The use of tree planters is not recommended as correct positioning of the roots is not possible; roots should not be bent upwards in the hole or furrow as this discourages growth and can result in root diseases, such as blackfoot (Cylindrocarpon and Campylocarpon spp.), becoming established. After planting, and after new growth first appears, prune the plant back to two buds on each stem. Grapes need some type of support such as a fence, arbour, trellis, or horizontal wires between posts set between 2 and $2.7 \mathrm{~m}$ apart. For the first year, a large depression should be left around the plant to allow for ample watering. Mulch with bark or compost for the first two years or until the plant is well established.

\section{Training, trellising and pruning}

Trellising is the art of arranging the vine in a designated space. The goals are to maximize light interception, to minimize the number of additional inputs (e.g. labour, material costs, maintenance, etc.), to provide physical support and to be compatible with the management situation, which includes machinery. Types of support system and factors to consider include:

- Self- or stake-supported systems.

- Single wire system.

- Hedge-type system.

- Systems which divide the canopies (Geneva Double Curtain "GDC", Lyre System, Vertical Shoot Positioning "VSP", Scott-Henry, Smart-Dyson). Often these will separate vegetative and fruiting areas.

- Other trellising systems (pergola and parronal).

- Vineyard floor management.

- Frost management.

- Canopy management.

The goal for canopy management is to optimize light interception by both leaves and fruit. It can be achieved by:

- Shoot thinning.

- Shoot positioning.

- Shoot topping and hedging.

- Leaf removal.

The principal method of pruning is cane and spur (also known as cordon pruning). The aims of pruning are to:

- Establish / maintain the vine in the desired form.

- Produce fruit of the target composition.

- Select nodes that will produce fruitful shoots.

- Regulate shoot number/crop load.

- Regulate vegetative growth. 
The most significant fact to remember is that all fruit will develop on shoots that come from buds on the previous year's growth. The bark of last year's growth is smooth. All previous, and now unproductive wood, has rough bark. Each year in spring, prune last year's growth back to leave only two, three, or four buds. These buds will produce long shoots and bear fruit. Once fruit is set, canes producing clusters of grapes need to be pruned back to allow only two leaves beyond the last cluster of grapes. This helps direct the vine's energy into producing grapes rather than growing more leaves.

\section{Pollination}

Pollination is mostly by wind, though insects may also contribute. Self-pollination is the norm, though some studies have suggested that cross-pollination results in bigger fruit and higher seed counts.

\section{Irrigation}

In some areas, natural rainfall is sufficient for commercial production of grapes and even for the establishment of young vines. In other areas application of supplementary water is necessary. Water may be applied by hand, by flood irrigation or some type of tubular drip irrigation water system. Overhead sprinkler irrigation is not recommended for grape production due to the adverse effect it has on disease incidence. Irrigation with a lateral tube with built-in emitters is also utilized.

\section{Weeding}

Weeds can be prevented from growing, or be destroyed at a critical growth stage, usually by cultural or mechanical methods.

\section{Disease and pest problems, physiological disorders and other abiotic damage}

\section{Fungal diseases:}

- Botrytis bunch rot or grey mould - Botrytis cinerea.

- Powdery mildew - Erysiphe necator.

- Downy mildew - Plasmopara viticola.

- Cane and leaf spot - Phomopsis viticola.

- Eutypa dieback - Eutypa lata.

- Black rot - Guignardia bidwellii.

- Anthracnose - Elsinoe ampelina.

- Blackfoot disease - Cylindrocarpon \& Campylocarpon spp.

\section{Bacterial diseases:}

- Pierce's disease - Xylella fastidiosa.

- Crown gall - Agrobacterium tumefaciens.

\section{Viral diseases:}

- Grapevine fanleaf virus "GFLV" - genus Nepovirus.

- Grapevine leafroll virus - genus Closterovirus.

\section{Insects:}

- Phylloxera - Phylloxera vitifoliae.

- Leafhoppers - Empoasca spp.

- Grapevine moth - Lobesia botrana.

- Mealybugs - Planococcus spp.

- Grape berry moth - Paralobesia viteana.

- Thrips - various species including Drepanothrips and Frankliniella spp.

- Vine leaf beetle - Bromius obscurus.

- Mites - various species including Panonychus and Tetranychus spp. 


\section{Other pests:}

- Nematodes (various species including Meloidogyne and Xiphinema).

- Vine-grazing pests (deer, rabbits etc.).

- Berry-eating pests (e.g. rodents etc.).

\section{Disorders:}

- Nutritional disorders (e.g. mineral deficiencies).

- Environmental disorders (drought, excess water, heat, winter injury, spring freeze.

- hail, salt and air pollution).

For a detailed description of diseases and pests on vines see the European and Mediterranean Plant Protection Organization website: http://www.eppo.int.

\section{Assessments at harvest}

The timing of harvest has perhaps the greatest impact on grape composition. Therefore, knowing what the grapes are going to be used for is vital in determining when and how to harvest. The harvesting method is also of importance to product quality. In some cases, hand harvesting is required and machine harvesting is not acceptable.

Conventional crop estimation depends upon a reasonably accurate projected bunch size. The average weight per bunch for a given cultivar harvested from a particular vineyard is crucial to good crop estimation. The more years for which data have been acquired (a sort of "track record"), the better the accuracy of crop estimation.

\section{Information required:}

Number of bunches per vine. Select a random sample of vines (equivalent to $5 \%$ of the vineyard is recommended), count the number of bunches for each vine and determine the average number of bunches per vine (sample at least 20 vines).

Number of bearing vines per hectare (e.g. 1090 vines/ha at $2.4 \mathrm{~m} \times 3.6 \mathrm{~m}$ spacing or 1300 vines/ha at $2.4 \times 3 \mathrm{~m}$ spacing).

The average cluster weight for that cultivar from that vineyard (in $\mathrm{kg}$ ).

The simple formula is:

Yield $=$ Clusters per vine $\mathrm{x}$ vines hectare $\mathrm{x}$ weight per cluster

The harvested crop is sorted quantitatively according to recognised quality standards into marketable and nonmarketable fractions. The non-marketable crop is categorised according to the main reasons for its rejection (weight, berry size, rot, etc.).

Further parameters to measure might include:

- Quality of the grapes (e.g. ${ }^{\circ}$ Brix using a refractometer).

- The size and the form of the berries.

- The amount of seeds in berries.

- Colour of berries.

\section{Overall value score}

This takes into account all criteria for the cultivation and marketing based on expert opinion as evaluated by researchers using information from farmers, wholesalers and consumers ( 1 = very low , $3=$ low, $5=$ medium, 7 = high , 9 = very high).

\section{References and further information}

Glen L. Creasy and Leory L. Creasy. Grapes. 2009.

CABI International.

University of Nebraska - Lincoln,

Department of Agronomy and Horticulture website (www.agronomy.unl.edu) - details of the Viticulture Programme can be found under the Horticulture/Crops section. 


\subsubsection{Papaya}

\section{By Virginia Pinillos}

Botanical name: Carica papaya

Common names: papaya, pawpaw

\section{General crop requirements}

Papaya is a semi-woody, latex-producing, usually single-stemmed and short-lived perennial herb. The plant can live up to 20 years but it is normally cultivated in 24-36 months cycles. Major commercial production of papaya is found primarily between $23^{\circ} \mathrm{N}$ and S latitudes, but it is also grown, especially in greenhouses, in higher latitudes (up to $32^{\circ}$ ). The papaya plant is a tropical species very sensitive to frost with high thermal requirements to grow, develop and ripen fruits. Normal growing and development occurs between $21-33^{\circ} \mathrm{C}\left(22-28^{\circ} \mathrm{C}\right.$ optimum). Greenhouses would normally be heated to $25-30^{\circ} \mathrm{C}$ (day) and $11-16^{\circ} \mathrm{C}$ (night).

Low temperatures $\left(<17^{\circ} \mathrm{C}\right)$ favour carpellody (a plant disorder that results in misshapen fruits caused by abnormal development of the ovule-bearing part of the flower) and a decrease in fruit size and sweetness; high temperatures $\left(>35^{\circ} \mathrm{C}\right)$ favour female sterility. High relative humidity is required $(>65 \%)$. Papaya grows best in well-drained, aerated soils rich in organic matter. It is easily killed by an excess of soil moisture. The optimum $\mathrm{pH}$ ranges between 5.5 and 7. Papaya is moderately sensitive to salinity in the soil or the irrigation water ( $2 \mathrm{dS} / \mathrm{m})$.
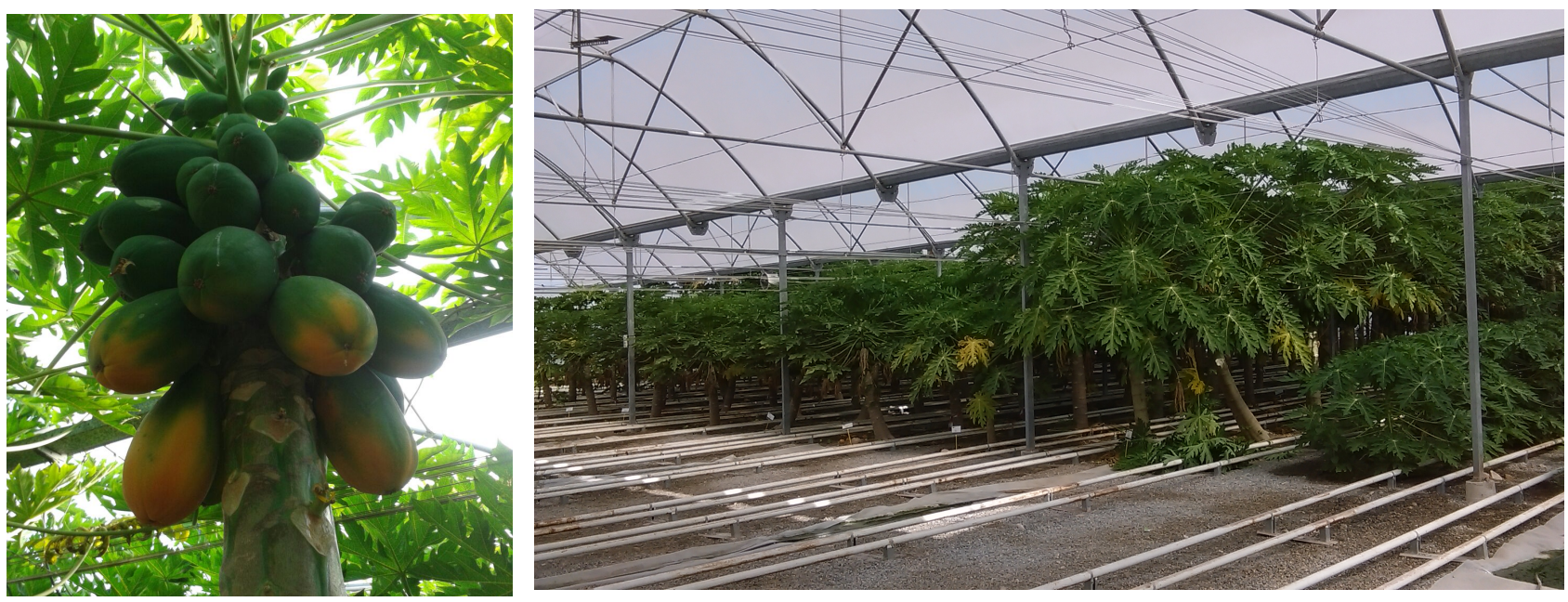

Figure 4.24 Papaya fruit (left) and commercial production in polytunnels in Spain (right).

\section{Experimental design}

Recommended replicates: at least three. 
Table 4.71

Typical papaya plant spacing and number of plants required for trials.

Mediterranean

Unheated

\begin{tabular}{ll} 
Minimum number of plants/ core plot & 5 \\
\hline Minimum size of core plot $\left(\mathrm{m}^{2}\right)$ & 15 \\
\hline Plant density / $\mathrm{m}^{2}$ & $0.17-0.22$ \\
\hline Row distance $(\mathrm{m})$ & $2-3$ \\
\hline Distance within the row $(\mathrm{m})$ & $1.5-2$
\end{tabular}

\section{Sowing and planting}

Papaya is propagated mostly through seeds although vegetative propagation methods may be used (cutting, grafting or micropropagation).

Planting may be done at different times of year depending on local conditions and growers preferences. First fruit maturation may occur 7-10 months after planting. In subtropical climates the fruit set declines during the colder winter months.

Table 4.72

Typical papaya sowing and harvesting times.

\begin{tabular}{|c|c|c|c|c|}
\hline $\begin{array}{l}\text { Region } \\
\text { - Production type }\end{array}$ & Sowing at & Planting at & Start of harvest & End of harvest \\
\hline \multirow{3}{*}{$\begin{array}{l}\text { Mediterranean } \\
\text { Greenhouses } \\
\text { (and Canary Islands) }\end{array}$} & April - May (year I) & June - July (year I) & $\begin{array}{l}\text { March - April } \\
\text { (year II) }\end{array}$ & $\begin{array}{l}\text { November } \\
\text { (year III) }\end{array}$ \\
\hline & $\begin{array}{l}\text { September } \\
\text { (year I) }\end{array}$ & $\begin{array}{l}\text { November } \\
\text { (year I) }\end{array}$ & $\begin{array}{l}\text { November } \\
\text { (year II) }\end{array}$ & $\begin{array}{l}\text { November } \\
\text { (year III) }\end{array}$ \\
\hline & $\begin{array}{l}\text { Jan - Feb } \\
\text { (year I) }\end{array}$ & March - April (year I) & $\begin{array}{l}\text { Nov - Dec } \\
\text { (year I) }\end{array}$ & $\begin{array}{l}\text { November } \\
\text { (year III) }\end{array}$ \\
\hline
\end{tabular}

\section{Table 4.73}

Temperature required for production of papaya seedling and plants.

$\begin{array}{llll}\begin{array}{l}\text { Germination } \\ \text { temperature } \\ { }^{\circ} \mathrm{C}\end{array} & \begin{array}{l}\text { Days until } \\ \text { germination }\end{array} & \begin{array}{l}\text { Temperature for } \\ \text { seedlings in }{ }^{\circ} \mathrm{C} \\ \text { (day / night) }\end{array} & \text { Pots } \\ 25-30 * & 7-21 & \begin{array}{l}25-30 / \\ 11-16\end{array} & \begin{array}{l}10 \mathrm{~cm} \text { diameter } \\ \text { pot with growing } \\ \text { media }\end{array}\end{array}$

*Seed germination is improved by the removal of the sarcotesta (the fleshy seed coat) or gibberellic acid application.

Table 4.74

Papaya plant nutrient requirement.

\begin{tabular}{lll}
$N$ & $P$ & $K$ \\
$180 \mathrm{~g}$ plant / year & $35 \mathrm{~g}$ plant / year & $224 \mathrm{~g}$ plant / year \\
\hline
\end{tabular}

It is particularly important that sufficient $\mathrm{K}$ is available during fruit development 


\section{Crop management}

Papaya plants can be hermaphrodite, monoecious or dioecious; a change of sex may even occur depending on temperature. For cultivation hermaphrodite plants (self-pollinated) are preferred. Because the sex of the plant is not known until flowering, additional plants need to be planted in each planting hole (3-4 plants if growing hermaphrodite plants is intended). Later, after the first flowering, undesired female plants are thinned and only one hermaphrodite plant is kept.

Papaya plants are not pruned because their main growing point is terminal, and branched trees do not produce as well. Leaf removal is recommended to increase ventilation. Fruit thinning to avoid overcrowding may be needed to improve fruit quality. Also, abnormal flowers and misshapen fruits must to be removed as soon as possible.

Drip and micro-sprinklers are recommended for irrigating papaya (5-12 I per plant per day). Overhead sprinklers may be useful to increase relative humidity.

\section{Disease and pest problems and physiological disorders}

\section{Diseases:}

- Oidium - Oidium caricae.

- Root/shoot rot - Phytophthora palmivora.

- Anthracnose - Colletotrichum gloeosporioides.

- PRSV (Papaya Ring Spot Virus).

\section{Pests:}

- White fly - Trialeurodes vaporariorum.

- Broad mite - Polyphagotarsonemus latus.

- Red mite - Tetranychus spp.

- Mealybug - Pseudococcus grasii.

- Banana moth - Opogona sacchari.

- Nematodes - Meloidogyne spp. (causes root nodules).

\section{Physiological disorders:}

- Skin freckle - the cause is unknown but related to low temperatures, high daily thermal oscillation, and high relative humidity.

\section{Assessments during growth}

These can include:

- Plant height.

- Leaf production rate.

- Stem diameter.

- Time and height of initial bearing.

- Number of flowers and fruits per node.

- Incidence of carpellody and sterility.

- Resistance to papaya spot virus.

\section{Assessments at harvest}

Papaya is a climacteric fruit. Fruit must be harvested after the colour begins to change but before it becomes fully yellow. Fruit must reach at least $11.5^{\circ}$ Brix (it does not increase in sweetness after harvest). The size depends on the variety.

The harvest is divided according to recognised quality standards for marketable and non- marketable produce. The non-marketable crop is sorted by the main reasons for rejection (e.g. diseased fruits, insect-damaged fruits, fruits with skin bruises, latex burn and mechanical injuries, shrivelled and discoloured fruits). The yield can be expressed as number of fruits/plant, $\mathrm{kg}$ fruits/plant or $\mathrm{kg} / \mathrm{ha}$. 
Specific aspects of crop quality can be evaluated quantitatively or using a 1-9 scale:

- Length, diameter and weight of the fruit.

- Soluble solids content ( ${ }^{\circ} \mathrm{Brix}$ ).

- Colour of the skin.

- Freedom of defects (sunburn, skin abrasions, pitting, blotchy coloration).

- Freedom of decay.

- Colour of flesh.

- Flesh and skin firmness.

\section{Overall value}

The overall takes into account all criteria for the cultivation and marketing of a variety, based on expert opinion as evaluated by researchers using information from farmers, wholesalers and consumers ( $1=$ very low, $3=$ low, 5 = medium, 7 = high, 9 = very high).

\section{References and further information}

Jiménez, V. M., Mora-Newcomer E., Gutierrez-Soto, M.V. 2014.

Biology of the Papaya Plant. In: Genetics and Genomics of the Papaya, Plant Genetics and Genomics:

Crops and models, R. Ming and P.H. Moore (eds.). DOI 10.1007/978-1-4614-8087-7_2, (C Springer Science+Business Media New York.

Marin, S.L.D., Gomes, J.A., Salgado, J.S., Martins, D.S., Fullin, E.A. 1995.

Recomendações para a cultura do mamoeiro dos grupos Solo e Formosa no Estado do Espírito Santo. 4.ed. Vitória: EMCAPA, 57p.

Morton, J. 1987.

Papaya. https://www.hort.purdue.edu/.../morton/papaya_ars. html

International Union for the Protection of New Varieties of Plants (UPOV). 2004.

Papaya TG/264/1. www.upov.int 


\subsubsection{Mango}

\section{By Ulrich Schmutz}

\section{Botanical name: Mangifera indica}

\section{Origin, Common Name, Botanical Name and Family}

The mango is one of the oldest cultivated plants and is considered to be the most ancient fruit of the Indian subcontinent. The main commercial mango cultivars are from the species Mangifera indica. M. indica is only one of about 70 tropical tree species in the genus Mangifera, from which more than 30 species are reported to produce edible fruit and could be used as rootstocks.
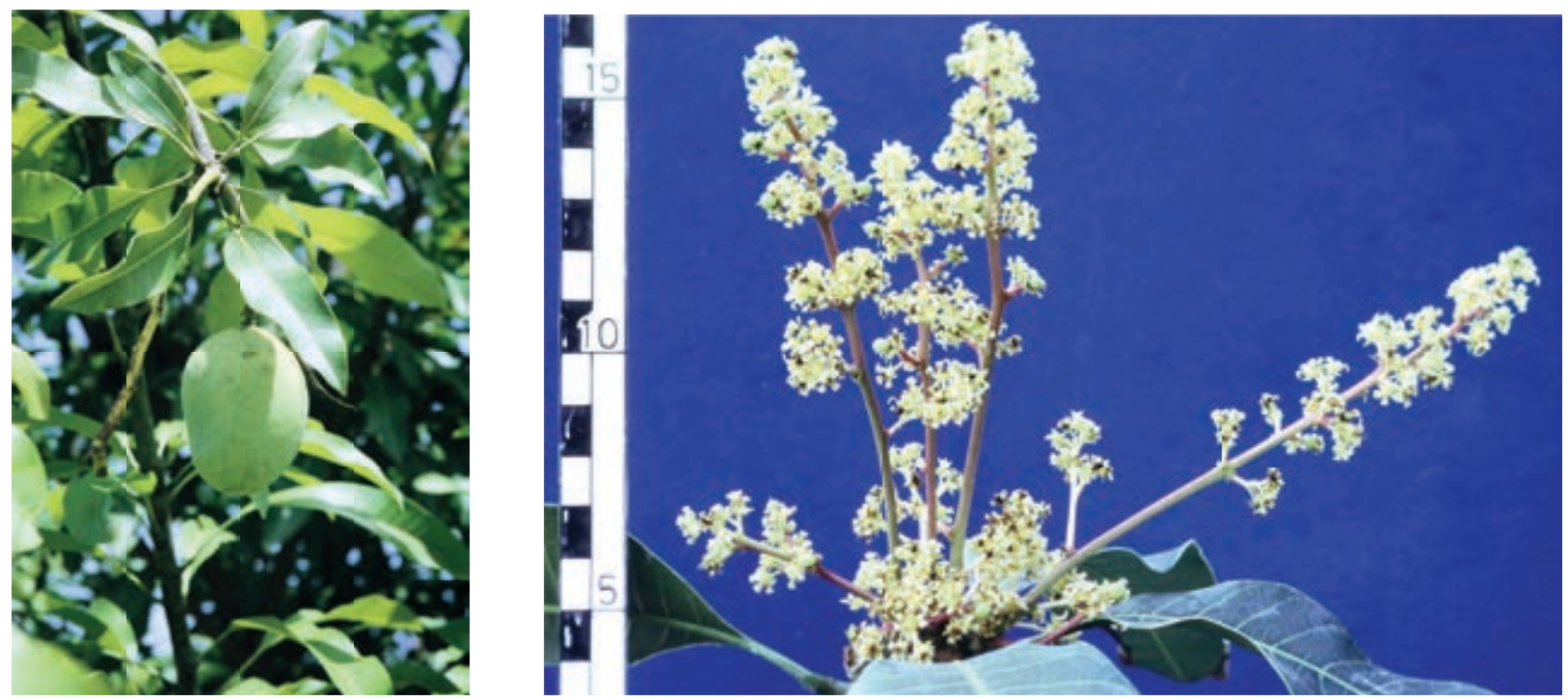

Figure 4.25 Mango fruit (left) and flower (right).

\section{General Crop Requirements}

As a tropical tree, mango has considerable drought tolerance, which enables it to grow in both subtropical and semi-arid areas. Within the EU it is mainly grown in the open field or in polytunnels in Southern Spain and the Canary Islands. It is also grown in neighbouring countries including Israel, Jordan and Egypt. Mango nursery stock, rootstock plants and fruit trees can also be grown in heated greenhouses in temperate climates. This, however, is not done for commercial fruit production. Growing mangoes in a dry subtropical climate has several advantages. Trees are more regular flowering, have fewer disease problems and a more moderate in growth habit. Using polytunnels in organic systems can add to these advantages and help with biological pest control and efficient use of irrigation water. Current mango rootstocks have a low or moderate tolerance to salinity and saline irrigation water; research into salt tolerance in mango is on-going.

Since the 1980s the mango area in the south-eastern mainland Spain has increased from a few trees to over 3,300 ha (Calatrava et al. 2013). This trend is expected to continue but there are risks: orchards in the open are often protected by windbreaks but e.g. in January 2005 a light frost $\left(-0.5^{\circ} \mathrm{C}\right)$ seriously damaged some trees. Protected cropping like with papaya could help with this problem and make also flowering, fruit set and pest control better manageable in a Mediterranean climate.

\section{Biological control of mango pests and diseases}

Information on organic mango production (Rivera, 2009) and non-chemical pest management can be found in a PAN field guide The pests and diseases covered in this guide are: fruit fly, mango leafhoppers, mango shoot caterpillar, mango tip borer, mealy bugs, scales, anthracnose, pink disease, scab and stem-end rot (PAN, 2005). 


\section{Experimental design}

For field experiments and experiments in polytunnels, usually one tree or a group of two to three trees are used as a plot. Because of the size of the trees and the limited size of polytunnels, the number of trees per plot and the number of replications is severely limited. However, to test fertiliser or irrigation water treatments, semihardwood cuttings from stock plants can be used to achieve uniform plant material. When grown in pots they can be kept much smaller and can be produced in large numbers, which make larger plots and replication numbers of three to six possible $(n=6)$. Such a design represents a compromise to achieve larger replication numbers and statistically significant results. However, the trees are not full-size and the 'model plants' only represent larger trees in the field or in polytunnels.

To produce semi-hardwood cuttings, 15 to $20 \mathrm{~cm}$ long cuttings from new growth (from the previous six months) of mango stock plants are taken. To induce rooting, cuttings are dipped for a few seconds in an auxin solution. Prior to dipping, two $2 \mathrm{~cm}$ deep crosswise cuts are made at the basal end of the cutting and 4 to 5 leaves are left. Leaf tips are then cut to reduce transpiration and enhance new growth. Cuttings are placed in a mist chamber within a growing medium containing coarse and fine sand and kept at $28^{\circ} \mathrm{C}$. Depending on the variety, a large proportion of uniform cuttings can be rooted, ready for further experiments.

\section{Example of a greenhouse experiment:}

The cuttings can be transplanted in the soil or into plastic pots (e.g. 2.5 litre) and then should be grown for at least another four weeks before treatments start. In a greenhouse, each pot with a uniform cutting can be treated as a plot and then a randomized complete block design with six replications per treatment is possible. The statistical analysis is then done using ANOVA and F-test. To give an example, a greenhouse pot plant experiment with seven different irrigation water treatments (one of them a control) and six replications would require $7 \times 6=42$ experimental plants as uniform cuttings. Assuming an $80 \%$ success rate at rooting and some additional selection for poorly-rooted plants, about 80 cuttings from stockplants are necessary for this experiment $(n=6)$.
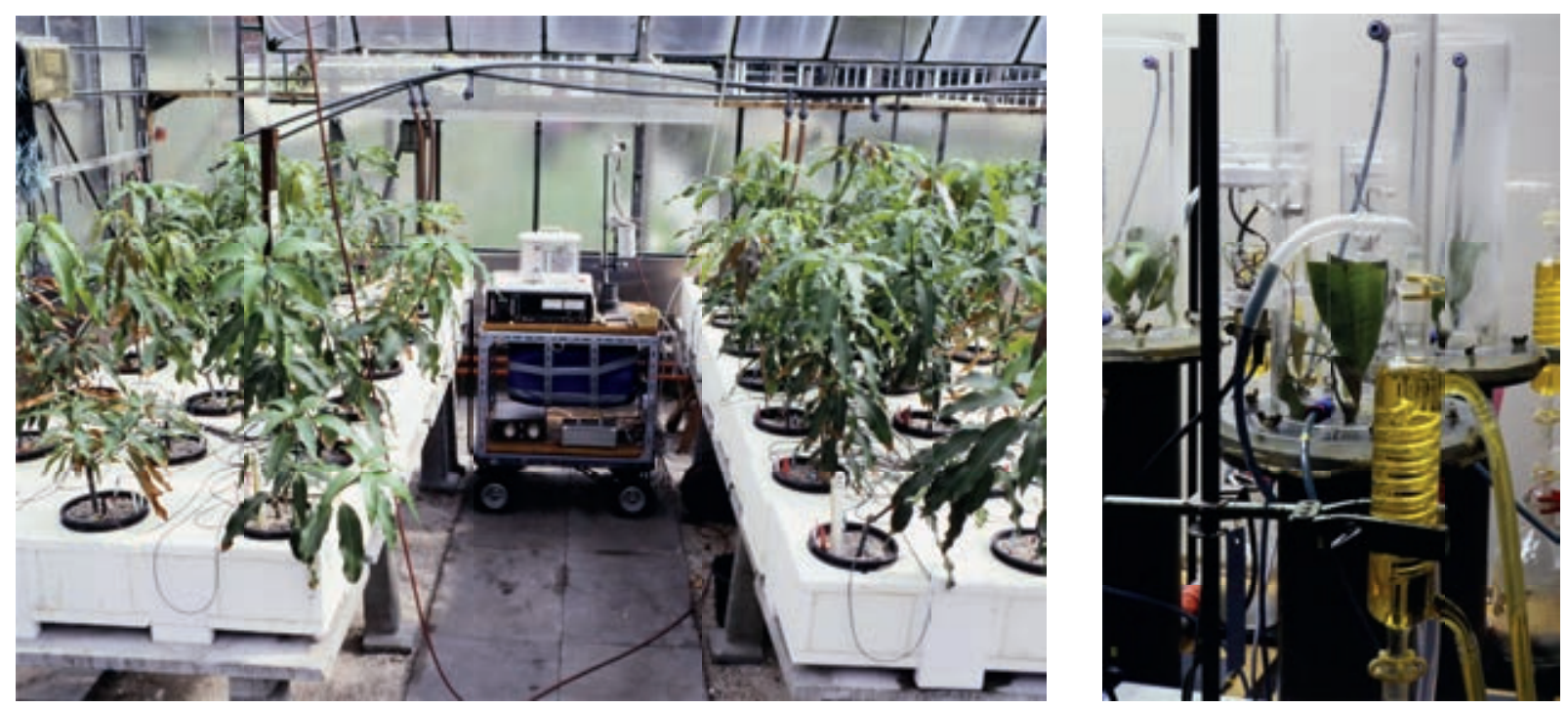

Figure 4.26 Mango experiments, in a greenhouse (left) and in a growth chamber (right).

Using pot plants also has the advantage of controlling the root temperature and using this as a treatment in greenhouse experiments. In growth chambers and environmental simulation labs, even more controlled environments are possible, however this comes at the expense of replication and treatment number. For example, to continuously measure root and shoot respiration of tree crops cuvettes are necessary and expensive gas chromatographs are needed which allow only 2 treatments and 3 replications with uniform cuttings from the same stockplant $(n=3)$. 


\section{References and further information}

Calatrava, J., Sayadi, S., Sarmiento, D. and Guirado, E. (2013)

Return analysis of 'Osteen' and 'Kent' mango orchards in south-eastern mainland Spain. Acta Hort. 992:8592, DOI: 10.17660/ActaHortic.2013.992.9

Hermoso, J.M., Guirado, E., González-Fernández, J.J. and Farré, J.M. (2015)

Study on performance of 'Keitt' mango on different rootstocks in a Mediterranean climate. Acta Hort. 1075, 115-119, DOI: $10.17660 /$ ActaHortic.2015.1075.11

PAN (2005)

Field Guide to Non-chemical pest management in Mango Production, Pesticide action network, Germany, Hamburg, www.oisat.org/downloads/field_guide_mango.pdf

Rivera R. (2009)

A guide to growing organic mango with natural farming system. Philippines, FAO Asian Regional Pesticide Risk Reduction Programme www.vegetableipmasia.org

Sayadi, S., Calatrava, J., Guirado, E. and Sarmiento, D. (2013)

An economic analysis of culture mechanization: the case of the Spanish mango. Acta Hort. 992:221-224, DOI: 10.17660/ActaHortic.2013.992.28

Sayadi, S. and Calatrava, J. (2009).

Structure and Productivity of Spanish Mango Industry: a Farmers Survey Analysis. Acta Hort. 820, 47-56 DOI: $10.17660 /$ ActaHortic.2009.820.2

International Union for the Protection of New Varieties of Plants (UPOV). 2004.

Mango TG/112/4. www.upov.int 


\subsection{Ornamentals}

Many different bedding and pot plant species are grown. Out of them Pelargonium is the most important bedding plant and it is described here as an example for other ornamental bedding plants that may be grown in pots.

\subsubsection{Pelargoniums cultivated in pots}

\section{By Martin Koller and Robert Koch}

Botanical name: Pelargonium zonale and Pelargonium peltatum

\section{General crop requirements}

Pelargoniums are sensitive to frost. Mostly they are propagated vegetatively and rooted cuttings are transplanted directly into the final pot. For organic growing a moderate temperature (between $12-16^{\circ} \mathrm{C}$ ) is recommended in order to obtain strong plants with short internodes. The two important species ( $P$. peltatum (ivy leaved) and $P$. zonale) have compact growth types that are better suited to organic cultivation than stronger-growing types.

The cultivation period depends on the temperature, light, the size of the pot and the stage at which plants are to be sold; it can vary from 10 to 16 weeks. A shorter cultivation period is needed for plants in smaller pots (less than $11 \mathrm{~cm}$ diameter). The plants should be irrigated with caution in order not to stimulate the longitudinal growth.

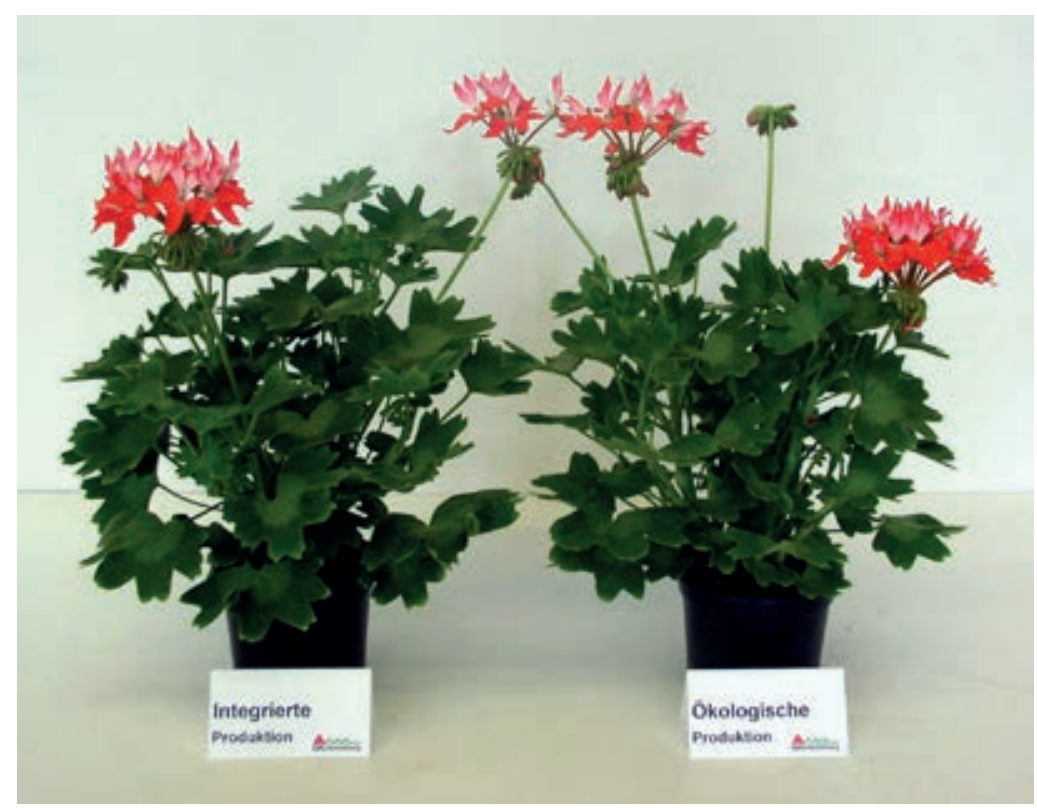

Figure 4.27 Plants from a pelargonium pot trial to compare integrated with organic production.

\section{Experimental design}

Recommended replicates: at least four. 
Table 4.75

Typical plant spacing for pelargoniums.

Pot diameter

$12 \mathrm{~cm}$

Minimum number of plants / core plot 20

Pot density / $\mathrm{m}^{2}$

Plants per pot 1

Table 4.76

Recommended heating temperature after transplanting the rooted transplant into the pot.

\begin{tabular}{llll} 
Growing stage & Day ${ }^{\circ} \mathrm{C}$ & Night ${ }^{\circ} \mathrm{C}$ & Ventilation from $\left({ }^{\circ} \mathrm{C}\right)$ \\
\hline Direct after transplanting & 20 & 18 & 25 \\
\hline $\begin{array}{l}\text { Cultivation after roots are } \\
\text { established }\end{array}$ & $14-16$ & $12-14$ & 18 \\
\hline
\end{tabular}

Temperatures below $12^{\circ} \mathrm{C}$ should be avoided because nutrient mineralization in the growing medium will be too slow. A cultivation temperature of $16-18^{\circ} \mathrm{C}$ is usually recommended for conventional plants but will, in the absence of growth retardants, lead to elongated plants. A 'cool morning technique' (temperature drop of $8^{\circ} \mathrm{C}$ before or with the sunrise for $4 \mathrm{~h}$ ) is recommended to control shoot growth.

\section{Crop nutrition}

The nutrient demand will vary depending on the growth habit and pot size. If growing media with a composition of $20 \%$ or more of compost is used, additional phosphorus or potassium fertiliser is usually not needed. It should be noted that the availability rate for nitrogen in organic fertilisers is estimated at $60-70 \%\left(\mathrm{~N}_{\text {available }} / \mathrm{N}_{\text {total }}\right)$.

Table 4.77

Nutrient demand of a potted pelargonium plant.

$\begin{array}{lllll}\text { Pot size } & \text { N } & \text { P } & K & \text { Mg } \\ 12 \mathrm{~cm}(\mathrm{mg} / \mathrm{pot}) & 500-700^{(1)} & 40-60 & 420-580 & 40-80\end{array}$

\section{Crop management}

Pinch out shoot tips to promote bushiness is recommended for strong-growing Zonale-Types (once or twice) and for most of the Peltatum types (twice), possibly from two weeks after transplanting until eight weeks before marketing.

\section{Disease, pest problems and physiological disorders \\ Diseases:}

- Bacterial blight - Xanthomonas hortorum pv. pelargonii (Syn. X. campestris pv. pelargonii).

- Rust - Puccinia pelargonii-zonalis (Only a problem on P. zonale).

\section{Pests:}

Aphids - many different species

\section{Physiological disorder:}

Oedema (Edema) is caused by high substrate moisture and low transpiration. $P$. peltatum are especially susceptible. 
The occurrence of other diseases and pests (e.g. whiteflies) should be recorded in any report.

\section{Assessments of growth and quality}

For cultivar testing a detailed protocol for a wide range of characteristics is available from UPOV and CPVO.

Assessments are usually made at the stage when the plants are marketed. These can include:

- Uniformity of crop ( $1=$ absent or very weak, $3=$ low, $5=$ moderate, $7=$ strongly, $9=$ very strong $)$.

- Growth habit ( $1=$ very vigorous, $3=$ vigorous, $5=$ moderate, $7=$ compact, $9=$ very compact).

- Branching habit ( $1=$ very poorly branched, 3 poorly branched, $5=$ moderately branched, $7=$ highly branched, $9=$ very highly branched).

- Leaf colour (very light green, 3 = light green, 5 = medium green, $7=$ dark green, 9 = very dark green).

- Number of flowers. The numbers of flowers per plant is counted (or estimated) at least on 10 plants.

- Plant height. The height and the width of plant is measured at least on 10 plants at the stage at which the plants are normally marketed (and if appropriate also once or twice during the growing period). The width of the plant is measured at the maximum diameter of the plant and a second time in a $90^{\circ}$ angle (because of the irregularity of growth). Afterwards the mean of these two measurements is calculated.

- Root development. For at least ten plants the pot is removed and the root development on the surface of the growing media is assed at the stage at which the plants are normally marketed - and if appropriate also once or twice during the growing period ( 1 = very poor root development, $3=$ poor root development, $5=$ moderate root development, $7=$ densely rooted, $9=$ very densely rooted).

- Shoot weight. After the growth assessment, the weight of the shoot is measured fresh and also after drying until the sample reaches a constant weight.

\section{Overall value}

The overall value takes into account all criteria for the cultivation and marketing of a variety, based by expert opinion as evaluated by researchers using information from farmers, wholesalers, consumers $(1=$ very low, $3=$ low, $5=$ medium, $7=$ high, $9=$ very high .

\section{References and further information}

http://www.cpvo.europa.eu

International Union for the Protection of New Varieties of Plants (UPOV). 2004.

Zonale Pelargonium, Ivy Leaved- Pelargonium TG/28/9. http://www.upov.int 


\section{$5 \quad$ Appendices}

\subsection{Appendix A: General information}

\section{Useful books}

Davies, G \& Lennartsson, M.,

'Organic Vegetable Production - a complete guide' Crowood Press UK (2005). ISBN 1861267886

Cubison, S.,

'Organic Fruit Production - a complete guide', Crowood Press UK (2009).

ISBN 9781847970923

Baker, H. \& Waite, R.,

'Grapes: Indoors \& Out' - RHS Wisley Handbook, Cassell Illustrated (2003). ISBN 1844030644

Alford, D.V. 1999,

'A Colour Atlas of Fruit Pests' (Manson Publishing Ltd). ISBN 0723408165

Lind, K., Lafer, G., Schloffer, K., Innerhofer, G., Meister, H. 'Organic Fruit Growing' (2003),

CABI Publishing. ISBN 085199640X

George E. und Eghbal R. 2009.

Ökologischer Gemüsebau: Handbuch für Beratung und Praxis. 2. Auflage. Bioland Verlag Mainz. ISBN 978-3-

934239-14-2 (in German)

Institut Technique de l'Agriculture Biologique ITAB. 2015.

Produire des légumes biologiques. http://www.itab.asso.fr/ (2 folders, in French)

Cuijpers, Willemijn and Janmaat, Leen (2012)

Biowisselkas: Bredere vruchtwisseling voor een gezondere bodem. [Organic greenhouse intercropping:

Broadening crop rotations for a healthier soil.] Louis Bolk Instituut, Driebergen. www.orgprints.org/20824

\section{Useful websites}

http://www.eppo.int (European \& Mediterranean Plant Protection Organization - EPPO)

http://cpvo.europa.eu (Community Plant Variety Office - CPVO)

http://www.upov.int (International Union for the Protection of New Varieties of Plants)

www.rhs.org.uk (The Royal Horticultural Society, UK) 


\subsection{Appendix B: Summary table of crop nutrient demand}

\begin{tabular}{|c|c|c|c|c|c|c|c|c|c|c|}
\hline Crop & N $(\mathrm{g} / \mathrm{kg}$ y & Id) & & & & $P(g$ & kg yie & & & \\
\hline Source: & 1 & 2 & 3 & 4 & 5 & 1 & 2 & 3 & 4 & 5 \\
\hline Tomato & $2.3-3.2$ & 3.3 & $3.5(2-7.4)$ & 2.5 & 1.3 & 0.4 & 0.5 & $0.4(0.3-0.9)$ & 0.4 & 0.2 \\
\hline Pepper & $5.1-4.4$ & 4.4 & $4.5(3.0-8.0)$ & 3.9 & 2.7 & 0.6 & & $0.6(0.3-1.1)$ & 0.4 & 0.4 \\
\hline Eggplant & & & $5.0(3.0-7.0)$ & 5.4 & 2.2 & & & $0.7(0.1-1)$ & 0.9 & 0.5 \\
\hline Cucumber & $1.4-1.7$ & 1.5 & $2.1(1.5-3.6)$ & 1.6 & 1.2 & 0.4 & 0.4 & $0.5(0-1.4)$ & 0.3 & 0.3 \\
\hline Courgette & & & $4.5(3.8-5.0)$ & 3.8 & 2.7 & & & $1.3(0.7-1.7)$ & 0.7 & 0.2 \\
\hline Watermelon & & & $2.3(1.7-3.7)$ & 1.7 & & & & $0.6(0.3-0.8)$ & 0.6 & \\
\hline Melon & & & $4.4(2.5-6.4)$ & 3.0 & & & & $0.6(0.2-1.1)$ & 0.7 & \\
\hline Lamb's Lettuce & 4.0 & 4.0 & & & 4.2 & 0.7 & 0.7 & & & 0.4 \\
\hline Lettuce & 2.0 & 2.0 & $3.2(1.5-5.8)$ & 2.3 & 2.0 & 0.4 & 0.4 & $0.5(0.1-0.9)$ & 0.3 & 0.3 \\
\hline Rocket & & & & & 7.0 & & & & & 0.6 \\
\hline Climbing beans & 4.0 & 4.0 & $9.3(1.3-19)$ & 7.5 & 0.8 & 0.8 & 0.8 & $2(0.9-3.5)$ & 0.9 & 0.7 \\
\hline Kohlrabi & & & & & 3.1 & & & & & 0.6 \\
\hline Radish & 3.6 & 3.6 & $3.9(1.2-5.8)$ & 3.0 & 1.5 & 0.5 & 0.5 & $1.1(0.2-2.1)$ & 0.4 & 0.3 \\
\hline Spring Onion & & & $0.4(2.2-4.6)$ & 2.7 & & & & $0.7(0.2-1.2)$ & 0.6 & \\
\hline Parsley & 5.4 & 5.4 & $3.2(2.2-4.8)$ & 4.8 & 3.3 & 0.7 & 0.7 & $0.7(0.3-0.9)$ & 0.7 & 0.7 \\
\hline Strawberries & & & 4.7 & 3.5 & & & & $0.9(0.1-1.5)$ & 1.1 & \\
\hline
\end{tabular}




\begin{tabular}{|c|c|c|c|c|c|c|c|c|}
\hline Crop & \multicolumn{5}{|c|}{ K (g/ kg yield) } & \multicolumn{3}{|c|}{ Mg (g/kg yield) } \\
\hline Source: & 1 & 2 & 3 & 4 & 5 & 1 & 2 & 5 \\
\hline Tomato & $3.7-5.2$ & 5.0 & $5.2(2.9-11)$ & 4.0 & 1.9 & 0.5 & 0.5 & 0.4 \\
\hline Pepper & $5.35-5.2$ & & $5.4(3.7-11.3)$ & 4.2 & 3.5 & 0.5 & 0.45 & 0.5 \\
\hline Eggplant & & & $5.2(2.1-9.3)$ & 5.0 & 3.2 & & & 0.6 \\
\hline Cucumber & $2.2-2.9$ & 2.8 & $2.6(1.7-4)$ & 2.2 & 1.3 & 0.2 & 0.19 & 0.5 \\
\hline Courgette & & & $7.9(6.4-10.4)$ & 7.5 & 2.5 & & & 0.2 \\
\hline Watermelon & & & $2.9(2.3-5.6)$ & 2.3 & & & & \\
\hline Melon & & & $4.8(2.1-6.7)$ & 4.2 & & & & \\
\hline Lamb's Lettuce & 6.0 & 6.0 & 0 & & 4.2 & 0.3 & 0.33 & 0.8 \\
\hline Lettuce & 3.2 & 3.1 & $5(3.3-6.4)$ & 4.0 & 2.9 & 0.3 & 0.27 & 0.5 \\
\hline Rocket & & & 0 & & 5.0 & & & 0.7 \\
\hline Climbing beans & 3.6 & 3.6 & $6.9(5-8.3)$ & 5.0 & 3.0 & 0.6 & 0.6 & 0.6 \\
\hline KohIrabi & & & 0 & & 3.7 & & & 0.7 \\
\hline Radish & 4.4 & 4.4 & $3.1(2.4-4.2)$ & 2.5 & 2.1 & 0.2 & 0.2 & 0.5 \\
\hline Spring Onion & & & $3.2(1.5-4.4)$ & 2.3 & & & & \\
\hline Parsley & 9.4 & 9.4 & $3.8(3.3-4)$ & 4.0 & 2.8 & 0.4 & 0.40 & 0.7 \\
\hline Strawberries & & & $7.4(1.8-11.9)$ & 5.4 & & & & \\
\hline
\end{tabular}

Sources (indicated by numbers in column headings for each element):

1) Scharpf H. and Weier U. 1994. Düngung von Unterglasgemüse in Bodenkulturen. Gemüse, Heft 11, 623-626

2) Lattauschke, G. 2004. Anbau von Gewächshausgemüse. Hinweise zum umweltgerechten Anbau. Sächsische Landesanstalt für Landwirtschaft. Dresden. www.publikationen.sachsen.de/bdb/artikel/13405/documents/15179

3) Gianquinto, G., P. Muñoz, A. Pardossi, S. Ramazzotti \& D. Savvas. 2013. Soil fertility and plant nutrition. In: Good Agricultural Practices for greenhouse vegetable crops. Principles for Mediterranean climate areas. FAO Plant Production and Protection Paper 217. 4) RER-GAP. 2010. Regione Emilia Romagna GAP. CRPV. In: Gianquinto et al. 2013 (see Nr. 3).

5) Neuweiler R. 2011. Düngungsrichtlinien für den Gemüsebau. Agroscope Wädenswil. www.agroscope.admin.ch/publikationen 


\subsection{Appendix C: Summary of nutrient content of crop tissues}

\section{Table C1}

Optimal range of macronutrients in greenhouse crops in terms of percentage of dry matter (DM) (Gianquinto et al. 2013).

\begin{tabular}{lllllll} 
Crop & N & P & K & Ca & Mg & $\begin{array}{l}\text { Sampled } \\
\text { plant part }\end{array}$ \\
Tomato & $3.0-5.0$ & $0.20-0.60$ & $3.5-6.0$ & $2.0-4.0$ & $0.35-0.80$ & $1)$ \\
\hline Pepper & $3.0-4.5$ & $0.30-0.60$ & $3.0-7.5$ & $1.0-2.5$ & $0.35-0.90$ & $1)$ \\
\hline Eggplant & $4.0-5.5$ & $0.30-0.60$ & $4.0-6.5$ & $1.0-2.2$ & $0.30-1.00$ & $1)$ \\
\hline Cucumber & $4.5-6.0$ & $0.30-0.80$ & $2.5-5.5$ & $3.0-6.0$ & $0.50-1.20$ & $2)$ \\
\hline Zucchini & $4.0-6.0$ & $0.30-0.50$ & $2.5-5.0$ & $2.0-3.5$ & $0.25-1.00$ & $2)$ \\
\hline Melon & $4.0-5.5$ & $0.30-0.70$ & $3.5-5.5$ & $2.0-3.5$ & $0.35-0.80$ & $2)$ \\
\hline Watermelon & $2.0-5.0$ & $0.20-0.60$ & $2.5-4.5$ & $1.5-3.5$ & $0.40-0.80$ & $2)$ \\
\hline Bean & $3.0-6.0$ & $0.25-0.75$ & $3.0-7.5$ & $0.8-3.0$ & $0.25-0.80$ & $1)$ \\
\hline Lettuce & $4.0-5.5$ & $0.30-0.70$ & $5.5-12$ & $0.8-2.5$ & $0.25-0.90$ & $3)$ \\
\hline Strawberry & $2.1-4.0$ & $0.20-0.45$ & $1.5-2.5$ & $0.6-2.5$ & $0.25-0.70$ & $4)$
\end{tabular}

Table C2

Optimal range of micronutrients in greenhouse crops in terms of $\mathrm{mg}$ per $\mathrm{kg}$ dry matter (DM)

(Gianquinto et al. 2013).

\begin{tabular}{|c|c|c|c|c|c|c|}
\hline Crop & $\begin{array}{l}\mathrm{Fe} \\
\mathrm{mg} / \mathrm{kg} \mathrm{DM}\end{array}$ & $\begin{array}{l}\mathrm{Mn} \\
\mathrm{mg} / \mathrm{kg} \mathrm{DM}\end{array}$ & $\begin{array}{l}\mathrm{Zn} \\
\mathrm{mg} / \mathrm{kg} \mathrm{DM}\end{array}$ & $\begin{array}{l}\mathrm{Cu} \\
\mathrm{mg} / \mathrm{kg} \mathrm{DM}\end{array}$ & $\begin{array}{l}\mathrm{B} \\
\mathrm{mg} / \mathrm{kg} \mathrm{DM}\end{array}$ & $\begin{array}{l}\text { Sampled } \\
\text { plant part }\end{array}$ \\
\hline Tomato & $40-150$ & $30-150$ & $20-80$ & $5-20$ & $30-80$ & 1) \\
\hline Pepper & $60-300$ & $30-150$ & $20-100$ & $6-25$ & $25-80$ & 1) \\
\hline Eggplant & $50-300$ & $30-250$ & $20-200$ & $5-15$ & $25-80$ & 1) \\
\hline Cucumber & $50-300$ & $50-500$ & $25-300$ & $6-18$ & $30-10$ & 2) \\
\hline Zucchini & $50-200$ & $50-250$ & $20-200$ & $10-25$ & $25-75$ & 2) \\
\hline Melon & $50-300$ & $50-250$ & $20-200$ & $7-30$ & $25-60$ & 2) \\
\hline Watermelon & $50-300$ & $40-250$ & $20-250$ & $5-20$ & $25-80$ & 2) \\
\hline Bean & $50-400$ & $30-300$ & $20-200$ & $5-30$ & $25-80$ & 1) \\
\hline Lettuce & $50-300$ & $30-250$ & $25-250$ & $6-25$ & $25-60$ & 3) \\
\hline Strawberry & $50-250$ & $30-350$ & $20-70$ & $6-20$ & $25-70$ & 4) \\
\hline
\end{tabular}

Sampled plant part:

3. Most recent fully expanded leaf

4. Fifth leaf from the top of the shoot

5. All leaves at head formation

6. Young, fully expanded leaves

Source:

Gianquinto, G., P. Muñoz, A. Pardossi, S. Ramazzotti \& D. Savvas. 2013. Soil fertility and plant nutrition. In: Good Agricultural Practices for greenhouse vegetable crops. Principles for Mediterranean climate areas. FAO Plant Production and Protection Paper 217. 

COST (European Cooperation in Science and Technology) is a pan-European intergovernmental framework. Its mission is to enable break-through scientific and technological developments leading to new concepts and products and thereby contribute to strengthening Europe's research and innovation capacities. It allows researchers, engineers and scholars to jointly develop their own ideas and take new initiatives across all fields of science and technology, while promoting multi- and interdisciplinary approaches. COST aims at fostering a better integration of less research intensive countries to the knowledge hubs of the European Research Area. The COST Association, an International not-for-profit Association under Belgian Law, integrates all management, governing and administrative functions necessary for the operation of the framework. The COST Association has currently 36 Member Countries. www.cost.eu.

Link to the Action:

http://www.cost.eu/COST_Actions/fa/FA1105

And:

http://www.biogreenhouse.org/ 